Agrupamento de dados baseado em comportamento coletivo e auto-organização

\author{
Roberto Alves Gueleri
}



SERVIÇO DE PÓS-GRADUAÇÃO DO ICMC-USP

Data de Depósito:

Assinatura:

\title{
Agrupamento de dados baseado em comportamento coletivo e auto-organização
}

\author{
Roberto Alves Gueleri
}

Orientador: Prof. Dr. Zhao Liang

Dissertação apresentada ao Instituto de Ciências Matemáticas e de Computação - ICMC-USP, como parte dos requisitos para obtenção do título de Mestre em Ciências - Ciências de Computação e Matemática Computacional. EXEMPLAR DE DEFESA 
Ficha catalográfica elaborada pela Biblioteca Prof. Achille Bassi e Seção Técnica de Informática, ICMC/USP, com os dados fornecidos pelo(a) autor(a)

G925a $\begin{gathered}\text { Gueleri, Roberto Alves } \\ \text { Agrupamento de dados baseado em comportamento } \\ \text { coletivo e auto-organização / Roberto Alves Gueleri; } \\ \text { orientador Liang Zhao. -- São Carlos, 2013. } \\ 111 \text { p. } \\ \text { Dissertação (Mestrado - Programa de Pós-Graduação } \\ \text { em Ciências de Computação e Matemática } \\ \text { Computacional) -- Instituto de Ciências Matemáticas } \\ \text { e de Computação, Universidade de São Paulo, 2013. } \\ \text { 1. Agrupamento de dados. 2. Aprendizado } \\ \text { semissupervisionado. 3. Aprendizado de máquina. 4. } \\ \text { Comportamento coletivo (swarms). 5. Sistemas auto- } \\ \text { organizáveis. I. Zhao, Liang, orient. II. Título. }\end{gathered}$




\section{Agradecimentos}

Primeiramente, sou grato à minha família, por apoiar-me em todas as decisões que tomei na vida, e por compreender que, mesmo estando eu ausente durante longos períodos, tal ausência teve bons motivos, dentre eles, a concretização deste trabalho. Agradeço ao Prof. Dr. Zhao Liang, pela orientação, paciência e dedicação, mantendo-me na linha e, ao mesmo tempo, oferecendo-me a liberdade de tomar diversas decisões. Um equilíbrio perfeito: liberdade, mas com moderação. Agradeço a todos os demais professores, do ICMC-USP e de outras instituições, do mestrado e de outras épocas, que durante toda a minha vida ajudaram a formar a pessoa que sou hoje. Agradeço a todos os amigos, pelos momentos de descontração, afinal nem só de estudo e trabalho vive o homem. Prefiro não citar nomes para não correr o risco de esquecer alguém. Quem comigo esteve presente sabe o quanto foi importante. Agradeço à Fundação de Amparo à Pesquisa do Estado de São Paulo (FAPESP) e à Coordenação de Aperfeiçoamento de Pessoal de Nível Superior (CAPES), pelo apoio financeiro concedido, por meio de bolsa, que viabilizou do desenvolvimento deste trabalho de mestrado. E claro, agradeço à Deus,

por manter o caminho livre para que eu pudesse realizar este trabalho, dando-me saúde e motivação, oferecendo-me oportunidades, colocando-me diante de pessoas fantásticas, livrando-me de eventos ruins que eu não pudesse superar, embora algumas noites mal dormidas tenham sido necessárias. Enfim, expresso minha gratidão a todas as pessoas que, direta ou indiretamente, contribuíram para mais esta etapa que agora estou completando. 


\section{Resumo}

O aprendizado de máquina consiste de conceitos e técnicas que permitem aos computadores melhorar seu desempenho com a experiência, ou, em outras palavras, "aprender" com dados. Um dos principais tópicos do aprendizado de máquina é o agrupamento de dados que, como o nome sugere, procura agrupar os dados de acordo com sua similaridade. Apesar de sua definição relativamente simples, o agrupamento é uma tarefa computacionalmente complexa, tornando proibitivo o emprego de algoritmos exaustivos, na busca pela solução ótima do problema. A importância do agrupamento de dados, aliada aos seus desafios, faz desse campo um ambiente de intensa pesquisa. Também a classe de fenômenos naturais conhecida como comportamento coletivo tem despertado muito interesse. Isso decorre da observação de um estado organizado e global que surge espontaneamente das interações locais presentes em grandes grupos de indivíduos, caracterizando, pois, o que se chama auto-organização — ou "emergência", para ser mais preciso. Os desafios intrínsecos e a relevância do tema vêm motivando sua pesquisa em diversos ramos da ciência e da engenharia. Ao mesmo tempo, técnicas baseadas em comportamento coletivo vêm sendo empregadas em tarefas de aprendizado de máquina, mostrando-se promissoras e ganhando bastante atenção. No presente trabalho, objetivou-se o desenvolvimento de técnicas de agrupamento baseadas em comportamento coletivo. Faz-se cada item do conjunto de dados corresponder a um indivíduo, definem-se as leis de interação local, e então os indivíduos são colocados a interagir entre si, de modo que os padrões que surgem reflitam os padrões originalmente presentes no conjunto de dados. Abordagens baseadas em dinâmica de troca de energia foram propostas. Os dados permanecem fixos em seu espaço de atributos, mas carregam certa informação — a "energia" —, a qual é progressivamente trocada entre eles. Os grupos são estabelecidos entre dados que tomam estados de energia semelhantes. Este trabalho abordou também o aprendizado semissupervisionado, cuja tarefa é rotular dados em bases parcialmente rotuladas. Nesse caso, foi adotada uma abordagem baseada na movimentação dos próprios dados pelo espaço de atributos. Procurou-se, durante todo este trabalho, não apenas propor novas técnicas de aprendizado, mas principalmente, por meio de muitas simulações e ilustrações, mostrar como elas se comportam em diferentes cenários, num esforço em mostrar onde reside a vantagem de se utilizar a dinâmica coletiva na concepção dessas técnicas. 
Palavras-chave: agrupamento de dados; clustering; aprendizado semissupervisionado; aprendizado de máquina; comportamento coletivo; swarms; movimento coletivo; flocking; emergência; sistemas auto-organizáveis; análise de dados; sistemas complexos. 


\section{Abstract}

Machine learning consists of concepts and techniques that enable computers to improve their performance with experience, i.e., enable computers to "learn" from data. Data clustering (or just clustering) is one of its main topics, which aims to group data according to their similarities. Regardless of its simple definition, clustering is a complex computational task. Its relevance and challenges make this field an environment of intense research. The class of natural phenomena known as collective behavior has also attracted much interest. This is due to the observation that global patterns may spontaneously arise from local interactions among large groups of individuals, what is know as self-organization (or "emergence"). The challenges and relevance of the subject are encouraging its research in many branches of science and engineering. At the same time, techniques based on collective behavior are being employed in machine learning tasks, showing to be promising. The objective of the present work was to develop clustering techniques based on collective behavior. Each dataset item corresponds to an individual. Once the local interactions are defined, the individuals begin to interact with each other. It is expected that the patterns arising from these interactions match the patterns originally present in the dataset. Approaches based on dynamics of energy exchange have been proposed. The data are kept fixed in their feature space, but they carry some sort of information (the "energy"), which is progressively exchanged among them. The groups are established among data that take similar energy states. This work has also addressed the semi-supervised learning task, which aims to label data in partially labeled datasets. In this case, it has been proposed an approach based on the motion of the data themselves around the feature space. More than just providing new machine learning techniques, this research has tried to show how the techniques behave in different scenarios, in an effort to show where lies the advantage of using collective dynamics in the design of such techniques.

Keywords: clustering; semi-supervised learning; machine learning; collective behavior; swarms; collective motion; flocking; emergence; self-organizing systems; data analysis; complex systems. 


\section{Conteúdo}

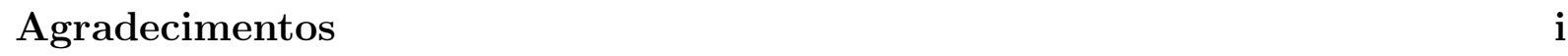

Resumo iii

$\begin{array}{ll}\text { Abstract } & \text { v }\end{array}$

Conteúdo vii

Lista de Figuras $\quad$ ix

Lista de Tabelas $\quad$ xiii

$\begin{array}{lll}1 & \text { Introdução } & 1\end{array}$

1.1 Motivação e objetivos . . . . . . . . . . . . . . . . . . . . . . . 2

$1.2 \quad$ Organização do documento . . . . . . . . . . . . . . . . . . . . 4

2 Agrupamento de dados $\quad 5$

2.1 Definição e critério de agrupamento . . . . . . . . . . . . . . . . . . . . . 5

2.2 O tamanho do problema . . . . . . . . . . . . . . . . . . . 8

2.3 Medidas de similaridade . . . . . . . . . . . . . . . . . . . . . . . 9

$2.4 \quad$ Algoritmos de agrupamento $\ldots \ldots \ldots \ldots$

2.4 .1 K-médias . . . . . . . . . . . . . . . . . . . . . . . . 11

$2.4 .2 \quad$ Agrupamento hierárquico aglomerativo . . . . . . . . . . . . . . . . 12

2.4 .3 DBSCAN $\ldots \ldots \ldots \ldots \ldots$

2.5 Critérios de validação $\ldots \ldots \ldots \ldots$. . . . . . . . . . . . . . . . . 15

2.6 Aprendizado semissupervisionado . . . . . . . . . . . . . . . . . . . . . 16

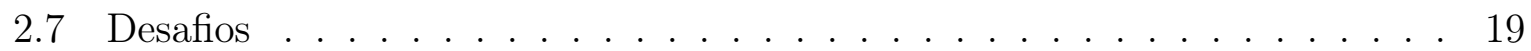

2.8 Considerações finais $\ldots \ldots \ldots$. . . . . . . . . . . . . . . . . . . . . 20

\begin{tabular}{|lll}
3 & Comportamento coletivo e auto-organização & 21
\end{tabular}

3.1 Os estudos sobre comportamento coletivo . . . . . . . . . . . . . . . . . 23

3.2 Trabalhos relacionados . . . . . . . . . . . . . . . . . . . 26

3.2.1 $\quad$ Agrupamento baseado em propriedades ferromagnéticas . . . . . . . 26 
3.2 .2 Agrupamento por atração de objetos similares . . . . . . . . . . . . 30

$3.2 .3 \quad$ Agrupamento através de otimização por nuvem de partículas . . . . 32

3.3 Desafios . . . . . . . . . . . . . . . . . . . . . 36

3.4 Considerações finais . . . . . . . . . . . . . . . . . . . . . . . 37

4 Agrupamento por dinâmica de troca de energia 39

4.1 Descrição formal da técnica . . . . . . . . . . . . . . . . . . 40

4.2 Experimentos realizados $\ldots \ldots \ldots \ldots$. . . . . . . . . . . . . . . . . . 45

$4.2 .1 \quad$ Experimentos com dados artificiais . . . . . . . . . . . . . . . 46

$4.2 .2 \quad$ Experimentos com dados reais . . . . . . . . . . . . . . . . . . . . . 48

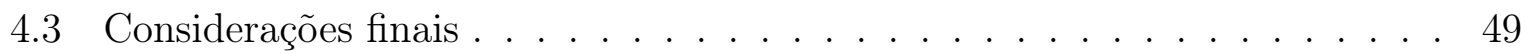

5 Agrupamento guiado por troca positiva e negativa de energia 51

5.1 Descrição da técnica . . . . . . . . . . . . . . . . . . . . . . . 51

5.2 Experimentos realizados . . . . . . . . . . . . . . . . . 54

$5.2 .1 \quad$ Experimento 1: arcos entrelaçados . . . . . . . . . . . . . 56

5.2 .2 Experimento 2: um anel ao redor . . . . . . . . . . . . . 58

5.2 .3 Experimento 3: tamanhos diferentes . . . . . . . . . . . . . 60

5.3 Redução da dimensionalidade do espaço de energia: "agrupamento por cores" 60

5.4 Considerações finais . . . . . . . . . . . . . . . . . . . . . . . 80

6 Aprendizado semissupervisionado via movimentação dos dados 83

6.1 Descrição da técnica . . . . . . . . . . . . . . . . . . . . . . . . 83

6.2 Análise de parâmetros, experimentos e análise dos resultados . . . . . . . . 85

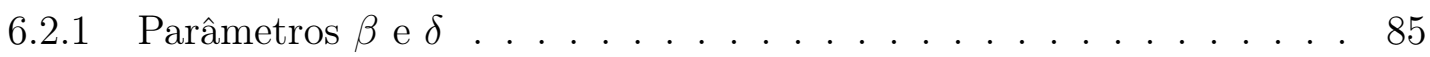

6.2 .2 Parâmetro $\alpha \ldots \ldots \ldots \ldots \ldots \ldots$

$6.2 .3 \quad$ O comportamento dinâmico da técnica . . . . . . . . . . . . . . . 87

6.2 .4 Experimentos e análise dos resultados . . . . . . . . . . . . . . . . . 88

6.3 Técnica proposta vs. $1-\mathrm{NN}$. . . . . . . . . . . . . . . . . . . . . . . . . 98

$6.4 \quad$ O efeito da rotulação equivocada $\quad \ldots \ldots \ldots$. . . . . . . . . . . . . . . . . . . . 98

\begin{tabular}{lll}
\hline & Conclusões e trabalhos futuros & 103
\end{tabular}

\begin{tabular}{ll}
\hline Referências bibliográficas & 107
\end{tabular} 


\section{Lista de Figuras}

2.1 Diferentes distribuições de dados em um espaço bidimensional. . . . . . . . 6

2.2 Exemplo de um dendrograma . . . . . . . . . . . . . . . . . . . . . 13

2.3 Os conceitos de alcançabilidade-por-densidade e conectividade-por-densidade. 14

2.4 Conjunto artificial de dados formado por duas gaussianas. . . . . . . . . . 17

3.1 Velocidade das partículas após algum tempo de evolução, para diferentes valores de densidade e ruído. . . . . . . . . . . . . . . . . . . 25

3.2 Valor absoluto da média normalizada das velocidades $\left(v_{a}\right)$ em função do nível de ruído $\eta$, para diferentes quantidades de partículas $N \ldots$. . . . . . 26

3.3 Conjunto de dados empregado no experimento, já mostrando o agrupamento resultante para $T=0,05 \ldots$. . . . . . . . . . . . . . 29

3.4 Tamanho dos clusters em função da temperatura T. . . . . . . . . . . . 30

3.5 Processo de movimentação dos objetos. Três clusters são formados.... . . . 32

$3.6 \quad$ Processo de movimentação dos objetos. Cinco clusters são formados... . . 33

3.7 Rede formada a partir de um conjunto de dados. . . . . . . . . . . . . . 35

3.8 llustração dos ângulos dos vértices. . . . . . . . . . . . . . . . . . . 35

3.9 Evolução do processo de atualização dos ângulos. . . . . . . . . . . . . . . . 35

4.1 Ilustração do processo de agrupamento. . . . . . . . . . . . . . . . . 40

4.2 Dois estados de energia num movimento simétrico de aproximação... . . . 44

4.3 Dois conjuntos artificiais de dados utilizados nas simulações. . . . . . . . . 46

4.4 Resultados das simulações sobre o Conjunto de dados 1.

4.5 Evolução do cluster representativo da Classe $C$, nas últimas iterações da simulação sobre o Conjunto de dados 1. . . . . . . . . . . . . . . . . . . . 47

4.6 Resultados das simulações sobre o Conjunto de dados $2 . \quad$. . . . . . . . . . 48

4.7 Resultados das simulações sobre o conjunto Iris. . . . . . . . . . . . . . . . 49

5.1 Como as interações positiva e negativa atuam sobre os estados de energia dos objetos. . . . . . . . . . . . . . . . . 54

5.2 Comportamento da função de interação. . . . . . . . . . . . . . . . 55

5.3 Resultados do Experimento 1: arcos entrelaçados. . . . . . . . . . . . . 57

5.4 Resultados do Experimento 2: um anel ao redor. . . . . . . . . . . . . . . 59 
5.5 Resultados do Experimento 3: tamanhos diferentes. . . . . . . . . . . . . . 61

5.6 Mapeamento da componente de energia $e_{i, k}$ para a componente de cor

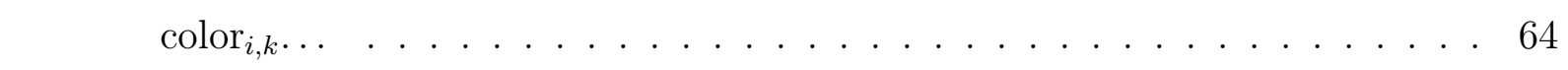

5.7 Conjunto bidimensional de dados formado por duas gaussianas: a da esquerda contendo 160 objetos e a da direita, mais ampla, contendo $640 \ldots .65$

5.8 Evolução da dinâmica de troca de energia sobre o conjunto da Figura 5.7 , utilizando-se zero a 2,5 unidades. . . . . . . . . . . . . . . . . . 66

5.9 O espaço de energia em três diferentes projeções (RxG, BxG e RxB), cor\begin{tabular}{|l|l|l|l|}
\hline respondente ao instante $t=5000$ do sistema mostrado na Figura & 5.8 & .. . . 67 \\
\hline
\end{tabular}

5.10 Evolução da dinâmica de troca de energia sobre o conjunto da Figura 5.7 , \begin{tabular}{|r}
\hline utilizando-se zero $a 1,5 \ldots \ldots \ldots \ldots \ldots$ \\
\hline
\end{tabular}

5.11 Evolução da dinâmica de troca de energia sobre o conjunto da Figura 5.7 ,

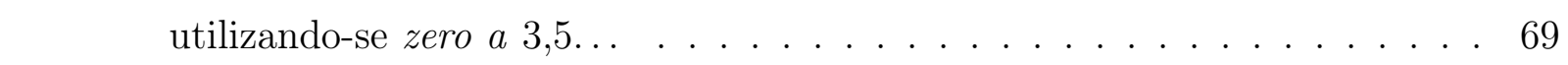

5.12 Evolução da dinâmica de troca de energia sobre conjunto bidimensional \begin{tabular}{|c|}
\hline formado por uma gaussiana ao centro, contendo 200 objetos, e um anel ao \\
\hline
\end{tabular}

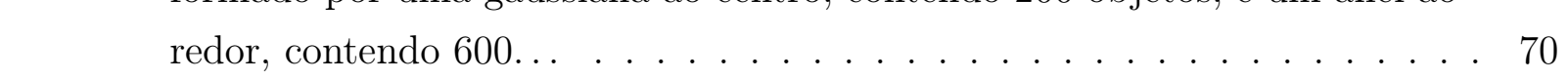

5.13 Evolução da dinâmica de troca de energia sobre conjunto formado por uma gaussiana ao centro e um anel ao redor (continuação). . . . . . . . . . . 71

5.14 O espaço de energia em três diferentes projeções, correspondente ao ins\begin{tabular}{ll|l|l|l|}
\hline tante $t=5000$ do sistema mostrado nas Figuras & 5.12 & $\mathrm{e}$ & 5.13 & $\ldots$
\end{tabular} . . . . . . . 72

5.15 Evolução da dinâmica de troca de energia sobre conjunto bidimensional \begin{tabular}{|c|}
\hline formado por três gaussianas: à esquerda (menor) com 150 objetos, à direita \\
\hline (maior) com 400 e acima (intermediária) com 250, totalizando 800 objetos... 73 \\
\hline
\end{tabular}

5.16 Evolução da dinâmica de troca de energia sobre conjunto formado por três gaussianas (continuação)... . . . . . . . . . . . . . . 74

5.17 O espaço de energia em três diferentes projeções, correspondente ao ins\begin{tabular}{|l|l|l|l|l|l|}
\hline tante $t=5000$ do sistema mostrado nas Figuras & 5.15 & $\mathrm{e}$ & 5.16 & $\ldots$
\end{tabular}$\ldots$. . . 75

5.18 Evolução da dinâmica de troca de energia sobre o conjunto da Figura 5.7 , onde cada objeto interage somente com 20 outros tomados aleatoriamente... 77

5.19 Evolução da dinâmica de troca de energia sobre o conjunto da Figura |5.7| \begin{tabular}{|c|}
\hline onde cada objeto interage somente com 20 outros: os 10 mais próximos e \\
\hline
\end{tabular} os 10 mais distantes. . . . . . . . . . . . . . . . . . . . 78

5.20 Evolução da dinâmica de troca de energia sobre o conjunto da Figura 5.7 , onde cada objeto interage somente com 20 outros: os 10 mais próximos e outros 10 tomados aleatoriamente. . . . . . . . . . . . . . . . 79

$6.1 \quad$ O comportamento da função $f\left(d_{i j}\right)=d_{i j} \cdot e^{-\beta d_{i j}{ }^{2}}$, para $\beta=1 . \quad \ldots . . \quad$. . 84

6.2 Configuração de um equilíbrio dinâmico. . . . . . . . . . . . . . . . . 85 
6.3 Conjunto artificial de dados, formado por duas gaussianas contendo 400 objetos cada, 20 deles previamente rotulados. . . . . . . . . . . . . . 88

6.4 Comportamento dinâmico da técnica proposta, sobre o conjunto da Figura $\mid 6.3$, empregando $\beta=1$ e $p=0,01 \ldots$. . . . . . . . . . . . . . 89

6.5 Comportamento dinâmico da técnica proposta, sobre o conjunto da Figura 6.3 , empregando $\beta=50$ e $p=0,01 \ldots$. . . . . . . . . . . . . . . . . . 90

6.6 Análise da influência dos parâmetros $\beta$ e $\delta$ na acurácia e no tempo de convergência... . . . . . . . . . . . . . . . . . . . . 91 91

6.7 Análise da influência do tamanho do conjunto de dados e da proporção de dados inicialmente rotulados na acurácia e no tempo de convergência... . . 92

6.8 Análise da influência dos parâmetros $\beta$ e $\delta$ na acurácia e no tempo de convergência, sobre o conjunto Digit1 . . . . . . . . . . . . . . . . . . . . . 94

6.9 Análise da influência dos parâmetros $\beta$ e $\delta$ na acurácia e no tempo de convergência, sobre o conjunto Digit1, mas considerando-se somente as 5 primeiras componentes PCA... . . . . . . . . . . . . . . 95

6.10 Conjunto artificial bidimensional de dados, formado por duas classes dispostas horizontalmente, uma sobre a outra. . . . . . . . . . . . . . . . . . 99

\begin{tabular}{|lll|l|l|l|}
\hline 6.11 Resultado do algoritmo 1-NN sobre o conjunto da Figura & 6.10 & . . . . . . . . 100
\end{tabular}

\begin{tabular}{|l|l|l|l|l|}
\hline 6.12 & Resultado da técnica proposta sobre o conjunto da Figura & 6.10 & . . . . . . . 101
\end{tabular}

6.13 Efeito da rotulação equivocada... . . . . . . . . . . . . . . . . . . 102 


\section{Lista de Tabelas}

4.1 Os parâmetros do método baseado em dinâmica de troca de energia. . . . . 45

$5.1 \quad$ Valores de $\alpha$ usados no Experimento 1. . . . . . . . . . . . . . 56

5.2 Valores de $\alpha$ usados nos Experimentos 2 e $3 . \quad$. . . . . . . . . . . . . . . . . 58

6.1 Características básicas dos conjuntos de dados de benchmark. . . . . . . . . 93

6.2 Abreviações das técnicas utilizadas para comparação. . . . . . . . . . . . . 96

6.3 Comparação da técnica proposta a outras técnicas da literatura. Bases com 10 dados inicialmente rotulados. . . . . . . . . . . . . . . . . . . . . . . 97

6.4 Comparação da técnica proposta a outras técnicas da literatura. Bases com 100 dados inicialmente rotulados. . . . . . . . . . . . . . . . . . . . . . 97 


\section{Capítulo 1}

\section{Introdução}

Tecnologias de aquisição de dados têm avançado muito nos últimos anos, disponibilizando quantidades massivas de dados nas diversas áreas da ciência e da indústria. Tecnologias capazes de processar todo esse volume de dados, porém, não têm acompanhado no mesmo ritmo. Logo, torna-se imprescindível o desenvolvimento e aprimoramento de ferramentas automatizadas e inteligentes capazes de processar esse alto volume de dados.

Resumidamente, o aprendizado de máquina é o campo responsável pelo desenvolvimento dos métodos que tornam os computadores capazes de aperfeiçoar seu desempenho, em determinada tarefa, através de exemplos ou experiências anteriores (Mitchell, 1997; Alpaydin, 2004, Bishop, 2006, Faceli et al., 2011). Em outras palavras, como o próprio nome sugere, é o campo responsável por tornar os computadores capazes de "aprender" com os dados adquiridos. Vastas são suas aplicações, dentre as quais: mineração de dados, reconhecimento de faces e fala, e robótica (Mitchell, 1997; Alpaydin, 2004; Bishop, 2006, Faceli et al., 2011).

Os métodos de aprendizado podem ser divididos em supervisionado e não-supervisionado (Mitchell, 1997; Hastie et al., 2001; Alpaydin, 2004, Bishop, 2006; Faceli et al., 2011). Tarefas de classificação enquadram-se no aprendizado supervisionado (conhecido também como aprendizado preditivo). Nelas, trabalha-se com coleções de dados (também chamados objetos, observações, instâncias ou itens) previamente classificados. O objetivo é encontrar uma função a ser posteriormente empregada para classificar novos dados, com base nos antigos já classificados. A essa função é dado o nome de classificador, e representa uma superfície de decisão que separa as diferentes classes.

O aprendizado não-supervisionado (ou aprendizado descritivo), por sua vez, parte de coleções de objetos não-rotulados, onde classes não estão previamente estabelecidas. $\mathrm{O}$ objetivo é descobrir padrões que regem a distribuição desses objetos. O agrupamento de dados (clustering, ou simplesmente agrupamento) figura como uma das tarefas de aprendizado não-supervisionado e, como o nome sugere, procura agrupar os objetos de acordo com sua similaridade (Jain et al., 1999; Xu \& Wunsch II, 2005; Faceli et al., 2011).

Embora o objetivo pareça simples - agrupar os objetos de acordo com sua similaridade 
-, o agrupamento é, na verdade, um problema computacionalmente complexo, sendo conhecido como um problema de otimização (Jain et al., 1999, Xu \& Wunsch II, 2005, Faceli et al. 2011). Tal complexidade torna proibitivo o emprego de algoritmos exaustivos, baseados em força bruta, na busca pela solução ótima do problema. Não bastando, a própria definição do quê é a tarefa de agrupamento é um tanto informal e subjetiva (Jain et al., 1999; Xu \& Wunsch II, 2005, Faceli et al., 2011). Isso tudo conduz à existência de uma diversidade de algoritmos propostos para agrupamento de dados. Esse assunto é discutido em detalhes no Capítulo 2.

O aprendizado pode ainda ser denominado semissupervisionado (Seeger, 2002, Chapelle et al., 2006a; Zhu, 2008, Zhu \& Goldberg, 2009, Silva \& Zhao, 2012b). Aqui, parte-se de uma mistura de alguns dados rotulados (classificados) em meio a muitos não-rotulados. Muitos dos problemas reais caem nessa configuração, pois a rotulação de dados costuma ser uma tarefa onerosa e tipicamente requer a intervenção de profissionais especialistas. Objetiva-se classificar os dados não-rotulados em função dos rotulados e do próprio padrão de distribuição dos não-rotulados.

Diversos sistemas naturais, como colônia de formigas, revoada (de pássaros) e cardume (de peixes), exibem características de comportamento coletivo, onde as ações de cada indivíduo são influenciadas pelas ações dos demais numa população (Bonabeau et al., 1999 Kennedy \& Eberhart, 2001; Engelbrecht, 2006, Vicsek \& Zafiris, 2010). A partir desse comportamento coletivo, sob determinadas circunstâncias, emerge-se um estado de ordem evidente, resultado de uma auto-organização. Tais características coletivas oferecem a esses seres a capacidade de, por exemplo, explorar com bastante eficiência em busca de alimentos.

Nas últimas décadas, problemas complexos passaram a ser resolvidos através de metáforas de sistemas naturais (Bonabeau et al., 1999, Kennedy \& Eberhart, 2001; Engelbrecht, 2006). Em especial, há na literatura casos bem-sucedidos de metáforas baseadas em comportamento coletivo, empregadas justamente na solução de problemas de agrupamento de dados. Alguns desses trabalhos são apresentados no Capítulo 3 . Ainda assim, não só a compreensão dos mecanismos que fazem dos sistemas naturais tão eficientes, como também o modo de construir sistemas computacionais a partir de metáforas dos sistemas naturais, ainda representam um grande desafio.

\subsection{Motivação e objetivos}

Este trabalho toma a hipótese de que sistemas dinâmicos baseados em comportamento coletivo são um mecanismo poderoso na solução de uma ampla classe de problemas computacionais complexos, o que inclui as tarefas do aprendizado de máquina, cujas soluções ótimas não podem ser obtidas exaustivamente (por força bruta), mas admitem soluções boas. 
No campo do agrupamento de dados, é constante a demanda por novos e melhores algoritmos (Jain et al., 1999, Xu \& Wunsch II, 2005). Tratando-se de uma tarefa um tanto subjetiva, o agrupamento tipicamente não possui solução única. Diferentes soluções são adequadas para diferentes propósitos (ver Capítulo 2). Mesmo após estabelecido um critério para determinada tarefa (critério de agrupamento), sua complexidade computacional impede a existência de algoritmo que resulte, eficientemente, na solução ótima do problema. E novas tecnologias geram tarefas mais complexas e desafiadoras, requerendo algoritmos cada vez mais poderosos.

Quanto aos estudos sobre comportamento coletivo e auto-organização, é crescente seu interesse nas diversas ciências (Vicsek et al., 1995, Toner \& Tu, 1995, 1998, Bonabeau et al., 1999; Heylighen, 1999; Kennedy \& Eberhart, 2001; Engelbrecht, 2006; Chaté et al., 2008, Banzhaf, 2009; Ginelli et al., 2010; Menon, 2010, Ramaswamy, 2010; Vicsek \& Zafiris, 2010; Ngo et al., 2012, Peshkov et al., 2012; Sumino et al., 2012; Toner, 2012a b). O comportamento coletivo ajuda a explicar a complexidade presente em diversos sistemas naturais. Ainda assim, muitas de suas questões fundamentais estão abertas e sendo exploradas. Uma delas é a relação entre as interações em escala local que originam os padrões organizados em escala global. Não é possível "programar" diretamente o padrão global, ele "emerge" das interações locais entre os indivíduos.

Abordagens baseadas em comportamento coletivo já vêm sendo aplicadas em problemas computacionais complexos. Por um lado, costuma ser impraticável a busca pela solução ótima desses problemas, exceto em casos muito restritos. Por outro, os sistemas dinâmicos baseados em comportamento coletivo oferecem maneiras naturais e eficientes de atingir boas soluções para esses problemas (ver Capítulo 3).

O presente trabalho de mestrado teve como objetivo o desenvolvimento de técnicas de agrupamento baseadas em comportamento coletivo e auto-organização. Essas técnicas tomam como entrada um conjunto de objetos — os dados. Faz-se cada objeto corresponder a um indivíduo do sistema. Os objetos são então colocados a interagir uns com os outros, de modo que os grupos apareçam a partir de uma organização promovida por eles próprios.

Adotaram-se abordagens em que os objetos são mantidos fixos em seu espaço de atributos, mas carregam certo tipo de "energia" (ou informação). Essa energia vai sendo gradualmente trocada entre eles. Ao final, os grupos são estabelecidos entre aqueles objetos que tomam estados de energia semelhantes.

As técnicas foram analisadas em diferentes cenários, ou seja, executaram-se as técnicas em diferentes bases de dados, cada qual procurando explorar alguns dos aspectos comumente encontrados na literatura de agrupamento. Por exemplo, bases de dados com classes sobrepostas, classes alongadas e de diferentes formas, classes desbalanceadas e de diferentes extensões, com ruído em meio aos dados etc. Tudo isso permitiu realçar as potencialidades e as limitações das técnicas aqui propostas.

A visualização dos dados e, mais ainda, a visualização da dinâmica no processo de 
formação dos grupos, são fundamentais para a compreensão das técnicas e representam um desafio por si só. Nesse sentido, procurou-se explorar diferentes formas de visualização e diferentes medidas que reflitam a evolução de certas características presentes na dinâmica das técnicas desenvolvidas neste trabalho.

Foi também abordada a tarefa do aprendizado semissupervisionado. A técnica aqui desenvolvida, entretanto, adota uma abordagem um pouco diferente: os próprios dados se movimentam pelo espaço de atributos, guiados por forças que os objetos rotulados impõem sobre os não-rotulados, na intenção de propagar seus rótulos. Foram realizadas a análise de parâmetros, simulações extensivas em diferentes bases de dados e comparação com outras técnicas de aprendizado semissupervisionado. Foram também exploradas formas de visualizar sua dinâmica em diferentes cenários, realçando suas potencialidades e limitações.

\subsection{Organização do documento}

No Capítulo 2, é exposto o problema de agrupamento de dados, trazendo conceitos importantes e desafios que esse campo carrega. Nesse mesmo capítulo, é realizada uma breve discussão sobre a tarefa de aprendizado semissupervisionado. No Capítulo 3 , é realizada uma discussão sobre os sistemas naturais caracterizados por comportamento coletivo e auto-organização, e sobre a metáfora dos sistemas naturais na solução de problemas computacionais complexos. Alguns trabalhos relacionados, ou seja, algoritmos baseados em comportamento coletivo para agrupamento de dados são também relatados. As técnicas desenvolvidas durante este trabalho de mestrado são apresentadas nos Capítulos 4 , 5 e 6. Por fim, no Capítulo 7, são colocadas as conclusões e direcionamentos para trabalhos futuros. 


\section{Capítulo 2}

\section{Agrupamento de dados}

O agrupamento de dados, tarefa de aprendizado não-supervisionado, procura agrupar os objetos de acordo com sua similaridade. Tal definição, um tanto informal, está associada ao chamado critério de agrupamento e é discutida na seção seguinte. Pelas demais seções, são tratados os assuntos de medidas de similaridade, algoritmos de agrupamento e critérios de validação. São discutidos os desafios do campo de agrupamento de dados, mostrando a complexidade do problema de agrupamento, e enfatizando que a subjetividade presente na interpretação do quê é um grupo leva a uma multiplicidade de algoritmos e conceitos. Por fim, é apresentada a tarefa de aprendizado semissupervisionado, com uma breve discussão de seus conceitos e técnicas.

\subsection{Definição e critério de agrupamento}

Informalmente, a tarefa de agrupamento de dados (clustering) pode ser entendida como: dado um conjunto não-classificado de objetos, encontrar a melhor partição desse conjunto, de modo que objetos de um mesmo grupo (cluster) sejam mais similares entre si que objetos de grupos distintos (Jain et al., 1999, Xu \& Wunsch II, 2005, Faceli et al., 2011). Mas o que significa ser mais similar? Para responder essa pergunta, é necessário introduzir o conceito de critério de agrupamento.

Considere a Figura 2.1. Em (a), (c) e (e) são mostradas três diferentes distribuições de objetos, enquanto em (b), (d) e (f) são mostradas, respectivamente, as classes que originaram tais distribuições. Espera-se que o agrupamento de (a), (c) e (e) resulte, ao menos aproximadamente, em grupos correspondentes às classes de (b), (d) e (f). Importante notar que um algoritmo de agrupamento não conheceria, evidentemente, essas classes. Mas, novamente, o que caracteriza a similaridade entre os objetos nesses três diferentes conjuntos? Será que um mesmo conceito de similaridade poderia ser usado para os três conjuntos?

Segundo Jain et al. (1999), 

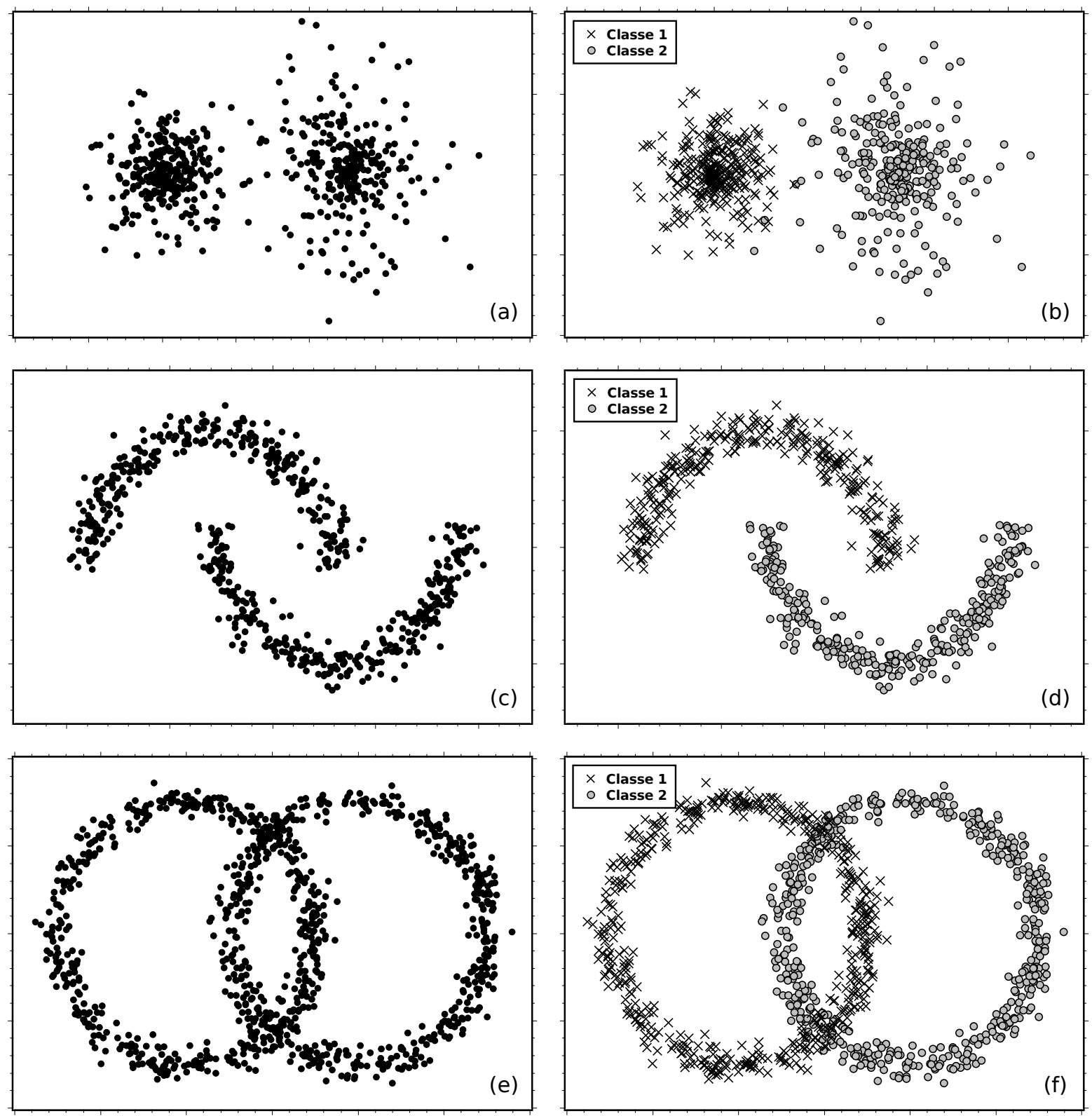

Figura 2.1: Diferentes distribuições de dados em um espaço bidimensional. (a): Dois grupos espalhados ao redor de um ponto, sendo que o da direita abrange uma área maior. (c): Objetos distribuídos por dois arcos entrelaçados. (e): Objetos distribuídos por dois anéis sobrepostos. (b), (d) e (f): Classes correspondentes às distribuições em (a), (c) e (e), respectivamente. 
"There is no clustering technique that is universally applicable in uncovering the variety of structures present in multidimensional data sets. (...) Not all clustering techniques can uncover all the clusters present here ${ }^{1}$ with equal facility, because clustering algorithms often contain implicit assumptions about cluster shape or multiple-cluster configurations based on the similarity measures and grouping criteria used."

Segundo $\mathrm{Xu} \&$ Wunsch II 2005),

"Nonpredictive clustering is a subjective process in nature, which precludes an absolute judgment as to the relative efficacy of all clustering techniques. As pointed out by Backer \& Jain (1981), 'in cluster analysis a group of objects is split up into a number of more or less homogeneous subgroups on the basis of an often subjectively chosen measure of similarity (i.e., chosen subjectively based on its ability to create "interesting" clusters), such that the similarity between objects within a subgroup is larger than the similarity between objects belonging to different subgroups'."

Segundo Faceli et al. (2011),

"(...) Embora a ideia do que constitui um cluster seja intuitiva (grupos de objetos similares), não existe uma definição formal única e precisa para esse conceito. Ao contrário, existe uma grande variedade de definições na literatura. Isso é resultado da grande diversidade de visões / objetivos dos pesquisadores de diferentes áreas que utilizam/desenvolvem algoritmos de agrupamento. (...)"

Ou seja, o conceito de similaridade entre objetos é algo subjetivo. Por exemplo, seja novamente a Figura 2.1. Alguém poderia dizer que a similaridade entre os objetos é caracterizada pela distância que os separa, sendo que objetos mais próximos são mais similares. Tudo bem, mas é possível observar que, em todas as três distribuições mostradas na figura, há pares de objetos muito próximos mas que são provenientes de classes distintas, e há pares muito distantes cujos objetos são provenientes de uma mesma classe. Faceli et al. (2011) trazem algumas definições comuns para cluster, dentre elas:

Cluster bem separado. Um cluster é um conjunto de objetos tal que qualquer objeto em um determinado cluster está mais próximo (é mais similar) a cada outro objeto nesse cluster do que a qualquer objeto que não pertence a ele. Nenhuma das distribuições da Figura 2.1 pertence a esta categoria.

Cluster baseado em centro. Um cluster é um conjunto de objetos tal que qualquer objeto em um determinado cluster está mais próximo ao centro desse cluster do

\footnotetext{
${ }^{1}$ Uma figura na qual são mostradas algumas distribuições de objetos.
} 
que ao centro de qualquer outro cluster. Na Figura 2.1(a), tomando os centros dos clusters como os pontos ao redor dos quais os objetos são distribuídos, essa configuração pertence, aproximadamente, à categoria de cluster baseado em centro. Aproximadamente porque, devido ao grupo da direita abranger uma área maior, seus objetos de fronteira acabam ficando mais perto do centro do outro grupo.

Cluster contínuo ou encadeado. Um cluster é um conjunto de objetos tal que qualquer objeto em um determinado cluster está mais próximo a um ou mais objetos nesse cluster do que a qualquer objeto que não pertence a ele. A distribuição da Figura 2.1(c) pertence a esta categoria.

Cluster baseado em densidade. Um cluster é uma região densa de objetos, separada de outras regiões de alta densidade por regiões de baixa densidade. As distribuições das Figuras 2.1(a) e (c) pertencem a esta categoria.

O critério de agrupamento é, pois, o critério usado para decidir quando dois objetos devem ou não pertencer ao mesmo grupo. Sua subjetividade impede que haja uma definição formal para a tarefa do agrupamento de dados. No entanto, uma vez definido um critério, a tarefa do agrupamento se torna encontrar a partição dos dados que melhor satisfaça o critério escolhido. Define-se assim uma função-objetivo, e a tarefa se torna minimizar (ou maximizar) essa função.

\subsection{O tamanho do problema}

Uma vez definido um critério de agrupamento e, consequentemente, uma função-objetivo a ser minimizada/maximizada, pode-se indagar se um modo simples de resolver o problema de agrupamento não seria gerar todas as possíveis partições, avaliar cada uma, e então escolher a melhor. A quantidade de partições possíveis para um conjunto contendo $n$ objetos é igual ao $n$-ésimo Bell number $B_{n}$, dado pela seguinte expressão recursiva (Wolfram MathWorld, 2013):

$$
\begin{gathered}
B_{0}=1 \\
B_{n+1}=\sum_{k=0}^{n}\left(\begin{array}{l}
n \\
k
\end{array}\right) B_{k}
\end{gathered}
$$

Para se ter uma ideia da dimensão do problema, suponha um conjunto singelo com 40 objetos. A quantidade de partições possíveis para esse conjunto ultrapassa ${ }^{2} 10^{35}$. Assumindo-se uma máquina capaz de avaliar $10^{10}$ partições por segundo (muito mais

\footnotetext{
${ }^{2}$ The First 1000 Bells numbers. Página da Web. http://www.dnull.com/bells/bell1000.html. Acessada em 10/05/2013.
} 
poderosa que as máquinas do nosso dia-a-dia), e sabendo-se que um ano possui aproximadamente $3,2 \cdot 10^{7}$ segundos, essa máquina demandaria mais de $10^{17}$ anos para avaliar todas as partições! Fica evidente a inviabilidade de algoritmos baseados em força bruta, que avaliam todas as possíveis partições a fim de escolher a melhor.

De fato, o agrupamento de dados é um problema complexo, NP-difícil, sendo considerado um problema de otimização (Jain et al., 1999; Xu \& Wunsch II, 2005; Faceli et al., 2011). Tal característica praticamente proíbe o emprego de técnicas exaustivas, baseadas em força bruta, e também explica a diversidade de algoritmos existentes para trabalhar com agrupamento de dados.

\subsection{Medidas de similaridade}

As medidas de similaridade estão diretamente relacionadas com os critérios de agrupamento e também constituem um ponto de partida para os algoritmos. Elas informam a semelhança entre dois objetos, entre dois clusters, ou entre um objeto e um cluster. No caso da similaridade entre objetos, essas medidas dependem também dos tipos de atributos que os caracterizam (qualitativos, quantitativos, ....).

Vale destacar, como exemplo, uma métrica de similaridade - ou melhor, dissimilaridade - entre dois objetos cujos atributos são numéricos e contínuos: a métrica de Minkowski $d_{p}\left(\mathbf{x}_{i}, \mathbf{x}_{j}\right)$ (Jain et al., 1999; Faceli et al., 2011):

$$
d_{p}\left(\mathbf{x}_{i}, \mathbf{x}_{j}\right)=\left(\sum_{k=1}^{D}\left|x_{i, k}-x_{j, k}\right|^{p}\right)^{\frac{1}{p}}
$$

onde $\mathbf{x}_{i}$ e $\mathbf{x}_{j}$ se referem aos objetos, $x_{i, k}$ e $x_{j, k}$ se referem aos valores de cada objeto para o atributo $k$, e $D$ se refere à dimensionalidade dos objetos, ou seja, a quantidade de atributos que os caracterizam. Trata-se, como se pode ver, de uma classe de medidas em função do parâmetro $p$. Para alguns valores de $p$, tais medidas recebem nomenclaturas especiais:

- $p=1$ : distância de Manhattan, ou bloco-cidade;

- $p=2$ : distância euclidiana, sendo esta a mais popular;

- $p \rightarrow \infty$ : distância de Chebyschev, ou supremum.

\subsection{Algoritmos de agrupamento}

Todos os algoritmos fundamentam-se em algum critério de agrupamento (Jain et al. 1999, Xu \& Wunsch II, 2005, Faceli et al., 2011). São, pois, diversos os algoritmos de agrupamento encontrados na literatura. 
Os algoritmos de agrupamento de dados costumam ser classificados em hierárquicos e particionais (Jain et al., 1999; Xu \& Wunsch II, 2005; Faceli et al., 2011). Um algoritmo hierárquico agrupa os objetos segundo uma sequência (hierarquia) de partições, desde aquela que atribui um cluster distinto para cada objeto até aquela que confina todos os objetos num único cluster. Já um algoritmo particional divide diretamente o conjunto de objetos num certo número de clusters. Ou seja, enquanto os algoritmos hierárquicos resultam numa hierarquia de partições, os algoritmos particionais resultam numa única partição.

Os algoritmos de agrupamento hierárquicos são, por sua vez, classificados em aglomerativos e divisivos (Jain et al., 1999, Xu \& Wunsch II, 2005, Faceli et al., 2011). A essencial diferença entre eles é a ordem da sequência de partições. Enquanto os algoritmos aglomerativos iniciam com uma partição que atribui um cluster distinto para cada objeto, os algoritmos divisivos seguem o caminho contrário, iniciando com uma partição que confina todos os objetos num único cluster.

$\mathrm{Xu} \&$ Wunsch II (2005), em seu survey sobre algoritmos de agrupamento, classifica-os da seguinte forma:

- Hierárquico

- Aglomerativo. Dentre seus representantes: single linkage, complete linkage e average linkage.

- Divisivo. Um desses algoritmos, desenvolvido por Oliveira (2008), é apresentado na Seção 3.2 .3 .

- Particional

- Baseado em erro quadrático, tendo o k-médias como principal representante (apresentado a seguir).

- Baseado em função densidade de probabilidade (probability density function, ou simplesmente $p d f$ ), tendo o expectation-maximization como um de seus representantes (Dempster et al., 1977).

- Outras abordagens, ora hierárquicas, ora particionais. Aqui são enquadrados os algoritmos baseados em grafo, em otimização combinatória, em redes neurais artificiais, em densidade (como o DBSCAN, apresentado a seguir) etc.

Descrevem-se, a seguir, alguns dos algoritmos de agrupamento. Um representante de três diferentes categorias:

- k-médias (baseado em erro quadrático);

- um conjunto clássico de algoritmos hierárquicos aglomerativos, que inclui o single linkage, complete linkage e average linkage; 
- DBSCAN (baseado em densidade).

\subsubsection{K-médias}

O k-médias é um dos mais populares algoritmos de agrupamento (MacQueen, 1967; Lloyd, 1982 Hastie et al., 2001; Alpaydin, 2004; Xu \& Wunsch II, 2009, Faceli et al., 2011). Pertence à classe dos algoritmos particionais baseados em erro quadrático. Cada cluster é denotado por seu centroide, ou seja, pelo vetor que representa a média de seus objetos. O objetivo é então encontrar $K$ centroides que minimize o erro quadrático da partição formada.

O centroide (mean) $\mathbf{m}_{k}$ de um cluster $C_{k}$ é definido como

$$
\mathbf{m}_{k}=\frac{1}{N_{k}} \sum_{\mathbf{x}_{i} \in C_{k}} \mathbf{x}_{i}
$$

onde $N_{k}$ representa a quantidade de objetos (cardinalidade) do cluster $C_{k}$ e $\mathbf{x}_{i}$ representa cada um dos objetos pertencentes a $C_{k}$.

Para alguma partição do conjunto de objetos, define-se o erro quadrático $E$ como sendo

$$
E=\sum_{k=1}^{K} \sum_{\mathbf{x}_{i} \in C_{k}}\left\|\mathbf{x}_{i}-\mathbf{m}_{k}\right\|^{2}
$$

onde $\left\|\mathbf{x}_{i}-\mathbf{m}_{k}\right\|$ representa a distância euclidiana entre $\mathbf{x}_{i}$ e $\mathbf{m}_{k}$.

O algoritmo k-médias oferece um procedimento iterativo para encontrar os $K$ centroides. Tal procedimento procura minimizar o erro quadrático intercalando-se duas operações: (1) atribuir cada objeto ao centroide mais próximo e (2) recalcular cada centroide. No Algoritmo 1 é mostrado todo o procedimento do algoritmo k-médias.

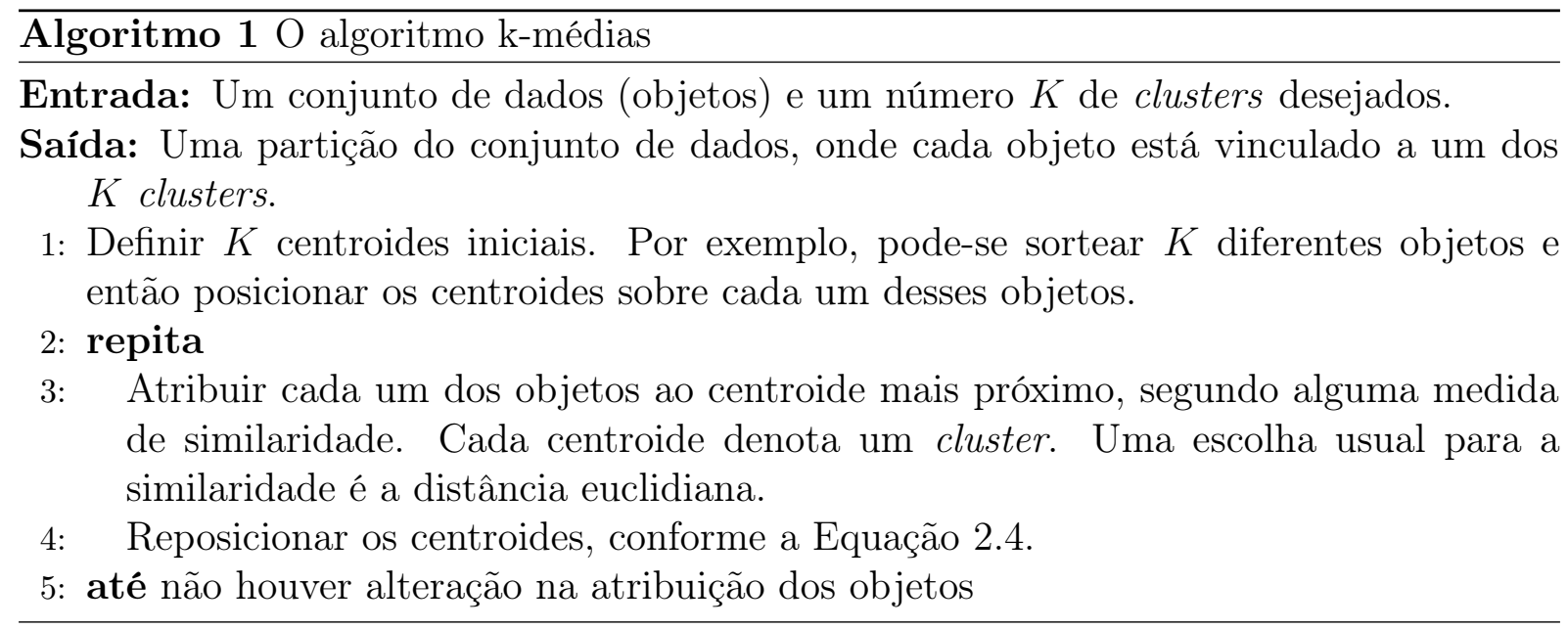

O algoritmo k-médias é adequado para conjuntos que exibam clusters hiperesféricos de tamanhos equivalentes ou clusters bem separados. Seu resultado é, entretanto, sensível 
à configuração inicial dos centroides. O algoritmo frequentemente fica preso em soluções sub-ótimas.

\subsubsection{Agrupamento hierárquico aglomerativo}

Existe, na literatura, um conjunto de algoritmos clássicos de agrupamento hierárquico aglomerativo (Hastie et al., 2001, Alpaydin, 2004; Xu \& Wunsch II, 2009; Faceli et al., 2011). Como tais, o resultado desses algoritmos é uma hierarquia de partições, desde aquela que atribui um cluster distinto para cada objeto, até aquela que confina todos os objetos num único cluster.

No Algoritmo2, é mostrado o procedimento comum aos algoritmos clássicos de agrupamento hierárquico aglomerativo. Pode-se observar, na linha 3, que é necessária a definição de alguma medida de similaridade entre clusters. São justamente as diferentes medidas que caracterizam os diferentes algoritmos. A seguir, são descritas três dessas medidas, caracterizando três algoritmos distintos: single linkage, complete linkage e average linkage.

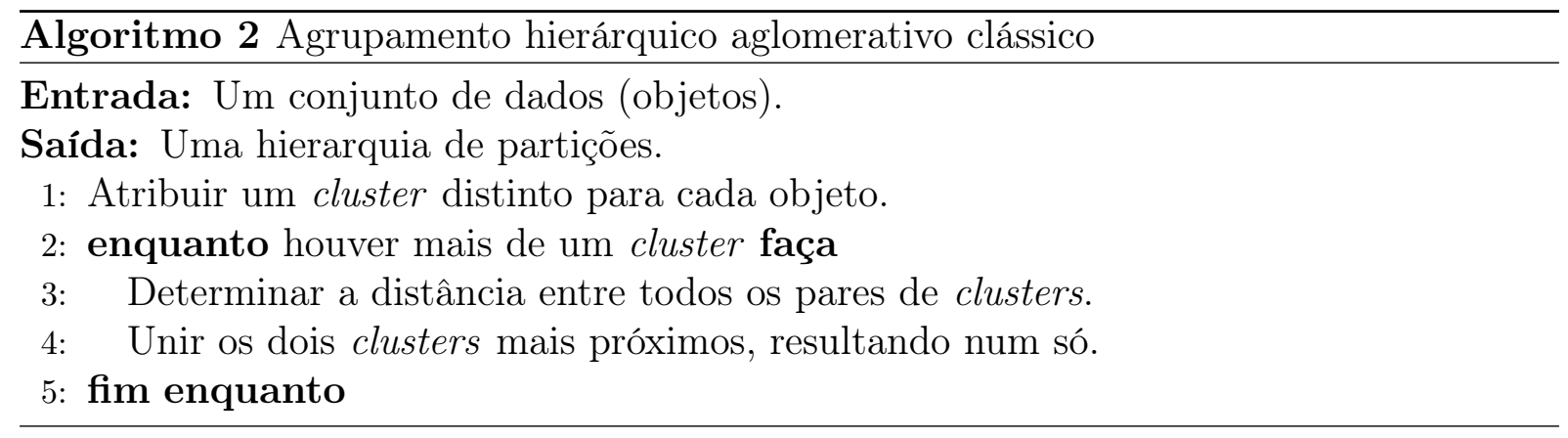

Single linkage. A distância $d\left(C_{i}, C_{j}\right)$ entre dois clusters $C_{i}$ e $C_{j}$ é dada pela distância entre os dois objetos mais próximos, sendo um objeto de cada cluster. Ou seja,

$$
d\left(C_{i}, C_{j}\right)=\min \left(d\left(\mathbf{x}_{m}, \mathbf{x}_{n}\right)\right), \quad \forall \mathbf{x}_{m} \in C_{i}, \mathbf{x}_{n} \in C_{j}
$$

onde $d\left(\mathbf{x}_{m}, \mathbf{x}_{n}\right)$ representa a distância entre dois objetos $\mathbf{x}_{m}$ e $\mathbf{x}_{n}$ segundo alguma medida de similaridade entre objetos, por exemplo, a distância euclidiana.

Complete linkage. A distância entre dois clusters é dada pela distância entre os dois objetos mais distantes, sendo um objeto de cada cluster. Ou seja,

$$
d\left(C_{i}, C_{j}\right)=\max \left(d\left(\mathbf{x}_{m}, \mathbf{x}_{n}\right)\right), \quad \forall \mathbf{x}_{m} \in C_{i}, \mathbf{x}_{n} \in C_{j}
$$

Average linkage. A distância entre dois clusters é dada pela média das distâncias de todos os pares de objetos, sendo um objeto de cada cluster. Ou seja,

$$
d\left(C_{i}, C_{j}\right)=\frac{1}{\left|C_{i}\right|\left|C_{j}\right|} \sum_{\mathbf{x}_{m} \in C_{i}} \sum_{\mathbf{x}_{n} \in C_{j}} d\left(\mathbf{x}_{m}, \mathbf{x}_{n}\right)
$$




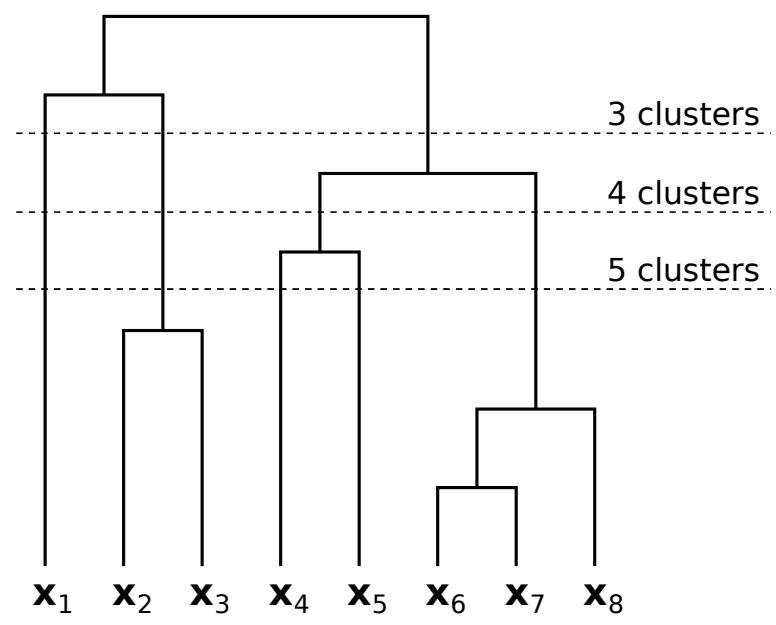

Figura 2.2: Exemplo de um dendrograma. 8 objetos $\left(\mathbf{x}_{1}, \ldots, \mathbf{x}_{8}\right)$ são agrupados segundo uma hierarquia de partições. As linhas tracejadas cortam o dendrograma em três diferentes partições, cada uma contendo um número diferente de clusters.

onde $\left|C_{i}\right|$ e $\left|C_{j}\right|$ denotam a quantidade de objetos dos clusters $C_{i}$ e $C_{j}$, respectivamente.

Uma hierarquia de partições pode ser visualizada por uma estrutura chamada dendrograma. Na Figura 2.2. é mostrado um exemplo de dendrograma. A partir dessa estrutura, é possível notar que a partição definitiva pode ser obtida escolhendo-se o número desejado de clusters e então tomando-se a correspondente partição.

\subsubsection{DBSCAN}

DBSCAN (Density-Based Spatial Clustering of Applications with Noise), como seu nome sugere, é um algoritmo de agrupamento baseado em densidade de objetos (Ester et al. 1996, Xu \& Wunsch II, 2009). Como tal, considera os clusters como sendo formados por regiões densas de objetos e separados uns dos outros por regiões de baixa densidade.

A fim de definir os clusters, o DBSCAN faz uso de dois conceitos: alcançabilidadepor-densidade (density-reachability) e conectividade-por-densidade (density-connectivity). Seja

$$
N_{\epsilon}(\mathbf{x})=\{\mathbf{y} \mid d(\mathbf{x}, \mathbf{y}) \leq \epsilon\}, \quad \mathbf{y} \neq \mathbf{x}
$$

onde $d(\mathbf{x}, \mathbf{y})$ é a distância ou dissimilaridade entre dois objetos $\mathbf{x}$ e $\mathbf{y}$. Esse conjunto é chamado de $\epsilon$-vizinhança de $\mathbf{x}$, e reúne todos os demais objetos cuja distância até $\mathbf{x}$ é menor ou igual a um dado parâmetro $\epsilon$. Seja também $\left|N_{\epsilon}(\mathbf{x})\right|$ a cardinalidade desse conjunto.

Um objeto $\mathbf{y}$ é dito ser alcançável-por-densidade a partir de outro objeto $\mathbf{x}$ se existir uma sequência finita de objetos $\mathbf{x}_{1}=\mathbf{x}, \mathbf{x}_{2}, \mathbf{x}_{3}, \ldots, \mathbf{y}$ tal que

1. $\mathbf{x}_{i+1} \in N_{\epsilon}\left(\mathbf{x}_{i}\right)$, e 


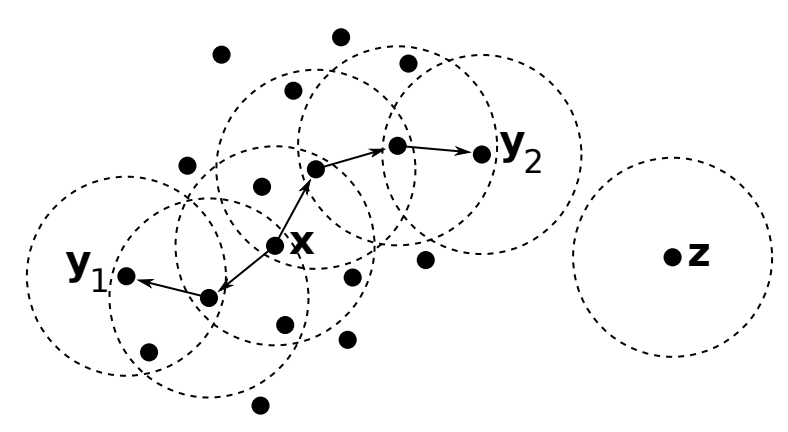

Figura 2.3: Os conceitos de alcançabilidade-por-densidade e conectividade-por-densidade. Assume-se MinPts $=3$. As linhas tracejadas delimitam a $\epsilon$-vizinhança de alguns objetos. $\mathbf{y}_{1}$ e $\mathbf{y}_{2}$ são objetos de borda e ambos são alcançáveis-por-densidade a partir de um mesmo objeto interior $\mathbf{x}$. Portanto $\mathbf{y}_{1}$ e $\mathbf{y}_{2}$ estão conectados-por-densidade. Já o objeto $\mathbf{z}$ não possui nenhum vizinho, portanto é considerado ser um outlier.

2. $\left|N_{\epsilon}\left(\mathbf{x}_{i}\right)\right| \geq$ MinPts, onde MinPts é um parâmetro que informa o número mínimo de objetos que deveriam estar presentes na vizinhança de $\mathbf{x}_{i}$.

De acordo com a condição 2, os objetos deveriam conter um número suficiente de vizinhos (MinPts) dentro de um cluster. Um objeto que satisfaz essa condição é chamado de objeto interior (core object). Trata-se de um objeto numa região considerada suficientemente densa. Em contrapartida, há outros dois tipos de objeto: objeto de borda (border object) e outlier. Objetos que não são interiores, mas que são alcançáveis-por-densidade a partir de outros objetos interiores, são chamados de objetos de borda. São justamente os objetos localizados nas bordas de um cluster. Por fim, objetos que não são nem interiores nem de borda são considerados outliers.

Uma vez que dois objetos de borda pertencentes a um mesmo cluster não são alcançáveispor-densidade um a partir do outro, é introduzido o conceito de conectividade-por-densidade. Um objeto $\mathbf{y}_{1}$ é dito estar conectado-por-densidade a outro objeto $\mathbf{y}_{2}$ se existir um objeto $\mathbf{x}$ tal que $\mathbf{y}_{1}$ e $\mathbf{y}_{2}$ sejam ambos alcançáveis-por-densidade a partir de $\mathbf{x}$. Dois objetos são também considerados conectados-por-densidade caso ao menos um deles seja alcançável-por-densidade a partir do outro. Ilustram-se, na Figura 2.3. os conceitos de alcançabilidade-por-densidade e conectividade-por-densidade.

Por fim, o algoritmo DBSCAN estabelece um cluster a partir da seguinte condição:

Para qualquer par de objetos $\mathbf{x}_{i}$ e $\mathbf{x}_{j}, \mathbf{x}_{i}$ e $\mathbf{x}_{j}$ pertencerão ambos a um mesmo cluster $C$ se e somente se estiverem conectados-por-densidade um ao outro.

Assim, o algoritmo DBSCAN constrói os clusters a partir de objetos interiores, absorvendo (agrupando) recursivamente todos os demais objetos em sua vizinhança. 


\subsection{Critérios de validação}

Qualquer algoritmo de agrupamento sempre encontrará clusters em qualquer conjunto de dados (Jain et al., 1999; Xu \& Wunsch II, 2005; Faceli et al., 2011). Contudo, resta saber se a partição encontrada realmente reflete estruturas existentes nos dados, ou é apenas um artefato do próprio algoritmo. Para tanto, critérios de validação são propostos a fim de mensurar o quanto essas partições refletem as estruturas possivelmente presentes nos conjuntos de dados.

Sabe-se, entretanto, que a tarefa de agrupamento é subjetiva e está sempre fundamentada em algum critério de agrupamento. Tal característica acaba sendo propagada aos algoritmos, que também são fundamentados em algum critério de agrupamento. Ainda assim, os critérios de validação não apenas são úteis, mas também necessários. Desse modo, a interpretação de seus resultados deve sempre levar em conta as dependências entre os diferentes algoritmos e os diferentes critérios de agrupamento. De acordo com Faceli et al. (2011), os critérios de agrupamento influenciarão, de alguma forma, os critérios de validação, devendo estes (validação) ser aplicados com cautela para assim produzir uma medida significativa.

Alguns índices estatísticos são propostos para avaliar de modo objetivo e quantitativo os resultados de diferentes agrupamentos (Jain et al., 1999; Xu \& Wunsch II, 2005; Faceli et al. 2011). Esses índices são classificados em três categorias: relativos, internos e externos:

Relativo. Compara diversos agrupamentos para decidir qual deles é o melhor em algum aspecto. Pode ser utilizado para comparar diferentes algoritmos ou para determinar o valor mais apropriado para um certo parâmetro de um algoritmo. Por exemplo, um índice relativo pode ser utilizado na determinação do número mais adequado de clusters. Nesse caso, o algoritmo é executado para todos os possíveis números de clusters $k$. A relação entre o valor $k$ e o valor do índice dirá o número mais apropriado de clusters existentes no conjunto de dados.

Interno. Mede o grau em que uma partição obtida por um algoritmo de agrupamento representa uma estrutura realmente presente nos dados, levando em conta apenas o próprio conjunto de dados. Claro que estes índices baseiam-se, por sua vez, em outras medidas, por exemplo o erro quadrático. Consequentemente, alguma suposição é feita com respeito à distribuição dos dados.

Externo. Mede o quanto o agrupamento obtido confirma uma hipótese pré-especificada. Baseia-se em algum conhecimento prévio sobre os dados. Por exemplo, pode-se comparar o resultado de um agrupamento com uma partição previamente conhecida (classes previamente conhecidas). 
Vale descrever em maiores detalhes um desses índices: o indice Rand. Trata-se de um índice externo bastante simples, porém muito útil. Como tal, compara a partição resultante do algoritmo com uma partição de referência, previamente conhecida. Sejam:

a: o número de pares de objetos do mesmo cluster (algoritmo) e da mesma classe (referência);

b: o número de pares de objetos do mesmo cluster (algoritmo) mas de diferentes classes (referência);

c: o número de pares de objetos de diferentes clusters (algoritmo) mas da mesma classe (referência);

d: o número de pares de objetos de diferentes clusters (algoritmo) e de diferentes classes (referência).

Então o indice Rand $R$ é dado por (Xu \& Wunsch II, 2009, Faceli et al., 2011)

$$
R=\frac{a+d}{a+b+c+d}
$$

Notar que $a+b+c+d$ equivale ao número total de pares presentes no conjunto de dados. Esse índice resulta em valores no intervalo $[0 ; 1]$. Na prática, contudo, valores muito pequenos não ocorrem. Até mesmo uma partição aleatória resulta em torno de 0,5. O valor 1 significa que as duas partições coincidem exatamente.

\subsection{Aprendizado semissupervisionado}

A tarefa de aprendizado semissupervisionado - especificamente o aprendizado transdutivo - pode ser entendida como: dado um conjunto contendo objetos rotulados (classificados) e não-rotulados (não-classificados), objetiva-se propagar os rótulos dos objetos previamente classificados aos ainda não-classificados (Seeger, 2002; Chapelle et al., 2006a; Zhu, 2008, Zhu \& Goldberg, 2009, Silva \& Zhao, 2012b). Nesse processo, leva-se em conta não somente a localização dos dados rotulados, mas também o padrão de distribuição dos próprios dados não-rotulados.

A fração de dados inicialmente rotulados costuma ser bem pequena, e é aí que reside uma característica fundamental do aprendizado semissupervisionado. Tipicamente, a rotulação de dados envolve a intervenção de um profissional especialista, o que torna tal tarefa onerosa. Ao mesmo tempo, a existência de poucos dados previamente rotulados já constitui uma informação valiosa aos algoritmos de aprendizado semissupervisionado, dando a estes uma certa vantagem em relação aos algoritmos de aprendizado não-supervisionado. Assim, o aprendizado semissupervisionado explora a vantagem de 


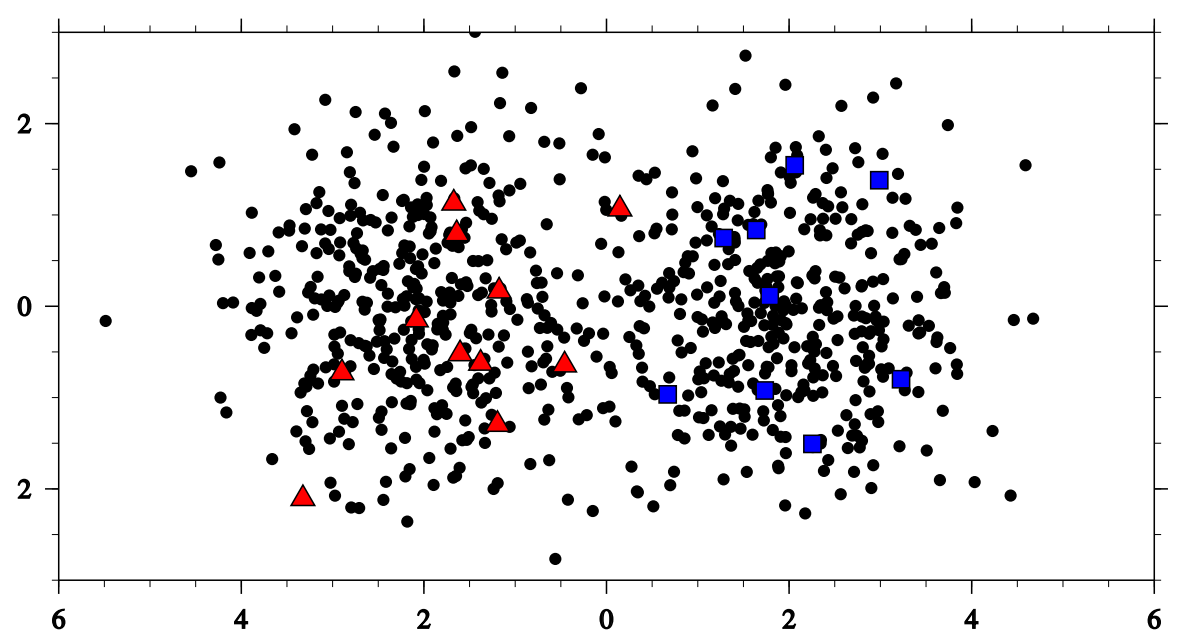

Figura 2.4: Conjunto artificial de dados formado por duas gaussianas. Os dados inicialmente rotulados, em menor quantidade, estão destacados na figura, e seus diferentes símbolos denotam seus diferentes rótulos: "triângulo" e "quadrado".

se ter dados rotulados por um especialista, mas mantendo viável seu custo, devido à necessidade de se rotular poucos dados.

Na Figura 2.4 mostra-se um típico conjunto de dados do aprendizado semissupervisionado. Nesse exemplo, mostra-se um conjunto artificial de dados, cada um caracterizado por dois atributos (conjunto bidimensional). O aprendizado semissupervisionado não se restringe, contudo, a conjuntos de dados semelhantes aos da figura. Ele abrange dados com atributos qualitativos (não-numéricos), dados caracterizados por redes, dados originados em fluxo (fluxo de dados) etc.

Como mencionado, a definição acima se refere ao aprendizado transdutivo, onde a tarefa é propagar os rótulos aos demais objetos já existentes. O aprendizado semissupervisionado não se restringe, porém, ao aprendizado transdutivo. Inclui também o aprendizado indutivo, onde objetiva-se encontrar uma função capaz de classificar novos objetos, ou seja, objetos indisponíveis durante o processo de aprendizado (Chapelle et al., 2006a).

Diversas abordagens têm sido propostas para aprendizado semissupervisionado. Os modelos gerativos procuram estimar os parâmetros das distribuições que supostamente "geraram" os padrões presentes no conjunto de dados. Há, por exemplo, extensões do algoritmo Expectation-Maximization (EM) para o aprendizado semissupervisionado (Nigam et al., 2006). O algoritmo, originalmente desenvolvido para o aprendizado nãosupervisionado, assume que os dados foram gerados por sobreposição de distribuições gaussianas (como as duas classes da Figura 2.4) (Dempster et al., 1977; Hastie et al., 2001; Xu \& Wunsch II, 2009). Então o algoritmo EM procura determinar quais são os parâmetros - médias e variâncias — cujas gaussianas melhor refletem os dados observados. Qualquer informação adicional sobre os dados pode ser útil. Quando estendido ao aprendizado semissupervisionado, o algoritmo tira proveito justamente das informações 
dos rótulos.

Outros algoritmos procuram afastar, dos dados não-rotulados, as superfícies de decisão, consequentemente empurrando essas superfícies para regiões de baixa densidade. As máquinas de vetores de suporte (support vector machines - SVMs), empregadas no aprendizado supervisionado, procuram posicionar as curvas de decisão de modo a mantê-las o mais afastado possível dos objetos, neste caso, rotulados (Hastie et al., 2001; Alpaydin, 2004 Faceli et al. 2011). Já as SVMs transdutivas (transductive SVMs - TSVMs) estendem essa ideia para o aprendizado semissupervisionado (Joachims, 2006). Aqui, as superfícies de decisão não apenas separam os objetos (rotulados) de classes distintas, mas utilizam os não-rotulados — presentes em grande número — de modo a posicionar tais superfícies onde haja a menor concentração desses objetos (regiões de baixa densidade).

Há ainda os métodos baseados em rede (grafo), que figuram entre os mais estudados em aprendizado semissupervisionado (Bengio et al., 2006, Sindhwani et al., 2006; Zhou \& Schölkopf, 2006; Silva \& Zhao, 2012b). Cada objeto torna-se um vértice da rede. As arestas podem ou não ser ponderadas, e definem se há e com que intensidade há uma relação entre dois objetos. Há conjuntos de dados que são naturalmente descritos como uma rede, como a Internet, a Web, redes sociais etc. Mas mesmo conjuntos cujos dados são vetores de atributos dispostos num espaço n-dimensional podem ser convertidos para uma representação em rede, ligando-se cada objeto aos seus vizinhos mais próximos. Os métodos baseados em rede são usualmente transdutivos (Bengio et al., 2006; Sindhwani et al. 2006, Zhou \& Schölkopf, 2006). Eles estimam os rótulos dos dados já presentes, não generalizam funções para classificar novos dados, embora abordagens para indução de funções têm também sido propostas (Sindhwani et al., 2006).

Dentre os métodos de aprendizado baseados em rede, vale destacar a técnica de competição de partículas em redes complexas (Silva \& Zhao, 2012a b c Silva et al., 2012). As redes complexas surgiram da representação de sistemas complexos em vários ramos da ciência, e são caracterizadas como redes (grafos) muito grandes e de topologia não-trivial (Albert \& Barabási, 2002, Newman, 2003, Barrat et al., 2008). A técnica de competição de partículas pode ser aplicada para detecção de comunidades $^{3}$ ou para agrupamento, dependendo da natureza dos dados. Em essência, a tarefa de agrupamento pode ser vista como uma tarefa de deteçã̃o de comunidades, uma vez que qualquer conjunto de dados pode ser modelado como uma rede, baseando-se em alguma medida de similaridade. Pode ainda ser aplicada, claro, no aprendizado semissupervisionado, onde há alguns vértices já classificados (Silva \& Zhao, 2012b). A técnica consiste em dispor um conjunto de partículas sobre a rede. Cada partícula (ou grupo de partículas) carrega um rótulo. Iterativamente elas caminham pela rede, mesclando movimentos aleatórios e preferenciais, de modo a dominar vértices frequentemente visitados por elas. As partículas vão então

\footnotetext{
${ }^{3} \mathrm{~A}$ tarefa de detecção de comunidades em redes consiste em identificar grupos de vértices densamente conectados.
} 
disputando territórios (as comunidades), e ao final cada partícula (ou grupo de partículas) se estabiliza numa região, marcando-a com o respectivo rótulo.

O aprendizado semissupervisionado encontra suas aplicações em cenários onde a obtenção dos dados é fácil, mas sua rotulação é onerosa e envolve, tipicamente, a intervenção de um especialista. Alguns exemplos são listados a seguir (Chapelle et al., 2006a).

- Em reconhecimento de fala, é fácil gravar grandes quantidades de fala, mas sua rotulação exige que uma pessoa ouça cada unidade e anote sua transcrição.

- Bilhões de páginas Web estão disponíveis para processamento automático, mas classificá-las adequadamente exige que pessoas as leiam.

- Sequências de proteínas são hoje adquiridas em escala industrial, mas resolver sua estrutura tridimensional ou determinar as funções de uma simples proteína pode exigir anos de trabalho científico.

\subsection{Desafios}

A tarefa do agrupamento de dados é um tanto desafiadora, assim como outras tarefas do aprendizado de máquina. A aliança entre (1) a presença do agrupamento de dados em diversas outras disciplinas, (2) a ausência de uma definição formal e única para a tarefa do agrupamento, e (3) sua complexidade computacional, conduz a uma multiplicidade de algoritmos, cada qual tratando o problema de um modo distinto (Jain et al., 1999, Xu \& Wunsch II, 2005, Faceli et al., 2011). Não bastando, novas tecnologias geram tarefas mais complexas e desafiadoras, requerendo algoritmos cada vez mais poderosos. Assim, sempre haverá espaço para pesquisa no campo de agrupamento de dados. Cada novo problema que surge tem, eventualmente, uma característica nova, demandando soluções também novas. E claro, os esforços para unificar toda essa diversidade de soluções continuarão.

$\mathrm{Xu} \&$ Wunsch II (2005), em seu survey sobre algoritmos de agrupamento, elencam alguns aspectos importantes que novos algoritmos devem procurar satisfazer:

- trabalhar com clusters de formas arbitrárias, ao invés de ser restrito a alguma forma particular;

- manipular grandes volumes de dados e dados de alta dimensionalidade (muitos atributos), mantendo as complexidades de tempo e espaço aceitáveis;

- detectar possíveis outliers e ruídos;

- minimizar sua dependência sobre parâmetros externos (parâmetros fornecidos por um analista); 
- ser incremental, ou seja, ser capaz de associar novos dados a algum resultado de agrupamento previamente obtido, sem a necessidade de reagrupar tudo de novo;

- ser insensível à ordem em que os dados são apresentados;

- prover alguma dica com respeito ao número potencial de clusters;

- prover, ao analista, uma boa visualização dos dados e prover resultados que realmente facilitem a análise desses dados;

- manipular objetos formados por atributos diversos (qualitativos, quantitativos, ... ).

\subsection{Considerações finais}

Foi visto, neste capítulo, que o agrupamento de dados é um problema com muitas facetas. Não há uma definição formal e única para ele. Tudo começa com o critério de agrupamento que, subjetivo, conduz a uma multiplicidade de algoritmos, cada qual tratando o problema de agrupamento sob uma ótica distinta. Até mesmo os critérios de validação, que são formas de comparar diferentes algoritmos, são influenciados pelos critérios de agrupamento. Isso faz com que os resultados da validação ainda devam levar em conta a influência dos critérios de agrupamento.

Pode-se dizer que (Jain et al., 1999, Xu \& Wunsch II, 2005, Faceli et al., 2011):

- não há algoritmo de agrupamento universal, capaz de resolver todos os problemas;

- apesar da existência de algoritmos bem-sucedidos, ainda há muitas questões nãoresolvidas, e os esforços para criar novos - e melhores - algoritmos continuarão;

- novas tecnologias geram tarefas mais complexas e desafiadoras, requerendo algoritmos cada vez mais poderosos.

No capítulo seguinte, é mostrado como algoritmos inspirados na natureza, em especial os baseados em comportamento coletivo, são capazes de lidar com a complexidade do agrupamento de dados, oferecendo bons resultados. Eles não solucionam a subjetividade presente nos critérios de agrupamento. Ainda assim, esses algoritmos oferecem alternativas elegantes e poderosas na descoberta de padrões existentes nos conjuntos de dados. 


\section{Capítulo 3}

\section{Comportamento coletivo e auto-organização}

Além de sua intrínseca elegância, a inspiração na natureza tem sido uma prática valiosa na solução de problemas computacionais, especialmente problemas complexos, de otimização. É vasta a quantidade dessas inspirações, tais como:

Redes neurais artificiais. Modelos computacionais inspirados na estrutura e funcionamento das redes neurais biológicas (Haykin, 1999, Alpaydin, 2004, Faceli et al., 2011). Constituem-se de unidades processadoras chamadas neurônios artificiais, cada qual capaz de computar uma função matemática. A interconexão de várias dessas unidades, formando a rede, torna tais sistemas capazes de realizar tarefas relativamente complexas de reconhecimento de padrões.

Otimização por colônia de formigas. Classe de técnicas computacionais para problemas que podem ser reduzidos a encontrar bons caminhos em grafos (Bonabeau et al., 1999, Engelbrecht, 2006). Inspira-se no comportamento coletivo das formigas. Estas, na procura por fontes de alimento, realizam percursos inicialmente aleatórios. Conforme caminham, as formigas vão depositando feromônio por onde passam. Tais caminhos marcados com feromônio tendem a ser seguidos por outras formigas, reforçando-os ainda mais. O resultado disso é que caminhos mais promissores (melhores soluções para um determinado problema) vão suprimindo caminhos inferiores.

Otimização por nuvem de partículas (particle swarm optimization). Inspira-se no movimento organizado de grandes grupos de animais, especialmente pássaros e peixes (Kennedy \& Eberhart, 1995, 2001; Engelbrecht, 2006). Essa técnica é constituída por uma população de partículas que exploram o espaço de busca (espaço de soluções de um determinado problema) de maneira inicialmente aleatória. À medida que algumas partículas encontram regiões do espaço mais promissoras, são seguidas 
pelas demais. Entretanto, as partículas ainda mantêm certa liberdade para explorar novas regiões, procurando soluções ainda melhores.

Algoritmo genético. Algoritmo evolutivo inspirado no processo de evolução natural (Kennedy \& Eberhart, 2001; Engelbrecht, 2006). Cada indivíduo representa uma solução do problema. Essa técnica se inicia com uma população de soluções aleatórias e segue geração a geração. Define-se aptidão (fitness) como sendo a capacidade do indivíduo transmitir suas características às gerações seguintes, ao mesmo tempo correspondendo à qualidade de uma solução. Assim, indivíduos com mais aptidão (melhores soluções) sofrem recombinações e mutações, criando-se uma nova geração diferente da anterior, mas ainda mantendo várias das características desses indivíduos. Indivíduos com menos aptidão, por outro lado, têm dificuldade em propagar suas características adiante. Desse modo, espera-se que cada nova geração contenha uma população de soluções melhores que as anteriores.

Algoritmo de pesquisa gravitacional (gravitational search algorithm). Baseado nas leis de gravitação, esse algoritmo espalha diversas partículas dotadas de massa pelo espaço de soluções do problema (Rashedi et al. 2009). Cada partícula representa uma solução. Sua massa é tão maior quanto melhor for a solução. Partículas com mais massa são mais inertes, portanto são mais resistentes ao movimento. Assim, as partículas se atraem mutuamente e o sistema é conduzido a boas soluções. Notar que, conforme as partículas se movem, suas massas são atualizadas conforme a qualidade da solução que cada qual representa.

Vicsek \& Zafiris (2010), em seu survey intitulado Collective Motion, mostram a fascinante beleza da natureza, presente no movimento coordenado de grandes grupos de indivíduos. Partindo de indivíduos relativamente simples, como macromoléculas, passando por colônias de bactérias, até grandes mamíferos, mostra-se que todos esses grupos são capazes de exibir movimento coletivamente coordenado a partir de interações relativamente simples entre seus indivíduos. Esse movimento coletivo é, na verdade, a manifestação de uma classe de fenômenos ainda mais geral: o comportamento coletivo.

Segundo Vicsek \& Zafiris, a mais notável característica do comportamento coletivo é que as ações de um indivíduo são dominadas pela influência dos outros, ou seja, o indivíduo se comporta de modo completamente diferente dentro de um grande grupo do que ele se comportaria isoladamente. É justamente a partir desse comportamento coletivo que, sob determinadas circunstâncias, emerge-se um estado de ordem evidente, resultado de uma auto-organização.

A auto-organização é, pois, caracterizada pelo surgimento de padrões globais originados espontaneamente das interações locais entre os indivíduos que constituem o sistema, fenômeno conhecido precisamente como emergência (Vicsek et al., 1995, Toner \& Tu, 1995, 
1998, Bonabeau et al., 1999, Heylighen, 1999, Kennedy \& Eberhart, 2001; Engelbrecht, 2006; Chaté et al., 2008; Banzhaf, 2009, Ginelli et al., 2010; Menon, 2010; Ramaswamy, 2010; Vicsek \& Zafiris, 2010, Ngo et al., 2012, Peshkov et al., 2012; Sumino et al., 2012, Toner, 2012a b). Essa ordem surge na ausência de uma autoridade central, eventualmente externa, planejando e ditando como o sistema deve se comportar.

O processo de auto-organização é usado para explicar diversos fenômenos nas Ciências Naturais (Banzhaf, 2009). Desde sistemas não-vivos, que vão de galáxias inteiras, passando por estrelas, até um minúsculo agregado de nanopartículas. Alcançando sistemas vivos como células, organismos e ecossistemas. Em todos está presente a auto-organização.

Sistemas auto-organizáveis costumam ser robustos e flexíveis, pois são tolerantes a imprecisões, ruídos e falhas (Heylighen, 1999). Toda essa robustez e flexibilidade é desejável em muitos sistemas computacionais, o que conduz muitos trabalhos a se apoiarem em sistemas auto-organizáveis (Heylighen, 1999). Além disso, a própria natureza descentralizada dos fenômenos auto-organizáveis os tornam perfeitamente adequados a serem implementados em arquiteturas paralelas, distribuídas, algo muito desejável hoje em dia (Heylighen, 1999).

No campo de agrupamento de dados, é crescente o interesse em abordagens alternativas aos métodos tradicionais. Abordagens inspiradas na natureza, em especial aquelas baseadas em grandes grupos de elementos que interagem entre si (comportamento coletivo), vêm ganhando espaço e mostrando-se muito eficientes (Blatt et al., 1997; Omran et al., 2002, Zhao et al., 2005; Abraham et al., 2007; Oliveira, 2008). Ou seja, os métodos inspirados em fenômenos naturais vêm se tornando uma alternativa aos métodos tradicionais.

Pelas seções seguintes, é primeiramente apresentada uma visão geral de como os estudos sobre comportamento coletivo são conduzidos em outras ciências. Depois, são apresentados alguns trabalhos relacionados, ou seja, algoritmos baseados em comportamento coletivo para agrupamento de dados. É feita, por fim, uma breve discussão com respeito aos desafios presentes nos estudos sobre comportamento coletivo e auto-organização.

\subsection{Os estudos sobre comportamento coletivo}

Um dos grandes desafios dos sistemas baseados em comportamento coletivo é que não se pode "programar" o padrão global emergente, mas apenas as interações locais entre os indivíduos. Em outras palavras, é difícil compreender as leis locais que originam um fenômeno coletivo global, se somente o próprio fenômeno global pode ser observado. Nesse sentido, cientistas têm procurado por características comuns, talvez universais, presentes no movimento coletivo de animais, bactérias, células em geral, motores moleculares etc., caracterizando o que vem sendo chamado de matéria ativa (Vicsek et al., 1995, Toner \& $\mathrm{Tu}, 1995$, 1998, Chaté et al., 2008; Ginelli et al., 2010, Menon, 2010, Ramaswamy, 2010, 
Vicsek \& Zafiris, 2010; Ngo et al., 2012, Peshkov et al., 2012, Sumino et al., 2012, Toner, 2012a b). Trata-se de um campo de pesquisa interdisciplinar que vem ganhando muita atenção. Toda essa pesquisa nos equipa, hoje, com resultados práticos e teóricos, embora haja muito ainda a ser feito.

Sumino et al. (2012) evidenciam a existência de certas classes universais do fenômeno de movimento coletivo (flocking). Eles realizaram experimentos com microtúbulos (motores moleculares) capazes de se alinhar quando colidem entre si. Em altas concentrações, um fenômeno de auto-organização se torna visível numa macroescala: a população de microtúbulos dá origem a um retículo de vórtices (turbilhões ou redemoinhos). Os autores confirmaram os mesmos resultados modelando matematicamente e simulando o comportamento dos microtúbulos, o que permitiu conhecer os eventos locais que originam a organização global observada. Enquanto trabalhos como o de Sumino et al. (2012) trazem uma visão mais empírica, outros como os de Toner \& Tu (1995, 1998), Ramaswamy (2010), Peshkov et al. (2012) e Toner (2012a b) enfatizam também um lado mais teórico do assunto.

A fim de ilustrar tais estudos sobre movimento coletivo, consideremos o trabalho de Vicsek et al. (1995). Trata-se de um trabalho bastante referenciado sobre o assunto (Toner \& Tu, 1995; Chaté et al., 2008; Ginelli et al., 2010; Menon, 2010; Ramaswamy, 2010; Ngo et al., 2012 Peshkov et al., 2012; Sumino et al., 2012). Nele, os autores propõem um modelo dinâmico e coletivo formado por partículas autopropulsionadas (semelhante aos motores moleculares). Seu intuito é estudar as diferentes fases que o sistema exibe. Mostra-se que a partir de um modelo relativamente simples, com interações simples entre os indivíduos, o sistema é capaz de exibir um comportamento global mais complexo, resultando no movimento coordenado das partículas. Em algumas circunstâncias, o sistema parte de um estado sem transporte ${ }^{1}$ (média das velocidades aproximadamente zero) e espontaneamente entra num estado de transporte.

Cada partícula mantém velocidade absoluta constante e a cada iteração toma a direção média das partículas vizinhas. Simulações foram realizadas em uma região quadrada de lado L, considerando uma condição de contorno periódica (periodic boundary condition) ${ }^{2}$. Inicialmente (tempo $t=0$ ), $N$ partículas são aleatoriamente dispostas, todas com a mesma velocidade absoluta $v$ mas com direções $\theta$ aleatórias. A posição da $i$-ésima partícula é atualizada conforme

$$
\mathbf{x}_{i}(t+1)=\mathbf{x}_{i}(t)+\mathbf{v}_{i}(t) \Delta t
$$

A nova velocidade de cada partícula, $\mathbf{v}_{i}(t+1)$, continua tendo valor absoluto $v$, mas

\footnotetext{
${ }^{1}$ Conceito físico de fenômenos de transporte.

${ }^{2}$ Uma condição de contorno periódica é utilizada para simular um sistema homogêneo e infinitamente grande pela simulação de apenas uma pequena região (uma célula). Os objetos que saem da célula entram imediatamente na mesma célula através da face oposta, mantendo a mesma velocidade.
} 


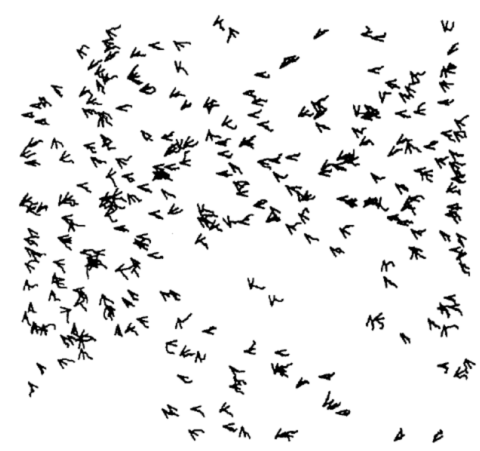

(a)

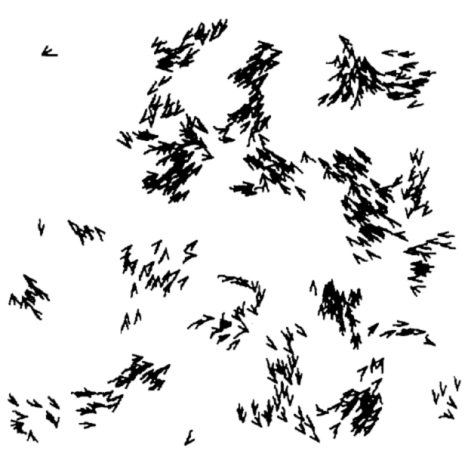

(b)

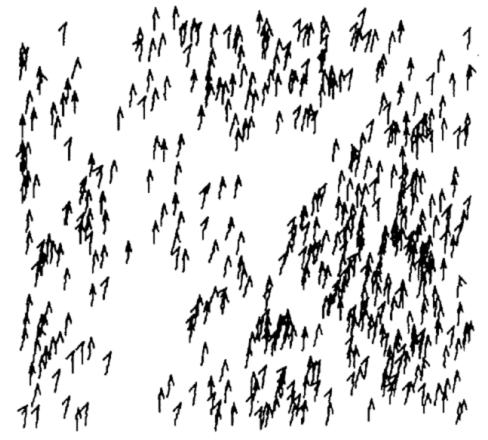

(c)

Figura 3.1: Velocidade das partículas após algum tempo de evolução, para diferentes valores de densidade e ruído. As três simulações empregam $N=300$ e $v=0,03$. (a): Densidade e ruído altos $(L=7, \eta=2,0)$, as partículas se movimentam aleatoriamente com alguma correlação. (b): Densidade e ruído baixos $(L=25, \eta=0,1)$, as partículas tendem a formar grupos. (c): Densidade alta e ruído baixo $(L=5, \eta=0,1)$, o movimento se torna completamente ordenado, todas as partículas tomam espontaneamente uma mesma direção (estado de transporte). Adaptada de Vicsek et al. (1995).

direção $\theta(t+1)$ conforme

$$
\theta(t+1)=\langle\theta(t)\rangle_{r}+\Delta \theta
$$

onde $\langle\theta(t)\rangle_{r}$ denota a direção média das partículas (incluindo a partícula $i$ ) dentro de um círculo de raio $r$ centrado na partícula $i$. $\Delta \theta$ denota uma perturbação aleatória cujo valor se encontra no intervalo $[-\eta / 2, \eta / 2]$. Ou seja, $\Delta \theta$ representa ruído. Fixando $\Delta t=1 \mathrm{e}$ $r=1$, o modelo apresenta três parâmetros: a velocidade $v$, o nível de ruído $\eta$ e a densidade inicial de partículas $\rho$, tal que $\rho=N / L^{2}$. Na Figura 3.1, exibe-se o resultado de algumas simulações.

Diz-se que há uma transição de fase quando a variação de algum parâmetro resulta em diferentes estados qualitativos (fases). No caso aqui mostrado, pode-se dizer que o sistema apresenta duas fases: fase sem transporte e fase de transporte. Para mensurar e evidenciar tal característica, adota-se o parâmetro de ordem $v_{a}$, a média normalizada das velocidades das partículas (valor absoluto):

$$
v_{a}=\frac{1}{N v}\left\|\sum_{i=1}^{N} \mathbf{v}_{i}\right\|
$$

$v_{a} \approx 0$ significa que não há transporte, enquanto $v_{a} \approx 1$ significa que as partículas tomaram uma mesma direção, portanto há transporte. Na Figura 3.2, mostra-se $v_{a}$ em função do nível de ruído $\eta$. O gráfico exibe justamente o intervalo de valores $\eta$ para o qual há a transição entre as duas fases do sistema. Observa-se que a diminuição gradual do nível de ruído $\eta$ leva à transição do movimento desordenado ao movimento coerente das partículas. Nota: cada entrada (amostra) do gráfico corresponde a uma simulação 


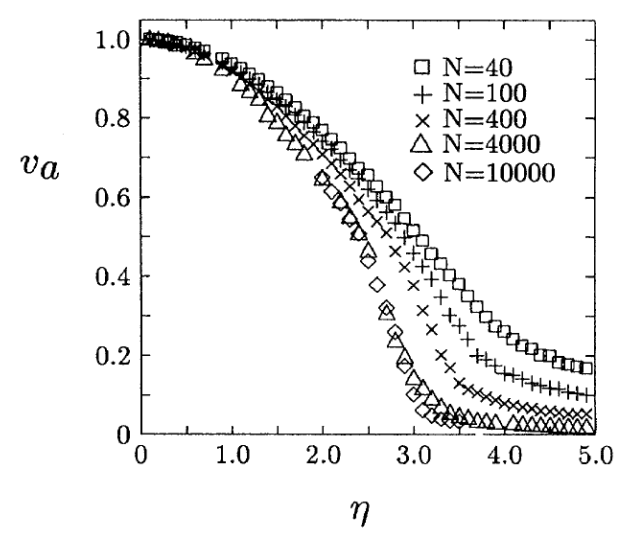

Figura 3.2: Valor absoluto da média normalizada das velocidades $\left(v_{a}\right)$ em função do nível de ruído $\eta$, para diferentes quantidades de partículas $N$. A densidade $\rho$ é mantida constante. Portanto, para $N=40, L=3,1$, para $N=100, L=5 \ldots$ Adaptada de Vicsek et al. (1995).

independente das demais.

\subsection{Trabalhos relacionados}

Mostram-se, aqui, três trabalhos que propõem solucionar o problema do agrupamento através de abordagens baseadas no comportamento coletivo de grandes grupos de indivíduos que mantêm interações relativamente simples entre si. Os padrões que emergem desses sistemas - a auto-organização - constituem, direta ou indiretamente, a solução do problema.

\subsubsection{Agrupamento baseado em propriedades ferromagnéticas}

Blatt et al. (1997) desenvolveram um algoritmo de agrupamento de dados baseado nas propriedades físicas de um ferromagneto heterogêneo. De maneira geral, um spin é atribuído a cada objeto, de modo que cada um desses spins será influenciado pelos spins dos objetos vizinhos. A influência entre cada par de objetos será tão maior quanto menor for a distância entre eles. Esse algoritmo faz uso do conceito de temperatura, tal que o sistema, a temperaturas muito baixas, encontra-se completamente ordenado, ou seja, todos os spins estão alinhados, enquanto a temperaturas muito altas, completamente desordenado. Em regimes intermediários, diferentes clusters são formados, cada um representando uma região que se torna ordenada. Dada uma temperatura, o agrupamento dos objetos levará em conta a correlação entre seus spins, de modo que um cluster será formado por um conjunto de objetos cujos spins se tornaram alinhados.

Precisamente, define-se uma variável spin $s$ que pode assumir um dentre $q$ valores inteiros: $s=1,2, \ldots q$. Cada objeto $\mathbf{x}_{i}$ do conjunto de dados está associado a um spin $s_{i}$. É dito que dois spins $s_{i}$ e $s_{j}$ estão alinhados quando assumem os mesmos valores. 
A essência desse algoritmo é, pois, agrupar objetos cujos spins têm grande chance de estarem alinhados. Define-se também a configuração $\mathcal{S}$ do sistema como sendo o conjunto dos estados de todos os seus spins, ou seja, $\mathcal{S}=\left\{s_{i}\right\}_{i=1}^{N}$, onde $N$ denota o tamanho do conjunto de dados.

Um grau de interação $J_{i j}$ é definido entre cada par de objetos $\mathbf{x}_{i}$ e $\mathbf{x}_{j}$. Essa interação é tão maior quanto menor for a distância (dissimilaridade) entre eles. Desse modo, dois objetos com alto grau de interação terão grande chance de possuírem seus spins alinhados, ou seja, terão grande chance de pertencerem ao mesmo cluster.

Define-se o conceito de temperatura $T$. Ela dita o estado de ordem do sistema, o qual pode se encontrar em três diferentes fases:

1. Ferromagnética (ferromagnetic). Ocorre a baixas temperaturas. Todos os spins estão alinhados, o que caracteriza um sistema completamente ordenado.

2. Super-paramagnética (superparamagnetic). Conforme a temperatura se eleva, em algum instante haverá uma ruptura na estrutura completamente ordenada (todos os spins alinhados) da fase ferromagnética. Chega-se, pois, à fase super-paramagnética. Nela, objetos em regiões densas ainda manterão seus spins alinhados, mas diferentes regiões estarão desalinhadas. Eis os clusters. Continuando-se a elevar a temperatura, uma estrutura hierárquica aparecerá, tal que grandes clusters vão sendo gradativamente quebrados em clusters menores.

3. Paramagnética (paramagnetic). Quando a temperatura atinge um valor suficientemente alto, o sistema entra na fase paramagnética, tornando-se completamente desordenado, ou seja, todos os spins se tornam desalinhados.

O processo de agrupamento parte do estabelecimento de uma temperatura $T$. Afinal, diferentes temperaturas conduzem a diferentes partições dos dados.

Foi dito que o algoritmo consiste em agrupar objetos cujos spins têm grande chance de estarem alinhados. Resta saber então como determinar essa chance. Para isso, obtémse uma amostra $\left\{\mathcal{S}_{1}, \mathcal{S}_{2}, \ldots, \mathcal{S}_{M}\right\}$ contendo $M$ diferentes configurações do sistema. Tal amostra deve ser representativa (ou característica) dentre todas as configurações possíveis. Algumas configurações são mais prováveis que outras, e isso tem que estar refletido na amostra. Isso é conseguido por uma sequência de configurações gerada por um processo de Markov, como a seguir.

A configuração inicial $\mathcal{S}_{1}$ é obtida fazendo-se cada spin $s_{i}$ receber aleatoriamente um valor entre 1 e $q$. Suponha então que já se têm $n$ configurações, $\left\{\mathcal{S}_{k}\right\}_{k=1}^{n}$. A configuração $\mathcal{S}_{n+1}$ é obtida do seguinte modo. Visitam-se todos os pares de spins $\langle i, j\rangle$ que interagem, ou seja, que possuem $J_{i j}>0$. Caso o par $\langle i, j\rangle$ esteja alinhado $\left(s_{i}=s_{j}\right)$ na configuração 
$\mathcal{S}_{n}$, diz-se que esse par estará congelado (frozen) com uma probabilidade $p_{i j}^{f}$ :

$$
p_{i j}^{f}=1-\exp \left(-\frac{J_{i j}}{T}\right)
$$

Do contrário, ou seja, caso $\langle i, j\rangle$ não esteja alinhado em $\mathcal{S}_{n}$, esse par não estará congelado. Feito isso, diversas componentes conexas terão sido formadas, cada qual caracterizada por um grupo de spins tal que haja, para qualquer par $\langle i, j\rangle$ desse grupo, um caminho $s_{i}, \ldots, s_{j}$ formado somente por ligações congeladas. A cada uma dessas componentes conexas é então atribuído um valor de spin aleatório entre 1 e $q$. Eis a configuração $\mathcal{S}_{n+1}$. Repetindo-se este processo um número suficiente de vezes, obtém-se a amostra $\left\{\mathcal{S}_{k}\right\}_{k=1}^{M}$. Tipicamente, para que a amostra "esqueça" a configuração aleatória inicial, as primeiras configurações são descartadas, mantendo-se somente as $M$ últimas.

Duas características importantes podem ser notadas na Equação 3.4 . Primeiro, altos valores de $J_{i j}$ favorecem o alinhamento entre os spins $s_{i}$ e $s_{j}$. Assim, a amostra $\left\{\mathcal{S}_{k}\right\}$ tende a conter várias configurações onde $s_{i}$ e $s_{j}$ estão alinhados. Por outro lado, altas temperaturas $T$ dificultam o alinhamento entre os spins. Isso está de acordo com a ideia de que altas temperaturas tendem a desorganizar o sistema, desalinhando os spins.

Finalmente, o processo de agrupamento consiste em colocar no mesmo cluster dois objetos cuja probabilidade de possuírem seus spins alinhados está acima de um certo limiar, tipicamente 0,5. Tal probabilidade é chamada de correlação spin-spin $G_{i j}$ entre dois objetos $\mathbf{x}_{i}$ e $\mathbf{x}_{j}$, obtida do seguinte modo. Em cada passo do processo de geração do conjunto de amostras $\left\{\mathcal{S}_{k}\right\}$, descrito anteriormente, obtém-se um conjunto de componentes conexas. Considerando-se os $M$ últimos passos deste processo, chama-se conectividade (connectedness) $C_{i j}$ entre dois objetos $\mathbf{x}_{i}$ e $\mathbf{x}_{j}$ a razão

$$
C_{i j}=\frac{\text { número de vezes que } s_{i} \text { e } s_{j} \text { aparecem na mesma componente conexa }}{M}
$$

Assim, a correlação spin-spin $G_{i j}$ é dada por

$$
G_{i j}=\frac{(q-1) C_{i j}+1}{q}
$$

Tipicamente, dois objetos $\mathbf{x}_{i}$ e $\mathbf{x}_{j}$ vizinhos e localizados numa região densa são altamente correlacionados, ou seja, $G_{i j} \approx 1$. Por outro lado, objetos muito distantes costumam resultar em correlação muito baixa, $G_{i j} \approx 1 / q$. Mas tudo isso depende da temperatura em que o sistema se encontra. A temperaturas muito elevadas, até mesmo objetos vizinhos podem resultar em $G_{i j} \approx 1 / q$, enquanto a temperaturas muito baixas, objetos distantes resultam em $G_{i j} \approx 1$.

Mais detalhes, claro, são encontrados no trabalho de Blatt et al. (1997). Lá também são encontrados alguns experimentos sobre conjuntos de dados artificiais e reais. 


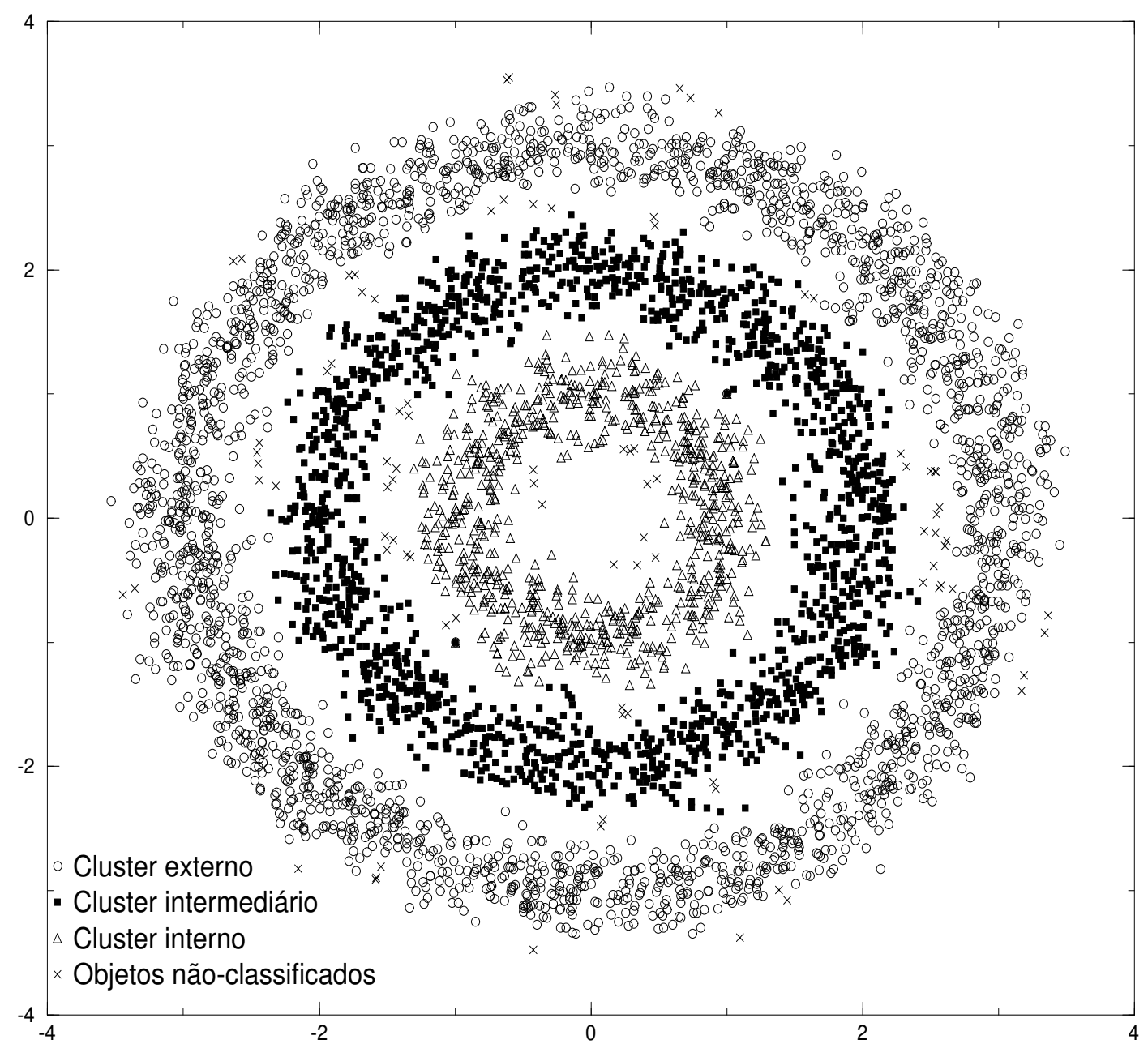

Figura 3.3: Conjunto de dados empregado no experimento, já mostrando o agrupamento resultante para $T=0,05$. Cada objeto é caracterizado por dois atributos, portanto situam-se num espaço bidimensional. Originalmente, a classe externa (correspondente ao cluster externo) contém 2400 objetos, a classe intermediária contém 1600 e a classe interna contém 800, perfazendo um total de 4800 objetos. Como resultado, o cluster externo contém 2358 objetos, o intermediário contém 1573 e o interno contém 779. Os objetos não-classificados se referem a objetos pertencentes a outros clusters. Adaptada de Blatt et al. (1997).

Mostram-se os resultados de um deles aqui, executado sobre o conjunto de dados mostrado na Figura 3.3, composto por objetos distribuídos em três diferentes classes. Nesse experimento, aplicou-se o algoritmo de agrupamento descrito anteriormente usando diferentes temperaturas T. q, o número de diferentes estados que a variável spin pode assumir, foi mantido em 20. Importante notar que isso não significa assumir a existência de 20 clusters no conjunto de dados. O tamanho dos maiores clusters em função de diferentes temperaturas $T$ é mostrado na Figura 3.4. Nessa figura, é possível notar as três diferentes fases que o sistema pode assumir. Para $T<0,035$, o sistema pode ser considerado estar na fase ferromagnética, devido à predominância de um único cluster, indicando o alinhamento entre quase todos os spins. Em $T \approx 0,035$, nota-se a transição para a fase super-paramagnética. É justamente nessa fase super-paramagnética que os resultados 


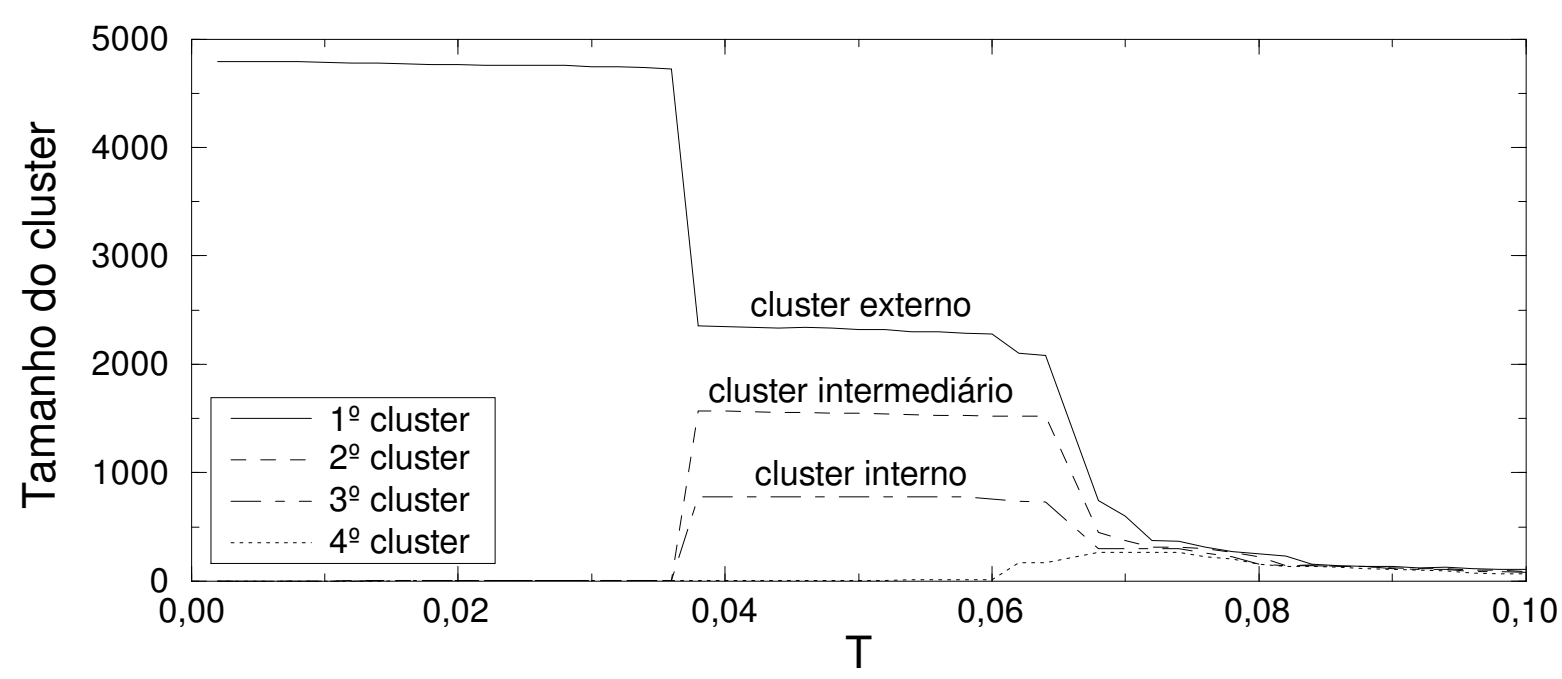

Figura 3.4: Tamanho dos clusters em função da temperatura T. Plotaram-se os resultados para os 4 maiores clusters obtidos em cada partição. Em destaque, os clusters externo, intermediário e interno. Adaptada de Blatt et al. (1997).

realmente relevantes são obtidos. Destacam-se os três clusters correspondentes às três classes do conjunto de dados. Conforme o valor de $T$ aumenta, o sistema caminha para a fase paramagnética, onde todos os clusters se tornam extremamente pequenos, pois a alta energia do sistema provoca o desalinhamento entre todos os spins. Na Figura 3.3, além do próprio conjunto de dados, é mostrado o resultado do agrupamento para $T=0,05$. Observa-se uma grande correspondência entre as classes originais e os clusters resultantes.

\subsubsection{Agrupamento por atração de objetos similares}

Zhao et al. (2005) propuseram um método de agrupamento dinâmico e auto-organizável baseado na atração de objetos similares. Os objetos se movimentam pelo espaço de atributos, guiados por forças de atração exercidas entre objetos similares. Assim, diferentes grupos de objetos convergirão para diferentes pontos, que são considerados os centros de cada cluster.

Formalmente, a evolução do sistema dinâmico é regida pelo seguinte conjunto de equações:

$$
\begin{gathered}
x_{i k}(t+1)=\left\{\begin{array}{cl}
0 & \text { se } x_{i k}(t)+\eta_{i}(t) F_{i k}(t) \leq 0 \\
x_{i k}(t)+\eta_{i}(t) F_{i k}(t) & \text { se } 0<x_{i k}(t)+\eta_{i}(t) F_{i k}(t)<1 \\
1 & \text { se } x_{i k}(t)+\eta_{i}(t) F_{i k}(t) \geq 1
\end{array}\right. \\
\mathbf{F}_{i}(t)=\frac{\sum_{j \in \Delta_{i}(t)} \frac{\mathbf{x}_{j}(t)-\mathbf{x}_{i}(t)}{\left\|\mathbf{x}_{j}(t)-\mathbf{x}_{i}(t)\right\|} \exp \left(-\alpha\left\|\mathbf{x}_{j}(t)-\mathbf{x}_{i}(t)\right\|\right)}{M_{i}(t)}
\end{gathered}
$$




$$
\begin{gathered}
j \in \Delta_{i}(t) \quad \text { se } \quad \exp \left(-\alpha\left\|\mathbf{x}_{j}(t)-\mathbf{x}_{i}(t)\right\|\right)>\theta \\
\eta_{i}(t)=\frac{\sum_{j \in \Delta_{i}(t)}\left\|\mathbf{x}_{j}(t)-\mathbf{x}_{i}(t)\right\|}{M_{i}(t)}
\end{gathered}
$$

$\mathbf{x}_{i}(t)=\left(x_{i 1}(t), x_{i 2}(t), \ldots, x_{i K}(t)\right)$ denota o $i$-ésimo objeto disposto no espaço de atributos $K$-dimensional, na iteração $t . t=0$ representa o estado inicial do sistema, ou seja, $\mathbf{x}_{i}(0)$ representa o $i$-ésimo objeto em sua posição original. $\mathbf{F}_{i}(t)=\left(F_{i 1}(t), F_{i 2}(t), \ldots, F_{i K}(t)\right)$ é a força total imposta sobre o objeto $\mathbf{x}_{i}$ na iteração $t$. Tal força é devida à presença dos demais objetos $\mathbf{x}_{j}(t)$ localizados dentro de uma região hiperesférica centrada em $\mathbf{x}_{i}(t)$. Essa região é denotada por $\Delta_{i}(t)$ e dá-se em função de dois parâmetros: $\alpha$ e $\theta$. Os objetos $\mathbf{x}_{j}(t)$ localizados dentro dessa região são considerados similares a $\mathbf{x}_{i}(t)$, por isso exercem influência sobre $\mathbf{F}_{i}(t)$ no sentido de atrair $\mathbf{x}_{i}(t)$. O aumento de $\theta$ provoca a redução da região $\Delta_{i}(t)$, reduzindo também a quantidade de objetos $\mathbf{x}_{j}(t)$ que influenciarão $\mathbf{x}_{i}(t)$. $M_{i}(t)$ representa simplesmente a quantidade de objetos $\mathbf{x}_{j}(t)$ contidos em $\Delta_{i}(t)$.

$\left\|\mathbf{x}_{j}(t)-\mathbf{x}_{i}(t)\right\|$ representa a distância euclidiana entre $\mathbf{x}_{i}(t)$ e $\mathbf{x}_{j}(t) \cdot \exp \left(-\alpha\left\|\mathbf{x}_{j}(t)-\mathbf{x}_{i}(t)\right\|\right)$ resulta em valores entre 0 e 1 , e diminui à medida que a distância entre $\mathbf{x}_{i}(t)$ e $\mathbf{x}_{j}(t)$ aumenta. Isso faz com que a influência de um objeto $\mathbf{x}_{j}(t)$ sobre $\mathbf{F}_{i}(t)$ seja tão maior quanto menor for a distância entre $\mathbf{x}_{i}(t)$ e $\mathbf{x}_{j}(t)$. O termo $\frac{\mathbf{x}_{j}(t)-\mathbf{x}_{i}(t)}{\left\|\mathbf{x}_{j}(t)-\mathbf{x}_{i}(t)\right\|}$ simplesmente dita a direção da força $\mathbf{F}_{i}(t)$. O significado de $\eta_{i}(t)$ será descrito a seguir.

O processo de agrupamento acontece do seguinte modo. Inicialmente, cada objeto está posicionado no espaço de atributos. O sistema dinâmico é então iniciado e os objetos começam a exercer influência uns aos outros. Objetos similares se atraem mutuamente. Assim, os objetos se organizam de modo que aqueles pertencentes a um mesmo cluster convergirão para um mesmo ponto, o qual é considerado o centro desse cluster. Por outro lado, clusters diferentes são caracterizados por pontos de convergência também diferentes.

Surge então um problema de convergência. A força exercida entre os objetos é tão maior quanto menor a distância entre eles. Ao mesmo tempo, objetos pertencentes a um mesmo cluster estarão convergindo para um mesmo ponto. Torna-se então necessário um mecanismo para evitar que tais objetos comecem a oscilar em torno do ponto de convergência. Eis o termo $\eta_{i}(t)$, tal que $\eta_{i}(t) \rightarrow 0$ conforme os objetos em torno de $\mathbf{x}_{i}(t)$ concentram-se num único ponto. Assim, também $\mathbf{F}_{i}(t) \rightarrow 0$ e os objetos não mais se movimentarão quando atingirem o ponto de convergência.

Nas Figuras 3.5 e 3.6 são mostrados os resultados de duas simulações realizadas sobre um conjunto artificial bidimensional de objetos. Ambas empregaram $\alpha=0.8$. Variou-se o parâmetro $\theta$. Nas Figuras 3.5.(a) e 3.6.(a) é exibido o estado inicial dos objetos. Pode-se notar a existência de três grupos num nível mais superficial e cinco grupos num nível mais refinado. Pois as simulações resultam justamente em cada uma dessas duas interpretações, 

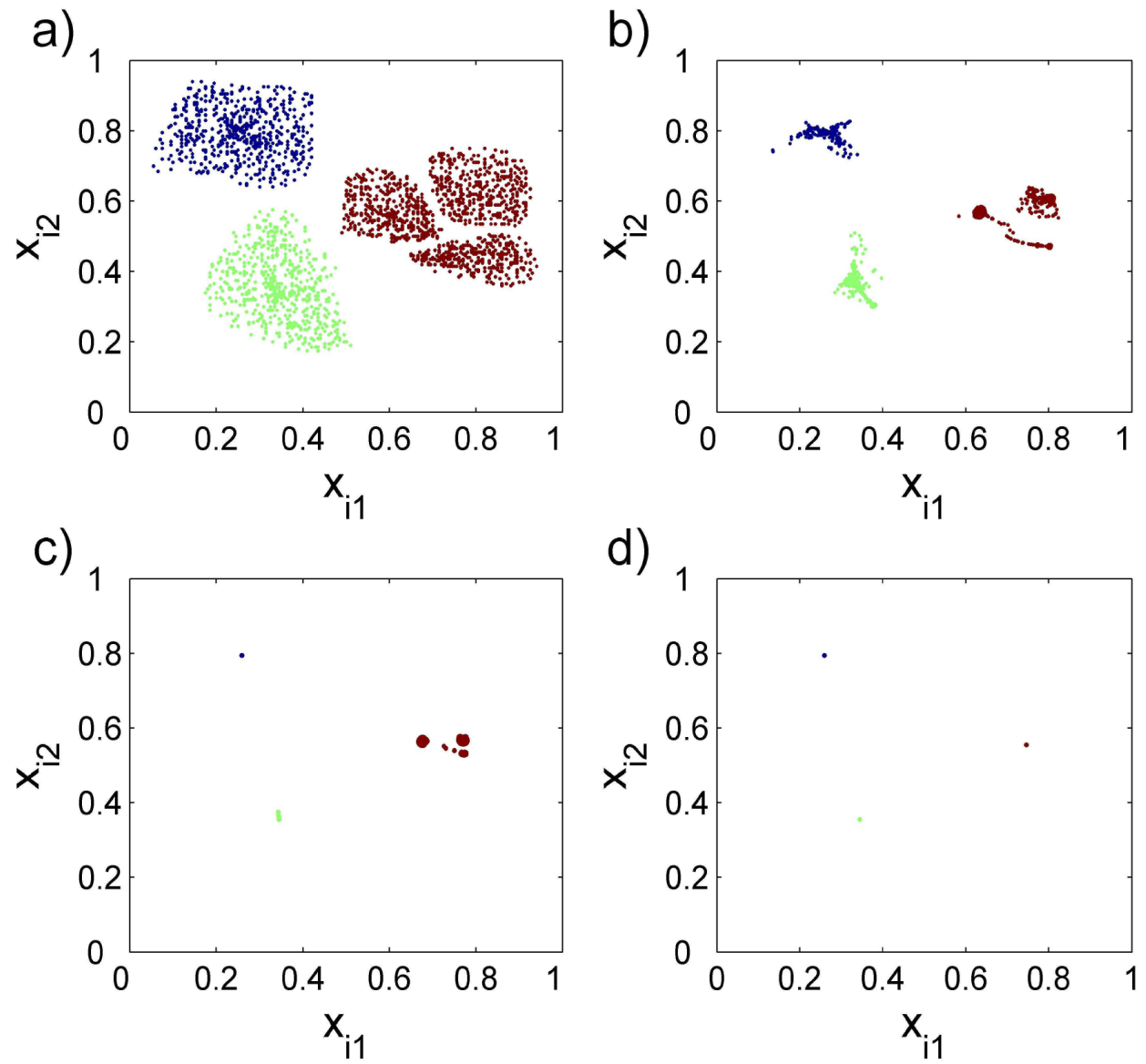

Figura 3.5: (Colorida na versão digital) Processo de movimentação dos objetos. Três clusters são formados. $\theta=0.1$. Obtida de Zhao et al. (2005).

modificando-se o parâmetro $\theta$.

Por fim, é possível observar que o método proposto por Zhao et al. (2005) não exige conhecimento prévio do número de clusters, tampouco de seus respectivos centros. O ajuste de poucos parâmetros é suficiente. Experimentos realizados com dados artificiais e reais mostraram bons resultados. Os autores destacam ainda a forma natural com que esse método pode ser implementado em arquiteturas paralelas, distribuídas.

\subsubsection{Agrupamento através de otimização por nuvem de partícu- las}

A Otimização por Nuvem de Partículas (Particle Swarm Optimization - PSO), técnica desenvolvida por Kennedy \& Eberhart (1995), toma como inspiração o movimento organizado de grandes grupos de animais, especialmente pássaros e peixes (Kennedy \& Eberhart, 1995, 2001; Omran et al., 2002; Engelbrecht, 2006; Oliveira, 2008). Em linhas gerais, a PSO é constituída por uma população de partículas que exploram o espaço de busca (espaço de soluções de um determinado problema) de maneira inicialmente aleatória. À medida que algumas partículas encontram regiões do espaço mais promissoras, 

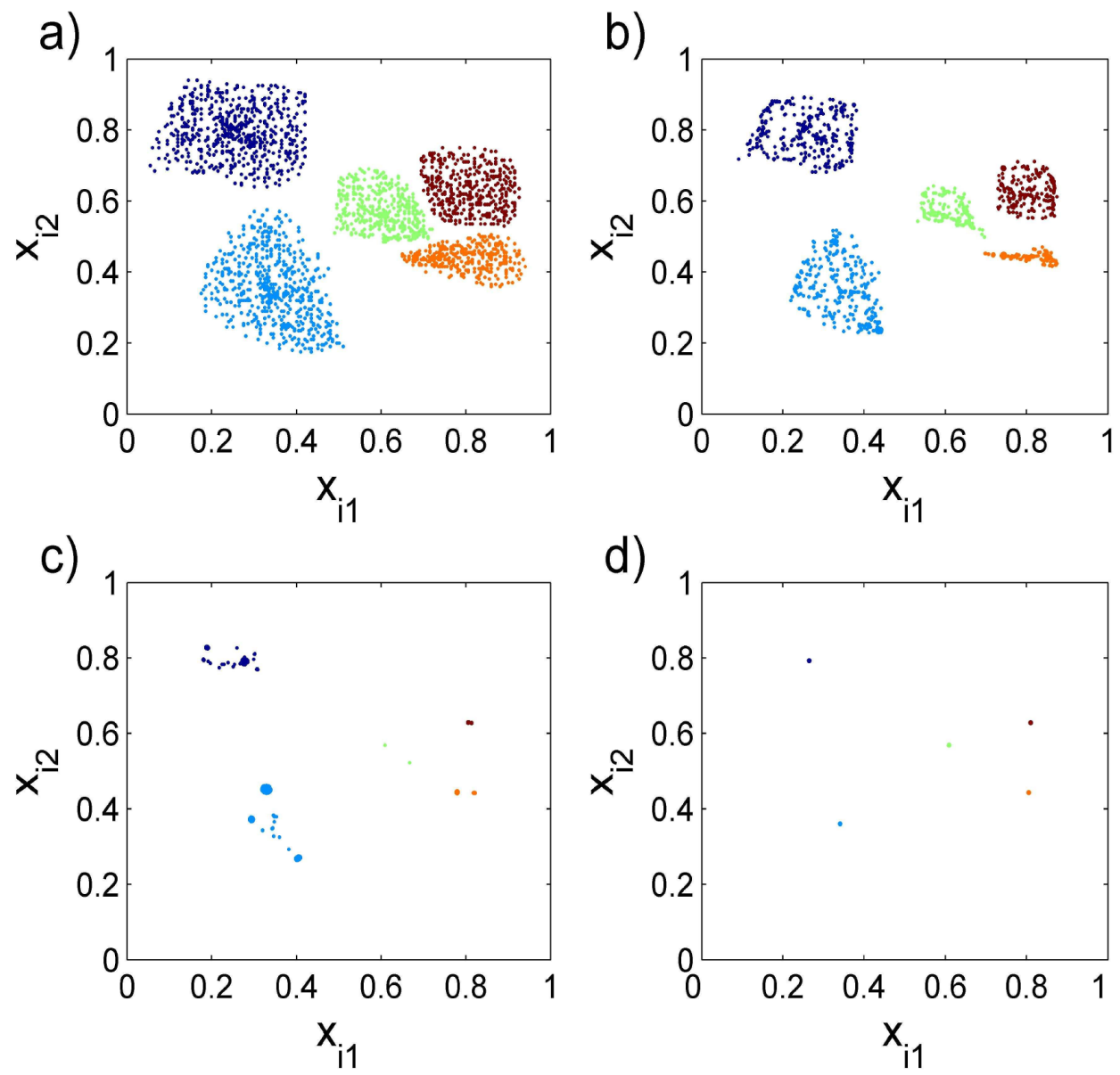

Figura 3.6: (Colorida na versão digital) Processo de movimentação dos objetos. Cinco clusters são formados. $\theta=0.3$. Obtida de Zhao et al. (2005).

são seguidas pelas demais. Entretanto, as partículas ainda mantêm certa liberdade para explorar novas regiões, procurando soluções ainda melhores.

Omran et al. (2002) propuseram um algoritmo de agrupamento baseado na PSO. Cada partícula, representando cada solução do problema, é formada por um conjunto de centroides (ver Seção 2.4.1). Portanto, cada partícula representa uma partição dos dados. Assim, esse algoritmo emprega a PSO na tentativa de melhorar cada solução obtida, gerando novas partições através da movimentação dos centroides. Importante ressaltar que, nesse algoritmo, cada partícula não é representada nem por um objeto do conjunto de dados nem por um centroide, mas sim pelo conjunto de todos os centroides de uma partição.

Oliveira (2008) também propôs um algoritmo de agrupamento baseado na PSO. Em seu trabalho, entretanto, não se emprega o conceito pleno da PSO, mas apenas parte dele. O trabalho se baseia na regra de atualização da velocidade das partículas.

O algoritmo proposto por Oliveira é constituído por duas etapas: (1) formação de uma rede (grafo) a partir do conjunto de dados e (2) partição dessa rede em diferentes comunidades. A primeira etapa faz cada objeto do conjunto de dados constituir um vértice 
da rede. A construção dessa rede emprega a técnica dos K-Vizinhos Mais Próximos ( $K$ Nearest Neighbors - KNN), técnica essa que, como o nome sugere, consiste em ligar cada objeto aos $K$ demais objetos mais semelhantes a ele. Haverá uma aresta ligando dois objetos $i$ e $j$ se $j$ pertencer à $K$-vizinhança de $i$ ou $i$ pertencer à $K$-vizinhança de $j$. Sabendo-se que uma comunidade em uma rede é caracterizada por um grupo de vértices densamente conectados, espera-se que a formação da rede faça cada grupo originalmente presente no conjunto de dados corresponder a uma comunidade da rede. A tarefa de agrupamento se torna então uma tarefa de detecção de comunidades.

$\mathrm{Na}$ segunda etapa, a cada vértice $\mathbf{v}_{i}$ (que representa um objeto) é atribuído um ângulo $\theta_{i}(t)$ (o ângulo do vetor velocidade na PSO). A ideia é fazer esses vértices interagirem uns com os outros, de modo que vértices da mesma comunidade tomem ângulos similares, mas comunidades distintas tomem ângulos também distintos. A variável $t$ denota o índice de iteração, tal que $t=0$ representa o estado inicial do sistema. Inicialmente, a cada vértice $\mathbf{v}_{i}$ é atribuído um ângulo $\theta_{i}(0)$ escolhido aleatoriamente no intervalo [0;2 $[$. A regra de atualização do ângulo é então dada por

$$
\theta_{i}(t+1)=\theta_{i}(t)+\eta_{i}(t)\left[\frac{\sum_{\mathbf{v}_{j}} w_{i j} \theta_{j}(t)}{\sum_{\mathbf{v}_{j}} w_{i j}}-\theta_{i}(t)\right]
$$

onde $\eta_{i}(t)$ é a taxa de atualização do ângulo do vértice $\mathbf{v}_{i}$ na iteração $t$ e $\mathbf{v}_{j}$ representa os vizinhos de $\mathbf{v}_{i}$.

$w_{i j}$ representa um peso dado a cada vizinho $\mathbf{v}_{j}$, definido como

$$
w_{i j}=\exp \left(-\alpha d_{i j}\right) \frac{C_{i j}}{M_{i}}
$$

onde $d_{i j}$ é a distância euclidiana (dissimilaridade) entre os objetos representados por $\mathbf{v}_{i}$ e $\mathbf{v}_{j}, C_{i j}$ é o número de vizinhos comuns a $\mathbf{v}_{i}$ e $\mathbf{v}_{j}$, e $M_{i}$ é o número de vizinhos de $\mathbf{v}_{i}$. Como se pode ver, o cálculo do peso $w_{i j}$ leva em conta duas componentes. A primeira, $\exp \left(-\alpha d_{i j}\right)$, faz com que objetos mais similares exerçam mais influência entre si. $\alpha$ é um parâmetro. A segunda, $C_{i j} / M_{i}$, leva em conta toda a vizinhança dos vértices. Dois vértices que têm muitos vizinhos em comum são mais influentes entre si. Pode-se notar, a partir desta componente $C_{i j} / M_{i}$, que $w_{i j}$ é diferente de $w_{j i}$.

A taxa de atualização $\eta_{i}(t)$ é definida como

$$
\eta_{i}(t)=\exp \left(-\frac{\beta}{\sigma_{i}(t)}\right)
$$

onde $\beta$ é um parâmetro e $\sigma_{i}(t)$ é o desvio-padrão dos ângulos entre $\mathbf{v}_{i}$ e seus vizinhos, na iteração $t$. Com isso, conforme os ângulos dos vértices se aproximam, menor tende a ser sua variação. Isso, claro, considerando valores adequados de $\beta$.

As Figuras 3.7, 3.8 e 3.9 ilustram as ideias apresentadas. Na Figura 3.7, uma rede 


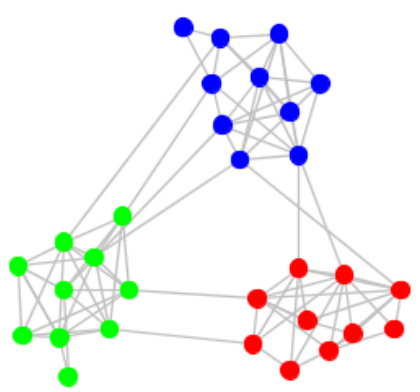

Figura 3.7: (Colorida) Rede formada a partir de um conjunto de dados. Diferentes cores representam diferentes grupos. Obtida de Oliveira (2008).

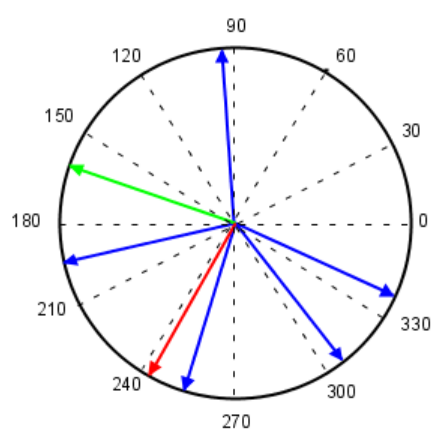

(a)

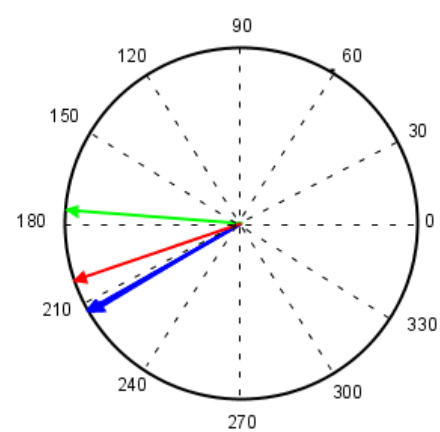

(b)

Figura 3.8: (Colorida) Ilustração dos ângulos dos vértices. Cada seta representa o valor do ângulo de um vértice. Cada cor está associada ao correspondente grupo. (a): Atribuição aleatória inicial. (b): Após algumas iterações, vértices de mesmo grupo tomam ângulos similares. Obtida de Oliveira (2008).

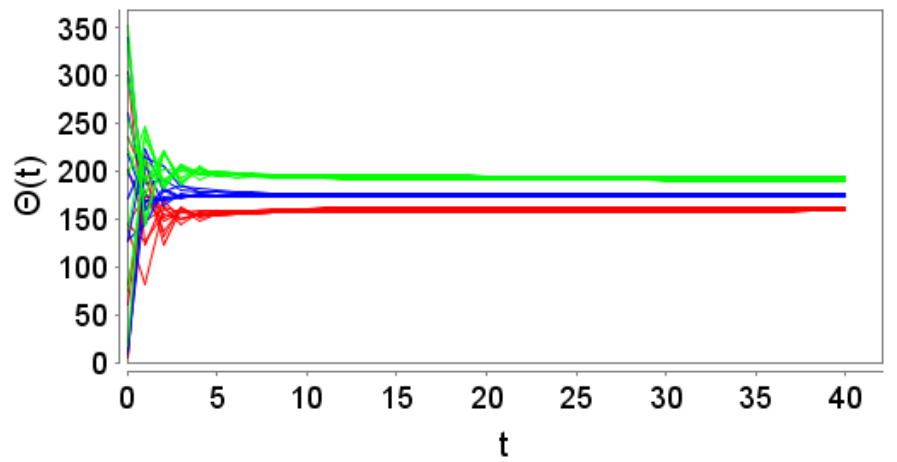

Figura 3.9: (Colorida) Evolução do processo de atualização dos ângulos. Cada cor está associada ao correspondente grupo. Nas primeiras iterações, os ângulos se encontram desordenados. Após algum tempo, eles se dividem em grupos razoavelmente estáveis. Obtida de Oliveira (2008). 
formada a partir de um conjunto de dados. É possível observar que os grupos se tornaram comunidades na rede. Na Figura 3.8, os ângulos dos vértices da Figura 3.7 em dois diferentes instantes. Finalmente, na Figura 3.9, a evolução desse sistema.

Resta então particionar, de fato, os vértices de acordo com os valores de seus ângulos. Para isso, após ser atingida certa estabilidade, o processo de atualização de ângulos é interrompido e os vértices são ordenados conforme o ângulo que tomaram. Procura-se, então, pelos dois vértices consecutivos - eles estão ordenados — que mantenham a maior diferença entre seus ângulos. Se essa diferença for suficientemente grande, trata-se de um bom local para separar o conjunto de vértices em dois novos conjuntos, ou dois clusters. O conjunto de vértices abaixo do ponto de ruptura (em termos do valor de seus ângulos) constituirá um cluster, e o conjunto acima constituirá o outro. Nota-se que, no início do processo de atualização de ângulos, todo o conjunto de vértices era considerado um único cluster, e após a separação, dois sub-clusters são formados. Então o processo de atualização de ângulos é aplicado recursivamente a cada novo cluster, separando-os em novos sub-clusters, fazendo com que o processo como um todo resulte numa hierarquia de partições.

\subsection{Desafios}

No que se refere ao uso das metáforas em problemas computacionais, a primeira coisa que se nota é justamente a relação entre o problema e o sistema natural tomado como metáfora, ou seja, as características que o problema tem em comum com o sistema natural. Há diversos problemas que já são resolvidos através das metáforas, como mostrado nas seções anteriores. Mas e quanto aos novos problemas, como encontrar metáforas para eles? Talvez não haja um método sistemático para isso, embora se possa observar os sistemas naturais, na busca por características que se assemelhem aos problemas que se quer resolver. Um sistema natural não foi "feito" — acredito — para resolver certo problema, mas o tempo e a evolução se encarregaram de torná-los eficientes. Buscar por metáforas significa buscar por características que o tempo se encarregou de selecionar e que, de alguma forma, podemos aproveitar.

Quanto aos sistemas baseados em comportamento coletivo, surge ainda uma dificuldade a mais. É importante ter em mente que a auto-organização emerge das interações locais entre os indivíduos que constituem o sistema. Assim, além da dificuldade em obter uma relação entre um problema e um sistema natural, surge a dificuldade em relacionar o estado de ordem global com as interações locais. Isso porque não é possível "programar" o estado de ordem, mas apenas as interações entre os indivíduos. A correspondência entre os diferentes tipos de padrões globais que emergem a partir dos diferentes tipos de interações locais é algo desafiador e vem motivando muito estudo (Vicsek et al., 1995, Toner \& Tu, 1995, 1998; Bonabeau et al., 1999; Heylighen, 1999; Kennedy \& Eberhart, 
2001; Engelbrecht, 2006, Chaté et al., 2008, Banzhaf, 2009; Ginelli et al., 2010, Menon, 2010; Ramaswamy, 2010; Vicsek \& Zafiris, 2010; Ngo et al., 2012, Peshkov et al., 2012, Sumino et al., 2012; Toner, 2012a b). Bonabeau et al. (1999) sugerem a elaboração de um catálogo relacionando tipos de padrões locais aos padrões globais resultantes. Ao mesmo tempo, dizem que essa tarefa pode se mostrar demasiadamente onerosa e interminável. Apesar desses desafios, foi mostrado, na Seção 3.2, que há abordagens bem-sucedidas na solução de problemas complexos, especificamente problemas de agrupamento, por meio de sistemas baseados em comportamento coletivo. Nos Capítulos 4 , 5 e 6, são apresentados os resultados obtidos no presente trabalho, o qual procura justamente desenvolver técnicas de agrupamento baseadas em comportamento coletivo.

Banzhaf (2009) destaca que, apesar de já terem encontrado aplicações nas Ciências Sociais e nas Engenharias, os sistemas auto-organizáveis ainda são objeto de intensa pesquisa, com questões fundamentais ainda sendo exploradas. Vicsek \& Zafiris (2010) também deixam claro, em seu trabalho, que o comportamento coletivo é um tema altamente multidisciplinar. Sua complexidade intrínseca e desafiadora vem, cada vez mais, motivando o trabalho de pesquisadores, nas mais diversas áreas.

\subsection{Considerações finais}

Foi visto, neste capítulo, que a inspiração na natureza é valiosa na solução de diversos problemas complexos. Foram também mostrados alguns trabalhos que empregam a ideia de comportamento coletivo na solução de problemas de agrupamento. Contudo, o estudo dos fenômenos relacionados ao comportamento coletivo ainda possui muitas questões a serem respondidas.

Nos próximos capítulos, são apresentados os resultados obtidos neste trabalho de mestrado, especificamente, abordagens bem-sucedidas na solução do problema de agrupamento através de técnicas baseadas em comportamento coletivo. 


\section{Capítulo 4}

\section{Agrupamento por dinâmica de troca de energia}

Exploraram-se, nesta pesquisa, abordagens de agrupamento em que os objetos do conjunto de dados são mantidos fixos em seu espaço de atributos, mas carregam certo tipo de "energia" (ou informação). Essa energia vai sendo gradualmente trocada entre eles. Ao final, os grupos são estabelecidos entre aqueles objetos que tomam estados de energia semelhantes. Nesta seção, apresenta-se a primeira das técnicas desenvolvidas, e publicada no seguinte trabalho:

Roberto Alves Gueleri \& Zhao Liang. Agrupamento de Dados baseado em Dinâmica de Troca de Energia. In: Anais do XXXI Congresso da Sociedade Brasileira de Computação (CSBC 2011). Páginas 418-429.

A técnica proposta nesse trabalho atua sobre objetos com atributos numéricos reais, onde cada objeto está disposto num espaço euclidiano. Trata-se de um algoritmo hierárquico aglomerativo, ou seja, parte-se de um estado onde cada objeto compreende um cluster distinto e chega-se a um estado onde todos os objetos estão contidos num único cluster. Nem o estado inicial nem o final são de interesse. Interessam sim os estados intermediários. Esse algoritmo pode ser resumido nas seguintes etapas:

1. No início, a cada objeto é atribuído um estado de energia. Sendo $n$ a quantidade de objetos, o estado de energia é caracterizado por um vetor $n$-dimensional. Assim, colocam-se os objetos em estados de energia completamente independentes uns dos outros.

2. O processo consiste então na gradativa troca de energia entre os objetos. O grau de interação entre cada par de objetos é tão maior quanto menor for a distância que os separa. E quanto maior o grau de interação, mais intensa se dá a troca de energia entre eles. 

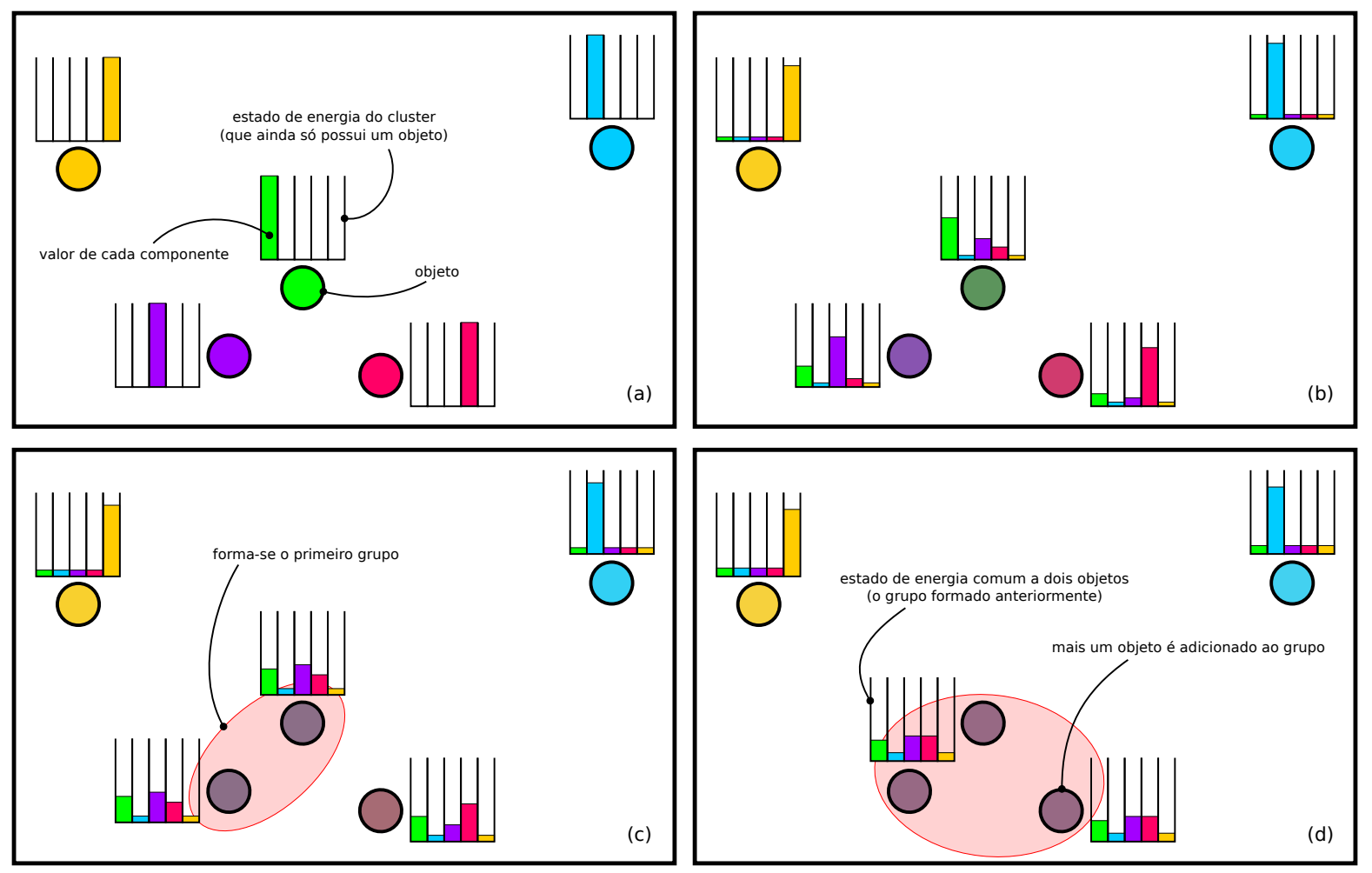

Figura 4.1: (Colorida) Ilustração do processo de agrupamento. (a): O estado inicial dos objetos. (b): Algum estado após a evolução do processo. (c): Dois dos objetos atingem estados de energia suficientemente semelhantes e são agrupados. (d): Um terceiro objeto é adicionado ao grupo.

3. Quando dois objetos atingem estados de energia suficientemente semelhantes, eles são agrupados. Uma vez que o grau de interação é maior entre objetos mais próximos, essa técnica tende a agrupar primeiro os objetos em regiões mais densas.

A fim de ilustrar o processo de agrupamento, na Figura 4.1 é mostrado um conjunto contendo cinco objetos. A cada objeto é atribuído um estado inicial de energia. Então eles começam a interagir entre si e os grupos vão se formando. Quanto menor a distância separando dois objetos, maior o grau de interação. Assim, os objetos mais próximos são os primeiros a atingirem estados de energia semelhantes, portanto os primeiros a serem agrupados.

Pelas seções seguintes, apresenta-se uma descrição formal dessa técnica de agrupamento baseada em dinâmica de troca de energia, seguida da apresentação e discussão de experimentos realizados sobre bases de dados artificiais e reais (benchmark).

\subsection{Descrição formal da técnica}

Duas são as entidades envolvidas no método aqui descrito: objetos e clusters. Os objetos são os elementos a serem agrupados, enquanto os clusters são justamente os grupos de objetos. Cada cluster é caracterizado por um estado de energia, significando que cada um 
de seus objetos compartilham esse estado de energia. O processo de agrupamento é então caracterizado pela progressiva troca de energia entre os clusters, agrupando-os conforme atingem estados de energia suficientemente semelhantes.

Seja natt a quantidade de atributos que caracterizam cada objeto. Assim, cada objeto $\mathbf{o}_{i} \in \mathbb{R}^{\text {natt }}$ é definido como

$$
\mathbf{o}_{i}=\left(o_{i, 1}, o_{i, 2}, o_{i, 3}, \ldots, o_{i, n a t t}\right)
$$

A evolução do processo de agrupamento dá-se através de sucessivas iterações, denotadas pela variável $t \in \mathbb{N}$, tal que $t=0$ refere-se ao estado inicial do sistema. A cada iteração, os clusters (representando seus objetos) trocam certa quantidade de energia entre si. Quando dois ou mais atingem estados de energia suficientemente semelhantes, eles combinam-se, originando um cluster maior. A essa combinação dá-se o nome de fusão. Assim, cada iteração $t$ é dividida em dois sub-estados: pré-fusão e pós-fusão.

Seja nobj a quantidade de objetos envolvidos no problema. Denota-se por $\mathbf{c}_{i}^{\prime}(t)$ e $\mathbf{c}_{i}(t) \in \mathbb{R}^{n o b j}$ os clusters na pré-fusão e na pós-fusão de $t$, respectivamente.

$$
\begin{aligned}
& \mathbf{c}_{i}^{\prime}(t)=\left(e_{i, 1}^{\prime}(t), e_{i, 2}^{\prime}(t), e_{i, 3}^{\prime}(t), \ldots, e_{i, n o b j}^{\prime}(t)\right) \\
& \mathbf{c}_{i}(t)=\left(e_{i, 1}(t), e_{i, 2}(t), e_{i, 3}(t), \ldots, e_{i, n o b j}(t)\right)
\end{aligned}
$$

Aqui, as componentes $e_{i, j}^{\prime}(t)$ e $e_{i, j}(t)$ representam o estado de energia do cluster. Denotamse também por $C^{\prime}(t)$ e $C(t)$ os conjuntos de todos os clusters existentes na pré-fusão e na pós-fusão de $t$, respectivamente.

Todo cluster está associado a seus objetos. Assim, definem-se cluster', cluster e obj como sendo as relações entre os clusters e seus respectivos objetos. Tais relações são definidas reciprocamente como

$$
\begin{aligned}
& \operatorname{cluster}^{\prime}\left(\mathbf{o}_{i}, t\right)=\mathbf{c}_{j}^{\prime}(t) \Longleftrightarrow \mathbf{o}_{i} \in \operatorname{obj}\left(\mathbf{c}_{j}^{\prime}(t)\right) \\
& \operatorname{cluster}\left(\mathbf{o}_{i}, t\right)=\mathbf{c}_{j}(t) \Longleftrightarrow \mathbf{o}_{i} \in \operatorname{obj}\left(\mathbf{c}_{j}(t)\right)
\end{aligned}
$$

Ou seja, cluster' e cluster resultam no cluster ao qual pertence um certo objeto. Já obj representa a relação inversa, resultando nos objetos que compõem um certo cluster.

Inicialmente, na pré-fusão de $t=0$, atribui-se um cluster distinto a cada objeto. Têmse pois nobj clusters. A cada um desses clusters é então atribuído um estado inicial de energia:

$$
e_{i, j}^{\prime}(0)= \begin{cases}0 & \text { para } i \neq j \\ 1 & \text { para } i=j\end{cases}
$$

A disposição simétrica assim concebida garante que nenhum dos objetos seja eventualmente privilegiado. Disso decorre a necessidade de tantas componentes de energia quantos 
são os objetos envolvidos no problema.

Descreve-se agora o processo de fusão. Essencialmente, há dois tipos de fusão: um para $t=0$ e outro para $t>0$. Após a disposição inicial dos clusters em $t=0$, é conveniente já agrupar objetos situados muito perto um do outro. Denomina-se essa proximidade por omin, tal que objetos cuja distância euclidiana seja menor ou igual a omin são agrupados. Essa é a fusão para $t=0$. Já para $t>0$, procura-se, a cada iteração, por clusters cujos estados de energia sejam suficientemente semelhantes. Denomina-se essa semelhança por emin, de modo que clusters cujos estados de energia tenham distância euclidiana menor ou igual a emin são agrupados.

A fim de realizar a fusão, é necessário criar uma partição do conjunto $C^{\prime}(t)$, tal que os clusters contidos numa mesma parte sejam todos agrupados entre si. A partição $P(t)$ procurada é definida como

$$
P(t)=\left\{M_{m}(t) \subseteq C^{\prime}(t)\right\}, \quad m=1 \ldots \text { tamanho da partição }
$$

onde $M_{m}(t)$ representa cada parte da partição. Todo cluster estará em uma e somente uma parte. Havendo dois clusters tal que a distância entre seus respectivos objetos seja menor ou igual a omin $(t=0)$, ou a distância entre seus estados de energia seja menor ou igual a emin $(t>0)$, esses clusters estarão na mesma parte e serão agrupados.

Define-se merge $\left(M_{m}(t)\right)$ como sendo uma operação capaz de tomar uma parte $M_{m}(t)$ de alguma partição e transformá-la num novo cluster, resultado da fusão dos clusters de $M_{m}(t)$ :

$$
\operatorname{merge}\left(M_{m}(t)\right)= \begin{cases}\sum_{\frac{\mathbf{c}_{i}^{\prime}(t) \in M_{m}(t)}{\left|M_{m}(t)\right|} \mathbf{c}_{i}^{\prime}(t)} & \text { para } t=0 \\ \frac{\sum_{\mathbf{c}_{i}^{\prime}(t) \in M_{m}(t)}\left[\mathbf{c}_{i}^{\prime}(t) \cdot\left|\operatorname{obj}\left(\mathbf{c}_{i}^{\prime}(t)\right)\right|\right]}{\sum_{\mathbf{c}_{i}^{\prime}(t) \in M_{m}(t)}\left|\operatorname{obj}\left(\mathbf{c}_{i}^{\prime}(t)\right)\right|} & \text { para } t>0\end{cases}
$$

onde $\left|M_{m}(t)\right|$ e $\left|\operatorname{obj}\left(\mathbf{c}_{i}^{\prime}(t)\right)\right|$ referem-se, respectivamente, ao tamanho da parte $M_{m}(t)$ e ao tamanho do conjunto $\operatorname{obj}\left(\mathbf{c}_{i}^{\prime}(t)\right)$ de objetos do cluster $\mathbf{c}_{i}^{\prime}(t)$. Nota-se que, para $t=0$, o cluster resultante possui estado de energia igual à média dos estados de energia dos clusters que entraram em fusão. Para $t>0$, o estado de energia resultante é igual à média ponderada pelo tamanho dos clusters, ou seja, quanto mais objetos um cluster possui, mais influente ele é. Na verdade, a primeira expressão, para $t=0$, é um caso especial da segunda, visto que em $t=0$ todo cluster tem tamanho igual a 1 . Então, o novo conjunto $C(t)$ resultante da fusão dos clusters em $C^{\prime}(t)$, agora organizados na 
partição $P(t)$, é

$$
C(t)=\left\{\operatorname{merge}\left(M_{m}(t)\right)\right\}, \quad m=1 \ldots \text { tamanho da partição }
$$

Passa-se agora ao processo de troca de energia. Define-se neighborhood $\left(\mathbf{o}_{i}, t\right) \operatorname{como}$ sendo o conjunto dos nneighbor $s \mathbf{o}_{j}$ mais próximos de $\mathbf{o}_{i}$, que não façam parte do mesmo cluster de $\mathbf{o}_{i}$ na pós-fusão da iteração $t$. O parâmetro nneighbors simplesmente limita a quantidade de vizinhos considerados na troca de energia. neighborhood $\left(\mathbf{o}_{i}, t\right)$ pode resultar num conjunto menor que nneighbors, caso a quantidade de objetos não seja mais suficiente. Observar que não faz sentido a interação entre objetos contidos num mesmo cluster, uma vez que já compartilham o estado de energia.

Então, define-se uma função chamada resultant que informa a variação do estado de energia que cada cluster "deseja" ter entre os instantes $t$ e $t+1$. Mais precisamente, trata-se de um par de funções, uma para os clusters:

$$
\text { resultant }\left(\mathbf{c}_{i}(t)\right)=\left(\text { resultant }\left(e_{i, 1}(t)\right), \ldots, \text { resultant }\left(e_{i, n o b j}(t)\right)\right)
$$

e outra para as componentes dos clusters:

$$
\begin{aligned}
& \text { resultant }\left(e_{i, k}(t)\right)= \sum_{\substack{\mathbf{o}_{m} \in \operatorname{obj}\left(\mathbf{c}_{i}(t)\right) \\
\mathbf{o}_{n} \in \operatorname{neighborhood}\left(\mathbf{o}_{m}, t\right)}}\left[\frac{e_{j, k}(t)-e_{i, k}(t)}{\left|\operatorname{obj}\left(\mathbf{c}_{i}(t)\right)\right|} \cdot\right. \\
&\left.\cdot \operatorname{exchange}\left(\mathbf{c}_{i}(t), \mathbf{c}_{j}(t), k\right) \cdot \operatorname{falloff}\left(\left\|\mathbf{o}_{m}-\mathbf{o}_{n}\right\|\right)\right]
\end{aligned}
$$

onde $\mathbf{c}_{j}(t)=\operatorname{cluster}\left(\mathbf{o}_{n}, t\right), e_{j, k}(t)$ refere-se às componentes de $\mathbf{c}_{j}(t)$ e $\left\|\mathbf{o}_{m}-\mathbf{o}_{n}\right\|$ é a distância entre $\mathbf{o}_{m}$ e $\mathbf{o}_{n}$. Observam-se, na definição de resultant, duas outras funções: exchange e falloff (fall off).

$$
\begin{gathered}
\text { exchange }: \mathbb{R}^{\text {nobj }} \times \mathbb{R}^{\text {nobj }} \times \mathbb{N} \longmapsto \mathbb{R} \\
\text { falloff }: \mathbb{R} \longmapsto \mathbb{R}
\end{gathered}
$$

Essas outras duas funções fornecem fatores para o cálculo de resultant e constituem parâmetros do presente método de agrupamento. Informalmente, exchange diz qual a taxa de troca de energia entre dois clusters em função da diferença entre seus estados de energia. Já falloff diz o quanto diminui a influência entre dois objetos em função da distância que os separa.

Foi dito que resultant refere-se à variação do estado de energia "desejada" por cada cluster. No entanto, quando os estados de energia de dois (ou mais) clusters caminham um em direção ao outro, convergindo ao equilíbrio, deve-se evitar que quando cheguem 

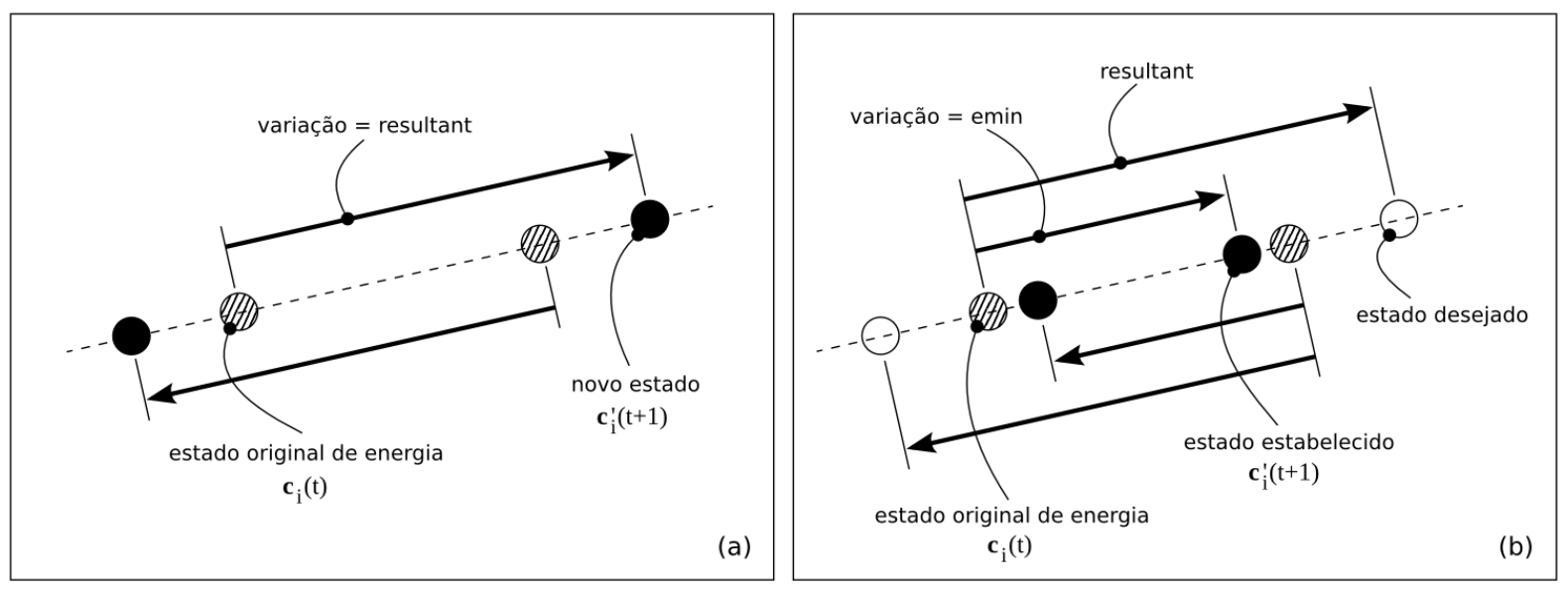

Figura 4.2: Dois estados de energia num movimento simétrico de aproximação. Em (a), a situação indesejada, onde a distância entre eles após a variação se torna maior que a distância antes da variação. Em (b), a variação sendo limitada por emin.

razoavelmente perto, uma próxima iteração lance-os com demasiada violência a lados opostos, tornando-os mais distantes do que estavam. A Figura 4.2 (a) ilustra essa situação indesejada. Introduz-se então a função normalization $(t)$, cujo objetivo é gerar um fator capaz de normalizar a variação de energia de todos os clusters, de modo que a maior das variações seja igual à constante emin:

$$
\operatorname{normalization}(t)=\frac{\operatorname{emin}}{\max \left(\left\{\left\|\operatorname{resultant}\left(\mathbf{c}_{i}(t)\right)\right\|\right\}\right)}, \quad i=1 \ldots|C(t)|
$$

onde $\|$ resultant $\left(\mathbf{c}_{i}(t)\right) \|$ e $|C(t)|$ denotam, respectivamente, a magnitude do vetor resultant $\left(\mathbf{c}_{i}(t)\right)$ e o tamanho do conjunto $C(t)$. A função max resulta, consequentemente, na maior das variações do estado de energia. A Figura 4.2(b) ilustra a variação dos estados de energia sendo limitada por emin. Essa figura ilustra o caso onde a variação é a máxima possível, ou seja, igual a emin. Vale lembrar que quando a distância entre os estados de energia de dois clusters torna-se menor ou igual a emin, esses clusters são definitivamente agrupados. Importante notar também que, caso o maior dos valores para resultant seja menor que a constante emin, normalization aumenta todas as variações de energia, evitando que a convergência do processo de agrupamento seja muito lenta. Assim, valores grandes de emin aumentam a velocidade de convergência, mas reduzem a precisão do processo de agrupamento.

Finalmente, a variação efetiva do estado de energia de cada cluster:

$$
e_{i, j}^{\prime}(t+1)=e_{i, j}(t)+\operatorname{resultant}\left(e_{i, j}(t)\right) \cdot \text { normalization }(t)
$$

Importante notar que todo o processo de agrupamento consiste na intercalação de dois sub-processos: fusão dos clusters e troca de energia entre os clusters. A fusão leva de um 
Tabela 4.1: Os parâmetros do método baseado em dinâmica de troca de energia.

\begin{tabular}{|c|l|}
\hline Parâmetro & Descrição \\
\hline omin & $\begin{array}{l}\text { Objetos cuja distância seja menor ou igual a omin são } \\
\text { agrupados já em } t=0 .\end{array}$ \\
\hline emin & $\begin{array}{l}\text { Clusters cuja diferença entre seus estados de energia seja } \\
\text { menor ou igual a emin são agrupados. Valores grandes } \\
\text { de emin aceleram a convergência, mas reduzem a preci- } \\
\text { são do processo de agrupamento. }\end{array}$ \\
\hline nneighbors & $\begin{array}{l}\text { Número de vizinhos considerados. Cada objeto, a cada } \\
\text { iteração, só troca energia com os nneighbors vizinhos } \\
\text { mais próximos que não pertencem ao mesmo cluster. }\end{array}$ \\
\hline exchange $\left(\mathbf{c}_{i}(t), \mathbf{c}_{j}(t), k\right)$ & $\begin{array}{l}\text { Define a taxa de troca de energia entre dois clusters em } \\
\text { função da diferença entre seus estados de energia. }\end{array}$ \\
\hline falloff $\left(\left\|\mathbf{o}_{m}-\mathbf{o}_{n}\right\|\right)$ & $\begin{array}{l}\text { Define o quanto diminui a influência entre dois objetos } \\
\text { em função da distância que os separa. }\end{array}$ \\
\hline
\end{tabular}

conjunto $C^{\prime}(t)$ de clusters a um novo conjunto $C(t)$, eventualmente menor que $C^{\prime}(t)$. A troca de energia leva o estado de energia de cada cluster $\mathbf{c}_{i}(t)$ a um novo valor em $\mathbf{c}_{i}^{\prime}(t+1)$. A Tabela 4.1 sumariza os parâmetros do método descrito.

\subsection{Experimentos realizados}

Simulações foram realizadas com o método de agrupamento de dados baseado em dinâmica de troca de energia proposto neste trabalho. As Seções 4.2.1 e 4.2.2 trazem, respectivamente, os resultados de simulações sobre conjuntos de dados artificiais e reais.

Todas as simulações empregaram os seguintes parâmetros: omin $=0,1$, emin $=0,02$, nneighbors $=20$ e exchange $\left(\mathbf{c}_{i}(t), \mathbf{c}_{j}(t), k\right)=1$. Esse valor para exchange, quando aplicado na Equação (4.11), faz a intensidade da troca de energia entre dois objetos ser diretamente proporcional à diferença entre seus valores de energia. O parâmetro variado foi a função falloff, que para todos os conjuntos testados, assumiu: falloff $=1 /\left\|\mathbf{o}_{m}-\mathbf{o}_{n}\right\|$ e falloff $=1 /\left\|\mathbf{o}_{m}-\mathbf{o}_{n}\right\|^{5}$, lembrando que $\left\|\mathbf{o}_{m}-\mathbf{o}_{n}\right\|$ representa a distância entre os objetos.

Os conjuntos de dados utilizados neste trabalho são formados por classes de objetos. Essas classes existem a priori. Contudo, o método de agrupamento não as "conhece", evidentemente. Seu objetivo é justamente "descobri-las". Assim, a fim de mensurar o processo de agrupamento, rastreou-se o crescimento de um cluster representativo de cada classe do conjunto de dados. Seja uma classe $A$. Então procurou-se pelo cluster que, ao longo de todo o processo de agrupamento, detivesse a maior quantidade de objetos da classe $A$. Mediu-se, então, a relação entre a quantidade de objetos da classe $A$ presentes no cluster e o tamanho do próprio cluster. 


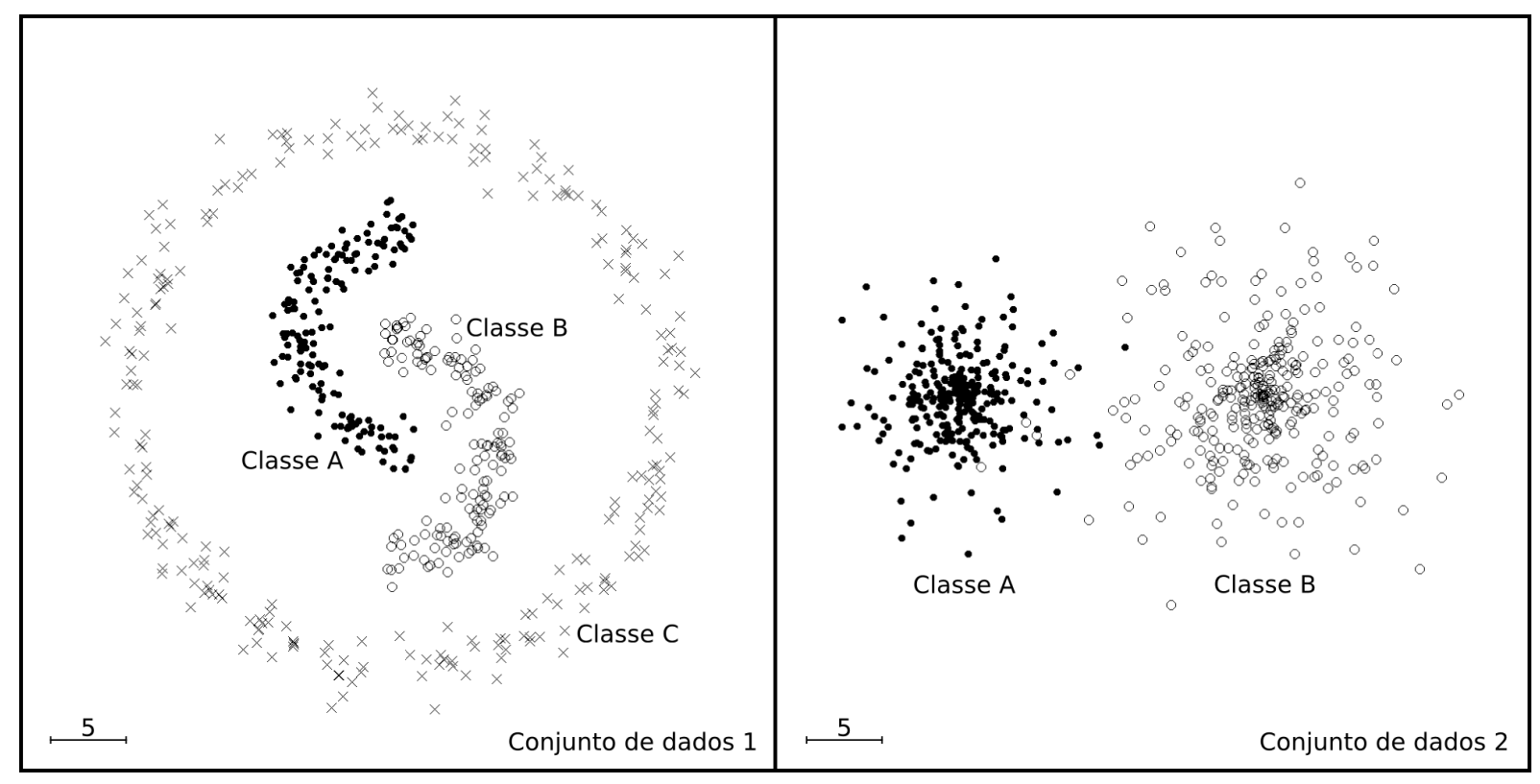

Figura 4.3: Dois conjuntos artificiais de dados utilizados nas simulações.

\subsubsection{Experimentos com dados artificiais}

Geraram-se dois conjuntos artificiais de dados, como mostrado na Figura 4.3. Cada conjunto é identificado simplesmente como Conjunto de dados 1 e Conjunto de dados 2.

O Conjunto de dados 1 contém três classes. As Classes A e B são formadas, cada uma, por 150 objetos distribuídos aleatoriamente por uma semicircunferência de raio 7,5. A Classe C, ao redor das outras duas, é formada por 250 objetos distribuídos aleatoriamente por uma circunferência de raio 18. Em todas as classes, o valor angular de cada objeto teve probabilidade uniforme pela circunferência (ou semicircunferência) e o valor radial seguiu uma distribuição de probabilidade normal (gaussiana) com valor esperado igual ao raio e desvio padrão igual a 1 .

O Conjunto de dados 2 contém duas classes. Cada uma delas é formada por 300 objetos distribuídos aleatoriamente ao redor de um ponto, seu centro. Seguiu-se uma distribuição de probabilidade normal bivariada, com desvio padrão igual a 4 para a Classe A e 6 para a Classe B, em ambas as dimensões. Os centros de cada classe distam 20 unidades um do outro.

Na Figura 4.4 mostram-se os resultados sobre o Conjunto de dados 1. Dentre os dois experimentos, observa-se desempenho consideravelmente melhor com falloff $=1 / \| \mathbf{o}_{m}$ $\mathbf{o}_{n} \|^{5}$. Nele, as Classes A e B são perfeitamente agrupadas, e permanecem assim por várias iterações, antes que comecem a se misturar. A Classe C atinge também seu estado ideal, permanecendo assim durante uma iteração somente, a iteração $t=329$, como detalhado na Figura 4.5 .

Na Figura 4.6, mostram-se os resultados sobre o Conjunto de dados 2. Observa-se desempenho ligeiramente melhor com falloff $=1 /\left\|\mathbf{o}_{m}-\mathbf{o}_{n}\right\|^{5}$. As duas classes mantêm- 


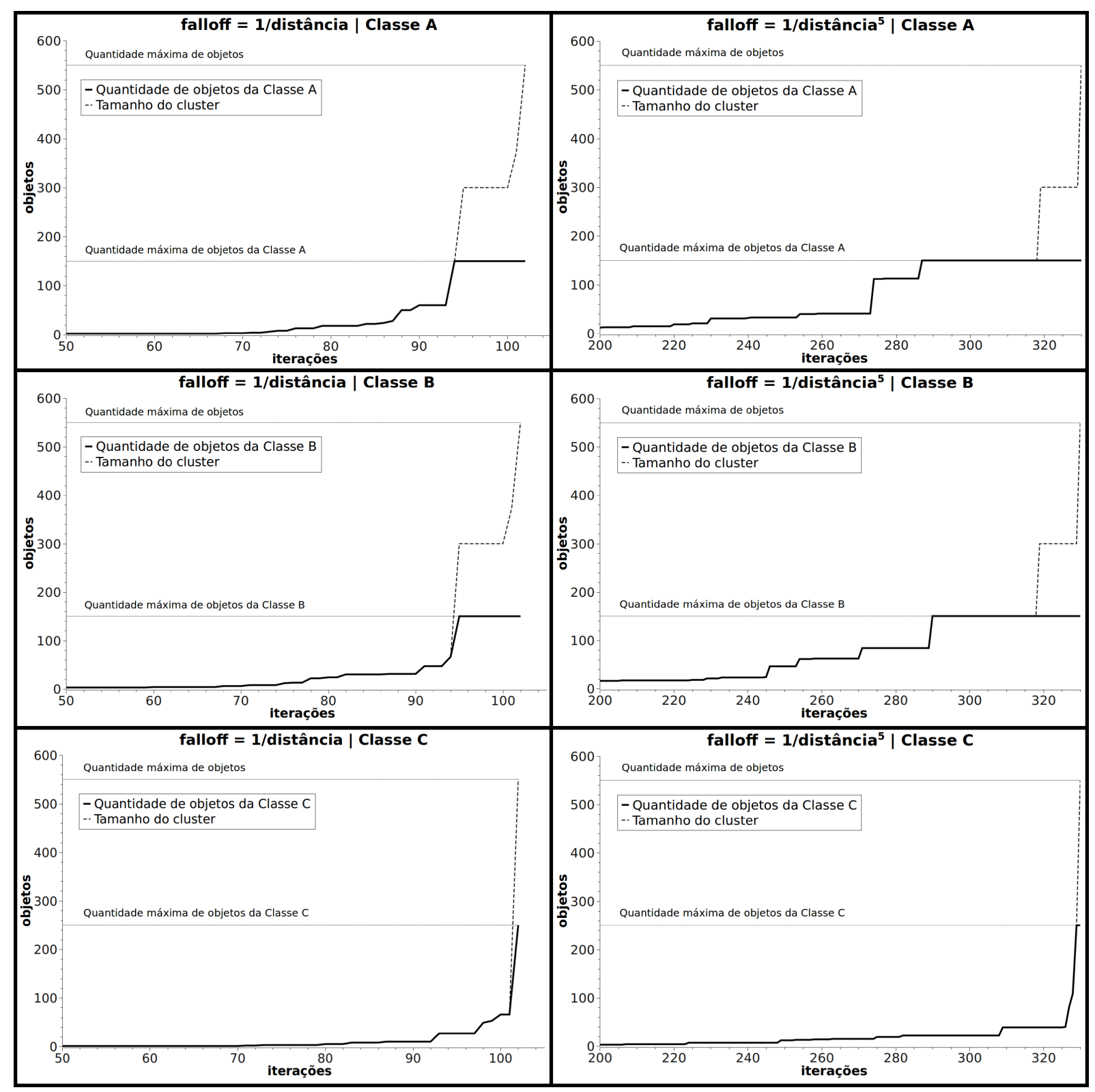

Figura 4.4: Resultados das simulações sobre o Conjunto de dados 1.

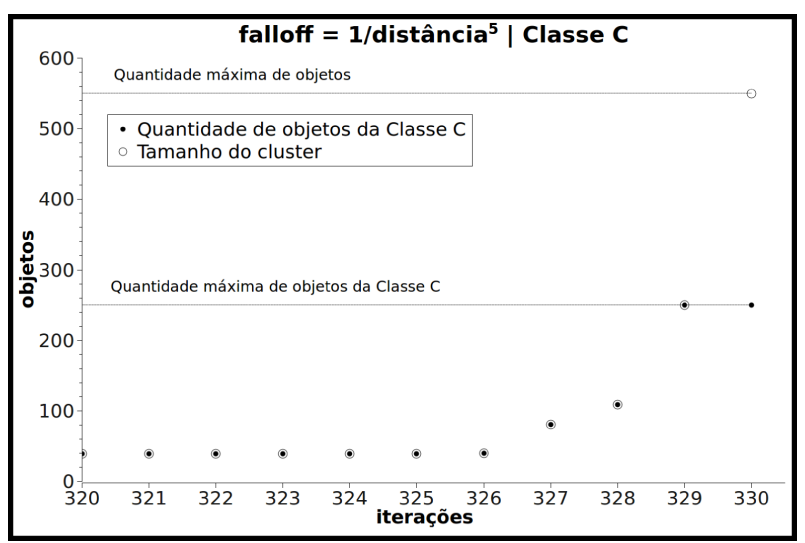

Figura 4.5: Evolução do cluster representativo da Classe $C$, nas últimas iterações da simulação sobre o Conjunto de dados 1, empregando falloff $=1 /\left\|\mathbf{o}_{m}-\mathbf{o}_{n}\right\|^{5}$. 


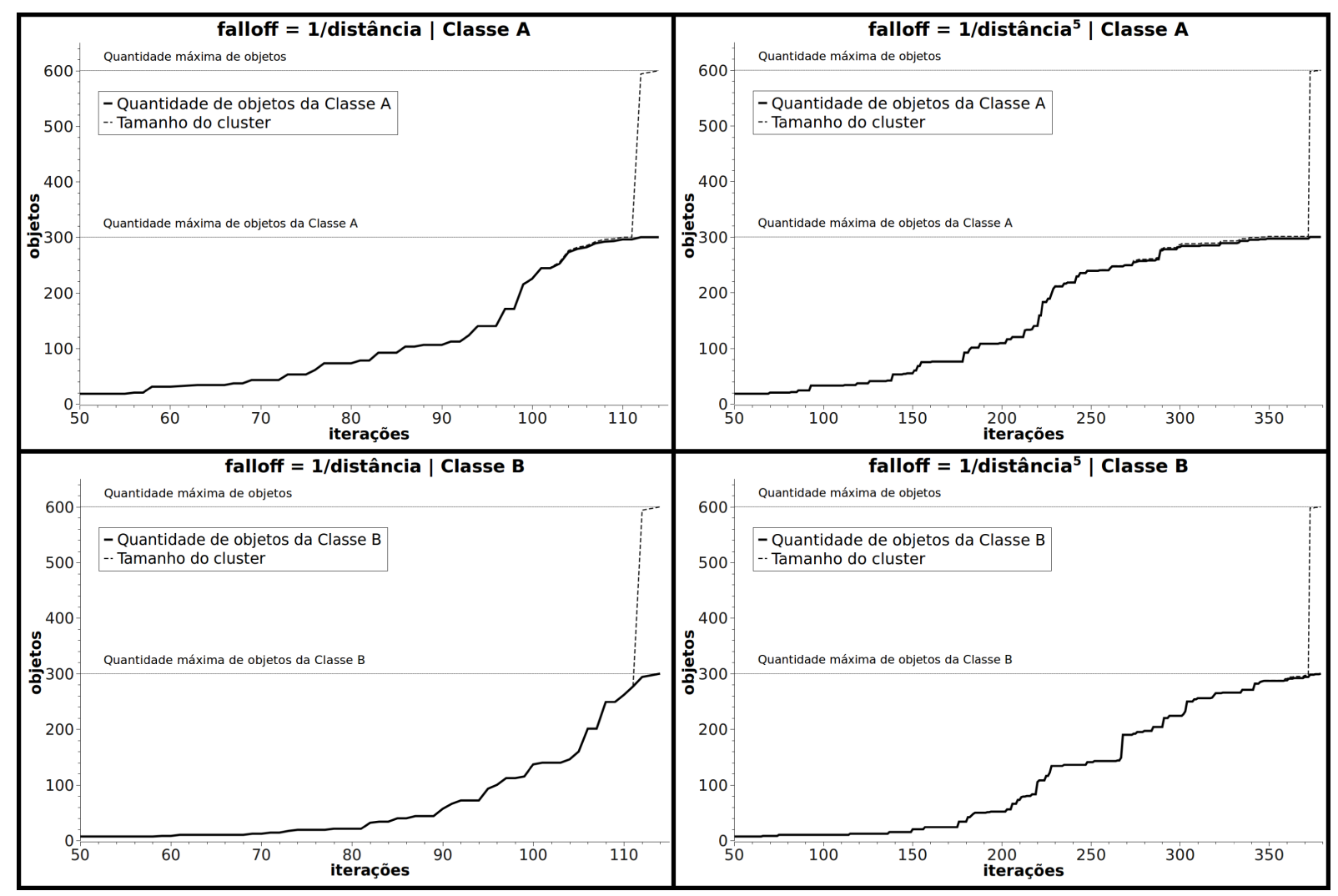

Figura 4.6: Resultados das simulações sobre o Conjunto de dados 2.

se praticamente puras por bastante tempo, mas quando chegam perto de tornarem-se completas, misturam-se bruscamente.

\subsubsection{Experimentos com dados reais}

Mostram-se aqui os resultados de simulações sobre um conjunto de dados denominado Iris Data Set, obtido do UCI Machine Learning Repository (http://archive.ics.uci. edu/ml/index.html). Esse conjunto é comumente empregado para avaliação de métodos de classificação ou agrupamento de dados. Ele é composto por três classes, cada uma contendo 50 objetos. Cada classe representa uma espécie da planta Iris: Iris setosa, Iris versicolor e Iris virginica. Cada objeto é formado por quatro atributos: tamanho e largura da sépala e da pétala, em centímetros.

Os resultados obtidos são mostrados na Figura 4.7. Observa-se bom desempenho para a classe Iris setosa, principalmente com falloff $=1 /\left\|\mathbf{o}_{m}-\mathbf{o}_{n}\right\|^{5}$. Ela chega perto de ser completamente agrupada antes que comece a se misturar com as duas outras. A partir daí, a mistura é brusca. Para as outras duas classes, no entanto, houve desempenho insatisfatório. De fato, as classes Iris versicolor e Iris virginica estão "encostadas" uma na outra, enquanto a classe Iris setosa mantém-se distante. 


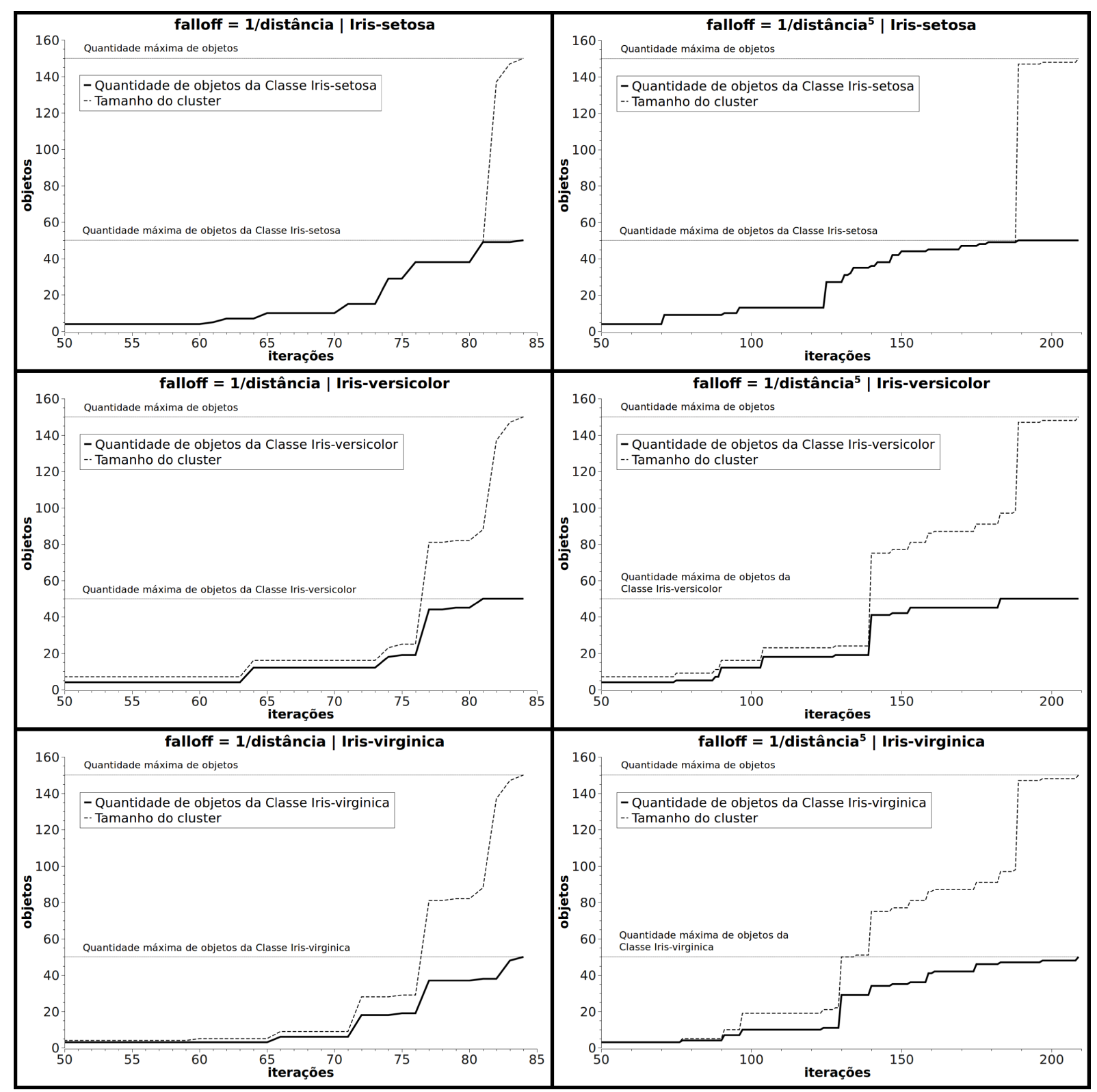

Figura 4.7: Resultados das simulações sobre o conjunto Iris.

\subsection{Considerações finais}

O método proposto e estudado neste trabalho exibe características interessantes. Conceitualmente, é um método simples, baseado na gradativa troca de energia entre os elementos constituintes do sistema, os objetos. Contudo, essa simplicidade mostra-se capaz de agrupar objetos com distribuição relativamente complexa, como mostraram as simulações sobre o Conjunto de dados 1 . Os resultados sugerem que esse método é capaz de separar e agrupar classes de formas arbitrárias, desde que a distância entre objetos adjacentes de uma mesma classe seja, em geral, menor que a distância entre objetos de classes distintas.

Alguns conjuntos de dados não exibem, entretanto, uma distribuição contendo classes tão bem-separadas. Neles ocorrem pareamento ou sobreposição de classes. Os resultados das simulações sobre o Conjunto de dados 2 e sobre o conjunto Iris exibem a dificuldade 
em se agrupar objetos com uma distribuição desse tipo.

Os experimentos aqui realizados compararam o resultado do agrupamento com a partição de referência. Na prática, entretanto, tal partição de referência não existe. Torna-se necessário, então, um estudo mais detalhado para saber qual é a partição — dentre a hierarquia de partições geradas - que melhor representa o conjunto de dados. Pode-se pesquisar por critérios internos e relativos de validação capazes de mensurar a qualidade de tais partições.

Como informado no texto, o estado de energia de cada objeto é caracterizado por um vetor de dimensão tão grande quanto a própria quantidade de objetos. Como vantagem, pode-se atribuir estados de energia completamente independentes entre os objetos, evitando que o processo de agrupamento seja dependente de atribuições aleatórias. Como desvantagem, o custo computacional, tanto em espaço quanto em tempo. Assim, a influência que a redução da dimensão desse vetor exerce sobre o processo de agrupamento representa um estudo ainda a ser realizado. 


\section{Capítulo 5}

\section{Agrupamento guiado por troca positiva e negativa de energia}

Um aspecto notável da técnica apresentada no capítulo anterior é que todos os objetos estão fadados a um mesmo estado de energia. Isso acontece pois há somente atração entre eles. Assim, desenvolveu-se uma segunda técnica de agrupamento em que, além da troca de energia no sentido de atração, há também troca no sentido de repulsão — chamada troca negativa - , tal que objetos muito diferentes tendam a tomar estados de energia também diferentes. Essa técnica foi publicada no seguinte trabalho:

\section{Roberto Alves Gueleri \& Zhao Liang. An Energy Exchanging Mechanism}

for Data Clustering. In: Proceedings of the 2012 Brazilian Symposium on Neural Networks (SBRN 2012). Pages 31-36. DOI 10.1109/SBRN.2012.34

Pelas seções seguintes, é descrita a técnica baseada em dinâmica de troca positiva e negativa de energia, seguida da apresentação de uma série de experimentos realizados e a discussão de seus resultados. No final, são apresentadas ideias para otimizar a técnica proposta, assunto que não foi publicado no trabalho acima mencionado.

\subsection{Descrição da técnica}

Inicialmente, a cada objeto é atribuído um estado de energia. Conforme o processo avança, os objetos vão trocando energia entre si. A distância que separa cada par de objetos define seu grau de interação. Essa interação diminui conforme a distância entre os objetos aumenta, sendo positiva para objetos próximos e negativa para objetos distantes. A interação positiva tende a aproximar os estados de energia, enquanto a negativa tende a afastá-los. Espera-se que, para uma escolha adequada de parâmetros, o sistema atinja um estado estacionário onde objetos similares mantenham estados de energia mais próximos que objetos diferentes. 
Rigorosamente, esse processo sozinho não caracteriza um algoritmo de agrupamento. Uma partição dos dados não é formada. Ao invés disso, ele mapeia os objetos de seu espaço original (o espaço de atributos) em um novo espaço chamado espaço de energia. Espera-se, com isso, que os objetos nesse novo espaço de energia sejam mais facilmente agrupáveis. Para completar o processo, aplica-se algum algoritmo de agrupamento, mas sobre os objetos no novo espaço de energia. Os experimentos realizados neste trabalho empregaram o algoritmo k-médias, descrito na Seção 2.4.1.

Agora, descreve-se formalmente esse processo dinâmico de troca de energia. Seja $m$ a quantidade de atributos que caracterizam os objetos. Assim, cada objeto $\mathbf{o}_{i}$ é dado pelo vetor

$$
\mathbf{o}_{i}=\left(o_{i, 1}, o_{i, 2}, \ldots, o_{i, m}\right)
$$

onde cada componente $o_{i, k}$ é um atributo numérico real.

Seja $n$ a quantidade de objetos e $t$ o índice de iteração do sistema dinâmico, tal que $t=0$ representa o estado inicial do sistema. Assim, cada objeto $\mathbf{o}_{i}$ está associado a um vetor estado de energia $\mathbf{e}_{i}$,

$$
\mathbf{e}_{i}(t)=\left(e_{i, 1}(t), e_{i, 2}(t), \ldots, e_{i, n}(t)\right)
$$

onde cada componente $e_{i, k}(t)$ representa um nível de energia do objeto $i$ na iteração $t$. Notar que, diferentemente dos objetos em seu espaço original, seus estados de energia variam com o tempo, ou seja, os estados de energia se movem pelo espaço de energia.

Um grau de interação inter $\left(\mathbf{o}_{i}, \mathbf{o}_{j}\right)$ é definido para cada par de objetos,

$$
\operatorname{inter}\left(\mathbf{o}_{i}, \mathbf{o}_{j}\right)=\operatorname{pos}\left(\left\|\mathbf{o}_{i}-\mathbf{o}_{j}\right\|\right)-\operatorname{neg}\left(\left\|\mathbf{o}_{i}-\mathbf{o}_{j}\right\|\right)
$$

onde $\left\|\mathbf{o}_{i}-\mathbf{o}_{j}\right\|$ é a distância euclidiana entre $\mathbf{o}_{i}$ e $\mathbf{o}_{j} \cdot \operatorname{pos}\left(\left\|\mathbf{o}_{i}-\mathbf{o}_{j}\right\|\right)$ e neg $\left(\left\|\mathbf{o}_{i}-\mathbf{o}_{j}\right\|\right)$, por sua vez, são funções tais que $\operatorname{pos}\left(\left\|\mathbf{o}_{i}-\mathbf{o}_{j}\right\|\right)$ seja estritamente decrescente, $\operatorname{neg}\left(\left\|\mathbf{o}_{i}-\mathbf{o}_{j}\right\|\right)$ seja estritamente crescente e ambas sejam positivas.

Desse modo, a função de interação resultante é estritamente decrescente e vale zero para alguma distância positiva. Isso está de acordo com a ideia de que objetos distantes devam manter menor interação. Essa função é também positiva para distâncias pequenas e negativa para grandes distâncias. Caso a distância entre algum par de objetos resulte numa interação igual a zero, então não haverá nenhuma troca de energia diretamente entre eles. 
A evolução do sistema é então regida por

$$
\begin{gathered}
e_{i, k}(0)= \begin{cases}0 & \text { para } i \neq k \\
1 & \text { para } i=k\end{cases} \\
e_{i, k}(t+1)=e_{i, k}(t)+\alpha \sum_{\mathbf{o}_{j}}\left(e_{j, k}(t)-e_{i, k}(t)\right) \operatorname{inter}\left(\mathbf{o}_{i}, \mathbf{o}_{j}\right)
\end{gathered}
$$

onde $\mathbf{o}_{j}$ representa todos os demais objetos tais que

$$
\operatorname{inter}\left(\mathbf{o}_{i}, \mathbf{o}_{j}\right)<0 \Longrightarrow\left(e_{i, k}(t)>0 \wedge e_{j, k}(t)>0\right)
$$

ou seja, se $\operatorname{inter}\left(\mathbf{o}_{i}, \mathbf{o}_{j}\right)<0$, então nem $e_{i, k}(t) \leq 0$ nem $e_{j, k}(t) \leq 0$, do contrário não haverá troca entre $\mathbf{o}_{i}$ e $\mathbf{o}_{j}$ para a componente de energia $k$. Essa restrição estabelece um limite inferior igual a zero para qualquer componente de energia. Precisamente, devido à natureza discreta desse processo, essas componentes poderão eventualmente tomar valores ligeiramente menores que zero.

A constante $\alpha$ determina a precisão do processo. Valores pequenos resultam em maior precisão, mas tornam lenta a convergência. Grandes valores, por sua vez, podem até mesmo tornar instável todo o processo. Uma boa escolha para $\alpha$ deve equilibrar precisão e tempo de convergência. Tal escolha é influenciada pela quantidade e disposição dos objetos, como também pela função de interação. Portanto, não é trivial uma escolha apropriada para $\alpha$, podendo até mesmo ser empírica tal escolha.

Da Equação 5.5 pode-se observar que para cada ganho corresponde uma perda de energia. Assim, a soma total de energia permanece constante durante todo o processo. Precisamente,

$$
\sum_{i} e_{i, k}(t)=1 \quad \forall k, t
$$

ou seja, em qualquer iteração $t$, a soma de qualquer componente $k$ sobre todos os objetos $i$ vale 1 .

Para interação positiva, esse processo é semelhante a um processo físico de condução de calor. Energia é transferida de objetos mais energizados para os menos energizados. A taxa com que acontece essa transferência é proporcional à diferença entre os níveis de energia, como pode ser visto na Equação 5.5. Conforme essa diferença diminui, a transferência de energia torna-se mais suave. Caso houvesse somente interação positiva entre os objetos, todos eles seriam conduzidos a um mesmo estado de energia. Para interação negativa, entretanto, o sistema se comporta de modo contrário, forçando os objetos a tomarem estados de energia cada vez mais distintos uns dos outros, lembrando que as componentes de energia estão limitadas a valores entre 0 e 1 . Uma ilustração de como esses dois tipos distintos de interação (positiva e negativa) atuam sobre os estados de energia dos objetos é dada na Figura 5.1 . 


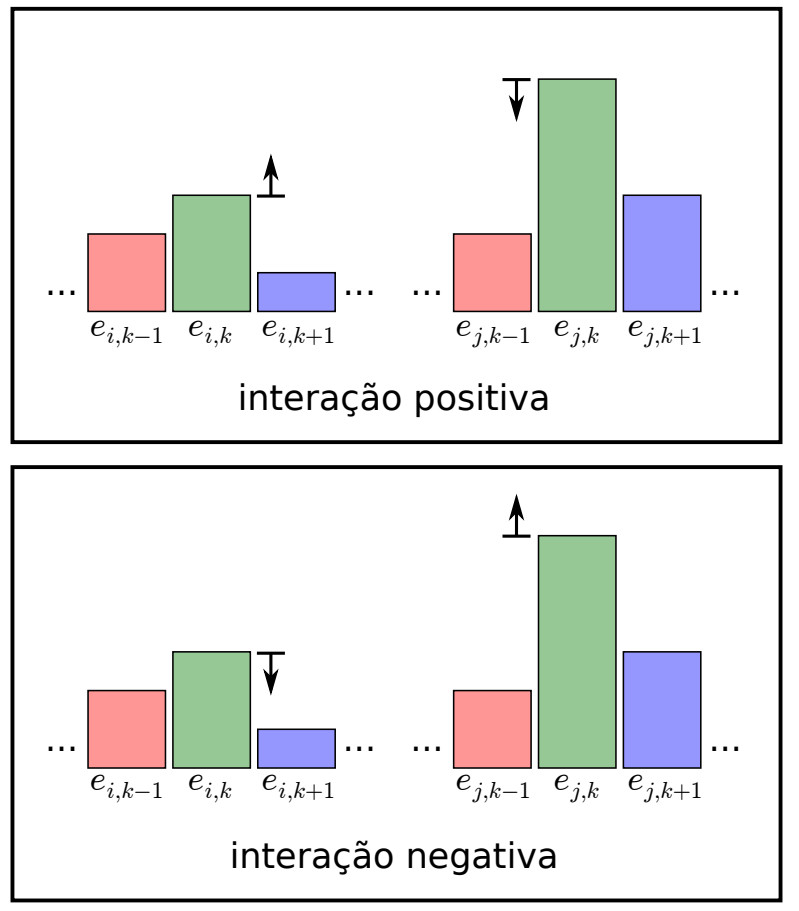

Figura 5.1: Como as interações positiva e negativa atuam sobre os estados de energia dos objetos.

Dado um conjunto de objetos e um conjunto de parâmetros, esse processo é completamente determinístico. Cada vetor estado de energia requer tantas componentes quantos são os objetos a serem agrupados. Como dito na Equação 5.4, essa alta dimensionalidade permite uma total independência entre os estados de energia dos objetos no início do processo. Como consequência, uma vez que esse processo não se apoia em nenhuma escolha aleatória para o estado inicial dos objetos, nenhum deles eventualmente tirará vantagem — ou desvantagem - dessas escolhas arbitrárias. Assim, o processo de formação dos clusters é completamente determinado pelo próprio conjunto de objetos, acompanhado de um conjunto de parâmetros.

\subsection{Experimentos realizados}

Experimentos foram realizados com esse processo dinâmico baseado em troca positiva e negativa de energia. Apresentam-se aqui seus resultados. Todos empregaram a seguinte classe de funções de interação:

$$
\begin{aligned}
& \operatorname{pos}(d)=p d^{-\beta} \\
& \operatorname{neg}(d)=n d^{\frac{1}{\gamma}}
\end{aligned}
$$

resultando

$$
\operatorname{inter}\left(\mathbf{o}_{i}, \mathbf{o}_{j}\right)=\operatorname{pos}(d)-\operatorname{neg}(d)=p d^{-\beta}-n d^{\frac{1}{\gamma}}
$$




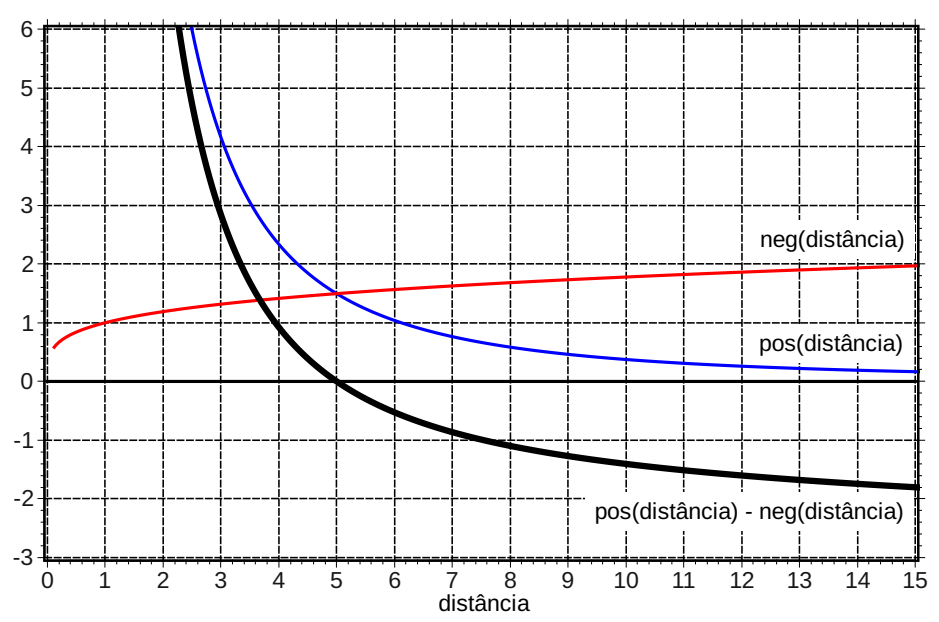

Figura 5.2: Comportamento da função de interação.

onde $d$ significa a distância entre os objetos $\mathbf{o}_{i}$ e $\mathbf{o}_{j}$, ou seja, $d=\left\|\mathbf{o}_{i}-\mathbf{o}_{j}\right\| \cdot p, n, \beta$ e $\gamma$ são constantes positivas tomadas como parâmetros.

É desejável que se possa controlar a distância para a qual a interação resulte em zero. Chamemos tal distância simplesmente de zero a. Essa é a distância a partir da qual a interação se torna negativa. Uma vez que

$$
\operatorname{inter}\left(\mathbf{o}_{i}, \mathbf{o}_{j}\right)=0 \Longleftrightarrow p d^{-\beta}=n d^{\frac{1}{\gamma}} \Longleftrightarrow p=n \frac{d^{\frac{1}{\gamma}}}{d^{-\beta}}
$$

fazendo-se $n=1$, tem-se $p$ em função de $d$,

$$
p=\frac{d^{\frac{1}{\gamma}}}{d^{-\beta}}
$$

Assim, definidos os parâmetros $\beta$ e $\gamma$, atribui-se $n=1$ e determina-se $p$ em função da distância $d$. Essa escolha de $p$ faz com que a interação seja zero para a distância desejada $d$.

Um exemplo de como essa classe de funções de interação se comporta é mostrado na Figura 5.2. Definiu-se $\beta=2, \gamma=4$ e valor zero para $d=5$.

Todos os experimentos foram conduzidos do seguinte modo:

1. Escolheram-se valores para $\alpha, \beta$ e $\gamma$, como também a distância para a qual a interação fosse zero, então calculando o correspondente valor de $p$. Valores apropriados para $\alpha$ foram obtidos empiricamente.

2. Iniciou-se o processo, deixando-o rodar por 3000 iterações.

3. Aplicou-se o algoritmo k-médias sobre o conjunto resultante de vetores de energia. Depois, obteve-se o índice Rand (ver Seção 2.5) sobre a partição resultante. 
Tabela 5.1: Valores de $\alpha$ usados no Experimento 1.

\begin{tabular}{|l|ll|}
\cline { 2 - 3 } \multicolumn{1}{c|}{} & Zero a 4 & Zero a 16 \\
\hline$\beta=1$ & 0,000125 & 0,000025 \\
$\beta=2$ & 0,000025 & 0,000005 \\
$\beta=3$ & 0,000005 & 0,000001 \\
\hline
\end{tabular}

Empregou-se uma versão do k-médias que posiciona os centroides iniciais sobre diferentes objetos tomados aleatoriamente. Sabendo que o k-médias é sensível à escolha inicial dos centroides e é propenso a ficar preso em soluções ruins (Hastie et al., 2001; Alpaydin, 2004; Xu \& Wunsch II, 2009; Faceli et al., 2011), aplicou-se o algoritmo k-médias 50 vezes, tomando-se então a média dos 10 melhores resultados.

\subsubsection{Experimento 1: arcos entrelaçados}

Os resultados do Experimento 1 são apresentados na Figura 5.3. Ele foi realizado sobre o conjunto de dados mostrado na Figura 5.3(a), composto por duas classes dispostas ao longo de duas semicircunferências. Cada classe possui 150 objetos. Há ainda mais 100 objetos representando ruído e dispostos por um quadrado de 24x24 unidades.

Resultados de diferentes combinações de $\beta$ e $\gamma$ são mostrados nas Figuras 5.3(c), (d) e (e). O ruído foi desconsiderado ao se calcular o índice Rand. O índice Rand obtido de uma mera atribuição aleatória dos objetos por dois clusters resulta em aproximadamente 0,5. Já o índice Rand obtido da aplicação do k-médias sobre o conjunto original de dados resulta em 0,775. Assim como acontece com o conjunto de dados processados, os resultados sobre o conjunto original são a média dos 10 melhores resultados dentre 50 execuções. Vale notar que o valor máximo que o índice Rand pode tomar é 1, significando que a partição resultante coincide exatamente com a partição de referência (Xu \& Wunsch II, 2009, Faceli et al., 2011).

Valores para $\alpha$ foram escolhidos conforme a Tabela 5.1. Por exemplo, para $\beta=1, \alpha$ varia de 0,000125 (zero a 4) até 0,000025 (zero a 16). Valores intermediários são gerados por interpolação linear. Por questões práticas, na primeira iteração foi atribuído um valor extremamente pequeno a $\alpha$ (bem menor que os correspondentes valores da tabela), incrementando-o progressivamente até o valor apropriado. Mas tudo isso somente durante as primeiras iterações. Em todo o restante do processo, os valores de $\alpha$ corresponderam aos valores indicados na tabela. Isso porque o processo de troca de energia se apresenta muito brusco no início, sendo suavizado por um valor pequeno de $\alpha$.

Considere um dos melhores resultados, especificamente um daqueles para $\beta=3$, $\gamma=6$ e zero a 8,5 , que resulta em um índice Rand igual a 1 . Sua evolução é mostrada na Figura 5.3(f). Ali, há seis medições tomadas durante o processo: $1^{\circ}$ quartil (Q1), mediana e $3^{\circ}$ quartil (Q3) das distâncias entre todos os pares de objetos (em termos de seus estados de energia), divididas em pares de uma mesma classe (intra-classe) e pares de 

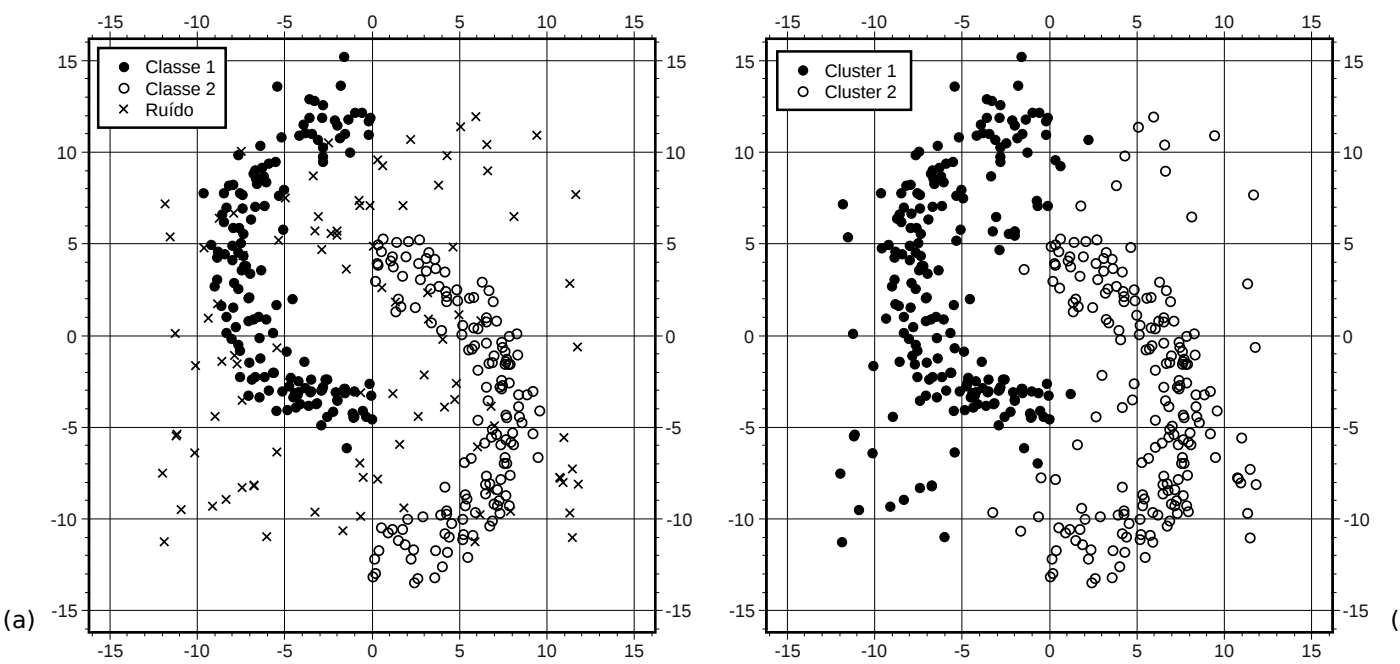

(b)

(c)
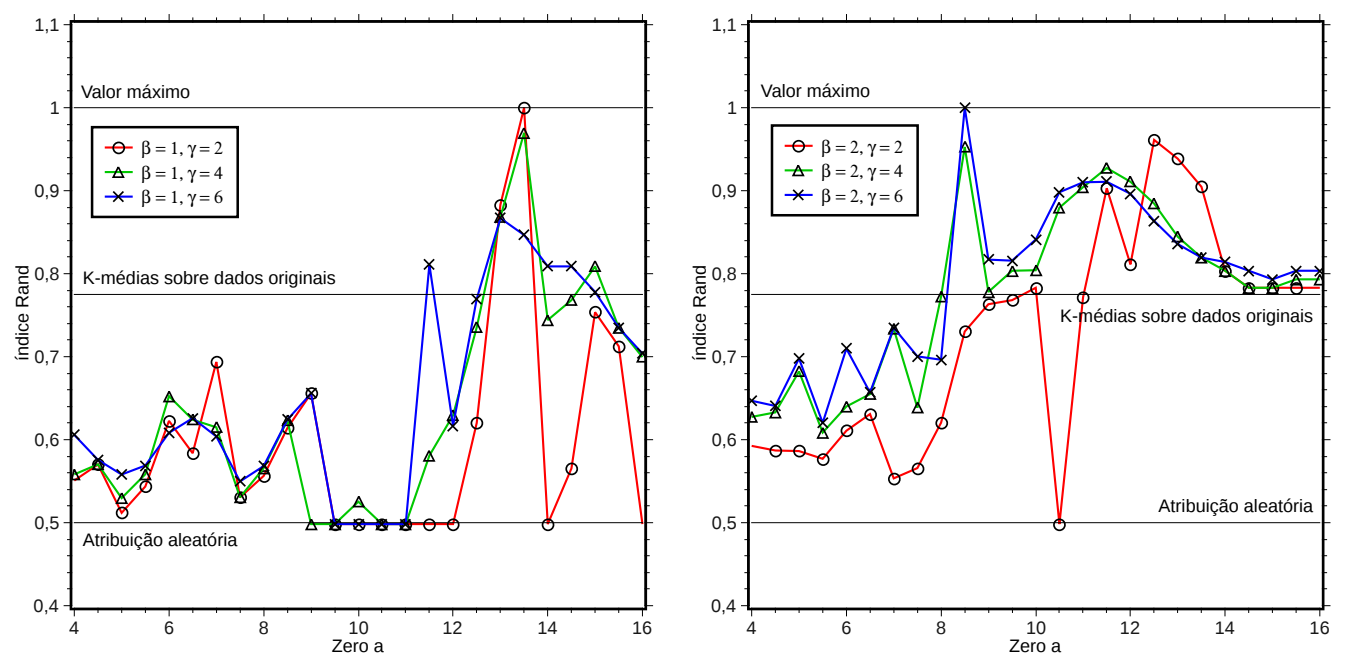

(d)
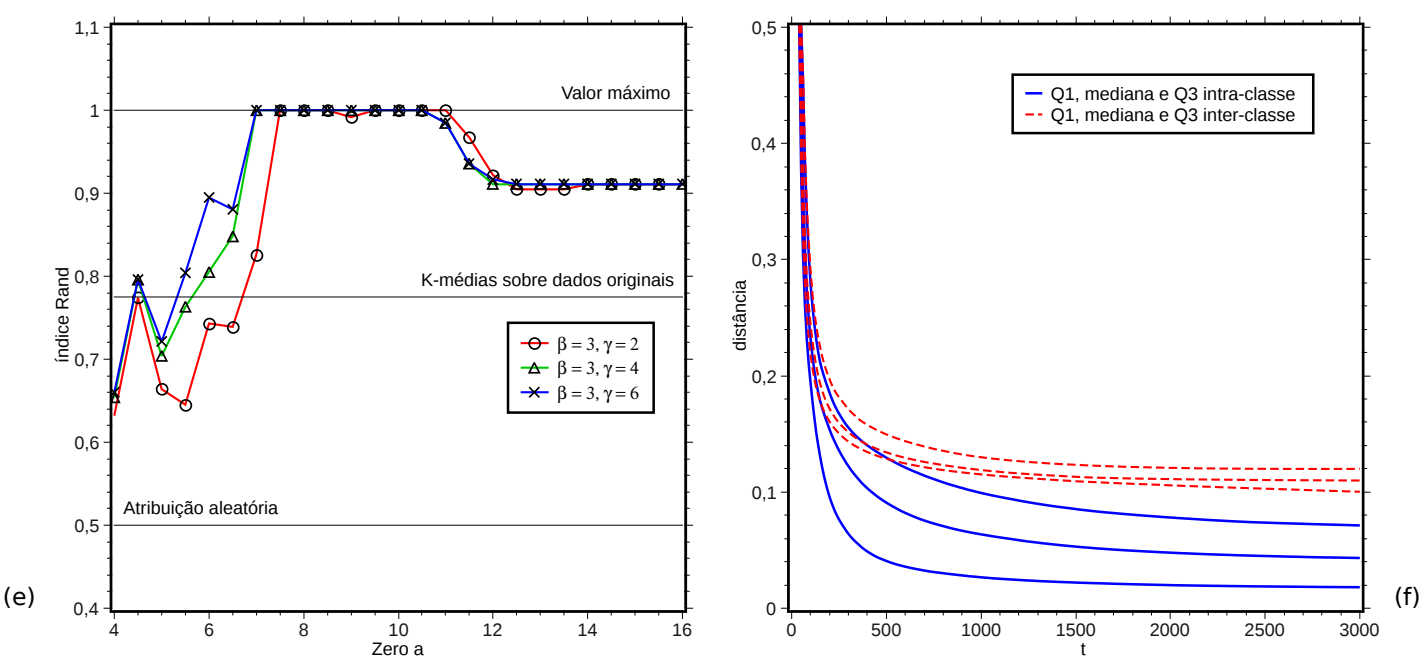

Figura 5.3: (Colorida na versão digital) Resultados de um dos experimentos. (a): O conjunto original de dados. (b): Um dos melhores resultados, especificamente, um daqueles para $\beta=3$, $\gamma=6$ e zero a 8,5 . (c), (d) e (e): Resultados para diferentes combinações de $\beta$ e $\gamma$. (f): Evolução do processo para $\beta=3, \gamma=6$ e zero a 8,5 . Mostram-se o $1^{\circ}$ quartil (Q1), a mediana e o $3^{\circ}$ quartil (Q3) das distâncias entre os estados de energia de todos os pares de objetos, separados em pares de uma mesma classe (intra-classe) e pares de classes distintas (inter-classe). 
Tabela 5.2: Valores de $\alpha$ usados nos Experimentos 2 e 3.

\begin{tabular}{|c|cc|}
\cline { 2 - 3 } \multicolumn{1}{c|}{} & Zero a 1 & Zero a 4 \\
\hline$\beta=1$ & 0,00025 & 0,00005 \\
$\beta=2$ & 0,00005 & 0,00001 \\
$\beta=3$ & 0,00001 & 0,000002 \\
\hline
\end{tabular}

classes distintas (inter-classe). Pode-se observar que o processo se apresenta razoavelmente estável após algum tempo e as diferentes classes parecem estar bem separadas. Por fim, a partição resultante é mostrada na Figura 5.3(b).

A partir desse experimento, observa-se que há certas faixas de parâmetros, especialmente para $\beta=3$, que conduz a resultados muito bons. Embora o k-médias não seja adequado para o conjunto original de dados, ele atua muito bem quando aplicado aos vetores de energia dos objetos. Esses resultados sugerem que o processo aqui apresentado é adequado a conjuntos de dados cujas classes desenham regiões densas de objetos, separadas umas das outras por regiões de baixa densidade. Esse processo também se mostra resistente a certa quantidade de ruído.

\subsubsection{Experimento 2: um anel ao redor}

Os resultados do Experimento 2 são apresentados na Figura 5.4. Ele foi realizado sobre o conjunto de dados mostrado na Figura 5.4(a). Tal conjunto é composto por duas classes: uma cujos objetos são espalhados ao redor de um ponto - uma gaussiana - (Classe 1) e a outra cujos objetos são espalhados ao redor de uma circunferência (Classe 2). A Classe 1 contém 100 objetos e a Classe 2 contém 300 objetos.

Assim como no experimento anterior, resultados de diferentes combinações de $\beta$ e $\gamma$ são mostrados nas Figuras 5.4(c), (d) e (e). Além do índice Rand obtido da atribuição aleatória, há uma comparação com o índice Rand obtido quando todos os objetos são atribuídos a um só cluster, este resultando em 0,624. Isso acontece porque o conjunto de dados é desbalanceado, ou seja, as classes possuem quantidades diferentes de objetos. Por outro lado, a aplicação do k-médias diretamente no conjunto original de dados nem faz sentido, visto que o k-médias não consegue lidar com o tipo de distribuição ali presente, o que resultaria em partições muito ruins (Hastie et al., 2001; Alpaydin, 2004; Xu \& Wunsch II, 2009, Faceli et al., 2011). Valores para $\alpha$ foram escolhidos de modo semelhante ao do experimento anterior, mas agora conforme a Tabela 5.2. A evolução de um dos melhores resultados, assim como sua partição resultante, são mostradas nas Figuras 5.4(f) e (b), respectivamente. Esse resultado é um daqueles para $\beta=3, \gamma=2$ e zero a 2, 2, que resulta em um índice Rand igual a 0,966.

A partir desse experimento, assim como no anterior, observa-se que há certas faixas de parâmetros, especialmente para $\beta=3$, que conduz a bons resultados. Da Figura 5.4(a), nota-se a existência de alguns objetos completamente misturados pelas diferentes classes, 

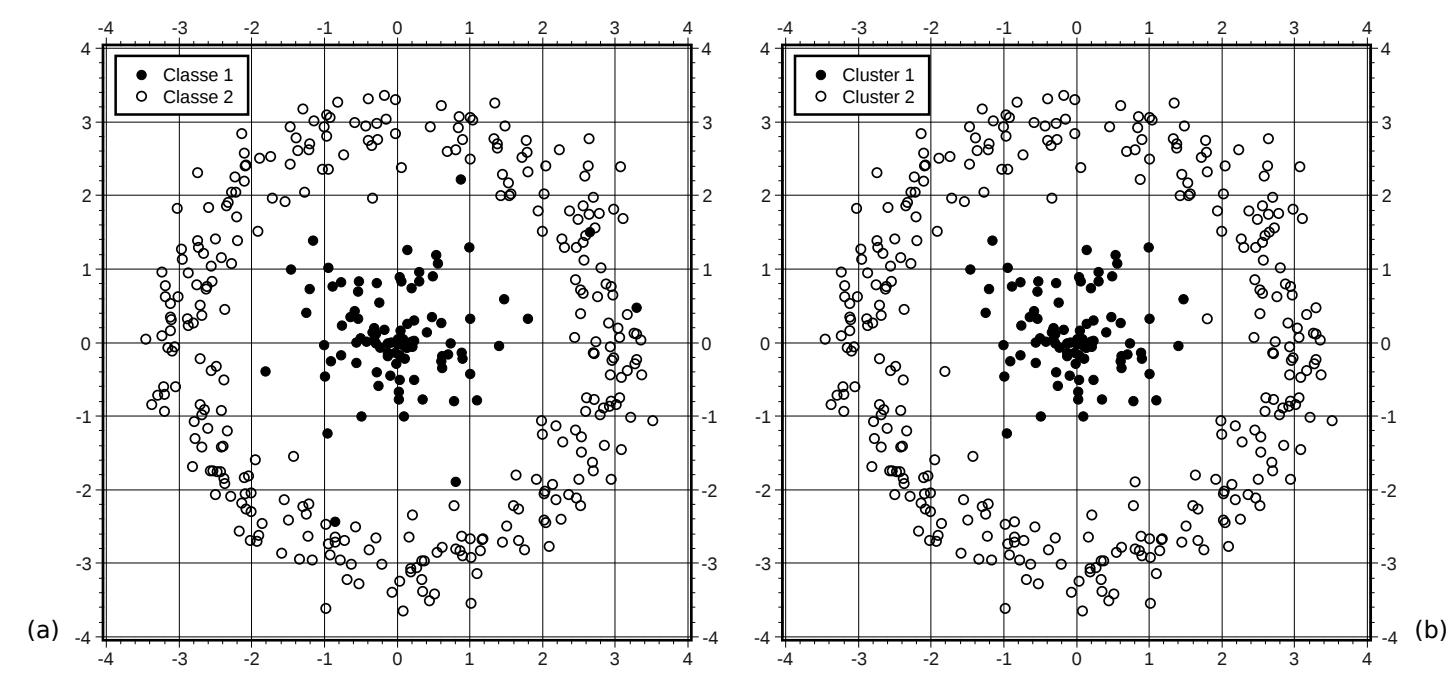

(c)
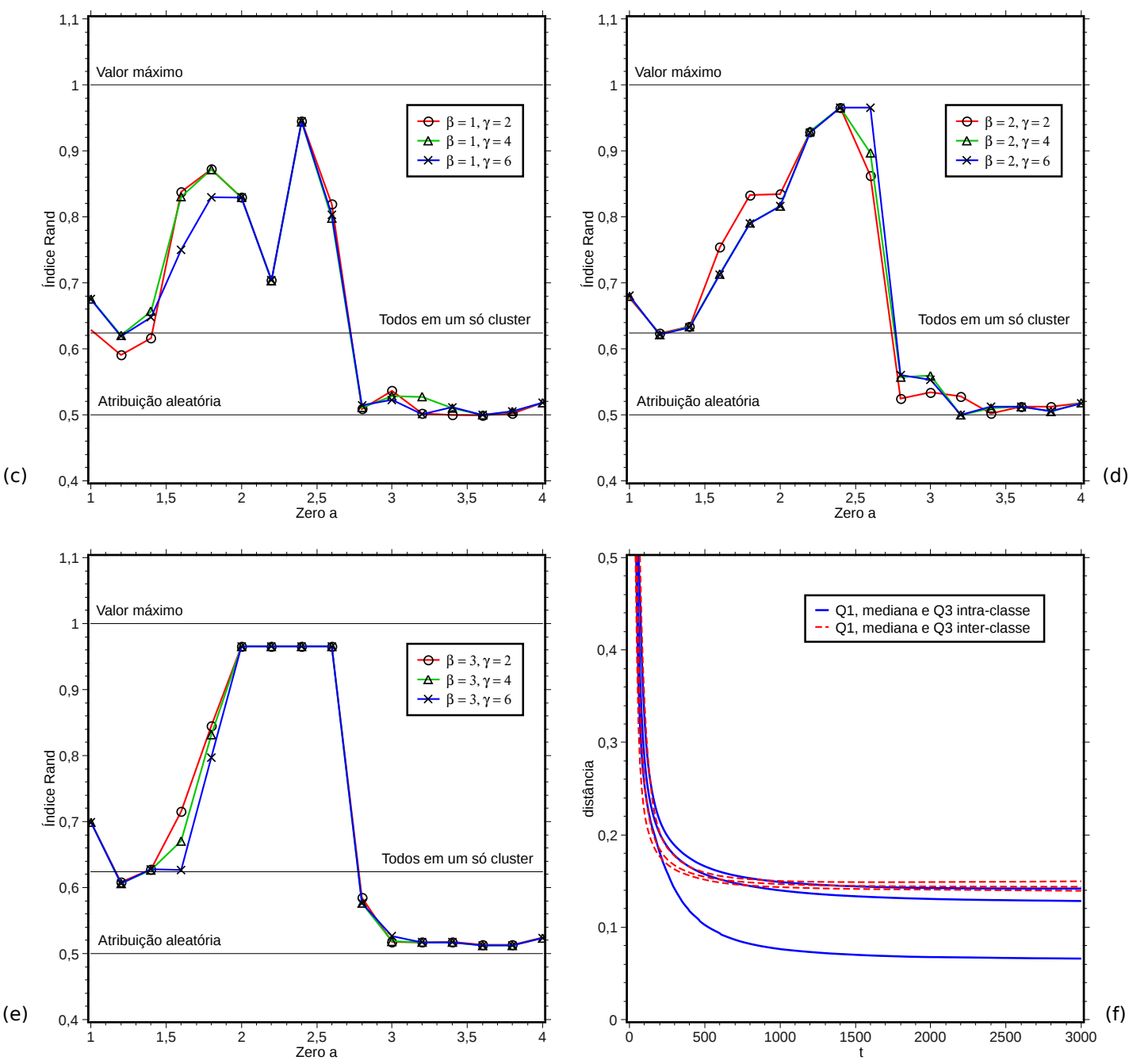

Figura 5.4: (Colorida na versão digital) Resultados de um dos experimentos. (a): O conjunto original de dados. (b): Um dos melhores resultados, especificamente, um daqueles para $\beta=3$, $\gamma=2$ e zero a 2, 2. (c), (d) e (e): Resultados para diferentes combinações de $\beta$ e $\gamma$. (f): Evolução do processo para $\beta=3, \gamma=2$ e zero a 2,2 . Mostram-se o $1^{\circ}$ quartil (Q1), a mediana e o $3^{\circ}$ quartil (Q3) das distâncias entre os estados de energia de todos os pares de objetos, separados em pares de uma mesma classe (intra-classe) e pares de classes distintas (inter-classe). 
fazendo com que o índice Rand resulte em valores ligeiramente inferiores a 1. Novamente, o k-médias atua muito bem no espaço de energia cujos vetores são transformados pela técnica proposta, em contraste com os dados em seu espaço original. Isso reforça a afirmação de que esse processo é adequado a conjuntos de dados cujas classes são formadas por densas regiões de objetos, separadas umas das outras por regiões de baixa densidade.

\subsubsection{Experimento 3: tamanhos diferentes}

Passemos, por fim, ao experimento da Figura 5.5. Ele foi realizado sobre o conjunto de dados mostrado na Figura 5.5(a), composto por duas classes cujos objetos são espalhados ao redor de um ponto - duas gaussuanas. A primeira classe (Classe 1) contém 80 objetos, enquanto a outra (Classe 2) contém 320 objetos e abrange uma área maior maior variância. Embora a forma de cada uma dessas classes (sozinhas) seja adequada ao algoritmo k-médias (objetos espalhados ao redor de um ponto), seus diferentes tamanhos (em termos de área) tornam a tarefa mais difícil (Hastie et al., 2001; Alpaydin, 2004, Xu \& Wunsch II, 2009, Faceli et al., 2011).

Como nos experimentos anteriores, os resultados de diferentes combinações de $\beta$ e $\gamma$ são mostrados nas Figuras 5.5(c), (d) e (e). Há uma comparação com o índice Rand de uma atribuição aleatória e da atribuição de todos os objetos a um só cluster, este último resultando em 0,679. O índice Rand obtido da aplicação do k-médias sobre o conjunto original de dados resulta em 0,874. Trata-se, mais uma vez, da média dos 10 melhores resultados dentre 50 execuções. Os valores de $\alpha$ são exatamente os mesmos do Experimento 2, mostrados na Tabela 5.2. A evolução de um dos melhores resultados e sua partição resultante são mostrados nas Figuras $5.5(\mathrm{f})$ e (b), respectivamente. Esse resultado é um daqueles para $\beta=3, \gamma=2$ e zero a 2,8 , que resulta num índice Rand igual a 0,980 .

Novamente, é possível observar resultados muito bons, mas desta vez para uma faixa mais ampla de parâmetros. Da Figura 5.5(a), nota-se também a existência de alguns objetos completamente misturados pelas diferentes classes, fazendo com que o índice Rand resulte em valores ligeiramente inferiores a 1. Esse conjunto de dados impõe uma mistura ainda maior na fronteira entre as duas classes. Ainda assim, a técnica aqui proposta mostra-se resistente a tal sobreposição.

\subsection{Redução da dimensionalidade do espaço de energia: "agrupamento por cores"}

Embora a técnica de dinâmica de troca de energia descrita neste capítulo possua características interessantes e mostre bons resultados com relação à sua acurácia, ela apresenta-se computacionalmente muito custosa. Cada vetor de energia requer tantas dimensões quan- 

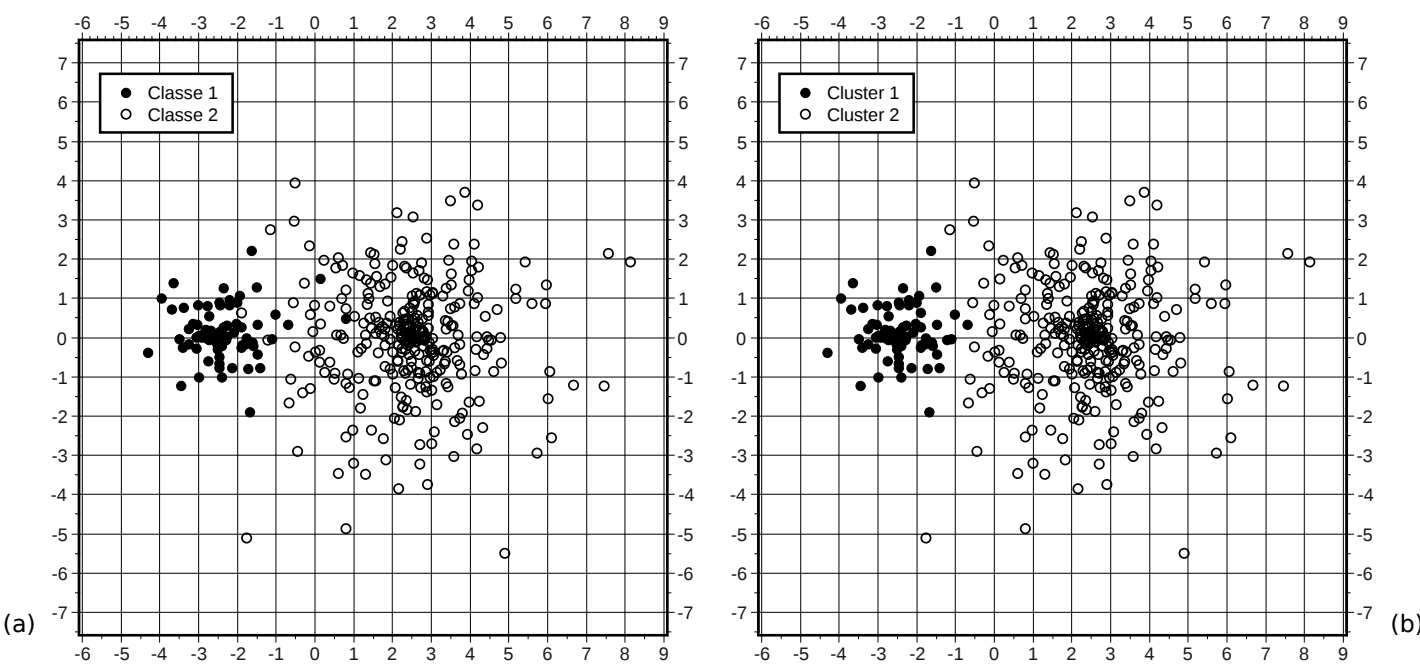

(c)
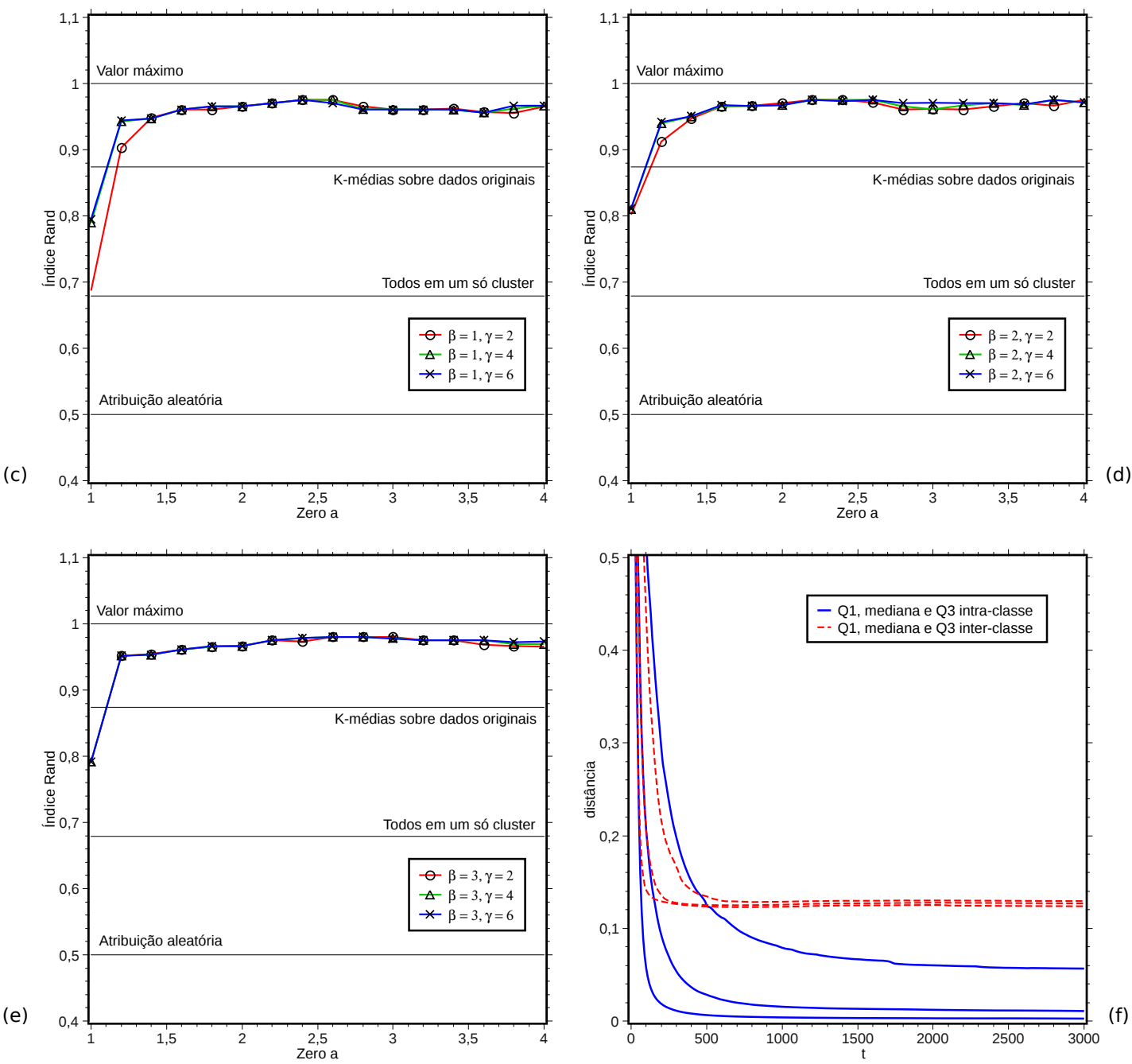

Figura 5.5: (Colorida na versão digital) Resultados de um dos experimentos. (a): O conjunto original de dados. (b): Um dos melhores resultados, especificamente, um daqueles para $\beta=3$, $\gamma=2$ e zero a 2, 8. (c), (d) e (e): Resultados para diferentes combinações de $\beta$ e $\gamma$. (f): Evolução do processo para $\beta=3, \gamma=2$ e zero a 2,8 . Mostram-se o $1^{\circ}$ quartil (Q1), a mediana e o $3^{\circ}$ quartil (Q3) das distâncias entre os estados de energia de todos os pares de objetos, separados em pares de uma mesma classe (intra-classe) e pares de classes distintas (inter-classe). 
tos são os objetos do conjunto de dados. E a cada passo (iteração), cada objeto interage com todos os demais.

Seja $N$ o número de objetos e $M$ a quantidade de atributos que os caracterizam. O cálculo do grau de interação (inter $\left(\mathbf{o}_{i}, \mathbf{o}_{j}\right)$ ) entre todos os pares de objetos demanda $\Theta\left(N^{2} \cdot M\right)$ operações. Após isso, os $M$ atributos originais não mais são processados. Seja $E$ a dimensionalidade do espaço de energia. Quando o processo dinâmico se inicia, cada passo requer $\Theta\left(N^{2} \cdot E\right)$ operações, e como $E=N$, resulta-se em $\Theta\left(N^{3}\right)$ operações a cada passo. Por fim, sendo $T$ o número total de passos do processo dinâmico, a complexidade de tempo de todo esse processo (desconsiderando a aplicação do k-médias ou outro algoritmo no final) é $\Theta\left(N^{2} \cdot M+T \cdot N^{3}\right)$, que pode ser considerado bastante caro. Se assumirmos que $M$ (a quantidade de atributos) é menor que $N$ (o tamanho do conjunto de dados), a complexidade total se torna $\Theta\left(T \cdot N^{3}\right)$.

Torna-se necessária, pois, a otimização dessa técnica de dinâmica de troca de energia. Nesse sentido, apresenta-se aqui um estudo - ainda parcial — do impacto que a redução da dimensionalidade do espaço de energia tem sobre a dinâmica e a acurácia da técnica. Investiga-se, especificamente, o espaço de energia formado por apenas três dimensões. Vinculando-se cada dimensão ao espaço de cores RGB (Red Green Blue), é apresentada, ao longo desta seção, uma série de figuras que procuram ilustrar a evolução da dinâmica de troca de energia em diferentes cenários. Mais ao final da seção, é apresentada também uma breve discussão sobre dinâmicas onde cada objeto não interage — diretamente — com todos os demais, mas com apenas alguns deles. Em particular, se considerarmos a técnica onde cada objeto interage com um número bem limitado - e fixo — de outros objetos tomados aleatoriamente, a complexidade total de tempo se torna $\Theta(N \cdot(M+T))$.

Para o estudo aqui proposto, algumas modificações foram realizadas no modelo apresentado na Seção 5.1. Primeiramente, é inapropriada a restrição de que cada componente de energia $e_{i, k}$ possa tomar somente valores dentro do intervalo $[0 ; 1]$. A descontinuidade causada pela existência dessas bordas no espaço de energia gera dificuldades se tivermos a intenção de analisar (futuramente) a dinâmica desse sistema sob um ponto de vista mais teórico. Contudo, do modo como foi concebido na Equação 5.5, a remoção dessas bordas limitantes faz com que dois vetores em repulsão (interação negativa) tenham a tendência de que, quanto mais se afastarem, mais intensa será a repulsão, provocando uma dispersão muito acelerada dos vetores pelo espaço de energia. O efeito contrário é desejável: quanto mais se afastarem, menos intensa a repulsão.

Nesse sentido, propõe-se um sistema dinâmico cuja evolução é regida por

$$
e_{i, k}(0)=\mathcal{N}(0,1)
$$




$$
\begin{aligned}
e_{i, k}(t+1)=e_{i, k}(t)+\alpha \cdot \sum_{\mathbf{o}_{j}} \operatorname{inter}\left(\mathbf{o}_{i}, \mathbf{o}_{j}\right) \cdot\left(e_{j, k}(t)-e_{i, k}(t)\right) \cdot \\
\cdot \begin{cases}\left\|\mathbf{e}_{i}(t)-\mathbf{e}_{j}(t)\right\| & \text { se } \operatorname{inter}\left(\mathbf{o}_{i}, \mathbf{o}_{j}\right)>0 \\
\frac{1}{\left\|\mathbf{e}_{i}(t)-\mathbf{e}_{j}(t)\right\|} & \text { se } \operatorname{inter}\left(\mathbf{o}_{i}, \mathbf{o}_{j}\right)<0\end{cases}
\end{aligned}
$$

onde $\mathcal{N}(0,1)$ representa um número aleatório proveniente de uma distribuição normal de média 0 e variância 1 , e $\left\|\mathbf{e}_{i}(t)-\mathbf{e}_{j}(t)\right\|$ representa a distância euclidiana entre os vetores de energia $\mathbf{e}_{i}$ e $\mathbf{e}_{j}$.

Quanto à classe de funções de interação, escolheu-se a mesma dos experimentos da Seção 5.2 .

$$
\begin{aligned}
& \operatorname{pos}(d)=p d^{-\beta} \\
& \operatorname{neg}(d)=n d^{\frac{1}{\gamma}}
\end{aligned}
$$

resultando

$$
\operatorname{inter}\left(\mathbf{o}_{i}, \mathbf{o}_{j}\right)=\operatorname{pos}(d)-\operatorname{neg}(d)=p d^{-\beta}-n d^{\frac{1}{\gamma}}
$$

lembrando que $d$ significa a distância entre os objetos $\mathbf{o}_{i}$ e $\mathbf{o}_{j}$, ou seja, $d=\left\|\mathbf{o}_{i}-\mathbf{o}_{j}\right\|$, enquanto $p, n, \beta$ e $\gamma$ são constantes positivas tomadas como parâmetros. Aqui também ajustaram-se os parâmetros $p$ e $n$ de modo que inter $\left(\mathbf{o}_{i}, \mathbf{o}_{j}\right)=0$ para alguma distância desejada (zero a).

Por razões práticas (tempo de simulação), ao invés de um valor fixo do parâmetro $\alpha$, este tem seu valor ajustado a cada iteração. O objetivo é fazer com que, a cada iteração, o deslocamento dos vetores de energia sejam normalizados de modo que o maior deles seja igual a uma precisão escolhida. Desse modo, o sistema é acalmado quando tiver a tendência de ser brusco e é acelerado quando tender a ser lento. A escolha da precisão e a normalização dos deslocamentos acaba tendo o efeito de se atribuir um valor diferente para $\alpha$ a cada iteração. Na prática, atribui-se $\alpha=1$ e realiza-se a normalização. Obs.: valor de precisão pequeno significa dinâmica mais suave, enquanto valor grande significa dinâmica brusca, embora a semântica da palavra "precisão" sugira o contrário.

Nas simulações aqui realizadas, foi escolhido um valor de precisão bem pequeno (dinâmica suave) nas primeiras iterações. Seu valor foi sendo incrementado progressivamente até a precisão final desejada, mas tudo isso somente durante as primeiras iterações. Isso permite que o sistema seja "acomodado" de modo mais suave durante os primeiros passos.

Também por razões práticas, como a função de interação inter $\left(\mathbf{o}_{i}, \mathbf{o}_{j}\right) \rightarrow \infty$, exponencialmente, quando $d \rightarrow 0$, é conveniente limitar a distância mínima que dois objetos podem tomar, consequentemente limitando o valor máximo de inter $\left(\mathbf{o}_{i}, \mathbf{o}_{j}\right)$. Denotaremos tal distância mínima por $d_{m i n}$. Mas já que a disposição dos objetos é dada e não se pode 


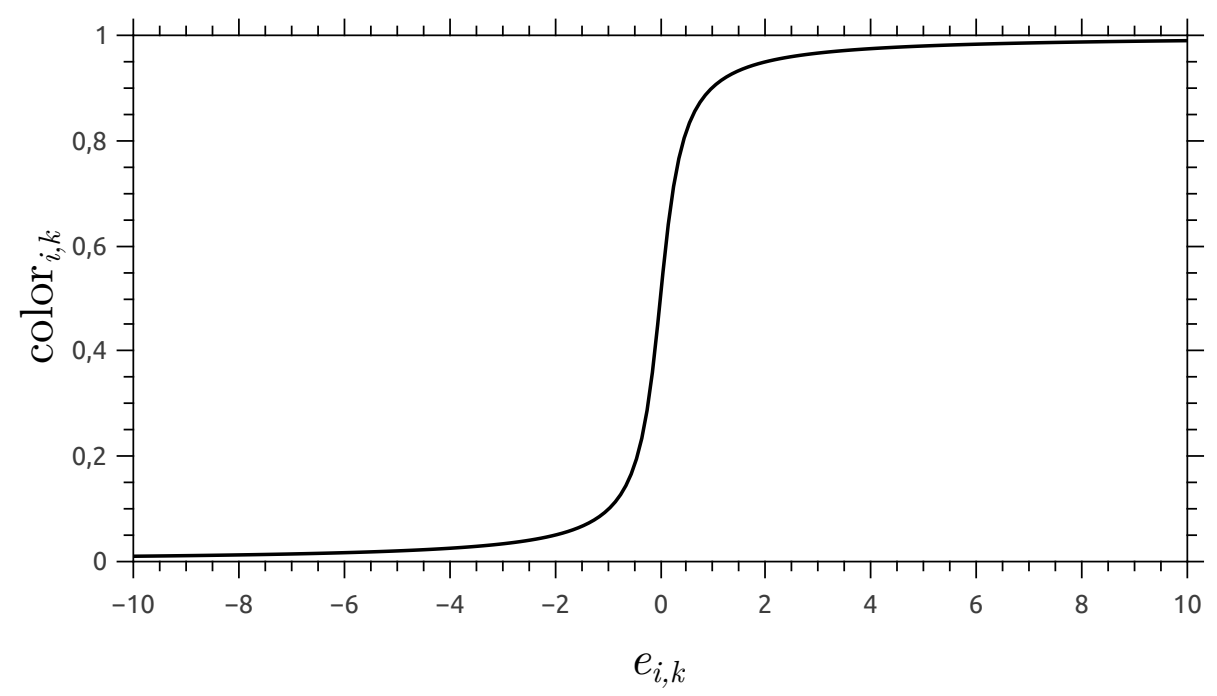

Figura 5.6: Mapeamento da componente de energia $e_{i, k}$ para a componente de cor $\operatorname{color}_{i, k}$. $\operatorname{color}_{i, k}=\left(\operatorname{arctg}\left(\pi \cdot e_{i, k}\right) / \pi\right)+0,5$.

mexer, faz-se o seguinte: caso a distância entre um par de objetos $\mathbf{o}_{i}$ e $\mathbf{o}_{j}$ seja menor que o $d_{\min }$ estabelecido, simplesmente atribui-se $\operatorname{inter}\left(\mathbf{o}_{i}, \mathbf{o}_{j}\right)$ como igual ao valor que teria se a distância entre $\mathbf{o}_{i}$ e $\mathbf{o}_{j}$ fosse, de fato, igual a $d_{\text {min }}$.

A visualização da dinâmica do processo de troca de energia foi concebida do seguinte modo. Utilizaram-se conjuntos de dados compostos por dois atributos, assim cada objeto é plotado diretamente num plano. Cada objeto é representado por um círculo, cuja cor está associada ao estado de energia do objeto. Uma vez que o espaço de energia é formado por três dimensões, é possível mapear cada dimensão a uma componente de cor do espaço RGB. Seja $\operatorname{color}_{i, k}$ o valor da $k$-ésima componente de cor (R, G ou B) do objeto $\mathbf{o}_{i}$. Seu valor varia de 0 (escuro) a 1 (intenso). O mapeamento é então obtido do seguinte modo:

$$
\operatorname{color}_{i, k}=\frac{\operatorname{arctg}\left(\pi \cdot e_{i, k}\right)}{\pi}+0,5
$$

A forma dessa função é ilustrada na Figura 5.6. A visualização da dinâmica agrega ainda mais uma informação: a área de cada círculo é diretamente proporcional à distância entre o estado de energia do objeto e a origem do espaço de energia (distância euclidiana). Ou seja, quanto maior o círculo, mais distante o estado de energia está da origem.

Apresentam-se, então, os experimentos realizados. Não se trata de séries extensivas sobre gamas amplas de parâmetros. É enfatizado, sim, o comportamento do processo dinâmico em diferentes cenários, ou seja, diferentes conjuntos de dados e diferentes parâmetros. A cada experimento realizado corresponde uma figura ilustrando sua evolução. Ao final de cada um, o algoritmo k-médias é aplicado e o índice Rand é calculado. O índice resultante da aplicação do k-médias sobre o conjunto original é usado para comparação. Conforme vinha sendo feito na Seção 5.2, o índice é a média dos 10 melhores resultados 


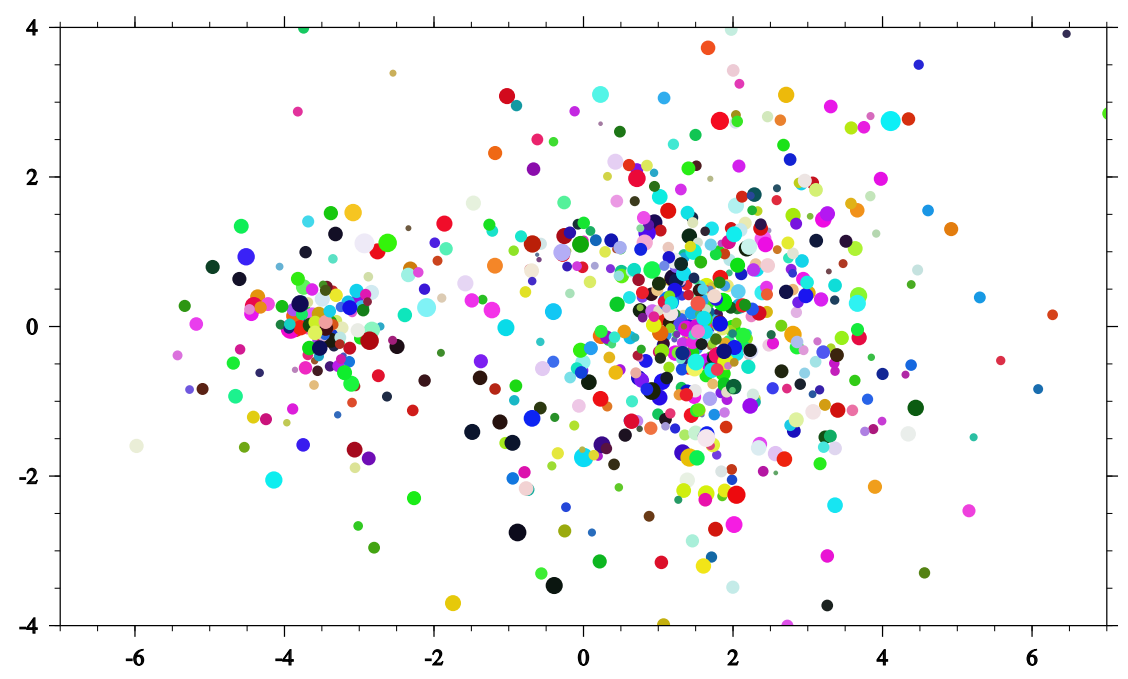

Figura 5.7: (Colorida) Conjunto bidimensional de dados formado por duas gaussianas: a da esquerda contendo 160 objetos e a da direita, mais ampla, contendo 640. O estado de energia inicial de cada objeto é mostrado, representado por círculos de diferentes cores (direção do vetor) e diferentes tamanhos (distância à origem). Índice Rand do k-médias aplicado no conjunto original de dados: 0,889 .

dentre 50 execuções do algoritmo k-médias.

Na Figura 5.7. mostra-se um conjunto artificial de dados formado por duas gaussianas, já representando o estado de energia inicial de cada objeto. O índice Rand obtido do conjunto original é 0,889 . Na Figura 5.8, o resultado de uma simulação, mostrando o estado do sistema em diferentes instantes. O índice Rand obtido ao final do processo é 0,949, mostrando um ganho substancial. Curioso notar que, no início do processo, os vetores de energia aproximam-se da origem, algo evidenciado pelos pequenos círculos. Após isso, eles dispersam-se e, após mais algum tempo, eles apresentam um comportamento razoavelmente estável. Esse fenômeno é observado em todas as simulações realizadas. É desejável que, quando o sistema atinja esse estado razoavelmente estável, os vetores de energia estejam separados segundo as diferentes classes. De fato, isso é observado e evidenciado pelas cores que os objetos tomam. Na Figura 5.9, é mostrada a disposição dos vetores de energia em $t=5000$, instante em que o processo foi interrompido. Exibem-se três diferentes projeções do espaço de energia. Exibe-se também a trajetória percorrida por cada vetor desde o início do processo. É possível notar que os vetores apresentam certa tendência de se disporem ao longo de uma reta. Por fim, nas Figuras 5.10 e 5.11 . mostram-se os resultados de duas outras simulações variando-se o parâmetro zero a. Os índices Rand obtidos são 0,951 e 0,944, equiparáveis ao da primeira simulação. O comportamento do sistema é, entretanto, visivelmente diferente: quanto menor o parâmetro zero $a$, mas repulsão há entre os objetos e mais eles se dispersam.

O resultado sobre um segundo conjunto de dados é apresentado nas Figuras 5.12 e 5.13 . Trata-se de uma gaussiana envolvida por um anel. A aplicação do k-médias diretamente 

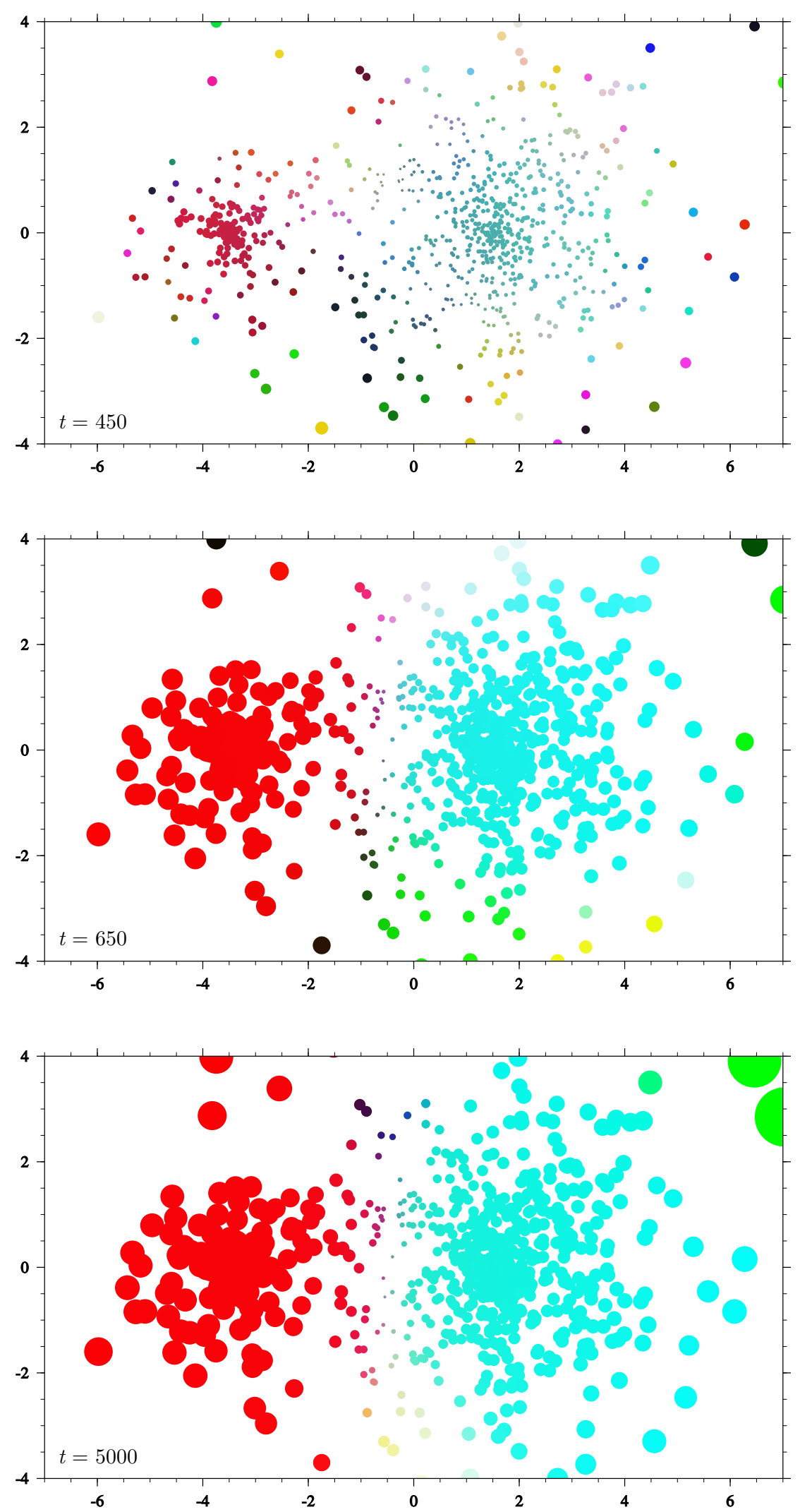

Figura 5.8: (Colorida) Evolução da dinâmica de troca de energia sobre o conjunto da Figura 5.7, utilizando-se zero a 2,5 unidades. Três diferentes instantes são mostrados. Demais parâmetros: $\beta=3, \gamma=2$, precisão 0,1 e $d_{\min }=0,1$. Índice Rand do k-médias aplicado nos vetores de energia em $t=5000: 0,949$. 

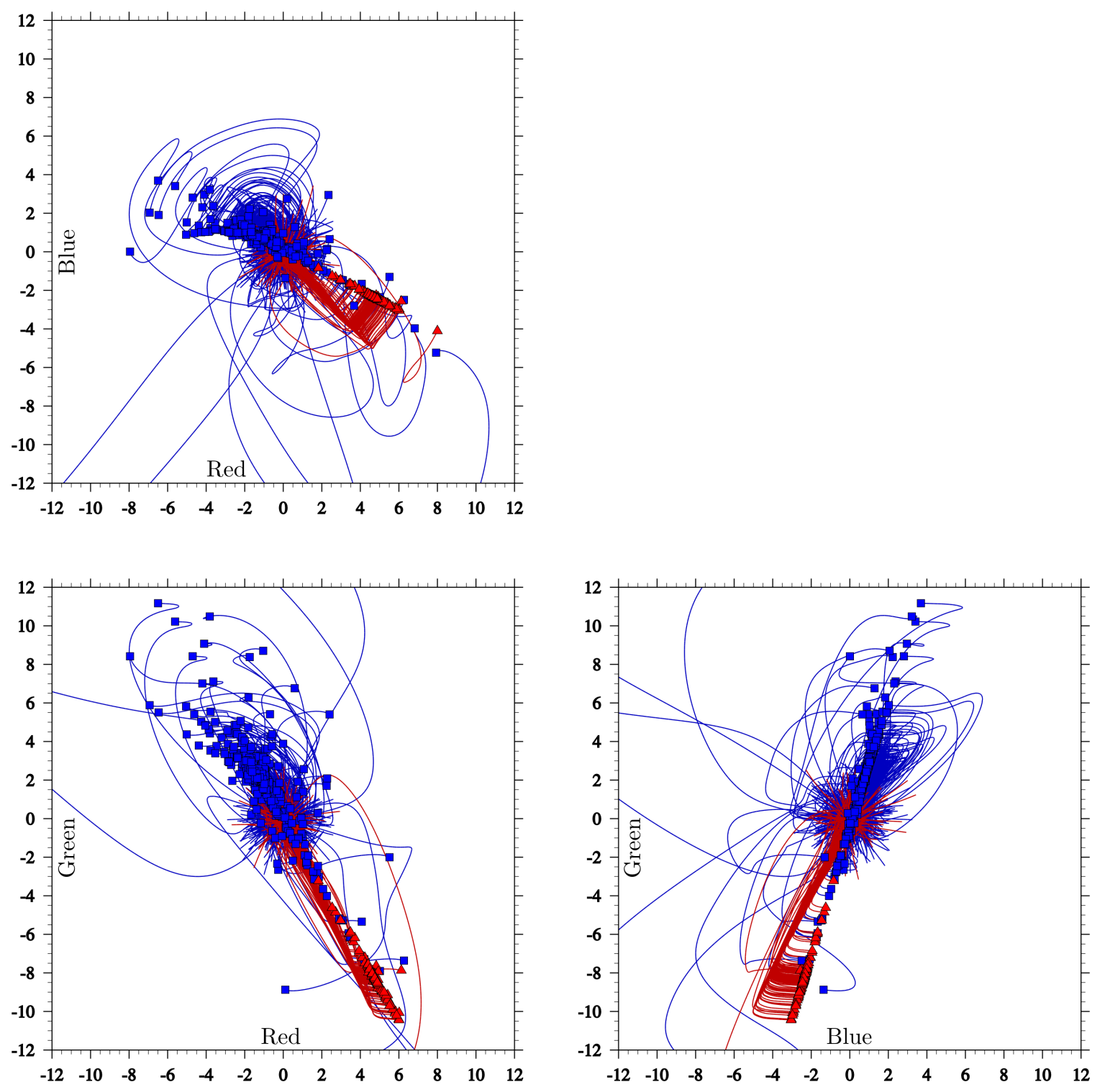

Figura 5.9: (Colorida) O espaço de energia em três diferentes projeções (RxG, BxG e RxB), correspondente ao instante $t=5000$ do sistema mostrado na Figura 5.8. A trajetória de cada vetor de energia é mostrada. Os vetores (e suas trajetórias) estão separados em diferentes cores, correspondendo às diferentes classes que originaram cada objeto: vermelha para a gaussiana menor à esquerda e azul para a gaussiana maior.

sobre o conjunto original não faz sentido. Contudo, para certa combinação de parâmetros, a aplicação do k-médias sobre os vetores de energia resultam em índice Rand 0,993, que significa um agrupamento quase perfeito. A disposição dos vetores de energia ao final do processo é mostrada na Figura 5.14. Observa-se que os vetores provenientes do anel dispõem-se também, no espaço de energia, ao longo de um anel. Já a gaussiana é expulsa do interior do anel, e é justamente isso que permite ao k-médias a chance de agrupar corretamente os dados. Duas questões podem ser levantadas desse experimento. (1) Se o espaço de energia tivesse apenas duas dimensões, será que a gaussiana conseguiria escapar 

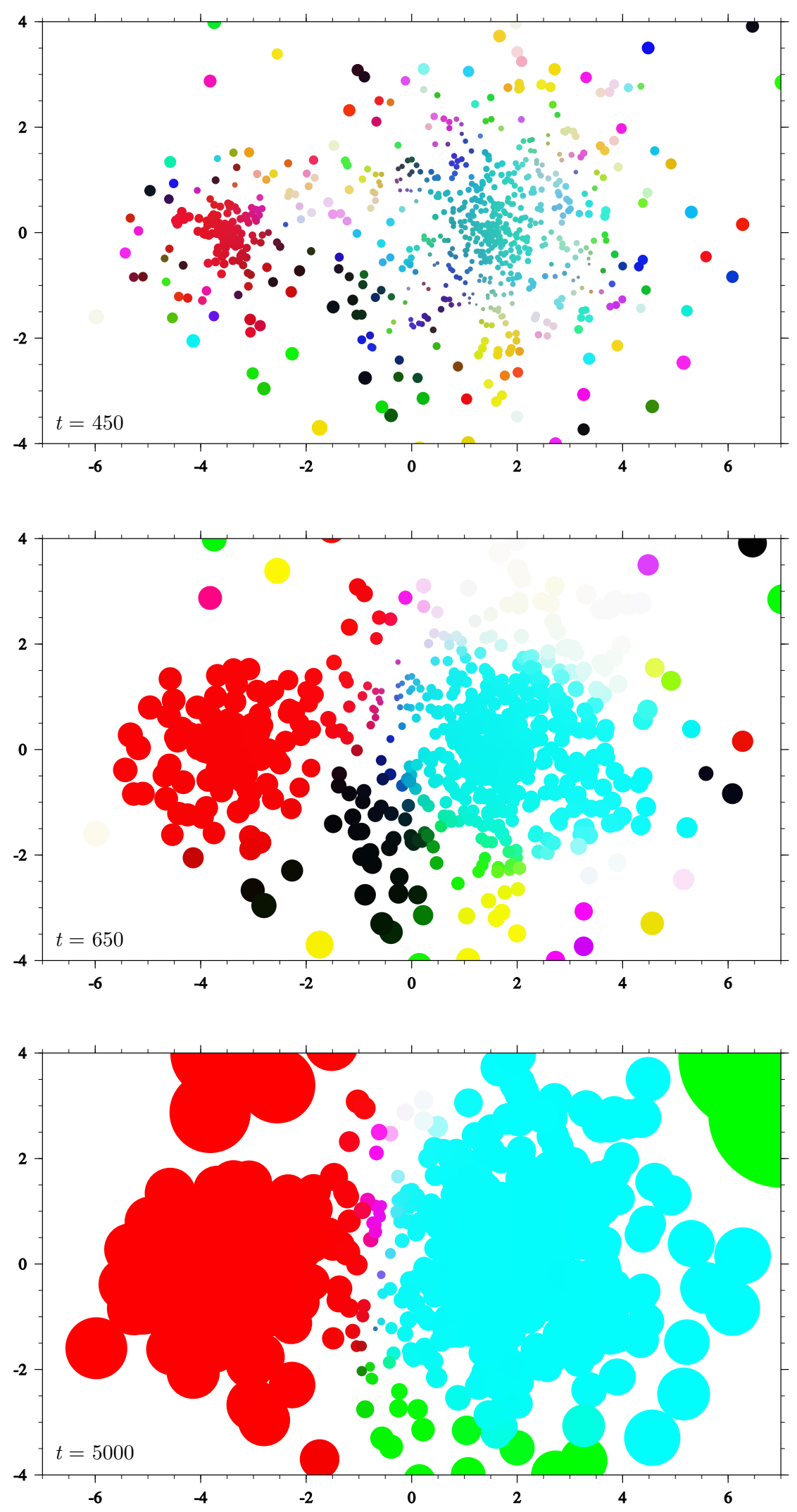

Figura 5.10: (Colorida) Evolução da dinâmica de troca de energia sobre o conjunto da Figura 5.7 , utilizando-se zero a 1,5 . Demais parâmetros: $\beta=3, \gamma=2$, precisão 0,1 e $d_{\min }=0,1$. Índice Rand do k-médias aplicado nos vetores de energia em $t=5000$ : 0,951. 

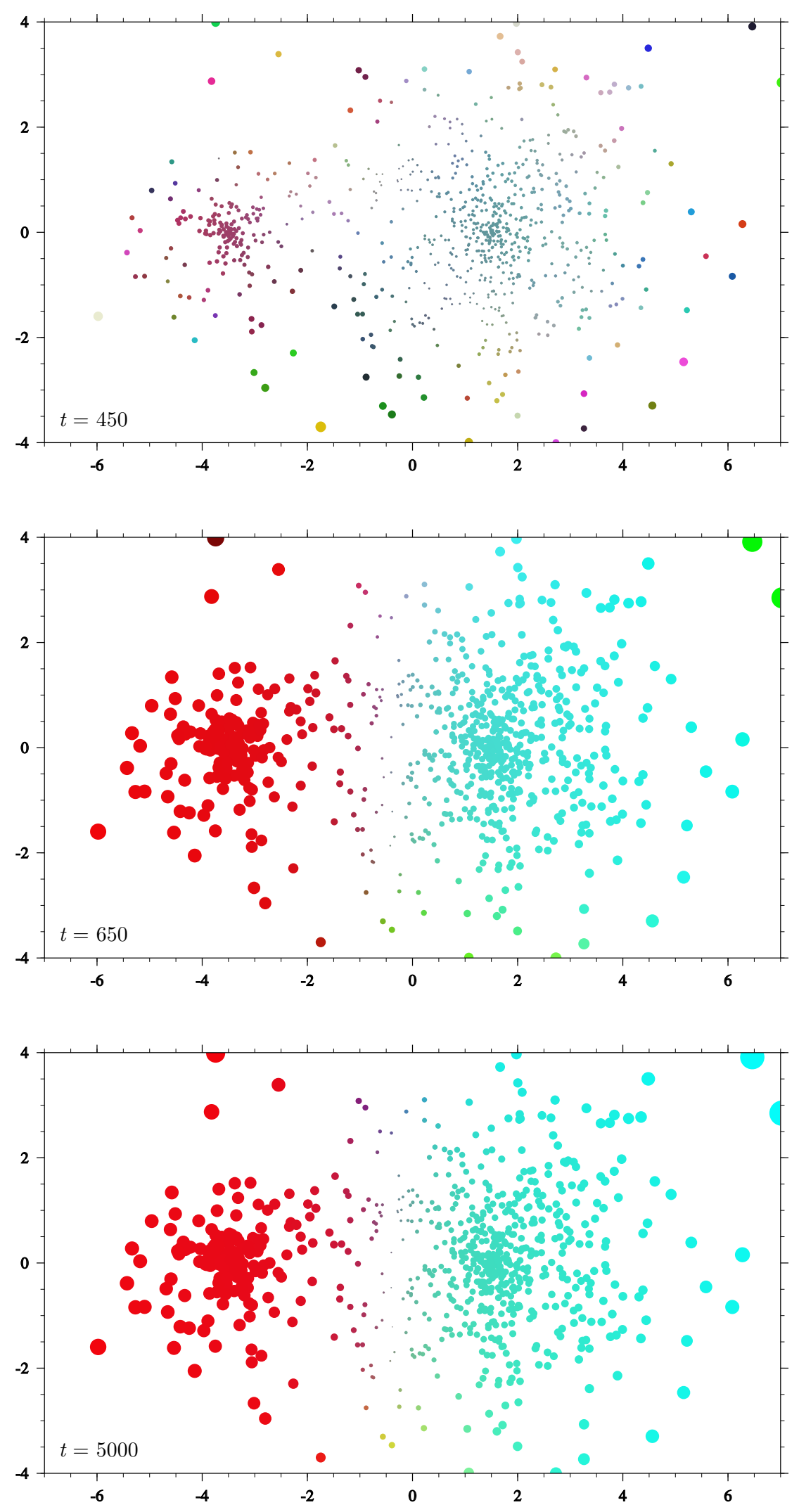

Figura 5.11: (Colorida) Evolução da dinâmica de troca de energia sobre o conjunto da Figura 5.7. utilizando-se zero a 3,5. Demais parâmetros: $\beta=3, \gamma=2$, precisão 0,1 e $d_{\text {min }}=0,1$. Índice Rand do k-médias aplicado nos vetores de energia em $t=5000$ : 0,944. 

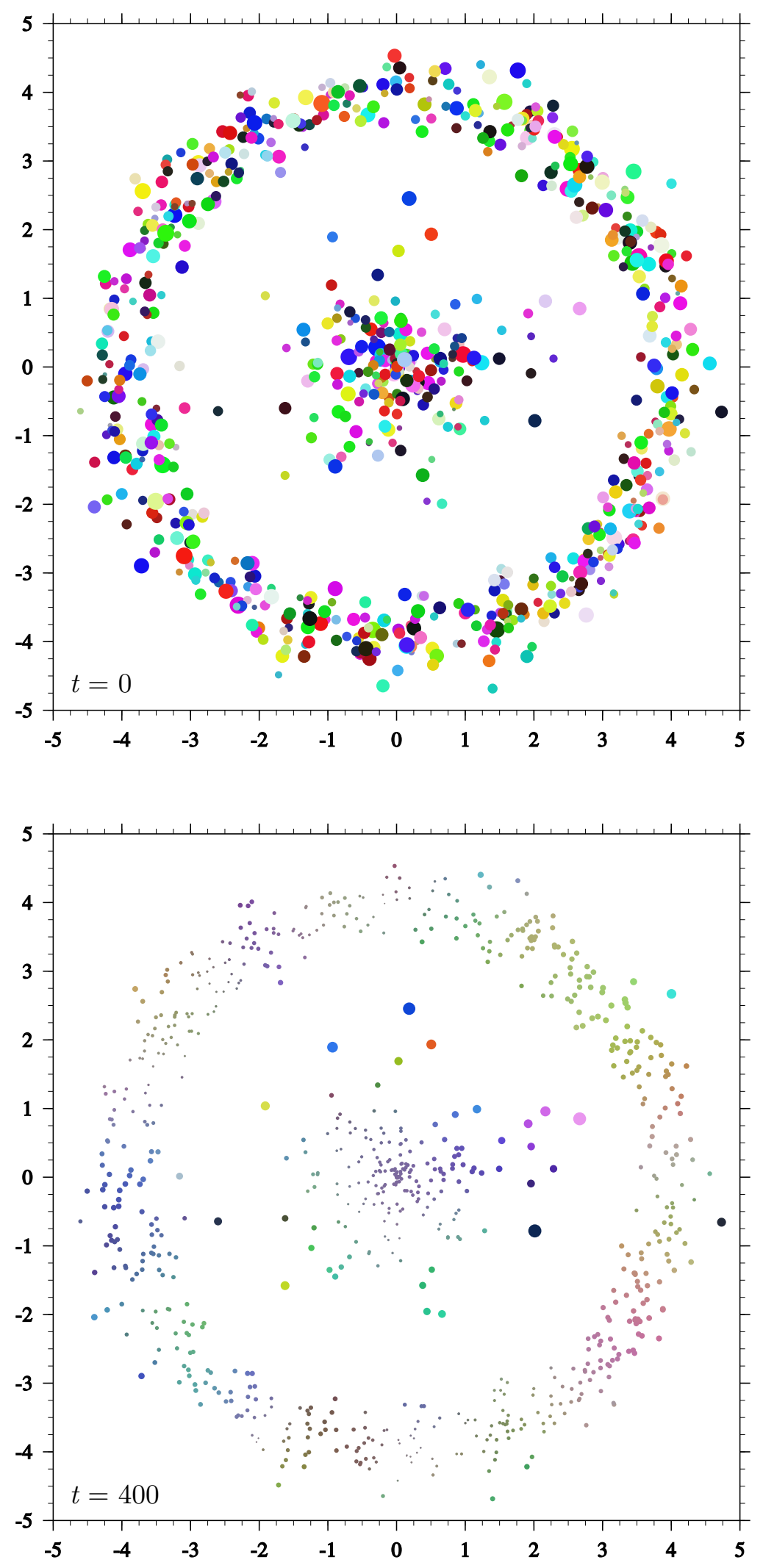

Figura 5.12: (Colorida) Evolução da dinâmica de troca de energia sobre conjunto bidimensional formado por uma gaussiana ao centro, contendo 200 objetos, e um anel ao redor, contendo 600 . Em $t=0$, mostra-se o estado de energia inicial de cada objeto. Parâmetros: $\beta=9, \gamma=1,5$, zero a 1,5 , precisão 0,1 e $d_{\min }=0,4$. A aplicação do k-médias no conjunto original nem faz sentido. Continua... 

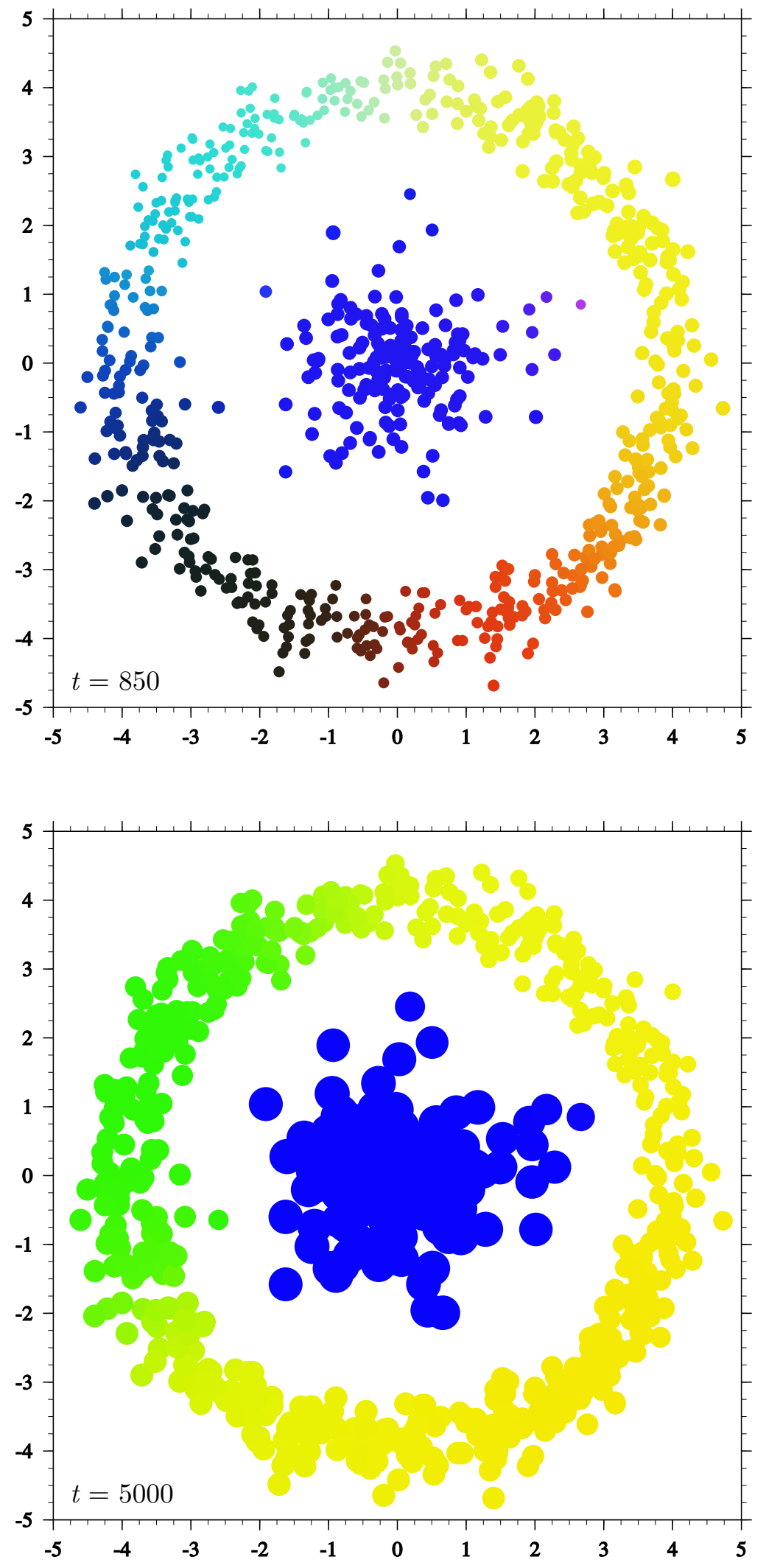

Figura 5.13: (Colorida) ... Continuação. Evolução da dinâmica de troca de energia sobre conjunto formado por uma gaussiana ao centro e um anel ao redor. Índice Rand do k-médias aplicado nos vetores de energia em $t=5000: 0,993$. 

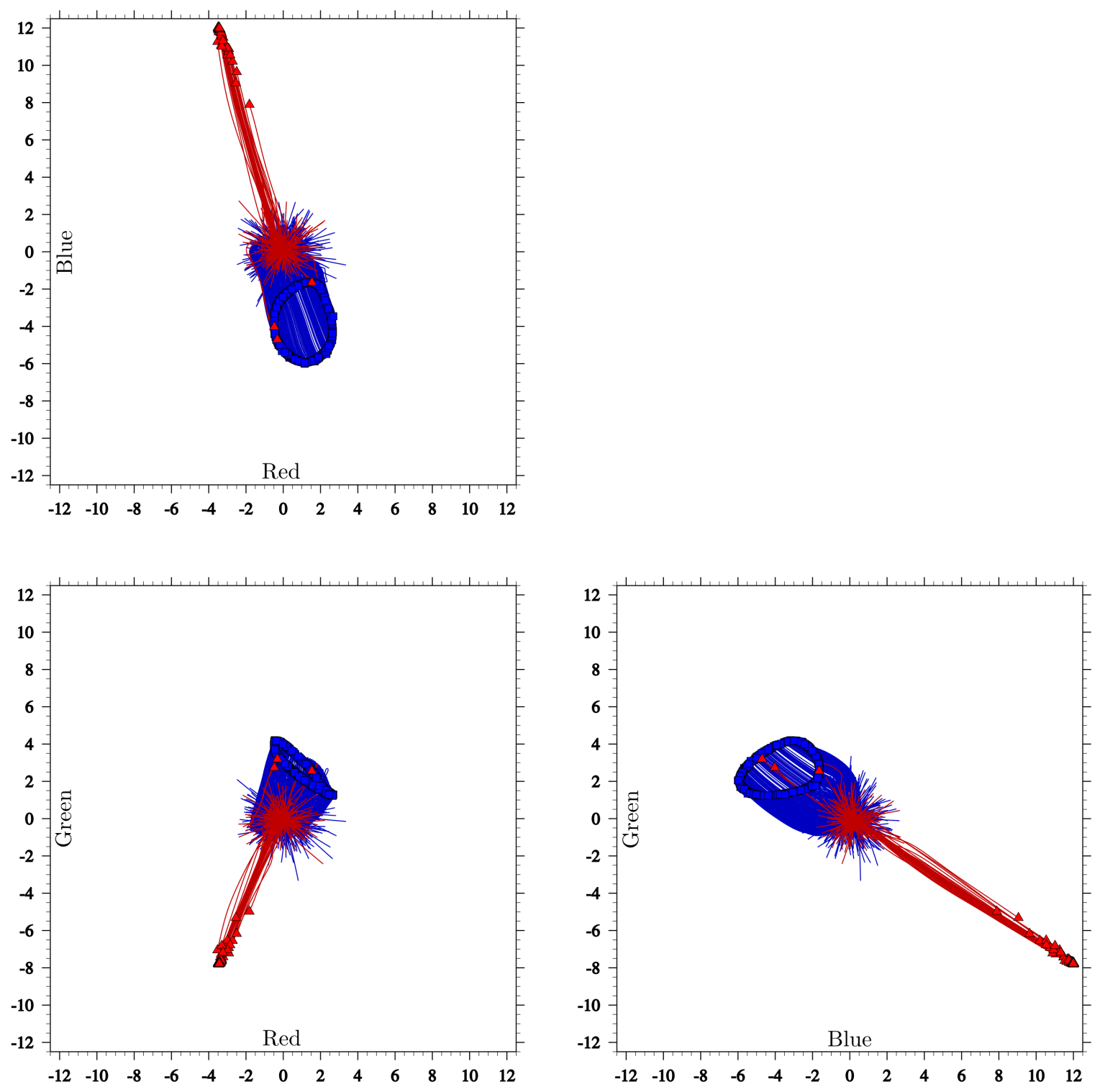

Figura 5.14: (Colorida) O espaço de energia em três diferentes projeções, correspondente ao instante $t=5000$ do sistema mostrado nas Figuras 5.12 e 5.13 . A trajetória de cada vetor de energia é mostrada. A cor vermelha denota os objetos da gaussiana ao centro, enquanto a azul denota os objetos do anel ao redor.

do interior do anel? (2) E se, ao invés de um anel, tivéssemos os objetos dispostos por uma superfície esférica (a extensão do anel para três dimensões), será que mesmo nesse espaço de energia de três dimensões a gaussiana conseguiria escapar? Generalizando, será necessária ao menos uma dimensão a mais do espaço de energia em relação à dimensionalidade do "anel" — ou superfície hiper-esférica — para que a gaussiana escape? O resultado do experimento mostrado sugere que sim, mas novos experimentos teriam que ser realizados para confirmar tal suposição. Essa questão ainda está aberta.

O resultado sobre um terceiro conjunto de dados é apresentado nas Figuras 5.15 e 5.16 . Trata-se de um conjunto composto por três gaussianas de tamanhos diferentes. Quanto ao 

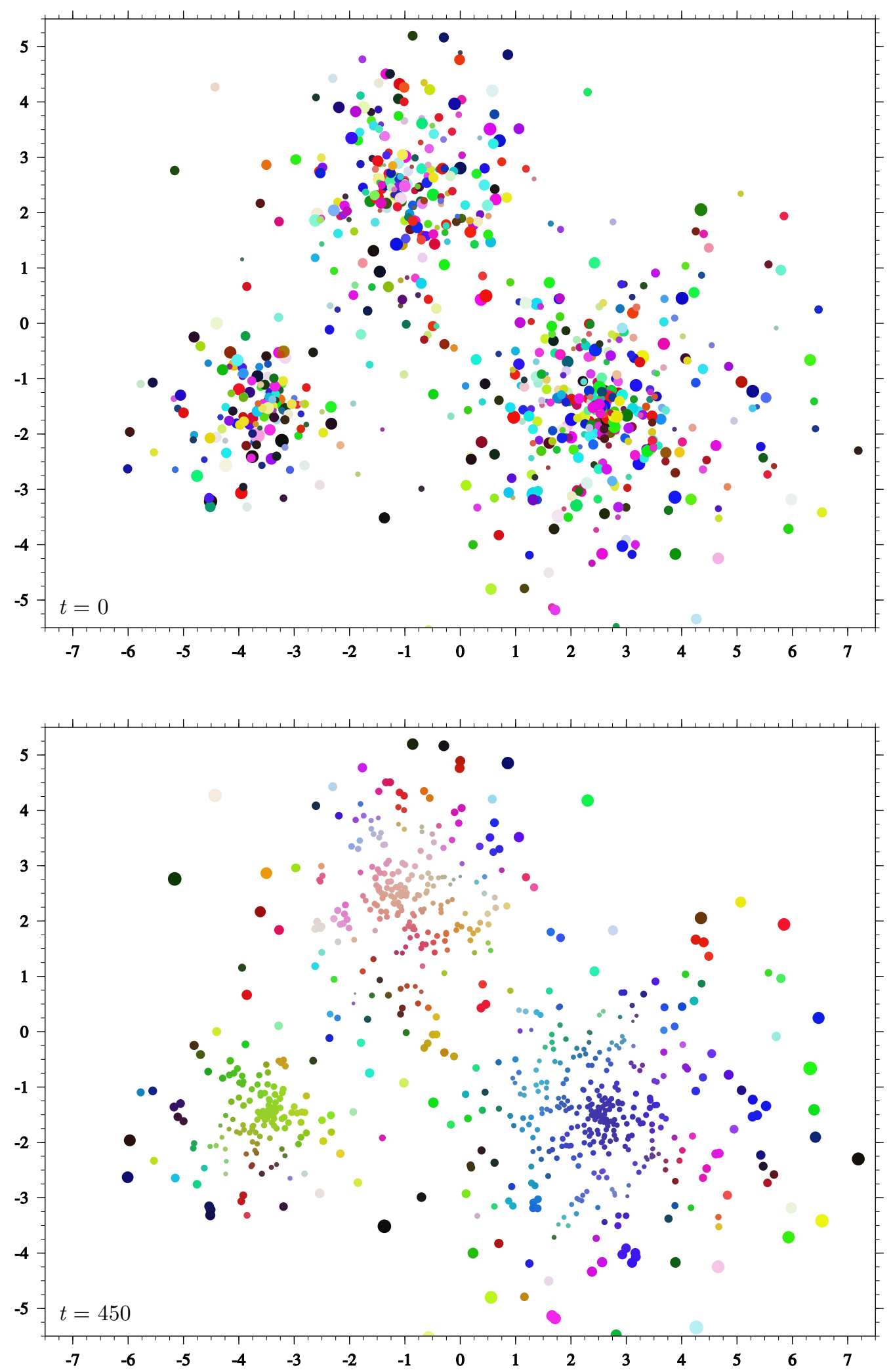

Figura 5.15: (Colorida) Evolução da dinâmica de troca de energia sobre conjunto bidimensional formado por três gaussianas: à esquerda (menor) com 150 objetos, à direita (maior) com 400 e acima (intermediária) com 250, totalizando 800 objetos. Em $t=0$, mostra-se o estado de energia inicial de cada objeto. Parâmetros: $\beta=3, \gamma=2$, zero a 2 , precisão 0,1 e $d_{\text {min }}=0,1$. Índice Rand do k-médias aplicado no conjunto original de dados: 0,949. Continua... 

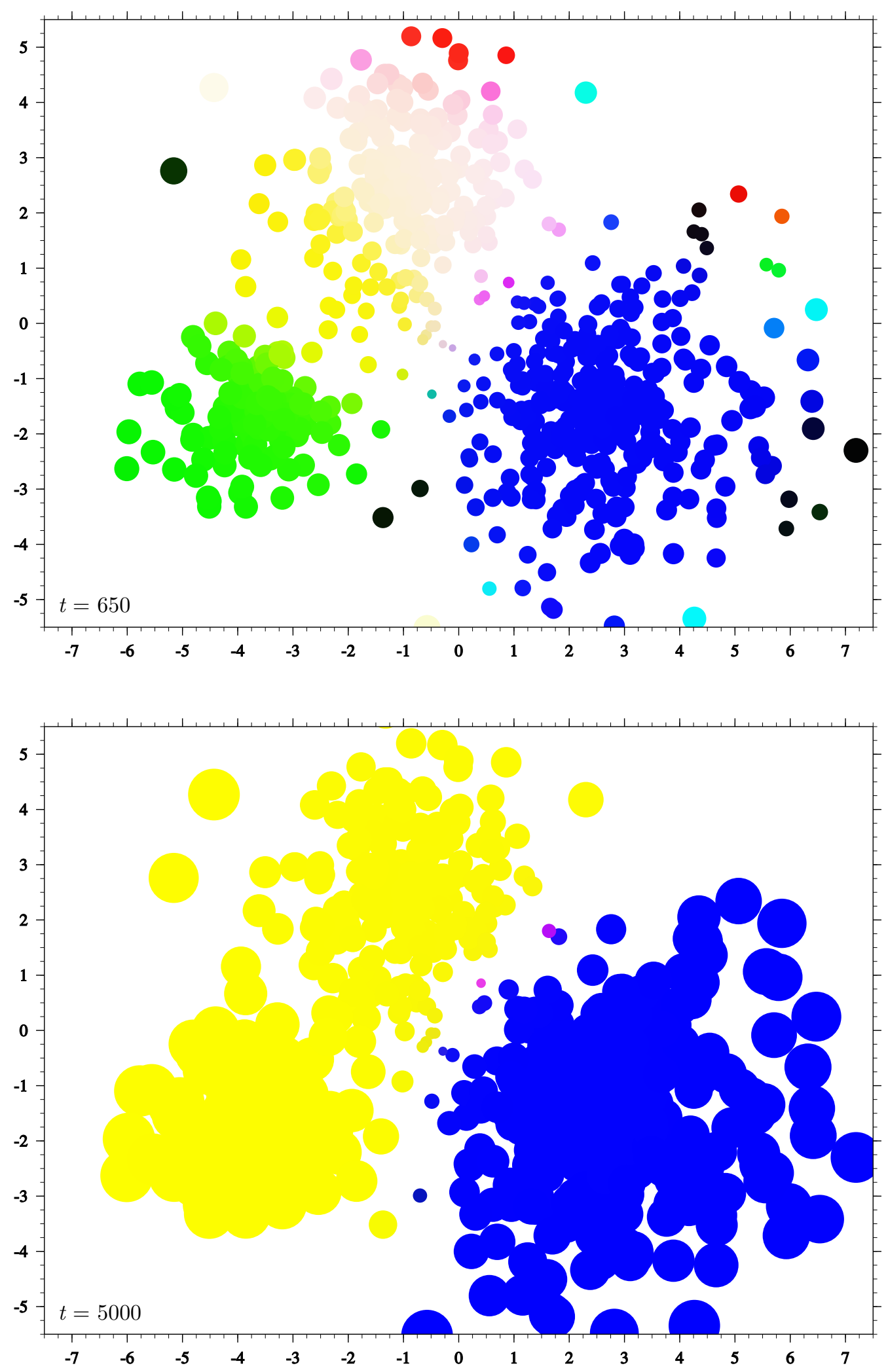

Figura 5.16: (Colorida) ... Continuação. Evolução da dinâmica de troca de energia sobre conjunto formado por três gaussianas. Índice Rand do k-médias aplicado nos vetores de energia em $t=5000: 0,948$. 

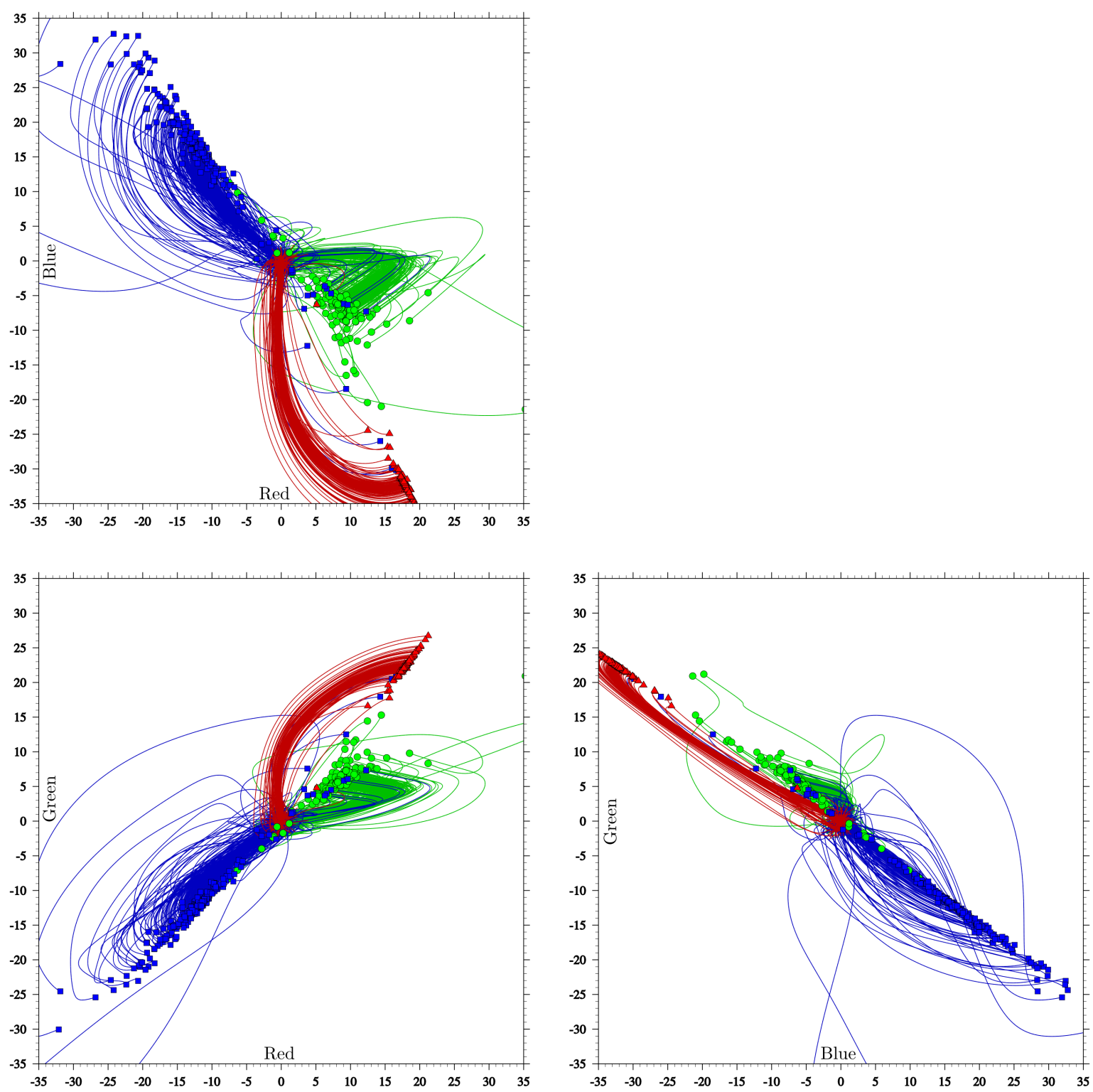

Figura 5.17: (Colorida) O espaço de energia em três diferentes projeções, correspondente ao instante $t=5000$ do sistema mostrado nas Figuras 5.15 e 5.16. A trajetória de cada vetor de energia é mostrada. A cor vermelha está associada à gaussiana menor à esquerda, a azul à maior à direita, e a verde à gaussiana intermediária, acima das outras.

índice Rand, não há ganho - nem perda — na aplicação do k-médias sobre os vetores resultantes de energia em relação ao conjunto original: 0,948 contra 0,949, respectivamente. $\mathrm{Na}$ Figura 5.17, a disposição dos vetores de energia ao final do processo. Importante ressaltar que, embora objetos de duas diferentes gaussianas tomaram a mesma cor amarela, na Figura 5.16 - cada gaussiana se posicionou numa região diferente do espaço, algo evidenciado pelos círculos de tamanhos diferentes e, de maneira mais clara, pela disposição dos vetores de energia mostrada na Figura 5.17. A tendência dos vetores de energia se disporem ao longo de uma reta fica, neste experimento, ainda mais evidente.

Para finalizar, apresentam-se os resultados de alguns experimentos ilustrando o efeito 
de uma interação que, ao invés de ocorrer entre todos os pares de objetos, ocorre somente entre um subconjunto deles. No entanto, a escolha de tal subconjunto não é imediata. Considerar somente a vizinhança mais próxima de cada objeto não faz sentido, pois isso praticamente anularia o efeito da repulsão, visto que a repulsão mais intensa se dá justamente entre objetos distantes. Na Figura 5.18, cada objeto interage com outros 20 tomados aleatoriamente. Para ser mais preciso, um objeto $\mathbf{o}_{i}$ "escolhe" outros 20 objetos com os quais interagirá. Mas, além desses 20, $\mathbf{o}_{i}$ pode também ter sido "escolhido" por outros objetos, interagindo com eles também. A interação é sempre mútua: se $\mathbf{o}_{i}$ considera $\mathbf{o}_{j}$, então obrigatoriamente $\mathbf{o}_{j}$ também considera $\mathbf{o}_{i}$ no cálculo da variação de energia da Equação 5.13 . Escolhendo-se um número fixo de objetos para interação (neste caso 20), e sendo essa escolha aleatória, o cálculo da função de interação (inter $\left(\mathbf{o}_{i}, \mathbf{o}_{j}\right)$ ) tem complexidade de tempo linear em $N$, precisamente $\Theta(N \cdot M)$. Sendo também o espaço de energia composto por apenas três dimensões, a complexidade de todo o processo dinâmico (desconsiderando o k-médias) é $\Theta(N \cdot(M+T))$. Observando que o índice Rand, neste cenário, resulta em 0,932, conclui-se que é possível conseguir um ganho muito alto de desempenho em troca de apenas uma pequena perda na acurácia.

O resultado de um experimento onde cada objeto interage com os 10 mais próximos e com os 10 mais distantes é mostrado na Figura 5.19. Somente a determinação dos objetos mais próximos - ou mais distantes - já tem complexidade quadrática em $N\left(\Theta\left(N^{2} \cdot M\right)\right)$, fazendo com que o processo todo resulte em $\Theta\left(N^{2} \cdot M+T \cdot N\right)$. Para piorar, neste caso a acurácia caiu drasticamente para índice 0,686. Conclui-se que a simples escolha dos 10 mais próximos e dos 10 mais distantes, os quais exercem maior atração e maior repulsão, respectivamente, não é capaz de sintetizar a dinâmica do processo como um todo.

Na Figura 5.20, um último experimento, onde cada objeto interage com os 10 mais próximos e com outros 10 tomados aleatoriamente. Embora o índice Rand resultante - 0,937 - seja razoavelmente bom e equiparável ao do experimento onde todos os 20 objetos são aleatórios, o custo $\Theta\left(N^{2} \cdot M\right)$ da determinação dos vizinhos mais próximos parece não compensar.

Tendo em vista os resultados apresentados nesta seção, pode-se dizer que é sim possível reduzir - e muito - o custo computacional do processo dinâmico proposto, ainda mantendo a acurácia relativamente alta. Somente a redução da dimensionalidade do espaço de energia já derruba a complexidade de $\Theta\left(T \cdot N^{3}\right)$ para $\Theta\left(N^{2} \cdot(T+M)\right)$, assumindo que a quantidade de atributos $M$ é menor que a quantidade de objetos $N$. Se fizermos cada objeto interagir somente com um número fixo de outros objetos tomados aleatoriamente, a complexidade cai ainda para $\Theta(N \cdot(M+T))$, ou seja, torna-se linear em $N$. Importante notar que qualquer algoritmo de agrupamento será, no mínimo, tão caro quanto $\Theta(N \cdot M)$, pois em algum momento ele terá que "ler" os $M$ atributos de cada um dos $N$ objetos. Seria interessante realizar um estudo mais extensivo, variando-se progressivamente a dimensionalidade do espaço de energia e a quantidade de pares de objetos que interagem, para 

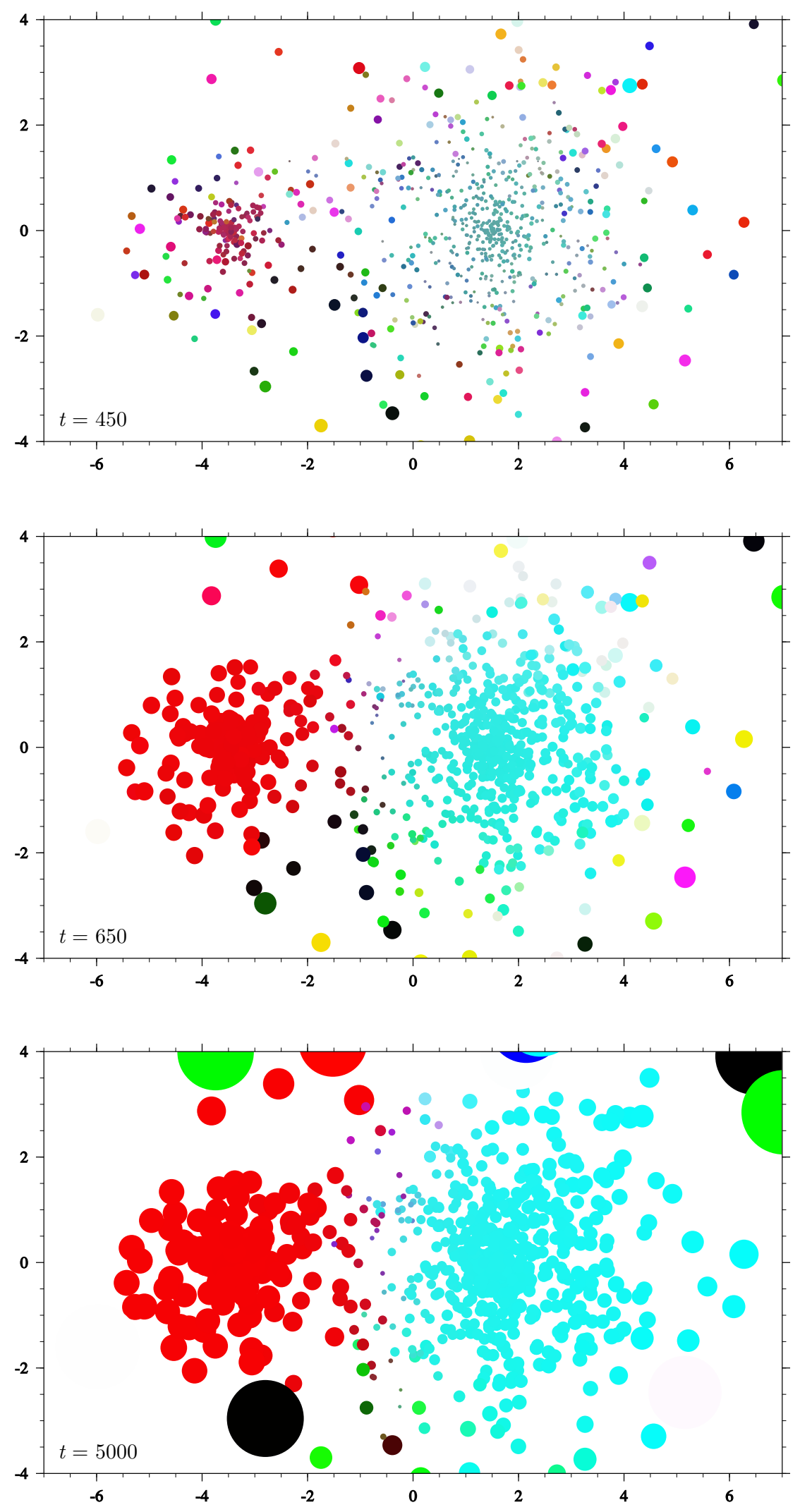

Figura 5.18: (Colorida) Evolução da dinâmica de troca de energia sobre o conjunto da Figura 5.7, onde cada objeto interage somente com 20 outros tomados aleatoriamente. Parâmetros: $\beta=3$, $\gamma=2$, zero a 2,5 , precisão 0,1 e $d_{\min }=0,1$. Índice Rand do k-médias aplicado nos vetores de energia em $t=5000$ : 0,932 . 

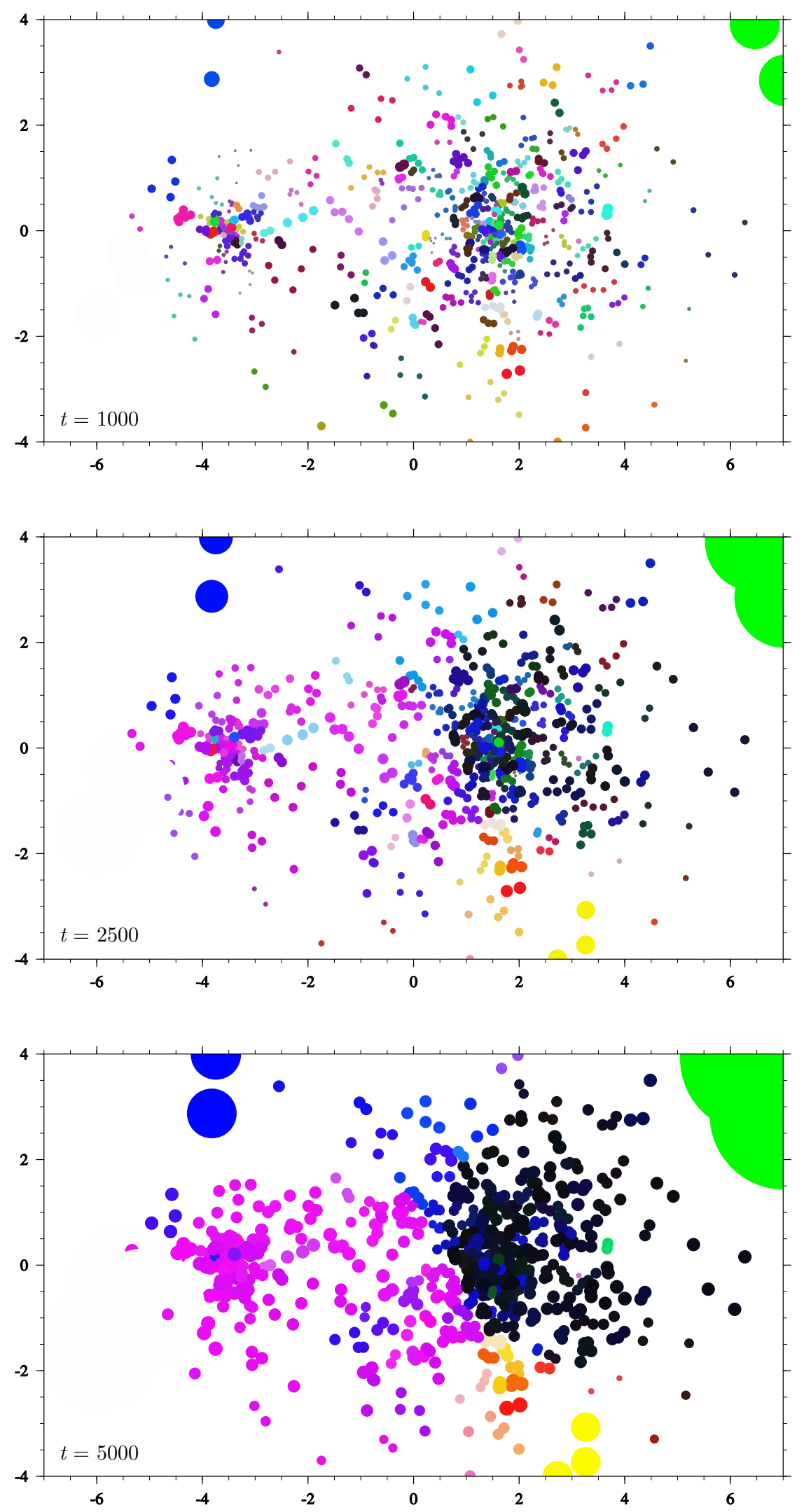

Figura 5.19: (Colorida) Evolução da dinâmica de troca de energia sobre o conjunto da Figura 5.7. onde cada objeto interage somente com 20 outros: os 10 mais próximos e os 10 mais distantes. Parâmetros: $\beta=3, \gamma=2$, zero a 2,5 , precisão 0,1 e $d_{\text {min }}=0,1$. Índice Rand do k-médias aplicado nos vetores de energia em $t=5000$ : 0,686 . 

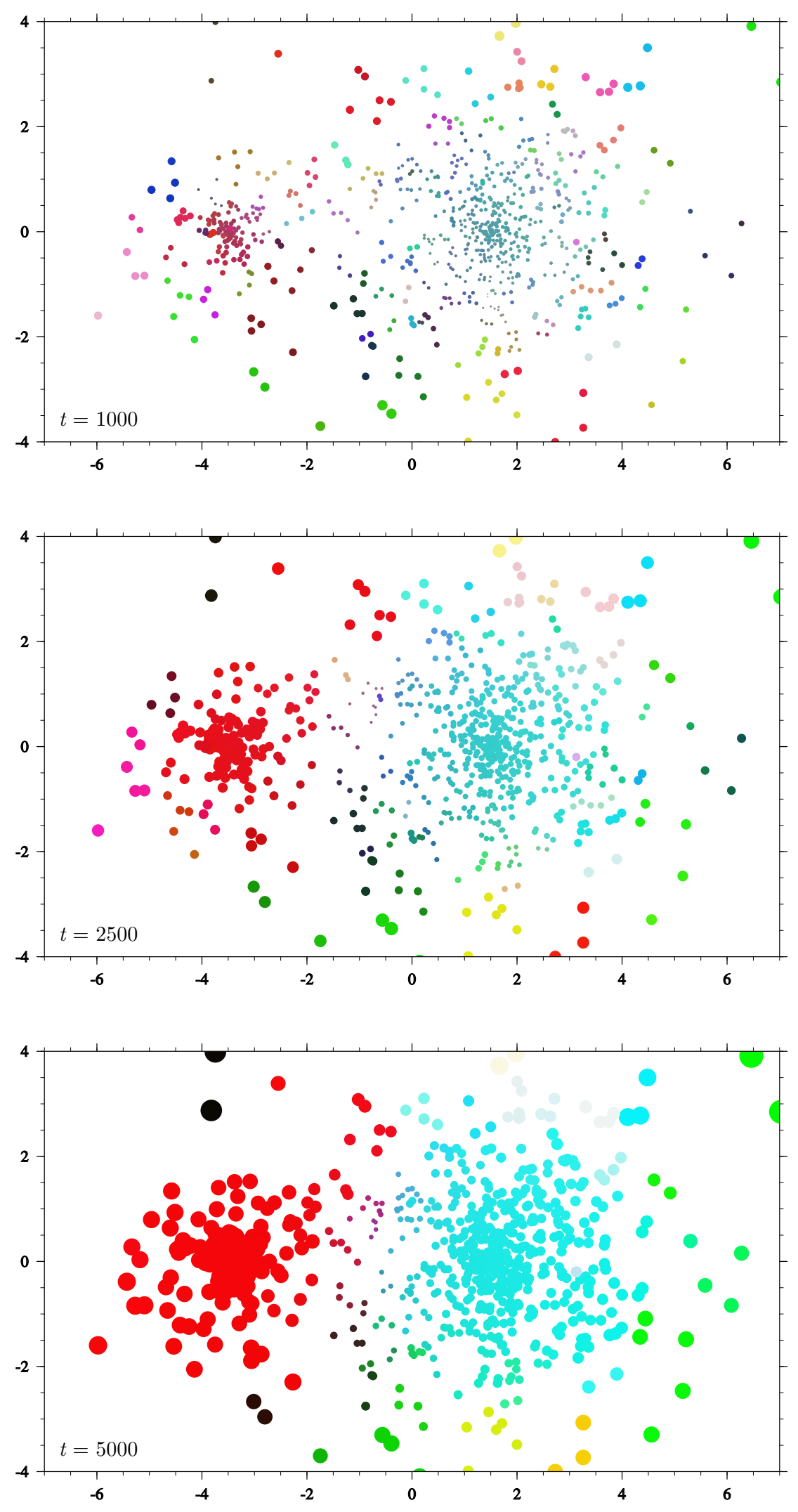

Figura 5.20: (Colorida) Evolução da dinâmica de troca de energia sobre o conjunto da Figura 5.7 , onde cada objeto interage somente com 20 outros: os 10 mais próximos e outros 10 tomados aleatoriamente. Parâmetros: $\beta=3, \gamma=2$, zero a 2,5 , precisão 0,1 e $d_{\min }=0,1$. Índice Rand do k-médias aplicado nos vetores de energia em $t=5000$ : 0,937 . 
diferentes conjuntos de dados e diferentes parâmetros $(\beta, \gamma$, zero $a \ldots)$, e avaliando-se o impacto sobre a acurácia da partição obtida. Outros algoritmos de agrupamento, além do k-médias, podem ser experimentados sobre os vetores de energia resultantes.

Há ainda uma variável que não foi estudada aqui: o número de passos $T$ que se deixa o sistema dinâmico rodar. Essa variável está diretamente associada ao parâmetro de precisão. Sabe-se que o aumento do valor de precisão, respeitando-se certos limites, acelera a convergência (diminui $T$ ). No entanto, é necessário investigar o impacto que a variação da precisão tem sobre a acurácia do resultado. Não se pode, ainda, sequer dizer que a aceleração do processo de convergência derruba a acurácia. Importante também investigar qual é o momento mais adequado de se interromper o processo dinâmico e se aplicar um algoritmo de agrupamento sobre os vetores de energia resultantes.

\subsection{Considerações finais}

Bons resultados são observados a partir dos experimentos apresentados nas seções anteriores. Embora o k-médias não seja adequado para alguns dos conjuntos originais de dados, ele atua muito bem quando aplicado aos vetores de energia. Ou seja, o processo de troca positiva e negativa de energia guia os objetos de modo que até mesmo um conjunto razoavelmente complexo se torna fácil de ser agrupado por um algoritmo clássico como o k-médias. Os resultados sugerem que o processo aqui apresentado é adequado a conjuntos de dados cujas classes são formadas por densas regiões de objetos, separadas umas das outras por regiões de baixa densidade. Esse processo também se mostra resistente a ruído e a uma certa mistura entre as diferentes classes.

Foi dito que o processo de troca de energia apresentado neste capítulo não representa, rigorosamente, um algoritmo. Ele transforma a tarefa de agrupar os objetos originais na tarefa de agrupar os vetores de energia. Espera-se que a nova tarefa seja mais "fácil" que a original. Mas como se pode mensurar tal facilidade? Foi mostrado que a tarefa se torna mais fácil segundo os critérios adotados pelo k-médias. É importante, porém, avaliar tal facilidade de uma forma mais ampla. Não só o emprego de outros algoritmos (além do k-médias) pode ser considerado, como pode-se também pesquisar por medidas que mostrem o quanto as diferentes classes ficaram separadas no espaço de energia em relação ao espaço original de atributos.

Um aspecto notável, mas não explorado neste trabalho, é o caráter suave (não-rígido) do resultado do processo dinâmico de troca de energia. Uma partição rígida dos dados não é obtida, mas sim, os vetores de energia dispõem-se formando padrões. A análise de tais padrões poderia ser utilizada para efetuar o chamado soft clustering, onde são estabelecidos grupos e são estabelecidos graus de pertinência dos objetos aos grupos (Yang, 1993 ; Hüllermeier, 2005; El-Zahhar, 2010).

O próprio caráter dinâmico da técnica aqui proposta é rico e a análise das informações 
geradas ao longo do tempo — valores das variáveis do sistema — pode revelar características importantes com relação aos dados. Além do mais, espera-se que a natureza suave com que o processo ocorre apresente robustez. E finalmente, o estudo empírico do processo dinâmico mostrado neste trabalho precisa ser complementado com um estudo mais teórico. 


\section{Capítulo 6}

\section{Aprendizado semissupervisionado via movimentação dos dados}

Desenvolveu-se uma técnica de aprendizado semissupervisionado baseada na movimentação dos dados, que são impulsionados por forças de interação entre eles. Essa técnica foi desenvolvida e analisada numa colaboração entre Thiago Henrique Cupertino, Roberto Alves Gueleri (autor da presente dissertação) e Zhao Liang (orientador dos dois). O seguinte trabalho foi então gerado:

Thiago Henrique Cupertino, Roberto Alves Gueleri e Zhao Liang. A SemiSupervised Classification Technique Based on Interacting Forces. Submetido para o periódico Neurocomputing. Atualmente, encontra-se na segunda rodada de revisão.

Trata-se, na verdade, de uma versão estendida (para uma edição especial - special issue) de outro trabalho de Cupertino \& Zhao (2012). Nessa técnica, os dados rotulados permanecem fixos, mas exercem forças de atração sobre os não-rotulados. Tão logo um objeto não-rotulado chegue suficientemente perto de um rotulado, o rótulo é propagado. Imediatamente, aquele originalmente não-rotulado - e que acabou de receber um rótulo - passa a agir como um rotulado, ou seja, permanece fixo e exerce forças de atração sobre os demais não-rotulados. O processo termina quando os rótulos são propagados a todos os dados. Como se pode notar, essa técnica é especificamente uma técnica de aprendizado transdutivo (Seção 2.6.).

\subsection{Descrição da técnica}

Como discutido na Seção 2.6, o aprendizado semissupervisionado é caracterizado por alguns dados previamente rotulados em meio a muitos não-rotulados. Seja $\left\{\mathbf{x}_{i}\right\}$ o conjunto de dados, onde cada objeto $\mathbf{x}_{i}$ é um vetor de atributos. Esse conjunto contém todos os objetos, rotulados e não-rotulados. Sejam também $d_{i j}$ a distância euclidiana entre os objetos 


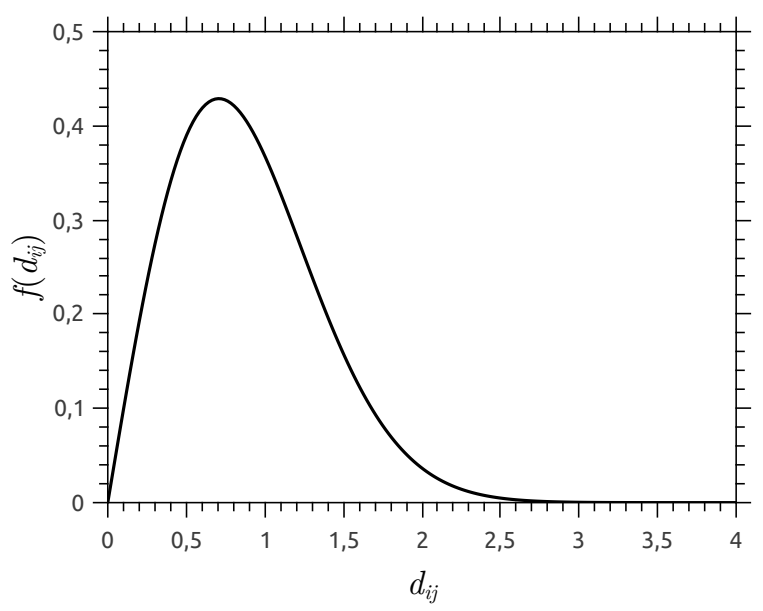

Figura 6.1: O comportamento da função $f\left(d_{i j}\right)=d_{i j} \cdot e^{-\beta d_{i j}{ }^{2}}$, para $\beta=1$.

$\mathbf{x}_{i}$ e $\mathbf{x}_{j}$, e $t$ o índice de iteração do sistema dinâmico (tempo). E denotaremos por $\mathcal{L}(t)$ e $\mathcal{U}(t)$ o conjunto dos objetos rotulados e não-rotulados no instante $t$, respectivamente. Então o movimento de cada objeto não-rotulado é regido por:

$$
\mathbf{x}_{i}(t+1)=\mathbf{x}_{i}(t)+\alpha \cdot \sum_{\mathbf{x}_{j} \in \mathcal{L}(t)} d_{i j} \cdot e^{-\beta d_{i j}{ }^{2}} \cdot \frac{\mathbf{x}_{j}(t)-\mathbf{x}_{i}(t)}{d_{i j}}
$$

Nesta equação, $e^{-\beta d_{i j}{ }^{2}}$ representa um campo gaussiano centralizado em $\mathbf{x}_{i}$ e com parâmetro $\beta, \beta>0$. Multiplicando isso por $d_{i j}$, temos uma função como a apresentada na Figura 6.1. O termo $\frac{\mathbf{x}_{j}(t)-\mathbf{x}_{i}(t)}{d_{i j}}$ representa um vetor unitário que define a direção da força sobre $\mathbf{x}_{i}$. Simplificando 6.1), temos:

$$
\mathbf{x}_{i}(t+1)=\mathbf{x}_{i}(t)+\alpha \cdot \sum_{\mathbf{x}_{j} \in \mathcal{L}(t)} e^{-\beta d_{i j}{ }^{2}} \cdot\left[\mathbf{x}_{j}(t)-\mathbf{x}_{i}(t)\right]
$$

A somatória sobre $\mathbf{x}_{j} \in \mathcal{L}(t)$ denota a somatória sobre todos os objetos rotulados no instante $t$. Por fim, $\alpha$ define o quão suave é o processo. Podemos ainda escrever a versão contínua de 6.2 , fazendo $\alpha \rightarrow 0$ :

$$
\dot{\mathbf{x}}_{i}=\sum_{\mathbf{x}_{j} \in \mathcal{L}} e^{-\beta d_{i j}^{2}} \cdot\left[\mathbf{x}_{j}-\mathbf{x}_{i}\right]
$$

Tão logo um objeto não-rotulado $\left(\mathbf{x}_{i}(t+1)\right)$ atinja uma distância suficientemente próxima de um rotulado, o rótulo é propagado e ele passa a integrar o conjunto dos rotulados $(\mathcal{L}(t+1))$. Chamaremos essa distância de $\delta$, tal que o objeto é rotulado quando $\left\|\mathbf{x}_{i}(t+1)-\mathbf{x}_{j}(t)\right\| \leq \delta$, para algum $\mathbf{x}_{j}(t) \in \mathcal{L}(t)$. Caso, após uma iteração, ele se torne suficientemente próximo a dois ou mais objetos rotulados, ele receberá o rótolo daquele mais próximo. 


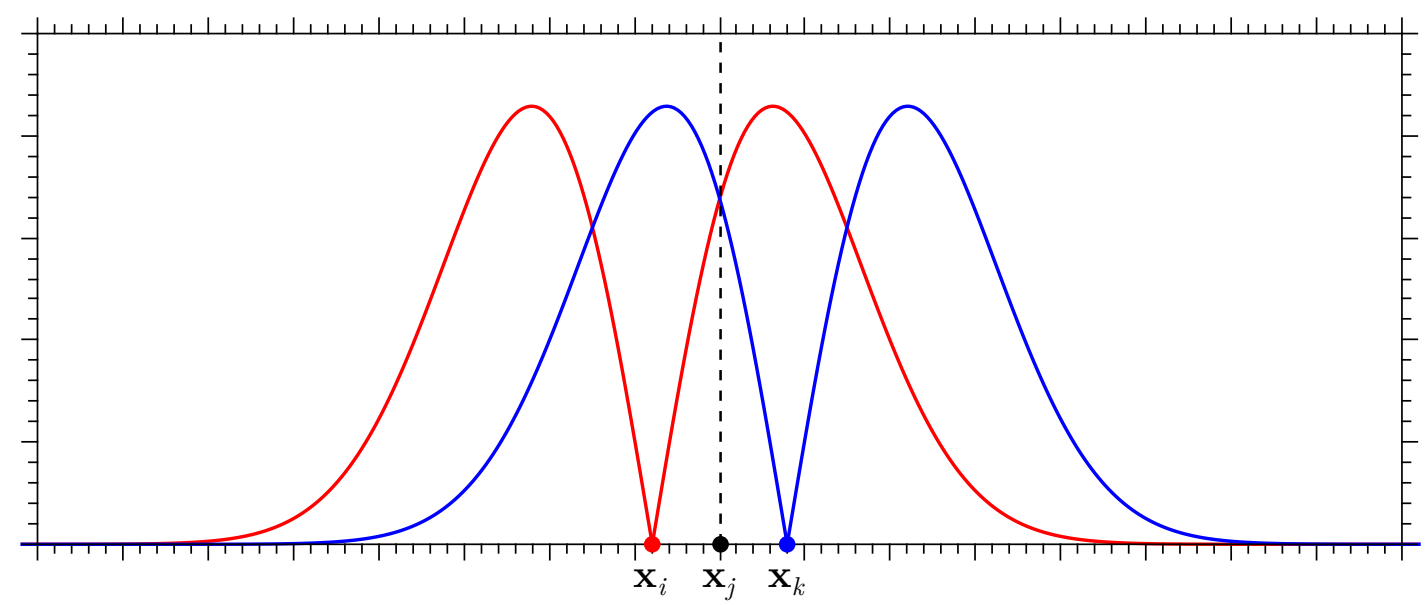

Figura 6.2: Configuração de um equilíbrio dinâmico. Um objeto não-rotulado $\mathbf{x}_{j}$ posiciona-se entre dois rotulados $\mathbf{x}_{i}$ e $\mathbf{x}_{k}$. O campo gaussiano dos dois objetos rotulados é mostrado.

\subsection{Análise de parâmetros, experimentos e análise dos resultados}

Nesta seção, procura-se investigar como a técnica proposta se comporta em diferentes cenários. Primeiramente, é discutido o ajuste de seus parâmetros. Depois, é ilustrado o efeito de diferentes combinações de parâmetros no comportamento dinâmico da técnica. Por fim, resultados de experimentos extensivos são apresentados e discutidos. Tais experimentos foram realizados sobre bases de dados artificiais - cujos parâmetros são rigorosamente controlados — e sobre bases de dados de benchmark. No caso dos benchmarks, foi possível comparar os resultados da técnica proposta aos de outras técnicas da literatura de aprendizado semissupervisionado.

\subsubsection{Parâmetros $\beta$ e $\delta$}

A força com que um objeto rotulado $\mathbf{x}_{j}$ atrai um não-rotulado $\mathbf{x}_{i}$ é dada por $f\left(d_{i j}\right)=$ $\alpha \cdot d_{i j} \cdot e^{-\beta d_{i j}{ }^{2}}$, conforme a Equação 6.1 e ilustrada na Figura 6.1 (para $\left.\alpha=1\right)$. Nota-se que a função $f\left(d_{i j}\right)$ tem seu valor máximo para uma certa distância $d_{i j}$. Chamaremos essa distância de $d_{i j}{ }^{*}$. Nota-se também que $f\left(d_{i j}\right)$ é crescente em $\left[0 ; d_{i j}{ }^{*}[\right.$ e decrescente $\mathrm{em}] d_{i j}{ }^{*} ;+\infty[$.

Agora imagine uma situação como a ilustrada na Figura 6.2. Um objeto não-rotulado $\mathbf{x}_{j}$ posiciona-se entre dois rotulados $\mathbf{x}_{i}$ e $\mathbf{x}_{k}$. Sendo as demais forças pequenas quando comparadas às exercidas por esses dois objetos rotulados, essa situação configura um equilíbrio dinâmico, tal que $\mathbf{x}_{j}$ não caminha nem na direção de $\mathbf{x}_{i}$ nem na direção de $\mathbf{x}_{k}$. Se começasse a ir na direção de $\mathbf{x}_{i}$, essa força decresceria e seria superada por $\mathbf{x}_{k}$, e vice-versa.

Uma forma de resolver isso é fazer com que o objeto seja imediatamente rotulado 
quando adentra a região $\left[0 ; d_{i j}{ }^{*}\right]$. Para isso, restringe-se $\delta$ para que seja maior que $d_{i j}{ }^{*}$. Isso é calculado achando-se o valor de $d_{i j}{ }^{*}$. Para isso, tira-se a primeira derivada de

$$
\alpha \cdot d_{i j} \cdot e^{-\beta d_{i j}^{2}}
$$

chegando-se a

$$
\alpha \cdot\left(1-2 \beta d_{i j}^{2}\right) \cdot e^{-\beta d_{i j}^{2}}
$$

$d_{i j}{ }^{*}$ é determinado igualando-se a expressão acima a zero, e chegando-se a

$$
\alpha \cdot\left(1-2 \beta\left(d_{i j}{ }^{*}\right)^{2}\right) \cdot e^{-\beta\left(d_{i j}{ }^{*}\right)^{2}}=0 \Longleftrightarrow 1-2 \beta\left(d_{i j}{ }^{*}\right)^{2}=0 \Longleftrightarrow d_{i j}{ }^{*}=\frac{1}{\sqrt{2 \beta}}
$$

E assim determinamos a relação entre os parâmetros $\beta$ e $\delta$ que evita o problema do equilíbrio dinâmico, lembrando que $\delta>d_{i j}{ }^{*}$ :

$$
\delta>\frac{1}{\sqrt{2 \beta}}
$$

que é equivalente a:

$$
\delta^{2}-\frac{1}{2 \beta}>0
$$

\subsubsection{Parâmetro $\alpha$}

A fim de realizar as simulações com a técnica proposta, a versão discreta — Equação 6.2 - deve ser empregada. Contudo, a evolução discreta do sistema pode resultar num problema de convergência: um objeto não-rotulado pode chegar perto de um rotulado, mas não tão perto, ficando ligeiramente fora da região $\delta$. Assim, ele não será rotulado e, na próxima iteração, poderá receber uma força demasiadamente grande - pois ele está perto do rotulado - que o fará, ao invés de entrar na região $\delta$, ultrapassar o objeto rotulado, colocando-se do outro lado e permanecendo ainda fora da região $\delta$. Desse modo, o objeto não-rotulado fica oscilando em torno do rotulado e não recebe seu rótulo. Outro problema que pode ocorrer é as forças atuantes ficarem pequenas demais, fazendo com que o sistema demore muito tempo para convergir ao resultado final.

Para resolver esses dois inconvenientes, ao invés de se atribuir um valor único ao parâmetro $\alpha$, este receberá valores distintos a cada iteração. Quando houver algum objeto perto de uma região $\delta$, $\alpha$ será diminuído, e vice-versa. Para tanto, define-se um parâmetro de precisão $p$, tal que o máximo deslocamento a cada iteração - dentre todos os objetos não-rotulados — será exatamente igual a $p$. Assim, o sistema torna-se suave quando tenderia a ser brusco, e vice-versa. Mas é importante que o valor de $p$ seja consistente com o valor de $\delta$. De fato, quanto menor o valor de $p$, mais suave é o processo - mais se aproxima do caso contínuo - , porém demanda mais iterações para terminar. 
Precisamente, o valor variante de $\alpha$ não necessita ser calculado, mas o parâmetro $p$ é empregado do seguinte modo:

1. calcula-se a força atuante sobre todos os objetos, considerando $\alpha=1$ na Equação (6.2);

2. calcula-se o deslocamento resultante — deslocamento "desejado" — de todos os objetos;

3. normalizam-se todos os deslocamentos de modo que o maior deles seja igual a $p$.

É como se $\alpha$ fosse implicitamente modificado.

Há, por fim, um terceiro inconveniente que precisa ser resolvido, desta vez associado ao desbalanceamento das classes. Do modo como foi descrito até então, caso haja alguma classe com maior número de objetos rotulados, esta será privilegiada, pois as forças resultantes que atuam sobre os não-rotulados tendem a direcioná-los a essa classe. Resolver isso é bem simples: no momento em que se calcula a força que um objeto rotulado exerce sobre um não-rotulado - passo 1 no procedimento acima —, essa força será imediatamente dividida pela quantidade total de objetos rotulados da correspondente classe.

Em suma, o parâmetro $\alpha$ pode ser entendido como uma composição das duas normalizações aqui descritas: a normalização em termos da precisão $p$ e a normalização em termos da quantidade de objetos rotulados de cada classe. Consequentemente, $\alpha$ toma valores distintos a cada iteração, e distintos para objetos de diferentes classes.

\subsubsection{O comportamento dinâmico da técnica}

A fim de ilustrar como a técnica se comporta dinamicamente, considere o conjunto de dados mostrado na Figura 6.3. Algumas simulações foram realizadas sobre esse conjunto, para diferentes combinações dos parâmetros $\beta$ e $\delta$. Os resultados são mostrados nas Figuras 6.4 e 6.5

Observa-se que o emprego de valores baixos de $\beta(\beta=1)$ faz com que o sistema exiba um comportamento mais "suave" — os objetos tendem a se movimentar simultaneamente. De fato, o parâmetro $\beta$ controla a sensibilidade às distâncias entre os objetos. Valores altos de $\beta$ aumentam radicalmente essa sensibilidade. Pode-se dizer que no limite quando $\beta \rightarrow \infty$, apenas um objeto será resolvido de cada vez: enquanto o objeto não-rotulado que estiver mais perto de um rotulado se movimenta, todos os demais permanecerão parados, até que aquele seja rotulado, e só então um segundo objeto se movimentará. Isso explica também porquê o emprego de valores altos de $\beta(\beta=50)$ implicam em mais iterações para o sistema chegar à solução final.

Já o parâmetro $\delta$ apresenta um comportamento mais evidente. Valores altos de $\delta$ fazem com que os objetos, quando rotulados, espalhem-se por uma área maior. Valores 


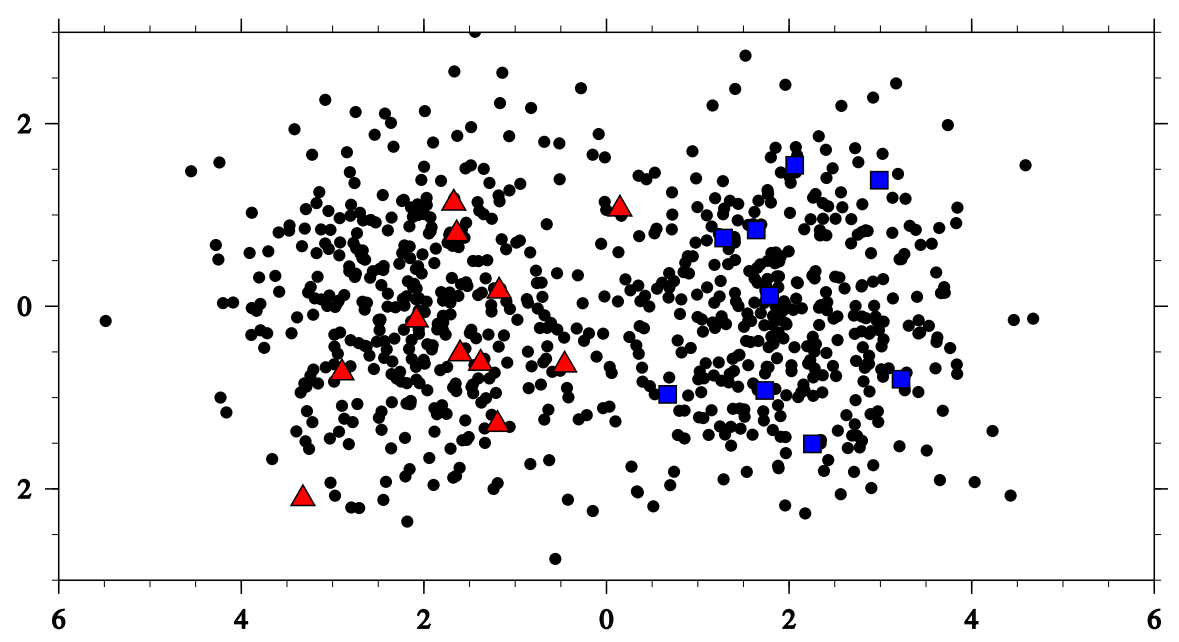

Figura 6.3: (Colorida) Conjunto artificial de dados, formado por duas gaussianas contendo 400 objetos cada, 20 deles previamente rotulados e destacados na figura: 11 na classe "triângulo" e 9 na classe "quadrado". Cada objeto é descrito por dois atributos, resultando num conjunto bidimensional. Cada gaussiana tem variância 1 e seus centros distam 4 unidades um do outro.

altos de $\delta$ implicam também em menos iterações, pois os objetos percorrem distâncias menores até serem rotulados.

Com relação à acurácia dos resultados, as diferenças não são tão significativas, embora neste caso, a simulação que demandou menos tempo também é a que apresentou melhor resultado - 482 iterações e taxa de erro de $2,7 \%$, para valor baixo de $\beta(\beta=1)$ e valor alto de $\delta(\delta=0,2)$.

\subsubsection{Experimentos e análise dos resultados}

Uma análise mais detalhada foi também realizada, simulando-se a técnica proposta sobre uma gama mais ampla de parâmetros e sobre diferentes conjuntos de dados. Na Figura 6.6. mostra-se a análise da influência dos parâmetros $\beta$ e $\delta$ na acurácia e no tempo de convergência, sobre conjuntos artificiais de dados gerados aleatoriamente. Trata-se de conjuntos formados por duas gaussianas, semelhantes ao da Figura 6.3, mas com diferentes parâmetros: 250 objetos em cada classe, $5 \%$ deles rotulados, variância 1 e 2,5 unidades separando seus centros ao longo da primeira dimensão (dimensão horizontal na figura).

É fácil observar que o aumento da dimensionalidade dos dados derruba drasticamente a acurácia da classificação. Isso acontece porque as dimensões adicionais - atributos adicionais - não agregam informação alguma que diferenciem as classes. Pior, elas acabam "ofuscando" as diferenciações promovidas pela primeira dimensão - primeiro atributo. Por exemplo, dois objetos muito próximos na primeira dimensão - objetos de mesma classe - podem facilmente se tornar muito distantes quando adicionadas as demais dimensões, mais distantes até que a média entre os demais pares de objetos. É possível 


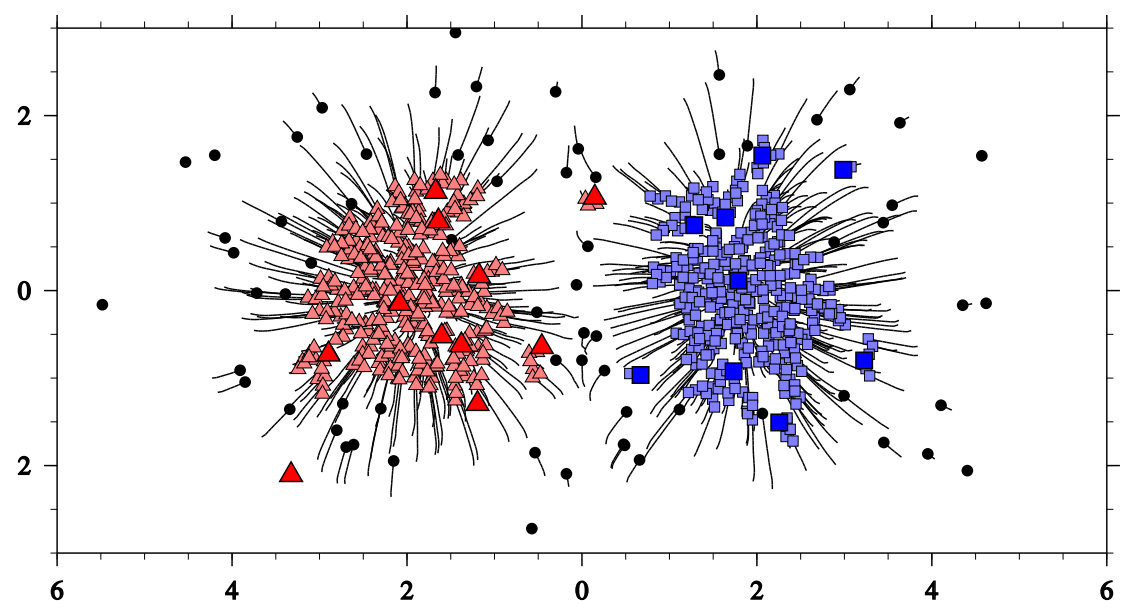

(a)

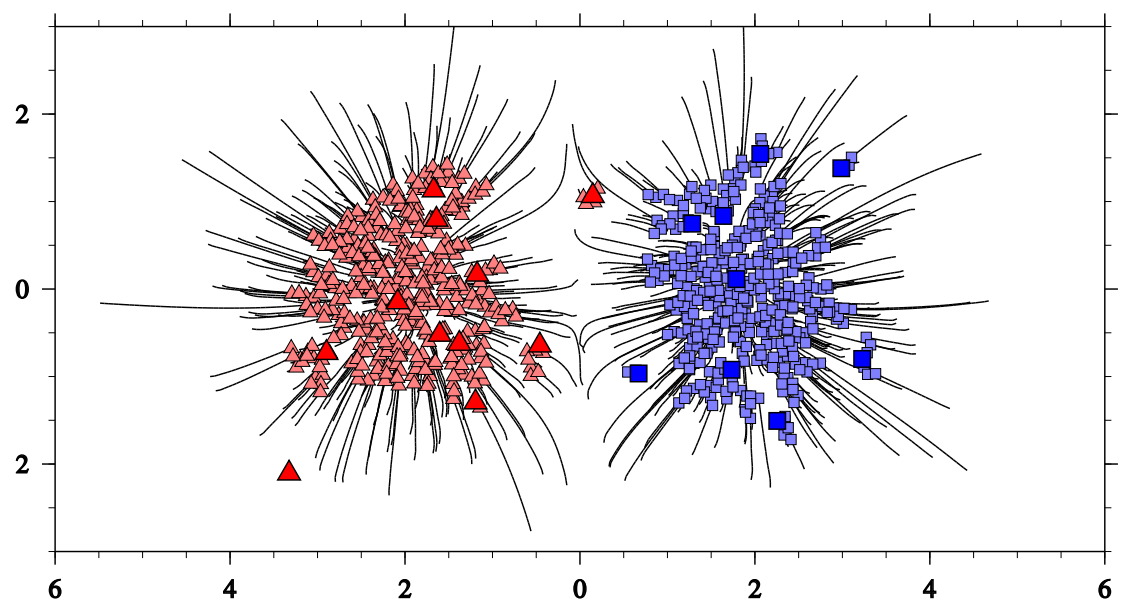

(b)

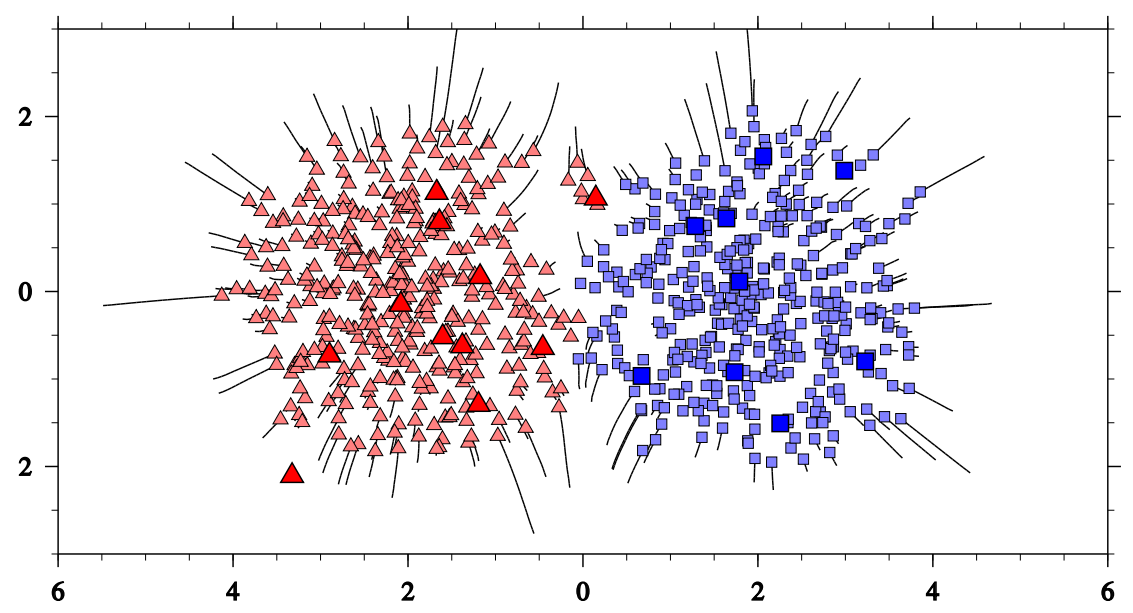

(c)

Figura 6.4: (Colorida) Comportamento dinâmico da técnica proposta, sobre o conjunto da Figura 6.3. empregando $\beta=1$ e $p=0,01$. A trajetória dos dados é mostrada. (a): $\delta=0,1$, após algum tempo de evolução $(t=200)$. (b): $\delta=0,1$, após a rotulação de todos os objetos $(t=1659)$. Taxa de erro: $2,9 \%$. (c): $\delta=0,2$, após a rotulação de todos os objetos $(t=482)$. Taxa de erro: $2,7 \%$. 


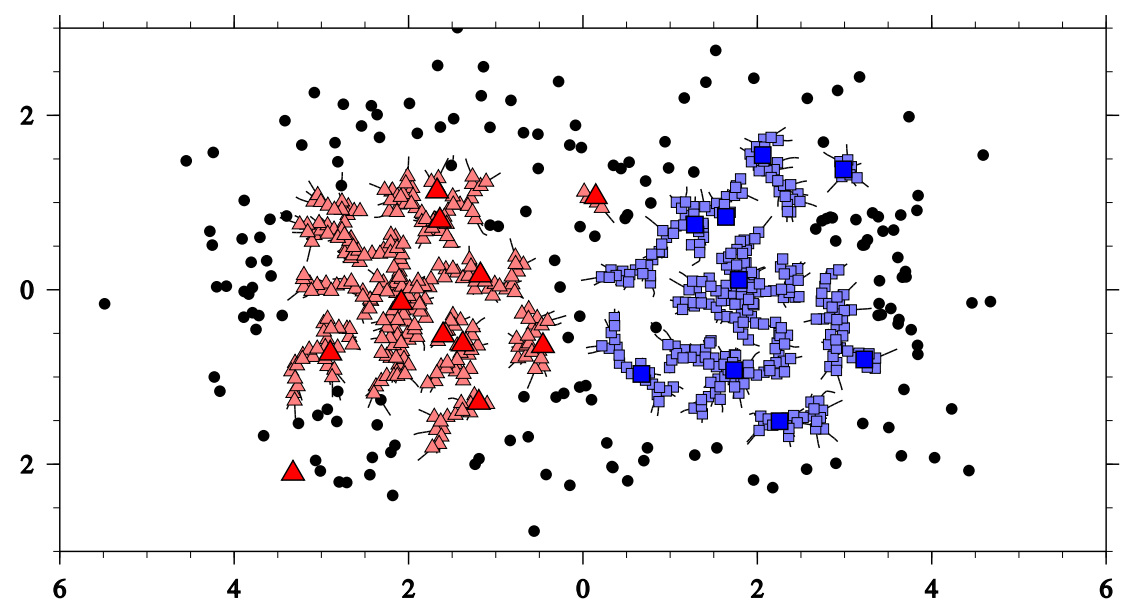

(a)

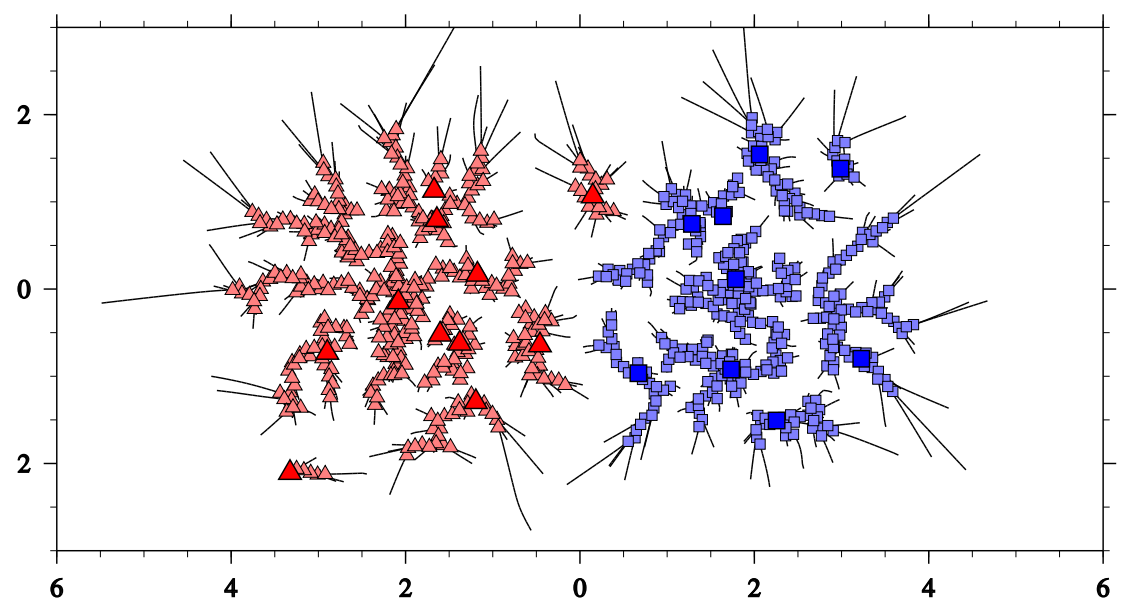

(b)

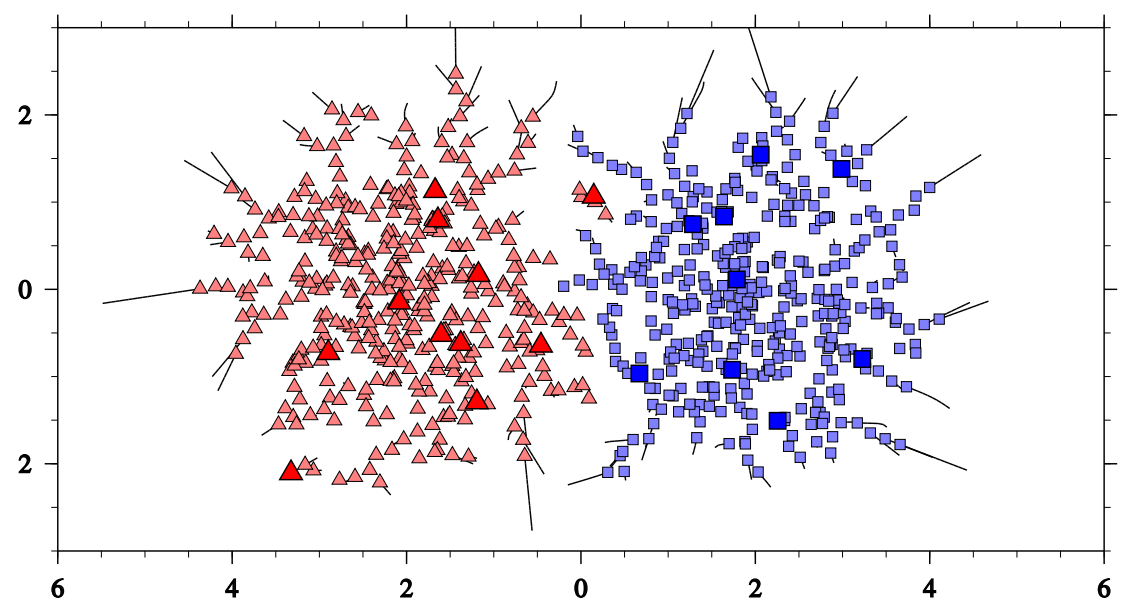

(c)

Figura 6.5: (Colorida) Comportamento dinâmico da técnica proposta, sobre o conjunto da Figura 6.3. empregando $\beta=50$ e $p=0,01$. A trajetória dos dados é mostrada. (a): $\delta=0,1$, após algum tempo de evolução $(t=500)$. (b): $\delta=0,1$, após a rotulação de todos os objetos $(t=6733)$. Taxa de erro: $3,2 \%$. (c): $\delta=0,2$, após a rotulação de todos os objetos $(t=2409)$.

Taxa de erro: $3,6 \%$. 

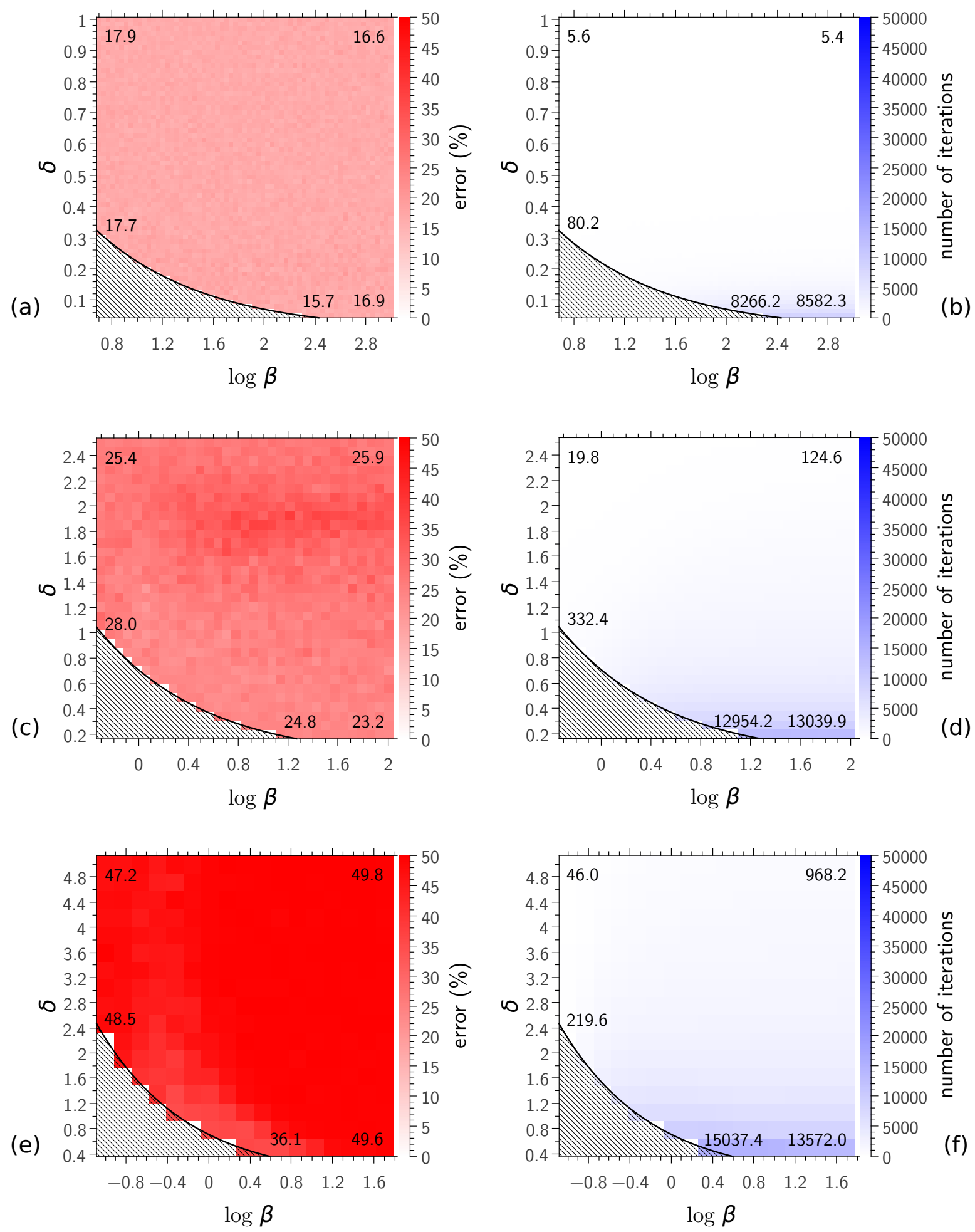

Figura 6.6: (Colorida) Análise da influência dos parâmetros $\beta$ e $\delta$ na acurácia e no tempo de convergência. Empregaram-se conjuntos artificiais de dados gerados aleatoriamente e formados por duas gaussianas (semelhantes ao da Figura 6.3), mas com diferentes parâmetros: 250 objetos em cada classe, $5 \%$ deles rotulados, variância 1 e 2,5 unidades separando seus centros ao longo da primeira dimensão (dimensão horizontal na figura). A área hachurada corresponde a $\delta^{2}-$ $1 /(2 \beta)<0$, portanto não foi simulada. Precisão $p=\delta / 2$. Cada entrada corresponde à média de 30 simulações. Variou-se o número de dimensões do conjunto de dados: (a), (b): 2 dimensões; (c), (d): 10 dimensões; (e), (f): 50 dimensões. Alguns valores são destacados nas figuras, para melhor referência. 

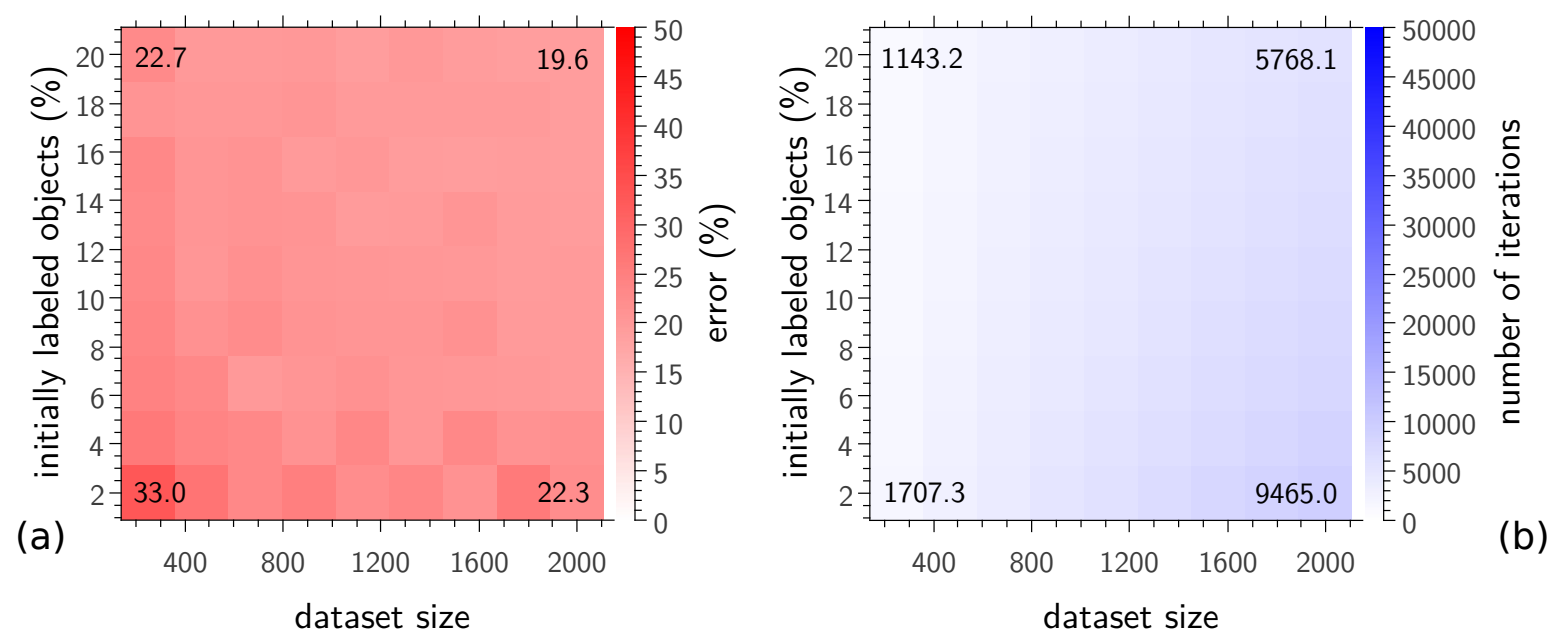

Figura 6.7: (Colorida) Análise da influência do tamanho do conjunto de dados e da proporção de dados inicialmente rotulados na acurácia e no tempo de convergência. Empregaram-se conjuntos artificiais de dados gerados aleatoriamente e formados por duas gaussianas (semelhantes aos da Figura 6.3), mas com diferentes parâmetros: 10 dimensões, variância 1 e 2,5 unidades separando seus centros ao longo da primeira dimensão. Parâmetros: $\beta=5, \delta=0,75$ e $p=\delta / 2$. Cada entrada corresponde à média de 30 simulações. Alguns valores são destacados nas figuras, para melhor referência.

notar também que o aumento da dimensionalidade acarreta um aumento no tempo de convergência. A explicação disso é que, em altas dimensões, os objetos necessitam percorrer distâncias maiores até serem rotulados. Não fica evidente, entretanto, qual é a combinação ideal dos parâmetros $\beta$ e $\delta$ na acurácia, embora valores altos de $\delta$ reduzam significativamente o número de iterações necessárias.

Outra análise foi também realizada, desta vez sobre a influência do tamanho do conjunto de dados e da proporção de dados inicialmente rotulados. Novamente, empregaramse conjuntos artificiais de dados gerados aleatoriamente e formados por duas gaussianas, semelhantes aos da Figura 6.3, mas agora com os seguintes parâmetros: 10 dimensões, variância 1 e 2,5 unidades separando seus centros ao longo da primeira dimensão. Os resultados dessa análise são mostrados na Figura 6.7.

Observa-se que a acurácia aumenta com o aumento da disponibilidade de dados e com o aumento da proporção de dados inicialmente rotulados. Quanto ao tempo para se rotular todos os dados, este aumenta com o aumento do tamanho do conjunto de dados. Isso pode ser explicado pois, dependendo do parâmetro $\beta$, os diferentes objetos não caminham na mesma velocidade, como discutido na Seção 6.2.3. Assim, os objetos acabam sendo resolvidos um após o outro, e portanto mais objetos para serem rotulados implica na demanda por mais tempo.

A técnica proposta foi também avaliada sobre 5 conjuntos de dados de benchmark, propostos por Chapelle et al. (2006b). A Tabela 6.1 sumariza as características básicas desses conjuntos. Cada base de dados é disponibilizada em duas versões, com 10 e com 
Tabela 6.1: Características básicas dos conjuntos de dados de benchmark (Chapelle et al., 2006b).

\begin{tabular}{ccccc}
\hline Conjunto & $\mathrm{N}^{\mathrm{o}}$ de classes & $\mathrm{N}^{\mathrm{o}}$ de dimensões & $\mathrm{N}^{\mathrm{o}}$ de dados & Comentário \\
\hline g241c & 2 & 241 & 1500 & artificial \\
g241d & 2 & 241 & 1500 & artificial \\
Digit1 & 2 & 241 & 1500 & artificial \\
USPS & 2 & 241 & 1500 & desbalanceado \\
BCI & 2 & 117 & 400 & \\
\hline
\end{tabular}

100 objetos inicialmente rotulados, cada qual disponibilizada em 12 splits. Os splits são idênticos. O que os diferenciam são os objetos inicialmente rotulados. Ou seja, diferentes splits possuem diferentes objetos rotulados.

Na Figura 6.8, mostra-se a análise da influência dos parâmetros $\beta$ e $\delta$ na acurácia e no tempo de convergência, sobre o conjunto Digit1. Já na Figura 6.9, mostra-se a mesma análise, mas sobre o conjunto de dados formado pelas 5 primeiras componentes PCA Principal Component Analysis (análise de componentes principais) — do conjunto Digit1.

É possível observar que a técnica proposta beneficia-se da aplicação da PCA, tanto na acurácia quanto no tempo de convergência. Novamente, o ganho na acurácia está associado à eliminação de dimensões irrelevantes, enquanto o ganho no tempo de convergência ocorre porque os objetos têm que percorrer distâncias menores até serem rotulados. E mais uma vez, não fica evidente qual é a combinação ideal dos parâmetros $\beta$ e $\delta$ na acurácia, embora valores altos de $\delta$ reduzam significativamente o número de iterações necessárias.

Por fim, simulou-se a técnica proposta nas demais bases de benchmark, e compararamse os resultados aos de outros algoritmos de aprendizado semissupervisionado. Na Tabela 6.2. mostram-se as abreviações referentes às demais técnicas. A comparação dos resultados é mostrada nas Tabelas 6.3 e 6.4 para 10 e 100 dados inicialmente rotulados, respectivamente. Nota-se que a técnica proposta é, de modo geral, comparável às demais técnicas da literatura. 

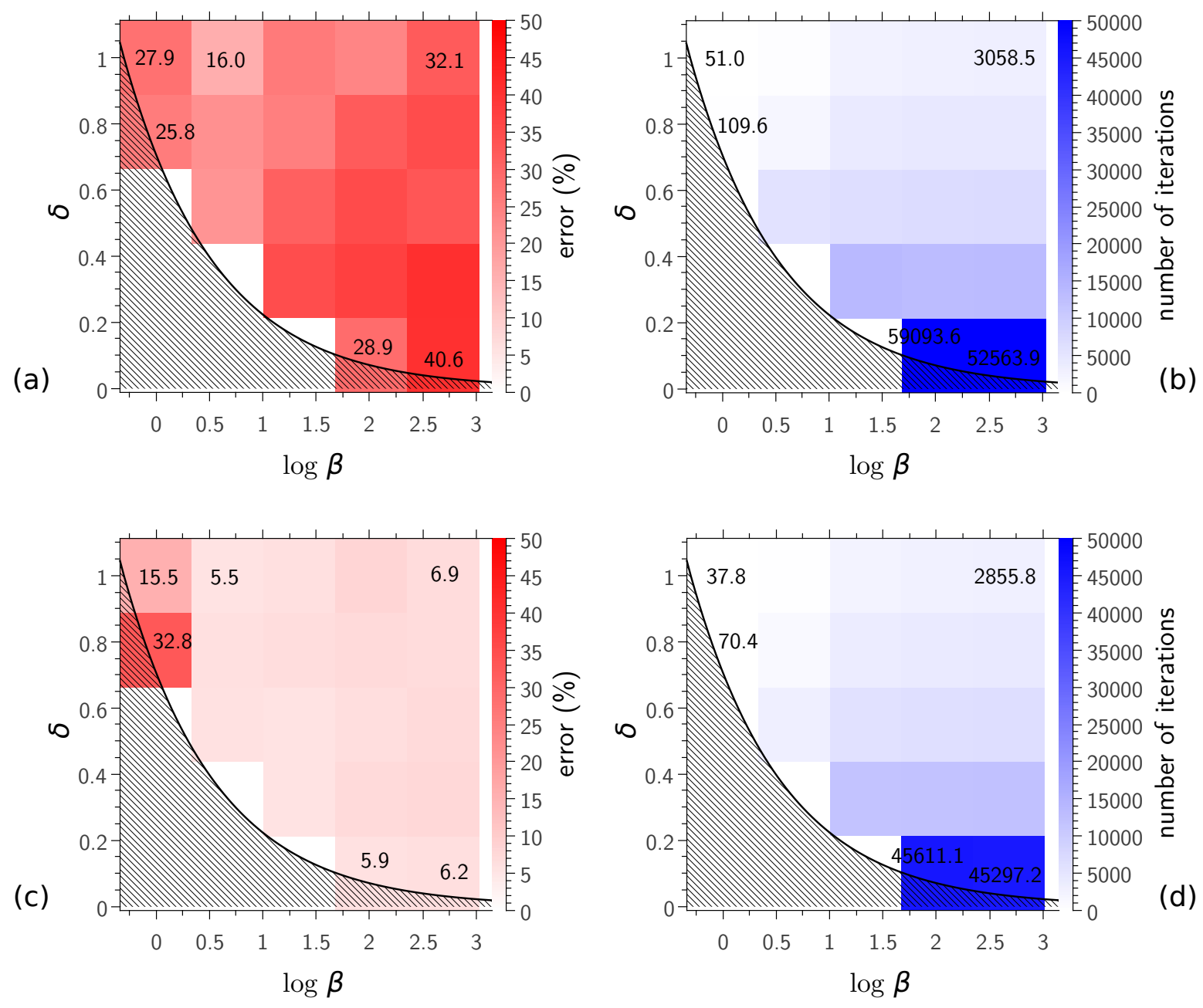

Figura 6.8: (Colorida) Análise da influência dos parâmetros $\beta$ e $\delta$ na acurácia e no tempo de convergência, sobre o conjunto Digit1. A área hachurada corresponde a $\delta^{2}-1 /(2 \beta)<0$, portanto não foi simulada. Precisão $p=\delta / 2$. Cada entrada corresponde à média de 12 simulações - 12 splits, como proposto por Chapelle et al. (2006b). (a), (b): 10 objetos inicialmente rotulados. (c), (d): 100 objetos inicialmente rotulados. Alguns valores são destacados nas figuras, para melhor referência. O melhor valor obtido também é mostrado. 

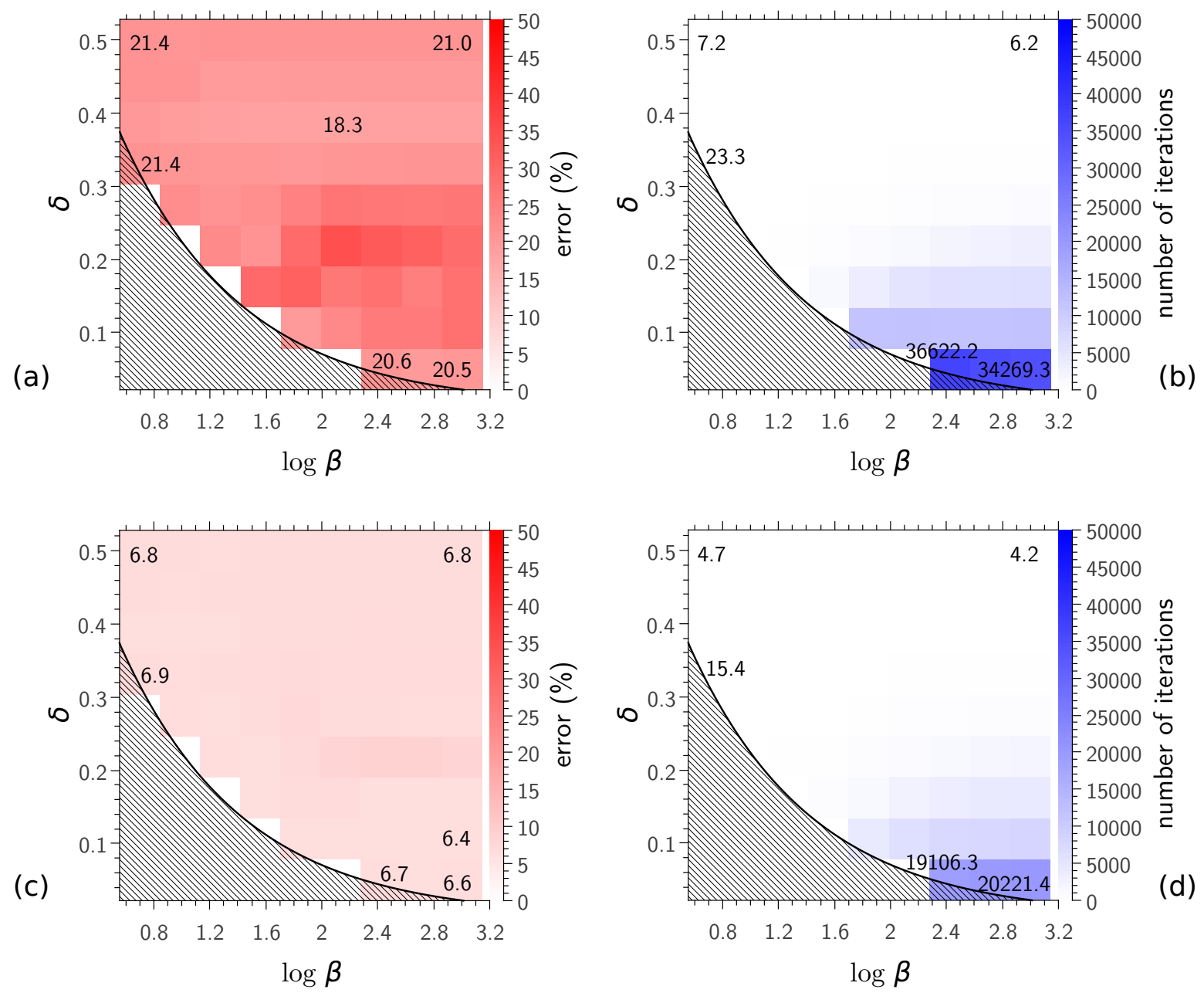

Figura 6.9: (Colorida) Análise da influência dos parâmetros $\beta$ e $\delta$ na acurácia e no tempo de convergência, sobre o conjunto Digit1, mas considerando-se somente as 5 primeiras componentes PCA. A área hachurada corresponde a $\delta^{2}-1 /(2 \beta)<0$, portanto não foi simulada. Precisão $p=\delta / 2$. Cada entrada corresponde à média de 12 simulações - 12 splits, como proposto por Chapelle et al. (2006b). (a), (b): 10 objetos inicialmente rotulados. (c), (d): 100 objetos inicialmente rotulados. Alguns valores são destacados nas figuras, para melhor referência. O melhor valor obtido também é mostrado. 
Tabela 6.2: Abreviações das técnicas utilizadas para comparação.

\begin{aligned} & \hline Abreviação Técnica \\ & \hline 1-NN 1-Nearest Neighbor \\ & SVM Support Vector Machines \\ & LEM Laximum Variance Unfolding \\ & QC + CMN Quadratic Criterion + Class Mass Normalization \\ & Discrete Reg. Discrete Regularization \\ & TSVM Transductive Support Vector Machines \\ & SGT Spectral Graph Transducer \\ & LDS Low-Density Separation \\ & Data-Dep. Reg. Data-Dependent Regularization \\ & Laplacian RLS Laplacian Regularized Least Squares \\ & CHM Conditional Harmonic Mixing \\ & \hline\end{aligned}


Tabela 6.3: Comparação da técnica proposta a outras técnicas da literatura. Bases com 10 dados inicialmente rotulados. Cada entrada denota a taxa de erro média (\%) de 12 simulações - 12 splits. A técnica proposta foi executada sobre as bases originais e sobre as 5 primeiras componentes PCA de cada uma. Os resultados das demais técnicas foram obtidos de Chapelle et al. (2006b).

\begin{tabular}{rccccc}
\hline & g241c & g241d & Digit1 & USPS & BCI \\
\hline 1-NN & 44,05 & 43,22 & 23,47 & 19,82 & 48,74 \\
SVM & 47,32 & 46,66 & 30,60 & 20,03 & 49,85 \\
MVU + 1-NN & 48,68 & 47,28 & 11,92 & 14,88 & 50,24 \\
LEM + 1-NN & 47,47 & 45,34 & 12,04 & 19,14 & 49,94 \\
QC + CMN & 39,96 & 46,55 & 9,80 & 13,61 & 50,36 \\
Discrete Reg. & 49,59 & 49,05 & 12,64 & 16,07 & 49,51 \\
TSVM & 24,71 & 50,08 & 17,77 & 25,20 & 49,15 \\
SGT & 22,76 & 18,64 & 8,92 & 25,36 & 49,59 \\
Cluster-Kernel & 48,28 & 42,05 & 18,73 & 19,41 & 48,31 \\
Data-Dep. Reg. & 41,25 & 45,89 & 12,49 & 17,96 & 50,21 \\
LDS & 28,85 & 50,63 & 15,63 & 17,57 & 49,27 \\
Laplacian RLS & 43,95 & 45,68 & 5,44 & 18,99 & 48,97 \\
CHM (normed) & 39,03 & 43,01 & 14,86 & 20,53 & 46,90 \\
\hline Técnica proposta & 49,77 & 49,37 & 16,00 & 14,61 & 48,72 \\
Técnica proposta (PCA) & 27,64 & 27,42 & 18,31 & 18,31 & 49,64 \\
\hline
\end{tabular}

Tabela 6.4: Comparação da técnica proposta a outras técnicas da literatura. Bases com 100 dados inicialmente rotulados. Cada entrada denota a taxa de erro média (\%) de 12 simulações - 12 splits. A técnica proposta foi executada sobre as bases originais e sobre as 5 primeiras componentes PCA de cada uma. Os resultados das demais técnicas foram obtidos de Chapelle et al. (2006b).

\begin{tabular}{rccccc}
\hline & g241c & g241d & Digit1 & USPS & BCI \\
\hline 1-NN & 40,28 & 37,49 & 6,12 & 7,64 & 44,83 \\
SVM & 23,11 & 24,64 & 5,53 & 9,75 & 34,31 \\
MVU + 1-NN & 44,05 & 43,21 & 3,99 & 6,09 & 47,42 \\
LEM + 1-NN & 42,14 & 39,43 & 2,52 & 6,09 & 48,64 \\
QC + CMN & 22,05 & 28,20 & 3,15 & 6,36 & 46,22 \\
Discrete Reg. & 43,65 & 41,65 & 2,77 & 4,68 & 47,67 \\
TSVM & 18,46 & 22,42 & 6,15 & 9,77 & 33,25 \\
SGT & 17,41 & 9,11 & 2,61 & 6,80 & 45,03 \\
Cluster-Kernel & 13,49 & 4,95 & 3,79 & 9,68 & 35,17 \\
Data-Dep. Reg. & 20,31 & 32,82 & 2,44 & 5,10 & 47,47 \\
LDS & 18,04 & 23,74 & 3,46 & 4,96 & 43,97 \\
Laplacian RLS & 24,36 & 26,46 & 2,92 & 4,68 & 31,36 \\
CHM (normed) & 24,82 & 25,67 & 3,79 & 7,65 & 36,03 \\
\hline Técnica proposta & 49,80 & 49,76 & 5,52 & 5,80 & 44,41 \\
Técnica proposta (PCA) & 21,63 & 10,24 & 6,41 & 12,44 & 45,63 \\
\hline & & & & &
\end{tabular}




\subsection{Técnica proposta vs. 1-NN}

Conforme mostrado nas Tabelas 6.3 e 6.4 da seção anterior, os resultados da técnica proposta são comparáveis aos resultados de uma técnica consideravelmente mais simples: 1-Nearest Neighbor, ou 1-NN. Essa técnica, também chamada de técnica do vizinho mais próximo, simplesmente atribui, ao objeto não-rotulado, o rótulo do objeto rotulado que estiver mais próximo. Embora os resultados sobre as bases de benchmark sejam comparáveis, há diferenças significativas entre as duas técnicas. A principal delas é que a técnica 1-NN não leva em conta o padrão de distribuição dos dados não-rotulados. Aliás, tratase de uma característica fundamental do aprendizado semissupervisionado: classificar os dados não-rotulados segundo os rotulados e segundo o próprio padrão de distribuição dos não-rotulados. Para ilustrar isso, considere a base artificial de dados mostrada na Figura 6.10. A correta classificação dos dados só é possível se for levado em conta o padrão formado pelos não-rotulados. Na Figura 6.11, mostra-se o resultado do algoritmo 1-NN, enquanto na Figura 6.12, mostra-se o resultado da técnica proposta.

\subsection{O efeito da rotulação equivocada}

Além dos aspectos positivos, é importante também apresentar as limitações da técnica proposta. Uma delas está associada à existência de dados com rotulação errônea. De fato, a técnica aqui apresentada não é capaz de tratar esses rótulos errados, tampouco conter sua propagação. A fim de ilustrar o efeito da rotulação equivocada, algumas simulações foram feitas sobre o conjunto de dados mostrado na Figura 6.3 (Seção 6.2.3). Aqui, entretanto, foram trocados os rótulos de um objeto de cada classe. Os resultados de três simulações são mostrados na Figura 6.13. Nota-se que a técnica se apresenta muito instável. Enquanto, por exemplo, em (b), o rótulo "quadrado" errôneo foi propagado a apenas um objeto, em (c), a propagação dos rótulos errados foi catastrófica. 


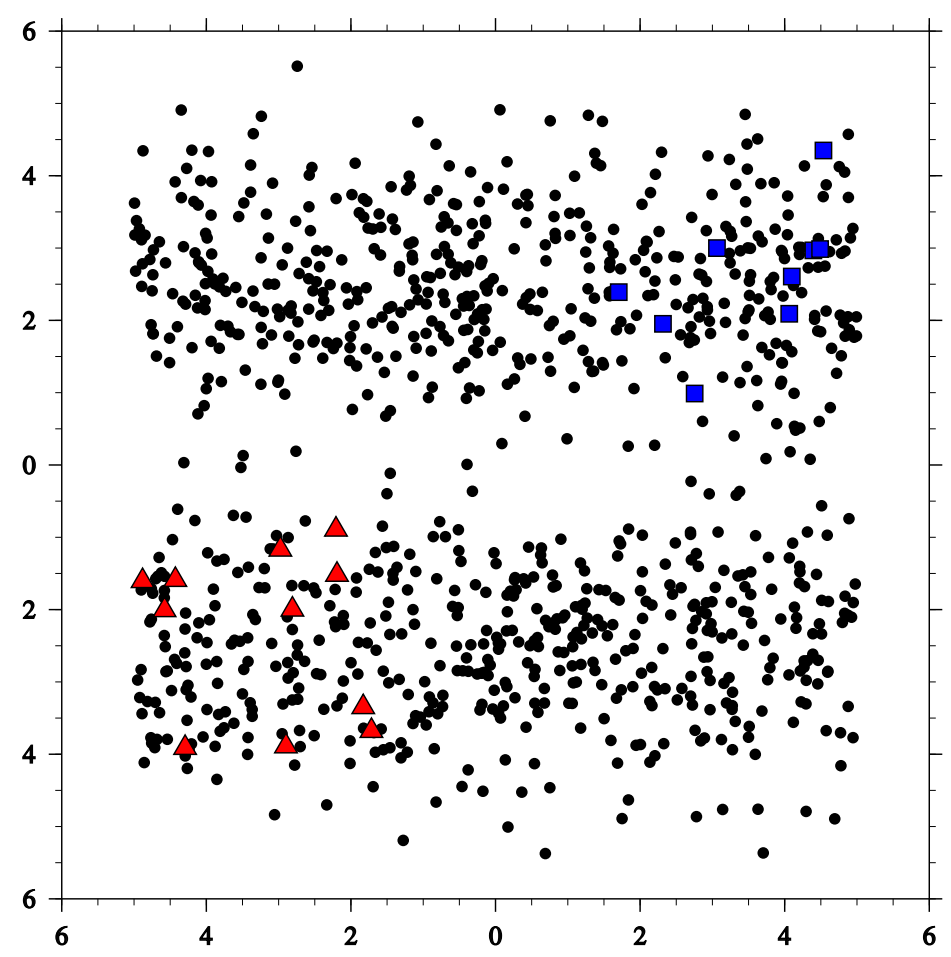

Figura 6.10: (Colorida) Conjunto artificial bidimensional de dados, formado por duas classes dispostas horizontalmente, uma sobre a outra. Horizontalmente, os dados foram gerados por uma distribuição uniforme, ao longo de 10 unidades. Verticalmente, foram gerados por uma distribuição normal de variância 1,0. Os centros de cada classe distam 5 unidades (verticalmente). Cada classe possui 500 objetos, totalizando 1000, 20 deles rotulados: 11 na classe "triângulo" e 9 na classe "quadrado". A rotulação, porém, não foi uniforme, sendo forçada a uma das extremidades de cada classe. 


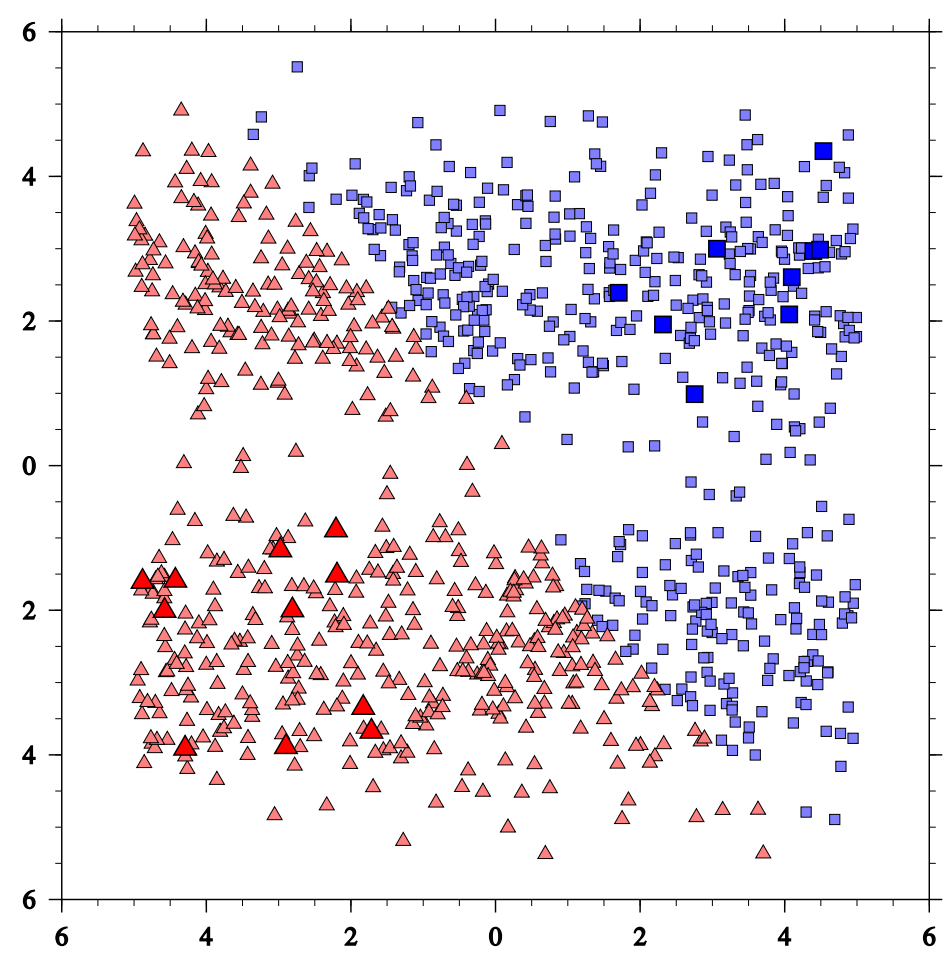

Figura 6.11: (Colorida) Resultado do algoritmo 1-NN sobre o conjunto da Figura 6.10. Taxa de erro: $31,8 \%$. 


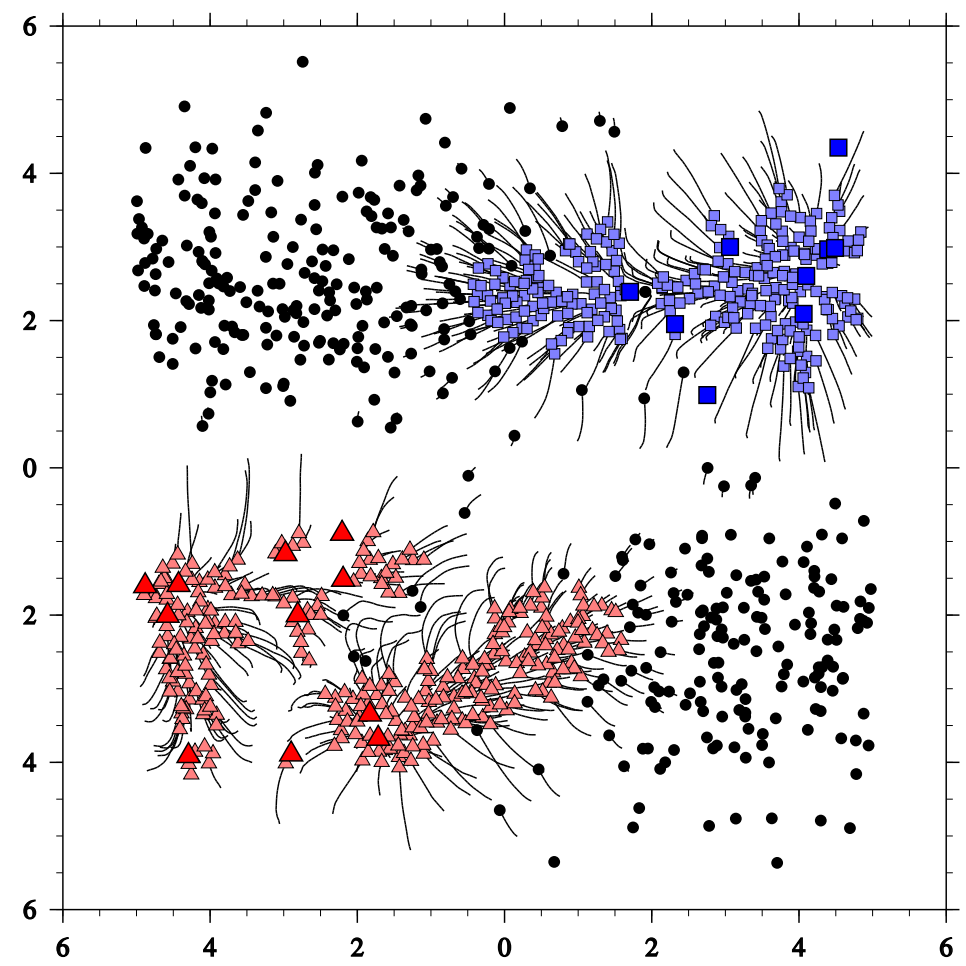

(a)

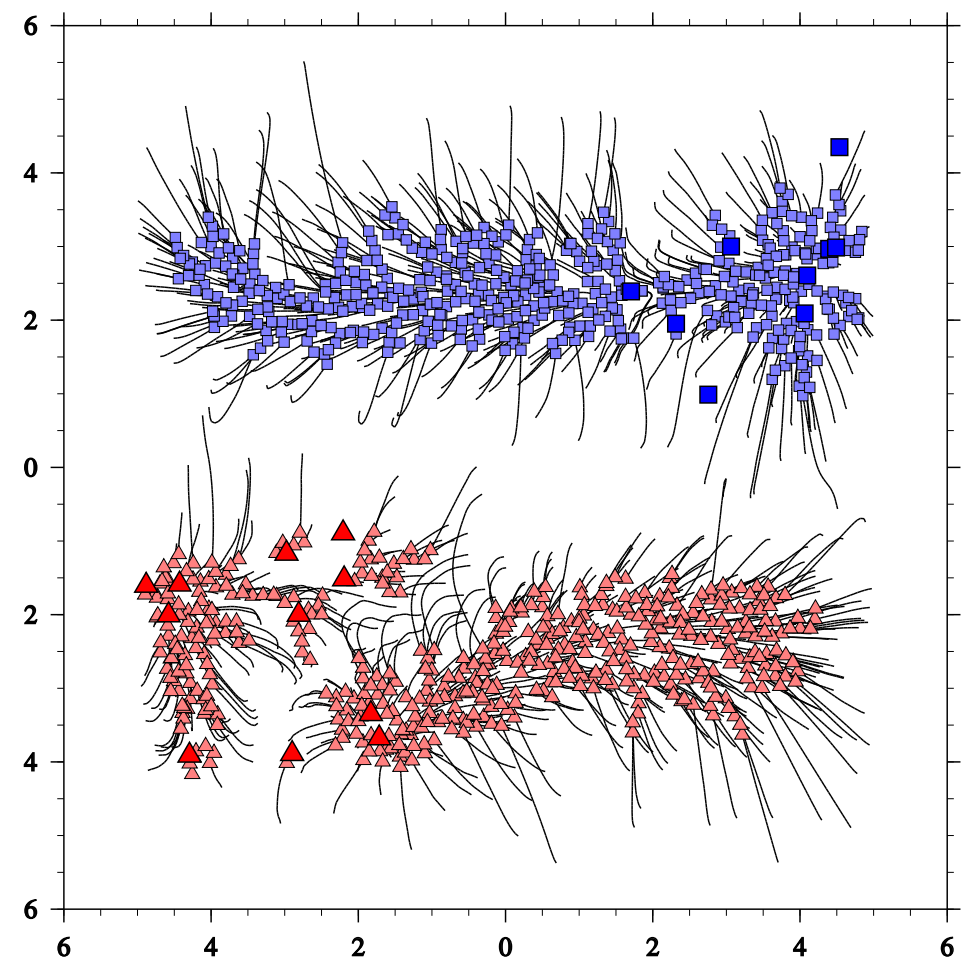

(b)

Figura 6.12: (Colorida) Resultado da técnica proposta sobre o conjunto da Figura 6.10. A trajetória dos dados é mostrada. Parâmetros: $\beta=1$ e $\delta=0,15$. (a): Após algum tempo de evolução $(t=500)$. (b): Após a rotulação de todos os objetos $(t=2654)$. Taxa de erro: $1,2 \%$. 


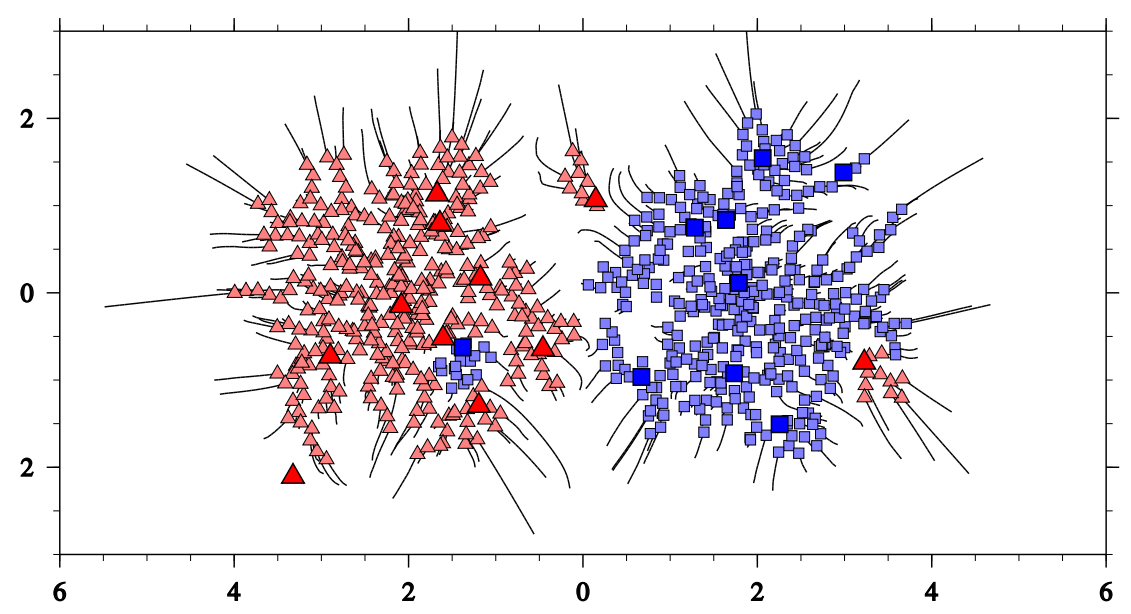

(a)

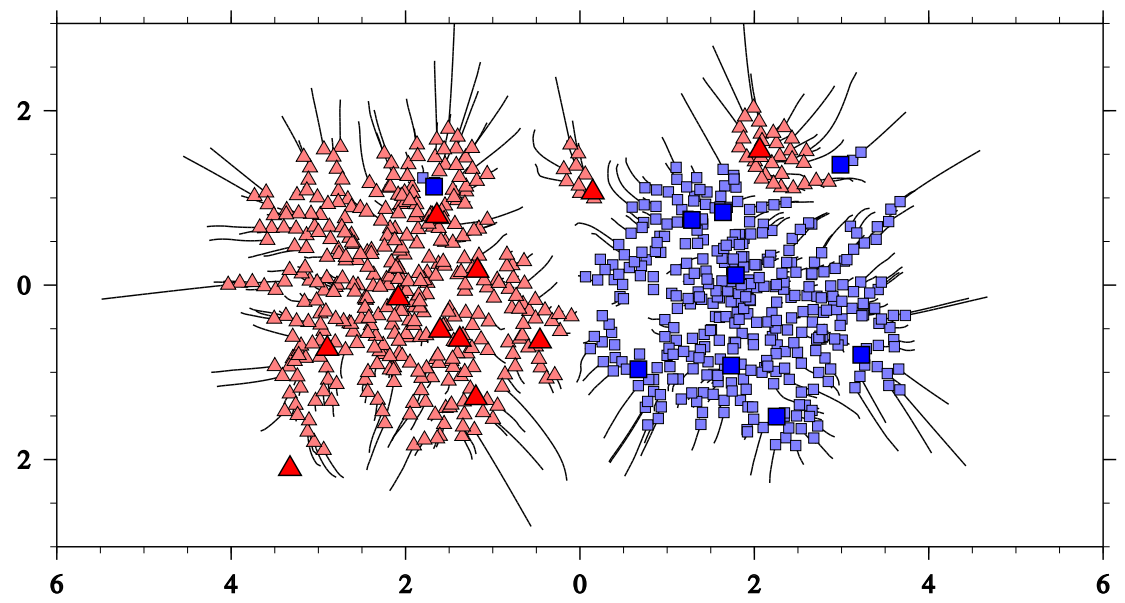

(b)

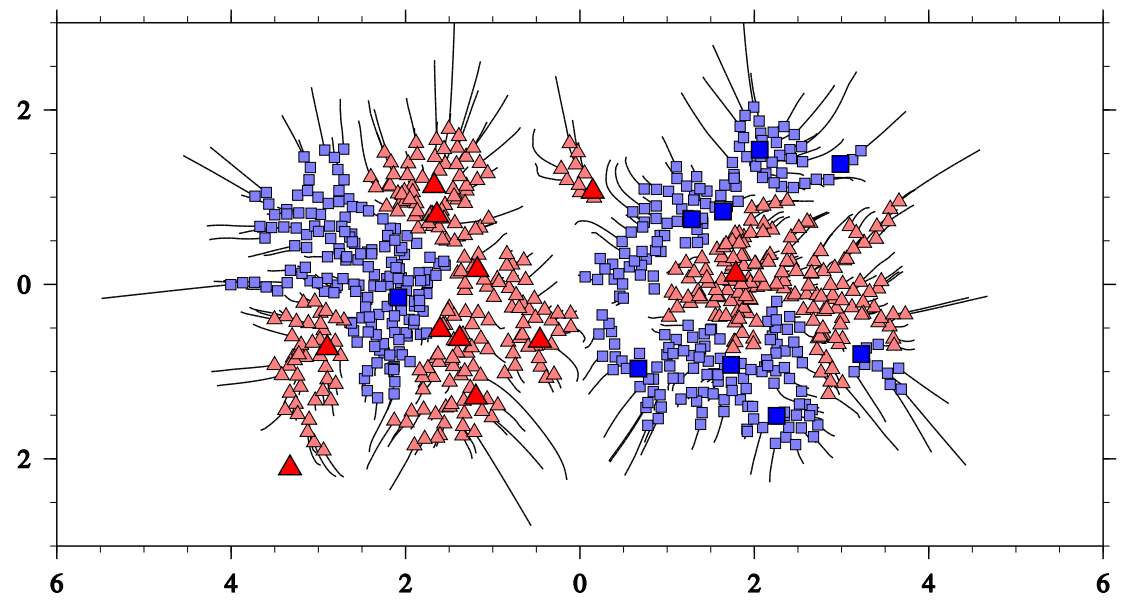

(c)

Figura 6.13: (Colorida) Efeito da rotulação equivocada. O conjunto é o mesmo da Figura 6.3, mas aqui, em cada figura, um objeto de cada classe teve seu rótulo trocado. A trajetória dos dados é mostrada. Parâmetros: $\beta=5$ e $\delta=0,15$. Taxas de erro: (a) $6,2 \%$, (b) $6,9 \%$ e (c) $45,5 \%$. 


\section{Capítulo 7}

\section{Conclusões e trabalhos futuros}

Essencialmente, três modelos dinâmicos foram concebidos durante esta dissertação, sendo dois para agrupamento e um para aprendizado semissupervisionado. Os dois primeiros, para agrupamento, baseiam-se na troca de energia entre os dados. Os dados permanecem fixos em seu espaço de atributos, mas carregam certa informação - a "energia" —, a qual é gradualmente trocada entre eles. Os grupos são estabelecidos entre objetos que tomam estados de energia semelhantes. No primeiro modelo, há troca de energia somente no sentido de atração, ou seja, os dados tomam estados de energia cada vez mais semelhantes. Uma consequência imediata é que todos eles terminam num mesmo estado de energia. $\mathrm{O}$ processo se inicia com cada objeto representando um grupo distinto, e termina com um único grupo contendo todos os objetos. Portanto, a técnica pode ser vista como um agrupamento hierárquico aglomerativo. Embora experimentos tenham sido realizados e sua evolução ao longo do tempo tenha sido medida, é ainda necessário um estudo mais detalhado sobre qual dos instantes intermediários contém a melhor partição dos dados.

No segundo modelo, foi proposta a troca de energia no sentido de atração e repulsão. Há, pois, uma diferença fundamental em relação ao primeiro modelo. Aqui, quanto mais o sistema avança, mais ele se aproxima de um estado de equilíbrio onde - espera-se os objetos tomam estados de energia similares quando são similares, e tomam estados de energia bem distintos caso contrário. Diferentemente do primeiro modelo, enfatizou-se a dinâmica de troca de energia ao invés da obtenção de partições. Nesse sentido, partições não são rigidamente estabelecidas, sendo necessária a aplicação de um algoritmo de agrupamento propriamente dito ao final do processo. É esperado, claro, que a dinâmica de troca de energia permita um agrupamento mais preciso. Mais que isso, justamente por não se obter partições rígidas dos dados, pode-se explorar técnicas de soft clustering, embora tal exploração não tenha sido realizada neste trabalho. A concepção desse modelo de troca positiva e negativa de energia, originalmente muito custoso, foi seguida da discussão e ilustração de meios para otimizá-lo. De fato, foi mostrado que é possível derrubar sua complexidade originalmente cúbica — em relação ao número de objetos para uma complexidade linear, com pouca ou praticamente nenhuma perda na acurácia 
de seus resultados. As variáveis envolvidas nesse processo de otimização podem, ainda, ser investigadas com mais detalhes.

Já o terceiro modelo desenvolvido, agora para aprendizado semissupervisionado, é baseado na movimentação dos próprios dados pelo espaço de atributos. Os dados rotulados permanecem fixos, mas exercem forças de atração sobre os não-rotulados. Quando atingem uma distância suficientemente pequena, o rótulo é propagado e aquele originalmente nãorotulado passa a agir como um rotulado, exercendo atração sobre os demais. Embora a dinâmica de movimentação dos dados seja suave e robusta, a rotulação rígida - e irreversível - que é promovida por essa técnica a torna instável quando alguns dos dados possuem rotulação inicialmente equivocada. A técnica pode, portanto, ser aprimorada no sentido de permitir um processo de rotulação também suave, e consequentemente reversível, podendo até mesmo tornar-se uma técnica de soft labeling.

A cada uma das três técnicas desenvolvidas durante esta dissertação de mestrado, correspondeu uma publicação:

1. Roberto Alves Gueleri \& Zhao Liang. Agrupamento de Dados baseado em Dinâmica de Troca de Energia. In: Anais do XXXI Congresso da Sociedade Brasileira de Computação (CSBC 2011). Páginas 418-429.

2. Roberto Alves Gueleri \& Zhao Liang. An Energy Exchanging Mechanism for Data Clustering. In: Proceedings of the 2012 Brazilian Symposium on Neural Networks (SBRN 2012). Pages 31-36. DOI 10.1109/SBRN.2012.34

3. Thiago Henrique Cupertino, Roberto Alves Gueleri e Zhao Liang. A Semi-Supervised Classification Technique Based on Interacting Forces. Submetido para o periódico Neurocomputing. Atualmente, encontra-se na segunda rodada de revisão.

Ao longo desta dissertação, foi mostrado que a tarefa de agrupamento de dados, inicialmente subjetiva, torna-se objetiva a partir da definição de um critério de agrupamento. Ainda assim, a tarefa de agrupamento é computacionalmente complexa, não admitindo o emprego de algoritmos baseados em força bruta. Justamente a subjetividade presente no critério de agrupamento, mais a complexidade computacional, fazem com que o agrupamento de dados seja um campo que vem sendo bastante estudado e diversos algoritmos venham sendo propostos.

Ao mesmo tempo, o estudo de sistemas naturais baseados em comportamento coletivo e auto-organização vem crescendo em outras ciências, motivado pela relevância do tema e seus desafios. Abordagens inspiradas nesses sistemas vêm sendo propostas para agrupamento de dados e, de modo mais geral, para aprendizado de máquina, tanto na literatura quanto, agora, no presente trabalho de mestrado, e vêm mostrando resultados promissores. Respeitados os diferentes objetivos de cada área - sistemas naturais e aprendizado de máquina —, é importante que haja, mais do que a simples "inspiração", 
um esforço em aproveitar todo o conhecimento teórico e prático que vem sendo gerado no estudo dos sistemas naturais, quando da concepção e análise das técnicas de aprendizado de máquina.

As técnicas dinâmicas e coletivas abordadas neste trabalho exibem características interessantes. Elas são naturalmente descentralizadas e suaves. Consequentemente, as técnicas são robustas e abrem espaço para a exploração de técnicas de soft clustering e soft labeling. As informações geradas ao longo do processo dinâmico — valores das variáveis do sistema - são ricas e sua análise pode revelar características importantes com relação aos dados. Embora diversos estudos tenham sido realizados ao longo deste trabalho, a análise das variáveis do sistema dinâmico é extensa e há, pois, muito ainda a ser feito. Visto que o sistema dinâmico é discretizado para ser processado pelo computador, é importante o estudo do quão precisa deve ser a discretização (parâmetro $\alpha$ nos Capítulos 5 e 6 ) para se obter a melhor relação entre custo computacional (tempo de convergência em termos do número de iterações) e acurácia do resultado.

Na presente dissertação de mestrado, exploraram-se diferentes técnicas baseadas em comportamento coletivo, aplicando-as para agrupamento e para aprendizado semissupervisionado. Procurou-se medir e ilustrar a evolução da dinâmica dessas técnicas, mostrando como elas se comportam em diferentes cenários. Este trabalho se restringiu a um estudo mais empírico, embora simulações extensivas tenham sido realizadas para a análise dos diversos parâmetros que as técnicas carregam. Procurou-se, com todo este trabalho, não apenas propor novas técnicas de aprendizado, mas mostrar onde reside a vantagem de se utilizar a dinâmica coletiva na concepção dessas técnicas. Como trabalho futuro, podese dizer que o principal deles é o estudo mais teórico sobre a dinâmica presente nessas técnicas. Nesse sentido, pode ser útil e importante o esforço em trazer, para a concepção e análise das técnicas de aprendizado de máquina, o conhecimento proveniente do estudo dos sistemas dinâmicos coletivos que vem sendo desenvolvido nas outras ciências. Tal estudo mais teórico não é simples, mas certamente revelará, com mais precisão, as vantagens e limitações dessas abordagens. Espera-se, com tudo isso, que este trabalho de mestrado venha a motivar o desenvolvimento de novos, melhores e mais precisos modelos de aprendizado baseados em dinâmica coletiva. 


\section{Referências bibliográficas}

Abraham, Ajith; Das, Swagatam; Roy, Sandip. Soft Computing for Knowledge Discovery and Data Mining, capítulo Swarm Intelligence Algorithms for Data Clustering. Springer Verlag, 2007.

Albert, R.; Barabási, A. L. Statistical mechanics of complex networks. Rev. Modern Phys., 74(1):47-97, 2002.

Alpaydin, Ethem. Introduction to Machine Learning. Adaptive Computation and Machine Learning Series. The MIT Press, 2004.

Backer, E.; Jain, A. A clustering performance measure based on fuzzy set decomposition. IEEE Transactions on Pattern Analysis and Machine Intelligence, PAMI-3(1):66-75, January 1981.

Banzhaf, Wolfgang. Encyclopedia of Complexity and Systems Science, capítulo SelfOrganizing Systems, páginas 8040-8050. Springer, 2009.

Barrat, Alain; Barthélemy, Marc; Vespignani, Alessandro. Dynamical Processes on Complex Networks. Cambridge University Press, 2008. ISBN 978-0-521-87950-7.

Bengio, Yoshua; Delalleau, Olivier; Roux, Nicolas Le. Semi-Supervised Learning, capítulo Label Propagation and Quadratic Criterion. The MIT Press, 2006. ISBN 978-0-26203358-9.

Bishop, Christopher M. Pattern Recognition and Machine Learning. Information Science and Statistics. Springer, 2006.

Blatt, Marcelo; Wilseman, Shai; Domany, Eytan. Data clustering using a model granular magnet. Neural Computation, 9(8):1805-1842, Novembro 1997.

Bonabeau, Eric; Dorigo, Marco; Theraulaz, Guy. Swarm Intelligence: From Natural to Artificial Systems. Oxford University Press, 1999.

Chapelle, Oliver; Schölkopf, Bernhard; Zien, Alexander, editores. Semi-Supervised Learning. The MIT Press, 2006a. ISBN 978-0-262-03358-9. URL http://www.kyb. tuebingen.mpg.de/ssl-book. 
Chapelle, Oliver; Schölkopf, Bernhard; Zien, Alexander. Semi-Supervised Learning, capítulo Analysis of Benchmarks. The MIT Press, 2006b. ISBN 978-0-262-03358-9.

Chaté, H.; Ginelli, F.; Grégoire, G.; Peruani, F.; Raynaud, F. Modeling collective motion: variations on the vicsek model. The European Physical Journal B, 64:451-456, 2008. doi: 10.1140/epjb/e2008-00275-9.

Cupertino, Thiago H.; Zhao, Liang. Using interacting forces to perform semi-supervised learning. In Proceedings of the 2012 Brazilian Symposium on Neural Networks (SBRN 2012), páginas 91-96, 2012. ISBN 978-0-7695-4823-4. doi: 10.1109/SBRN.2012.24.

Dempster, Arthur P.; Laird, Nan M.; Rubin, Donald B. Maximum likelihood from incomplete data via the em algorithm. Journal of the Royal Statistical Society, Series B, 39(1):1-38, 1977.

El-Zahhar, M. M. A semi-supervised learning approach for soft labeled data. In Proceedings of the 2010 10th International Conference on Intelligent Systems Design and Applications (ISDA), páginas 1136-1141, December 2010. ISBN 978-1-4244-8134-7. doi: 10.1109/ISDA.2010.5687034.

Engelbrecht, Andries P. Fundamentals of Computational Swarm Intelligence. Wiley, 2006.

Ester, Martin; Kriegel, Hans-Peter; Sander, Jorg; Xu, Xiaowei. A density-based algorithm for discovering clusters in large spatial databases with noise. In Proceedings of 2nd International Conference on Knowledge Discovery and Data Mining (KDD96), páginas 226-231, 1996.

Faceli, Katti; Lorena, Ana Carolina; Gama, João; Carvalho, André C. P. L. F. Inteligência Artificial: Uma abordagem de Aprendizado de Máquina. LTC, 2011.

Ginelli, Francesco; Peruani, Fernando; Bär, Markus; Chaté, Hugues. Large-scale collective properties of self-propelled rods. Physical Review Letters, 104(184502), May 2010. doi: 10.1103/PhysRevLett.104.184502.

Hastie, Trevor; Tibshirani, Robert; Friedman, Jerome. The Elements of Statistical Learning: Data Mining, Inference, and Prediction. Springer Series in Statistics. Springer, 2001.

Haykin, Simon. Neural Networks: A Comprehensive Foundation. Prentice-Hall, $2^{\mathrm{a}}$ edição, 1999.

Heylighen, Francis. Knowledge Management, Organizational Intelligence and Learning, and Complexity. In: The Encyclopedia of Life Support Systems, capítulo The Science of Self-Organization and Adaptivity. 1999. 
Hüllermeier, Eyke. Fuzzy methods in machine learning and data mining: Status and prospects. Fuzzy Sets and Systems, (156):387-406, June 2005. doi: 10.1016/j.fss.2005. 05.036 .

Jain, A. K.; Murty, M. N.; Flynn, P. J. Data clustering: A review. ACM Computing Surveys, 31(3):264-323, Setembro 1999.

Joachims, Thorsten. Semi-Supervised Learning, capítulo Transductive Support Vector Machines. The MIT Press, 2006. ISBN 978-0-262-03358-9.

Kennedy, James; Eberhart, Russel. Particle swarm optimization. In IEEE International Conference on Neural Networks, volume 4, páginas 1942-1948, 1995.

Kennedy, James; Eberhart, Russel C. Swarm Intelligence. Academic Press, 2001.

Lloyd, Stuart P. Least squares quantization in pcm. IEEE Transactions on Information Theory, 28(2):129-137, March 1982. doi: 10.1109/TIT.1982.1056489.

MacQueen, J. B. Some methods for classification and analysis of multivariate observations. In Proceedings of 5th Berkeley Symposium on Mathematical Statistics and Probability, páginas 281-297, 1967.

Menon, Gautam I. Active matter, March 2010. arXiv:1003.2032v1.

Mitchell, Tom M. Machine Learning. McGraw-Hill Series in Computer Science. McGrawHill, 1997.

Newman, M. The structure and function of complex networks. SIAM Rev., 45(2):167-256, 2003.

Ngo, Sandrine; Ginelli, Francesco; Chaté, Hugues. Competing ferromagnetic and nematic alignment in self-propelled polar particles. Physical Review E, 86(050101), 2012. doi: 10.1103/PhysRevE.86.050101.

Nigam, Kamal; McCallum, Andrew; Mitchell, Tom. Semi-Supervised Learning, capítulo Semi-Supervised Text Classification Using EM. The MIT Press, 2006. ISBN 978-0-26203358-9.

Oliveira, Tatyana Bitencourt Soares. Clusterização de dados utilizando técnicas de redes complexas e computação bioinspirada. Dissertação de mestrado, Instituto de Ciências Matemáticas e de Computação - Universidade de São Paulo, São Carlos, 2008.

Omran, M.; Salman, A.; Engelbrecht, A. P. Image classification using particle swarm optimization. In Conference on Simulated Evolution and Learning, volume 1, páginas 370-374, 2002. 
Peshkov, Anton; Aranson, Igor S.; Bertin, Eric; Chaté, Hugues; Ginelli, Francesco. Simple and faithful nonlinear field equations for aligning self-propelled rods, 2012. arXiv:1207.5751v1.

Ramaswamy, Sriram. The mechanics and statistics of active matter. Annual Review of Condensed Matter Physics, 1:323-345, August 2010. doi: 10.1146/ annurev-conmatphys-070909-104101.

Rashedi, Esmat; Nezamabadi-pour, Hossein; Saryazdi, Saeid. Gsa: A gravitational search algorithm. Information Sciences, 179(13):2232-2248, June 2009.

Seeger, Matthias. Learning with labeled and unlabeled data. Relatório técnico, Institute for Adaptive and Neural Computation, University of Edinburgh, 2002.

Silva, Thiago C.; Zhao, Liang; Cupertino, Thiago H. Handwritten data clustering using agents competition in networks. Journal of Mathematical Imaging and Vision, June 2012. doi: 10.1007/s10851-012-0353-z.

Silva, Thiago Christiano; Zhao, Liang. Stochastic competitive learning in complex networks. IEEE Transactions on Neural Networks and Learning Systems, 23(3):385398, March 2012a.

Silva, Thiago Christiano; Zhao, Liang. Network-based stochastic semisupervised learning. IEEE Transactions on Neural Networks and Learning Systems, 23(3):451-466, March $2012 b$.

Silva, Thiago Christiano; Zhao, Liang. Detecting overlapping structures via network-based competitive learning. In Proceedings of the 2012 IEEE World Congress on Computational Intelligence (WCCI 2012), June 2012c.

Sindhwani, Vikas; Belkin, Misha; Niyogi, Partha. Semi-Supervised Learning, capítulo The Geometric Basis of Semi-Supervised Learning. The MIT Press, 2006. ISBN 978-0-26203358-9.

Sumino, Yutaka; Nagai, Ken H.; Shitaka, Yuji; Tanaka, Dan; Yoshikawa, Kenichi; Chate, Hugues; Oiwa, Kazuhiro. Large-scale vortex lattice emerging from collectively moving microtubules. Nature, 483:448-452, March 2012. doi: 10.1038/nature10874.

Toner, John. Birth, death, and flight: A theory of malthusian flocks. Physical Review Letters, 108(8), February 2012a. doi: 10.1103/PhysRevLett.108.088102.

Toner, John. Reanalysis of the hydrodynamic theory of fluid, polar-ordered flocks. Physical Review E, 86(3), September 2012b. doi: 10.1103/PhysRevE.86.031918. 
Toner, John; Tu, Yuhai. Long-range order in a two-dimensional dynamical xy model: How birds fly together. Physical Review Letters, 75(23):4326-4329, December 1995. doi: 10.1103/PhysRevLett.75.4326.

Toner, John; Tu, Yuhai. Flocks, herds, and schools: A quantitative theory of flocking. Physical Review E, 58(4):4828-4858, October 1998. doi: 10.1103/PhysRevE.58.4828.

Vicsek, Tamás; Zafiris, Anna. Collective motion, 2010. arXiv: 1010.5017.

Vicsek, Tamás; Czirók, András; Ben-Jacob, Eshel; Cohen, Inon; Shochet, Ofer. Novel type of phase transition in a system of self-driven particles. Physical Review Letters, 75(6):1226-1229, August 1995.

Wolfram MathWorld, . Bell number. Página da Web, 2013. http://mathworld.wolfram. com/BellNumber.html. Acessado em 09/05/2013.

$\mathrm{Xu}$, Rui; Wunsch II, Donald. Survey of clustering algorithms. IEEE Transactions on Neural Networks, 16(3):645-678, May 2005.

Xu, Rui; Wunsch II, Donald C. Clustering. IEEE Press Series on Computational Intelligence. Wiley - IEEE Press, 2009.

Yang, M. S. A survey of fuzzy clustering. Mathl. Comput. Modelling, 18(11):1-16, 1993.

Zhao, Liang; Damiance Jr., Antonio P. G.; Carvalho, André C. P. L. F. Lecture Notes in Computer Science: Advances in Natural Computation, volume 3610, capítulo A Selforganized Network for Data Clustering. Springer, 2005.

Zhou, Dengyong; Schölkopf, Bernhard. Semi-Supervised Learning, capítulo Discrete Regularization. The MIT Press, 2006. ISBN 978-0-262-03358-9.

Zhu, Xiaojin. Semi-supervised learning literature survey. Relatório técnico 1530, Computer Sciences, University of Wisconsin-Madison, 2008.

Zhu, Xiaojin; Goldberg, Andrew B. Introduction to Semi-Supervised Learning. Synthesis Lectures on Artificial Intelligence and Machine Learning. Morgan \& Claypool, 2009. ISBN 9781598295474. doi: 10.2200/S00196ED1V01Y200906AIM006. 